CAROLINE SAYURI MIZUNO

APERFEIÇOAMENTO DE UM PRODUTO ATRAVÉS DO ESTUDO DE SUA CONFIABILIDADE COMO UM FATOR DE VALOR

São Paulo 
CAROLINE SAYURI MIZUNO

\section{APERFEIÇOAMENTO DE UM PRODUTO ATRAVÉS DO ESTUDO DE SUA CONFIABILIDADE COMO UM FATOR DE VALOR}

Dissertação apresentada à Escola Politécnica da Universidade de São

Paulo para obtenção de Título de Mestre em Engenharia

Área de Concentração:

Engenharia Mecânica de Projetos e Fabricação

Orientador: Professor Doutor Gilberto Francisco Martha 
CAROLINE SAYURI MIZUNO

\title{
APERFEIÇOAMENTO DE UM PRODUTO ATRAVÉS DO ESTUDO DE SUA CONFIABILIDADE COMO UM FATOR DE VALOR
}

\author{
Dissertação apresentada à Escola \\ Politécnica da Universidade de São \\ Paulo para obtenção de Título de \\ Mestre em Engenharia
}

São Paulo 
Este exemplar foi revisado e alterado em relação à versão original, sob responsabilidade única do autor e com a anuência de seu orientador.

São Paulo, de junho de 2010.

Assinatura do autor

Assinatura do orientador

FICHA CATALOGRÁFICA

Mizuno, Caroline Sayuri

Aperfeiçoamento de um produto através do estudo de sua confiabilidade como um fator de valor / C.S. Mizuno. -- ed.rev. -São Paulo, 2010.

$160 \mathrm{p}$.

Dissertação (Mestrado) - Escola Politécnica da Universidade de São Paulo. Departamento de Engenharia Mecatrônica e de Sistemas Mecânicos.

1.Produtos (Confiabilidade) 2.Ensaios acelerados 3.Engenharia de valor I.Universidade de São Paulo. Escola Politécnica. Departamento de Engenharia Mecatrônica e de Sistemas Mecânicos II.t. 


\section{AGRADECIMENTOS}

Agradeço ao professor Gilberto Francisco Martha pela orientação e todo conhecimento e apoio transmitido durante a execução deste trabalho.

Aos meus pais, Eduardo Massao Mizuno e Fátima Deroldo Mizuno pelo constante estímulo, auxílio e paciência, aos quais faltam palavras para demonstrar minha gratidão e carinho.

À Deus por iluminar e guiar meu caminho.

Agradeço a todos que colaboraram direta ou indiretamente na execução deste trabalho. 


\section{RESUMO}

A presente dissertação deseja mostrar a utilização do estudo de confiabilidade como uma ferramenta de melhoria de projeto de um produto. Para atingir o objetivo estudou-se a melhoria de um retentor automotivo através do estudo de sua confiabilidade e utilizando técnicas de engenharia do valor. Com esse estudo pretende-se mostrar a relação dos dados de campo e ensaios funcionais utilizados. Através da análise dos dados de campo, foi selecionada uma característica funcional a ser melhorada no produto. A técnica de engenharia do valor aplicada ao produto resultou na variável que deveria ser melhorada no produto, e a análise de confiabilidade antes e após a alteração no produto, juntamente com os ensaios funcionais acelerados mostram a eficácia da melhoria realizada no produto.

Palavras-chave: Confiabilidade. Dados de campo. Engenharia do valor. Ensaios funcionais acelerados. Retentor 


\begin{abstract}
This research aims to show a way to use the reliability study as a tool to guarantee the improvements in a product design. To reach the goal, a improvement in a oil seal was executed through the study of its reliability and using the value engineer technique. This study aims to show the relationship between the field information and functional tests. Through the analysis of field information, the functional characteristic that must be improved in the product was selected, and the value engineering technique application result in an element that must be improved in a product. The reliability study after and before the change in product, together with functional tests showed the efficiency of the change in the product aimingat improving its operational life.
\end{abstract}

Key-words: Reliability. Field information. Value engineer. Functional test. Oil Seal. 


\section{LISTA DE ILUSTRAÇÕES}

Figura 1 - Função de Probabilidade Acumulada F(t). (Leitch,1995).......................24

Figura 2 - Função de Confiabilidade R(t). (Leitch, 1995)......................................25

Figura 3 - Representação da Curva da Banheira (Lafraia, 2001)..........................26

Figura 4 - Procedimento de Análise do Ensaio de Vida Acelerado. (SOUZA, 2003).37

Figura 5 - Fluxo a ser utilizado para a aplicação da metodologia da análise do valor

(Csillag, 1991)

Figura 6 - Retentor divido de acordo com suas partes e respectivos nomes [CBV

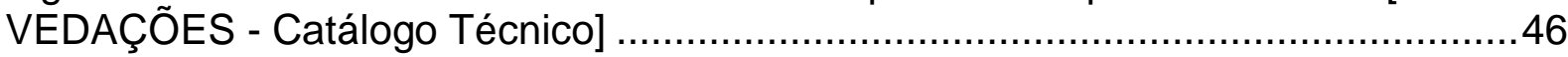

Figura 7 - Exemplos de construção externa para o retentor [DIN 3760]................48

Figura 8 - Exemplos de construção dos retentores tipo normais [DIN 3760] ...........49

Figura 9 - Exemplos de construção dos retentores tipo especiais [DIN 3760] -

Continua.

Figura 9 - Exemplos de construção dos retentores tipo especiais [DIN 3760]

(continuação)

Figura 10 - Exemplificação da construção das estrias hidrodinâmicas [DIN 3760] ..54

Figura 11 - Características básicas da mola [DIN 3760]

Figura 12 - Temperatura no ponto de vedação de um retentor na vedação de

diferentes produtos.

Figura 13 - Pressão permitida do produto a ser vedado para retentores [SABÓ -

Catálogo Técnico]

Figura 14 - Informações de dimensões básicas [SABÓ - Catálogo Técnico] .............59

Figura 15 - Informações de divergências permissíveis no alojamento [DIN 3760] ..60

Figura 16 - Informações de divergências permissíveis na circularidade do eixo [DIN

3760]

Figura 17 - Informações das nomenclaturas utilizadas na Tabela 1 [CBV Vedações -

Catálogo Técnico]

Figura 18 - Exemplificação da excentricidade estática que o retentor é submetido.

[CBV Vedações - Catálogo Técnico].

Figura 19 - Limite do excentricidade estática suportada pelo retentor [SABÓ -

Catálogo Técnico]

Figura 20 - Exemplificação da excentricidade dinâmica que o retentor é submetido.

[CBV Vedações - Catálogo Técnico]....

Figura 21 - Limite de excentricidade dinâmica suportada pelo retentor. [CBV

Vedações - Catálogo Técnico]

Figura 22 - Exemplos de dispositivos para montar o retentor no alojamento. [CBV

Vedações - Catálogo Técnico]

Figura 23 - Exemplos de proteção para vedação do retentor em relação ao eixo

[CBV Vedações - Catálogo Técnico]

Figura 24 - Fluxograma representando o método proposto neste texto.......................69

Figura 25 - Item X, retentor que estará sendo utilizado no estudo. ........................73

Figura 26 - Localização do retentor na aplicação .......................................... 74

Figura 27 - Diagrama de "Pizza" com as informações da analise de retorno ...........76

Figura 28 - Foto representativa das peças que retornaram de campo com laudo de

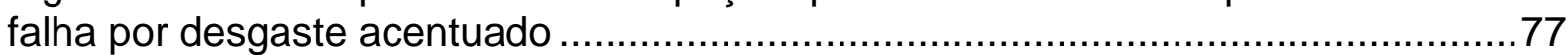

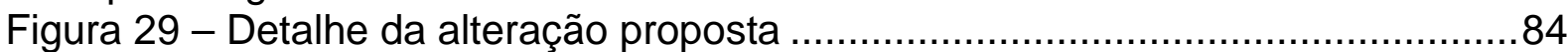

Figura 30 - Foto da maquina de teste utilizada.................................................. 85 
Figura 31 - Foto do dispositivo de simulação de contaminação externa ..................85

Figura 32 - Foto exemplificando condição de nível de centro do óleo.....................86

Figura 33 - Detalhe do comparativo em desgaste na região dos ribs na peça do teste \# 1

Figura 34 - Detalhe do comparativo em desgaste na região dos ribs na peça do teste \# 2

Figura 35 - Detalhe do comparativo em desgaste na região dos ribs na peça do teste \# 3

Figura 36 - Detalhe do comparativo em desgaste na região dos ribs na peça do teste \# 4

Figura 37 - Detalhe do comparativo em desgaste na região dos ribs na peça do teste \# 5

Figura 38 - Detalhe do comparativo em desgaste na região dos ribs na peça do teste \# 6

Figura 39 - Detalhe do comparativo em desgaste na região dos ribs na peça do teste \# 7

Figura 40 - Detalhe do comparativo em desgaste na região dos ribs na peça do teste \# 8

Figura 41 - Detalhe do comparativo em desgaste na região dos ribs na peça do teste \# 9

Figura 42 - Detalhe do comparativo em desgaste na região dos ribs na peça do

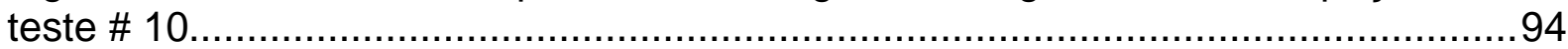

Figura 43 - Detalhe do comparativo em desgaste na região dos ribs na peça do teste \# 11

Figura 44 - Detalhe do comparativo em desgaste na região dos ribs na peça do teste \# 12

Figura 45 - Detalhe do comparativo em desgaste na região dos ribs na peça do teste \# 13.

Figura 46 - Detalhe do comparativo em desgaste na região dos ribs na peça do teste \# 14

Figura 47 - Detalhe do comparativo em desgaste na região dos ribs na peça do teste \# 15.

Figura 48 - Detalhe do comparativo em desgaste na região dos ribs na peça do teste \# 16 .

Figura 49 - Detalhe do comparativo em desgaste na região dos ribs na peça do teste \# 17

Figura 50 - Detalhe do comparativo em desgaste na região dos ribs na peça do teste \# 18.

Figura 51 - Detalhe do comparativo em desgaste na região dos ribs na peça do teste \# 19.

Figura 52 - Detalhe do comparativo em desgaste na região dos ribs na peça do teste \# 20.

Figura 53 - Detalhe do comparativo em desgaste na região dos ribs na peça do teste \# 21

Figura 54 - Detalhe do comparativo em desgaste na região dos ribs na peça do teste \# 22.

Figura 55 - Detalhe do comparativo em desgaste na região dos ribs na peça do teste \# 23.

Figura 56 - Detalhe do comparativo em desgaste na região dos ribs na peça do teste \# 24 
Figura 57 - Tabela de inserção de valores no software. 105

Figura 58 - Seleção de parâmetros para calculo de confiabilidade. 106

Figura 59 - Organização das curvas do resultado do teste de aderência para as curvas no calculo de confiabilidade.

Figura 60 - Parâmetros do resultado do teste de aderência para as distribuições. 107 Figura 61 - Resultados ordenados para o teste de aderência para as distribuições.

Figura 62 - Pesos utilizados nas ponderações de acordo com simulações de Monte Carlo. 109

Figura 63 - Valores para as variáveis da curva de Weibull para os dados de garantia.

Figura 64 - Curva de probabilidade para os dados de garantia. 110

Figura 65 - Gráfico de confiabilidade para os dados de garantia. 111

Figura 66 - Gráfico de probabilidade de falha para os dados de garantia.............112

Figura 67 - Gráfico da função densidade de probabilidade para os dados de garantia.

Figura 68 - Gráfico da taxa de falha para os dados de garantia.

Figura 69 - Tabela onde os resultados dos ensaios com a peça atual são inseridos.

Figura 70 - Ordenação resultante do teste de aderência para os dados de ensaio com a peça atual.

Figura 71 - Resultado do teste de aderência para os dados de ensaio com a peça atual.

Figura 72 - Valores para as variáveis da curva de Weibull que representa os resultados de ensaios com a peça atual.

Figura 73 - Curva de probabilidade para a peça atual.

Figura 74 - Curva de confiabilidade para a peça atual.

Figura 75 - Curva de probabilidade para a peça atual.

Figura 76 - Curva da função densidade de probabilidade para a peça atual. ........119

Figura 77 - Taxa de falha para a peça atual....................................................120

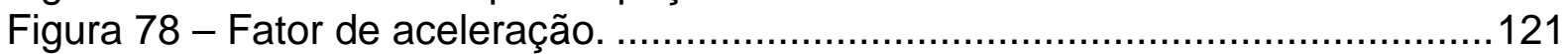

Figura 79 - Tabela onde são inseridos os resultados dos testes com a peça

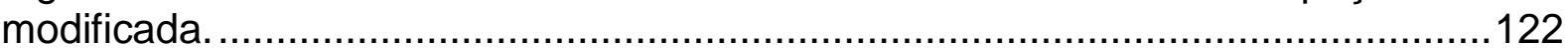

Figura 80 - Ordenação do resultado do testes de aderência................................123

Figura 81 - Resultado do teste de aderência..................................................123

Figura 82 - Valores para as variáveis da curva de Weibull que representa os

resultados de ensaios com a peça modificada....................................................124

Figura 83 - Curva de probabilidade para a peça modificada. ...............................125

Figura 84 - Curva de confiabilidade para a peça modificada.................................126

Figura 85 - Curva de probabilidade para a peça modificada...............................127

Figura 86 - Curva de função densidade de probabilidade para a peça modificada.

Figura 87 - Taxa de falha da peça modificada.................................................129

Figura 88 - Fator de aceleração gerado pelo teste..........................................131

Figura 89 - Gráfico comparativo com curvas de confiabilidade para dados de garantia, dados de ensaios em peça atual e ensaios em peça modificada.............134 Figura 90 - Comparativo dos cálculos de tempo médio até a falha para os dados de garantia, dados de ensaios em peça atual e ensaios em peça modificada..............135 


\section{LISTA DE TABELAS}

Tabela 1 - Tolerâncias para os diâmetros de eixo, alojamento, externo da peça [CBV Vedações - Catálogo Técnico] .......................................................................61

Tabela 2 - Identificação de rastreabilidade gravada na peça ..................................75

Tabela 3 - Informações da analise de retorno ……….......................................75

Tabela 4: Modos de falha dos dados de retorno ….........................................76

Tabela 5: Divisão de intervalos para os dados de retorno .....................................77

Tabela 6 : Tabela de vida para o retentor corrente …….....................................78

Tabela 7 : Tabela para cálculo do estimador de Kaplan-Meier ...............................78

Tabela 8: Tabela com relação de componentes do retentor e suas funções .............81

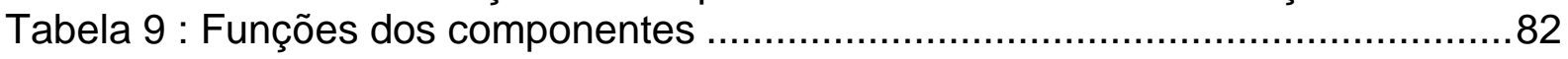

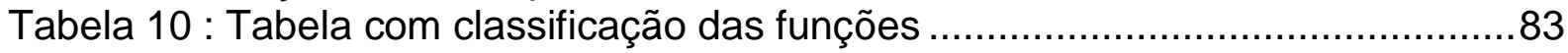

Tabela 11: Ciclo de solicitação utilizada no teste ...............................................87

Tabela 12: Tabela com resultados obtidos em teste de lama da peça corrente .......87

Tabela 13: Tabela com ciclagem utilizada nos testes de durabilidade acelerada .....91

Tabela 14: Tabela com resultados da peça corrente em teste de durabilidade

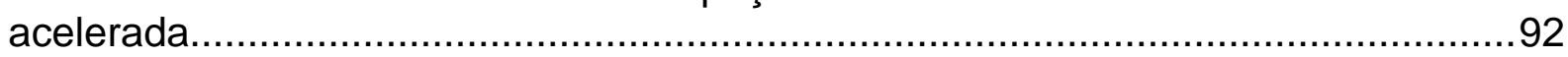

Tabela 15: tabela com resultados obtidos em teste de lama da peça alterada ..........96

Tabela 16: Tabela com resultados da peça alterada em teste de durabilidade

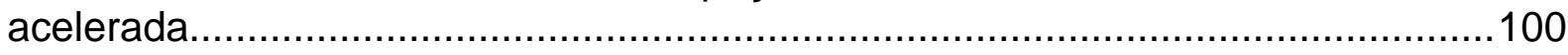

Tabela 17: Tabela com ciclagem utilizada nos testes de durabilidade acelerada ...130

Tabela 18: Tabela com ciclagem utilizada nos testes de durabilidade acelerada ...132 Tabela 19: Tabela comparativa com os resultados de confiabilidade para dados de testes com peça atual e modificada. 


\section{LISTA DE ABREVIATURAS E SIGLAS}

$\begin{array}{ll}\text { APQP } & \text { Advance Product Quality Planning } \\ \text { FMEA } & \text { Failure Mode and Effect Analysis } \\ E V & \text { Engenharia do Valor } \\ I Q A & \text { Instituto da Qualidade Automotiva } \\ V D A & \text { Verband der Automobilindustrie }\end{array}$




\section{LISTA DE SIMBOLOS}

$f(t)$

$F(t)$

$K$

$x m$

MTTF

MTTFCONDIÇÃO DE USO MTTFCONDIÇÃOACELRADA ${ }^{\wedge} \mathrm{q}$

$\wedge q(\%)$

$R(t)$

$t$

ti

tf

tteste

tuso

$\mathrm{Ta}$

$\lambda$

$\lambda b$

$\lambda(t)$

$\mathrm{mx}$
Função densidade de probabilidade

Função de probabilidade acumulada

Número de falhas observadas no ensaio

Estimativa do tempo médio entre falhas

Tempo médio até a falha

Tempo médio até a falha na condição de uso

Tempo médio até a falha na condição acelerada

Probabilidade de um item falhar no intervalo

Probabilidade percentual de um item falhar no intervalo

Função de confiabilidade

Tempo para ocorrência da falha

Tempo de ocorrência da i-ésima falha

Tempo até a falha

Tempo até a falha nas condições de teste

Tempo até a falha nas condições de uso

Tempo total operacional das unidades ao longo do ensaio

Taxa de falha

Taxa de falha básica relacionada com componente

Taxa de falha

Valor médio associado à uma função densidade de probabilidade 


\section{SUMÁRIO}

1 INTRODUÇÃO

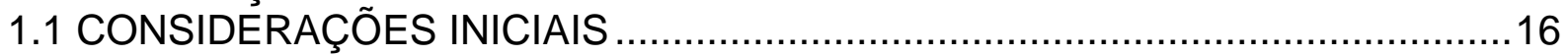

1.2. OBJETIVO

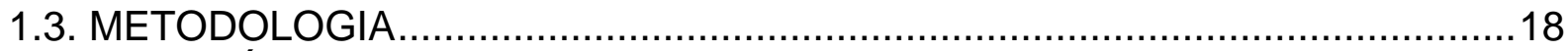

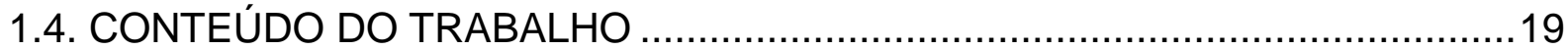

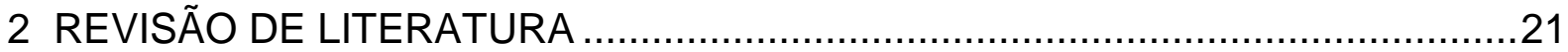

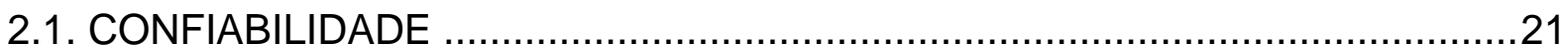

2.1.1 Definição e tratamento matemático da confiabilidade ..................................24

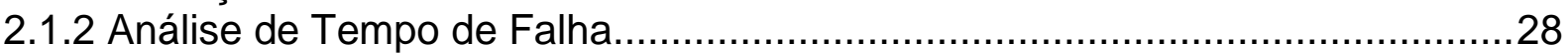

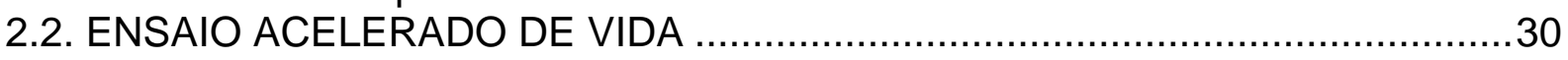

2.2.1 Métodos de Aceleração ...........................................................................

2.2.2 Análise de Resultados de um Ensaio Acelerado de Vida................................35

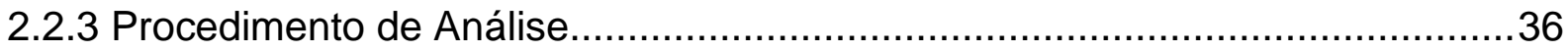

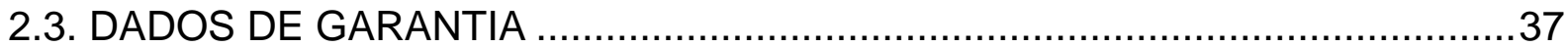

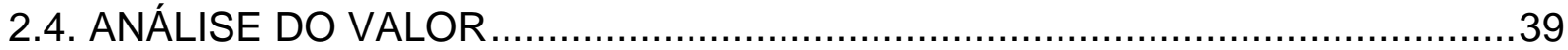

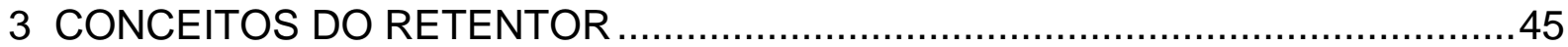

3.1 - EXTERNO CILÍNDRICO DE ELASTÔMERO OU DE METAL ….....................46

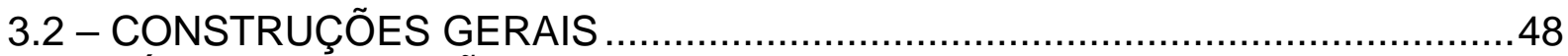

3.3 - LÁBIO DE VEEDAÇÃO PRINCIPAL COM CARGA DE MOLA …....................53

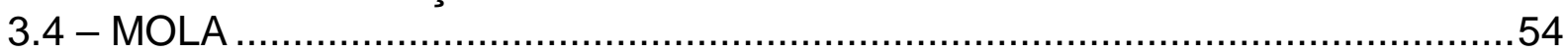

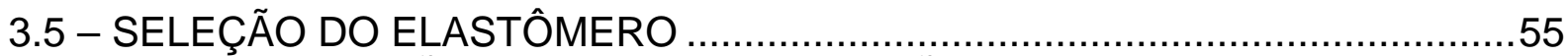

3.6 - RECOMENDAÇÕES QUANTO A APLICAÇÃO DO RETENTOR ....................58

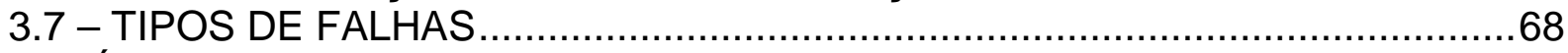

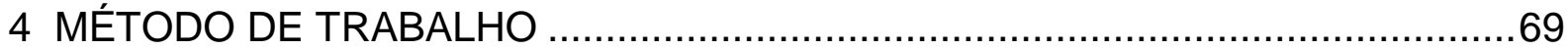

5 CASO EXEMPLO: METODOLOGIA PROPOSTA APLICADA A UM RETENTOR72 5.1. ESTUDO DETALHADO SOBRE O ITEM X, DE SUA FUNÇÃO NO CONJUNTO, E DE SEUS COMPOMENTES........................................................................ 5.2. ANÁLISE DOS DADOS DE GARANTIA E CÁLCULO DA CONFIABILIDADE DO

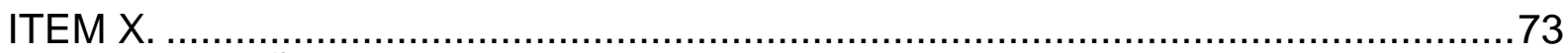
5.3. APLICAÇÃO DA METODOLOGIA DE ENGENHARIA DO VALOR PARA O ITEM

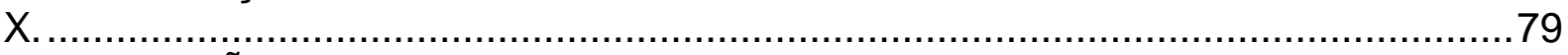
5.4. SELEÇÃO E ESTUDO DOS ITENS / COMPONENTES A SEREM

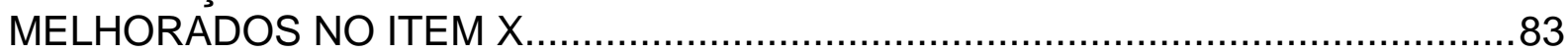
5.5. EXECUÇÃO DE ESNSAIOS DE VIDA ACELERADO NO PRODUTO ATUAL. . 84 5.5.1. Condições de teste para ensaio de contaminação externa na peça corrente .86

5.5.2. Resultados no teste de lama com a peça corrente .....................................87

5.5.3. Análise das peças corrente testadas em lama ..........................................88

5.5.4. Execução de ensaios de vida acelerado na peça corrente - Teste de durabilidade acelerado ...................................................................................91 5.5.5. Condições de teste para ensaio de durabilidade acelerado para peça corrente

5.5.6. Resultados no teste de durabilidade acelerado com a peça corrente ................92

5.5.7. Análise das peças corrente testadas em durabilidade acelerada....................92 5.6. EXECUÇÃO DE ENSAIOS DE VIDA ACELERADO NO PRODUTO MELHORADO. 
5.6.2. Resultados no teste de lama com a peça alterada.....................................95

5.6.3. Análise das peças alteradas testadas em lama ........................................96

5.6.4. Execução de ensaios de vida acelerado no produto alterado - Teste de

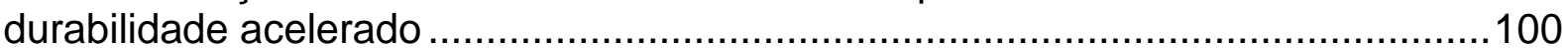

5.6.5. Condições de teste para ensaio de durabilidade acelerado no produto alterado

5.6.6. Resultados no teste de durabilidade acelerado com a peça alterada ..............100

5.6.7. Análise das peças alteradas testadas em durabilidade acelerada ................100

5.7. ESTUDO DE CONFIABILIDADE.......................................................103

5.7.1 Estudo de confiabilidade da peça atual através dos dados de garantia.........104

5.7.2 Estudo de confiabilidade da peça atual submetida à ensaio de vida acelerado

5.7.3 Estudo de confiabilidade da peça modificada submetida à ensaio de vida

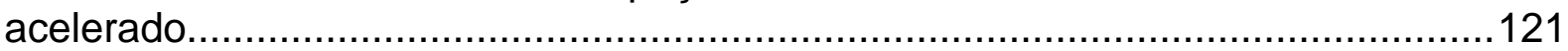

5.7.4 Comparativo entre dados de garantia e dados do ensaio de vida acelerado por

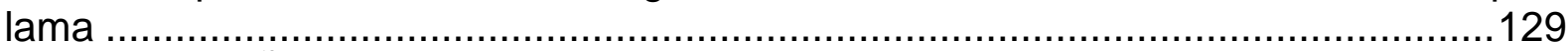

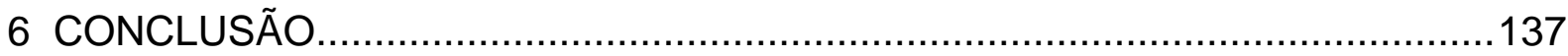

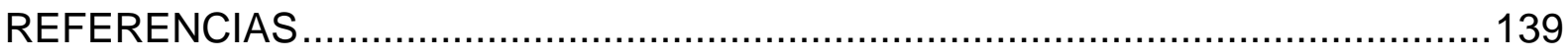




\section{INTRODUÇÃO}

\subsection{CONSIDERAÇÕES INICIAIS}

Devido às crescentes demandas de consumidores cada vez mais exigentes, a indústria observa um aumento na necessidade de desenvolver produtos em menor tempo, com maior qualidade e custo competitivo. Considerando a necessidade de se incrementar o valor agregado nos produtos, pode-se observar que os novos modelos usualmente se apresentam cada vez mais complexos se comparados aos seus antecessores. Em conjunto à esses fatos, observa-se também uma alteração temporal no ciclo de vida dos produtos, onde se pode constatar que apesar dos mesmos terem uma durabilidade maior devido à exigência de seus consumidores, o tempo de venda das gerações de produtos novos no mercado está se reduzindo. Um exemplo disso é a quantidade de gerações para um mesmo modelo de veículo, processo chamado também de "facelift", onde são realizadas alterações estéticas que geram uma nova geração para um mesmo modelo. Pode-se notar casos em que do lançamento de uma geração nova até sua paralisação de fabricação, tem-se em média três anos, e não pode-se deixar de salientar que para a elaboração de cada geração nova tem-se uma grande quantidade de peças, ferramentais e equipamentos de fabricação novos.

Observa-se também uma mudança de paradigmas na produção e desenvolvimento de novos produtos. Nesse contexto, a capacidade de rapidamente desenvolver, introduzir, difundir e manter inovações tanto no produto como no processo de fabricação passou a exercer papel fundamental para as empresas, auxiliando no deslocamento dos concorrentes de posições aparentemente intocáveis. Essas modificações se mostram ainda mais agressivas na indústria automobilística e de autopeças.

Nesse cenário, pode-se observar um aumento expressivo na utilização de ferramentas que possam auxiliar na resolução desses desafios. Dentre as ferramentas utilizadas na indústria de autopeças podem-se citar o FMEA e as demais presentes em manuais como o APQP e o VDA. As metodologias utilizadas 
para o planejamento e garantia da qualidade devem ser utilizadas já na fase de concepção do projeto do produto, pois é nessa fase que nasce em grande parte a qualidade e confiabilidade do produto.

Durante o desenvolvimento deste trabalho, procurou-se contextualizar os aspectos da confiabilidade do produto como parte integrante das ações de seu desenvolvimento e planejamento da qualidade, buscou-se também sua relação com a melhoria do produto considerando-a como um fator de valor.

\subsection{OBJETIVO}

O objetivo deste trabalho é exemplificar o processo de melhoria de um produto através da utilização dos estudos de confiabilidade somados à analise de valor como métodos para auxiliar a planejar e garantir que os requisitos dos clientes sejam atendidos na concepção do novo produto.

Pretende-se atingir esse objetivo através da análise de dados de projeto e confiabilidade do item, esta última obtida através de dados de garantia de campo, assim como aplicação da análise de valor para selecionar o item a ser melhorado no produto.

O produto escolhido para a análise mencionada é um vedador automotivo, também conhecido como retentor.

Foi escolhido um vedador devido à facilidade de acesso às informações necessárias para a elaboração do trabalho, assim como pelo fato desse produto possuir uma função importante nos sistemas, onde um exemplo de sua complexidade e importância pode ser observada no acidente do veículo espacial Challenger ocorrido em 28 de janeiro de 1986, sendo divulgado oficialmente que a causa da explosão foi determinada pela falha do retentor de vedação do tanque de combustível devido à variação abrupta de temperatura [Lynn Heimerl,2004]

Foi selecionado um retentor automotivo devido ao fato de que considerando o grau de desenvolvimento encontrado nesse tipo de indústria, pode-se observar que grande parte de seus produtos são a evolução de um produto existente e não um desenvolvimento de uma idéia totalmente nova. Portanto se observa uma possibilidade considerável para a atualização de um item existente. 
Outro fator que auxiliou na seleção de um produto automotivo se deve ao fato de sua importância no custo final de um automóvel, que pode ser comprovada pelo estudo de Ferraz et al. (1997), afirmando que a fabricação das autopeças corresponde de 60 a $80 \%$ do custo do veículo montado, sendo esta relação diretamente afetada pelas mudanças no padrão de concorrência das montadoras. Estas por sua vez, estão repassando cada vez mais responsabilidades e custos de projetos, como entregas no sistema "just in time" (JIT) com qualidade total, rapidez nas mudanças, fornecimento de componentes e subconjuntos já montados e testados, produtos mais leves, duráveis e menos poluidores, com o emprego da eletrônica, materiais plásticos, materiais compostos e alumínio, assim sendo, exigindo preços reduzidos, tecnologia de produtos, entrega e prazo, fatores extremamente importantes nas decisões de compra.

Para Silva (1999), os 20 a 40\% do custo do veículo que sobram à montadora para administrar é uma parcela muito pequena para se buscar reduções de custos e buscar a competitividade da empresa, se forem seguidas apenas as metodologias tradicionais de custos que operam sob o perímetro da empresa.

\subsection{METODOLOGIA}

Como método proposto, é primeiramente realizado um estudo detalhado sobre o produto retentor para que se possa ter uma base sólida de sua função no conjunto, assim como entendimento de seus componentes.

Em seguida, realiza-se um levantamento e análise dos dados de garantia dos itens candidatos ao estudo para que se possa selecionar o item que mais se adeqüe ao estudo proposto. Nessa análise são verificadas características como: quantidade de peças que falharam, volume de peças produzidas, período de operação até a falha, rastreabilidade e veracidade das informações coletadas, entre outros. Com os dados de garantia calcula-se a confiabilidade do retentor na versão de produção atual, e verifica-se qual o maior motivo de retorno de garantia. 
Na seqüência realiza-se a análise de valor do retentor, a fim de se determinar quais as funções que estão relacionadas ao maior motivo de retorno de garantia, oferecendo, portanto, potencial para otimização.

Após a execução das etapas anteriormente citadas, realizam-se ensaios no produto atual e no melhorado. Com resultados dos mesmos realiza-se uma análise de confiabilidade e regressão dos resultados obtidos, para determinação da confiabilidade do produto melhorado em relação ao modelo de produção.

Com o exposto acima, pretende-se criar uma metodologia para desenvolvimento de produtos otimizados sob o ponto de vista da confiabilidade.

Pode-se observar que durante a execução desse trabalho estamos:

- Estudando o produto retentor;

- Analisando dados de garantia através de estudos de confiabilidade

- Aplicação da técnica de análise do valor para o retentor, a fim de se obter a(s) característica(s) no produto a serem melhoradas;

- Seleção de uma característica de desempenho do retentor a ser melhorada;

- Realização de testes funcionais a fim de se obter o mesmo modo de falha observado nas peças devolvidas durantes o período de garantia para a característica de desempenho a ser melhorada;

- Realização da(s) melhoria(s) identificada(s) e realização de testes funcionais para a verificação de eficácia das mesmas;

- Análise dos resultados comparativos dos testes funcionais realizados antes e após a(s) melhoria(s), assim como execução da estimulação da nova confiabilidade do produto.

\subsection{CONTEÚDO DO TRABALHO}

O trabalho é dividido em 6 capítulos conforme a seguinte divisão:

No capítulo 1 > introdução e motivação do trabalho, onde são apresentados os motivos da realização deste, os objetivos pretendidos e o conteúdo do mesmo.

No capítulo 2 > revisão bibliográfica, onde será apresentado um histórico dos principais autores que trataram dos assuntos envolvidos neste trabalho e suas 
contribuições. Os assuntos selecionados são: confiabilidade, análise dos dados de garantia, engenharia do valor e testes acelerados.

No capítulo 3 > são apresentados conceitos do retentor, e sua aplicação (retirados de normas, manuais e catálogos)

No capítulo 4 > propor um método de trabalho a ser aplicado a um retentor, o qual é composto por 6 passos, os quais são:

1 - estudo detalhado sobre o produto, de sua função no conjunto, assim como de seus componentes.

2 - análise dos dados de garantia para caracterizar a confiabilidade do mesmo

3 - aplicar a metodologia de engenharia do valor para o produto

4 - selecionar e estudar itens / componentes a serem melhorados no produto

5 - execuções de ensaios de vida acelerado no produto atual

6 - execuções de ensaios de vida acelerado no produto melhorado

7 - estudo de confiabilidade com os dados do estudo de vida para estimar a nova confiabilidade do produto

No capítulo 5 > aplicação do método de trabalho e apresentação dos resultados para cada passo através do emprego de tabelas e gráficos juntamente com a análise dos resultados obtidos para a melhoria da confiabilidade do produto.

No capítulo 6 > conclusão do trabalho, avaliando-se as vantagens e desvantagens do método proposto e os resultados obtidos. 


\section{REVISÃO DE LITERATURA}

\subsection{CONFIABILIDADE}

Pode-se observar a existência de diversas definições de confiabilidade de acordo com autores e órgãos reguladores diferentes.

Segundo a European Organization for Quality Control (1965) apud Leitch (1995) confiabilidade é "A medida da capacidade de um produto operar com sucesso, quando solicitado, por um período de tempo pré-determinado, sob condições ambientais específicas. É medida como uma probabilidade".

Segundo a norma NBR-5462 ABNT (1994), confiabilidade pode ser definida como "A capacidade de um item desempenhar uma função requerida sob condições especificadas, durante um dado intervalo de tempo".

Já para Freitas e Colosimo (1997, p.5) "Confiabilidade é a probabilidade de um item desempenhar satisfatoriamente a função requerida, sob condições de operação estabelecidas, por um período de tempo pré-determinado".

De acordo com US Military Handbook (1970) apud Leitch (1995) confiabilidade pode ser definida como "A probabilidade de um item executar a sua função sob condições predefinidas de uso e manutenção por um período de tempo especifico".

Outra definição é a do BS Institution (1970) apud Leich (1995) e UK Army (1976) apud Leitch (1995) onde confiabilidade é definida como "A possibilidade de um item executar a sua função sob determinadas condições especificas, por um período prédeterminado".

Já segundo Borges et. al. (1996, p.2) "Confiabilidade de um produto é a probabilidade de bom funcionamento do mesmo durante período de tempo e condições de uso especificado."

Dentre as definições mostradas, pode-se destacar os seguintes pontos em comum:

- possibilidade de falha como uma grandeza estatística

- desempenho especificado do equipamento

- condição de uso pré-definida

- período de utilização pré-definido

E três aspectos devem ser salientados devido a sua importância: 
- A definição de desempenho do produto deve ser especificada.

- As condições de uso e do meio devem ser especificadas.

- O período de tempo de utilização deve ser especificado.

Devido a esses pontos, a confiabilidade é fator-chave em muitas decisões de compra, e vários dos requisitos para obtenção da qualidade do produto ou serviço são também aplicáveis à confiabilidade, segundo Oakland (1994, p.16).

O período de utilização não precisa ser necessariamente ser medido como uma grandeza temporal, mas também pode ser medido como uma distância percorrida ou através de ciclos de operação, Souza (2003)

Segundo Ramakumar (1993), após a 1a Guerra Mundial, com a expansão da indústria aeronáutica na década de 1930, foram utilizados pela primeira vez os conceitos de confiabilidade, pois até então, tudo era qualitativo. Lentamente foram quantificados, através de taxa média de falha e do número médio de falhas em aeroplanos e dirigíveis, uma avaliação inicial de sua confiabilidade. Outro fato histórico foi a baixa de confiabilidade de equipamentos eletrônicos durante a guerra da Coréia, o que levou os Estados Unidos a ter maior interesse no assunto, de tal modo que contratos militares começavam com cláusulas envolvendo multas e penalidades associadas ao grau de confiabilidade verificado durante a série de testes em relação ao exigido pelo projeto.

Nos dias atuais, a confiabilidade tem se tornado o centro das atenções de muitas corporações. Na indústria automotiva, pode-se observar que as montadoras desejam aumentar o período de garantia dos veículos, para ofertar essa característica como diferencial à seus consumidores. Isso faz com que haja um aumento na exigência de confiabilidade dos componentes utilizados. Assim as montadoras passam essa exigência para seus fornecedores e sub-fornecedores.

Portanto, é de suma importância criar mecanismos de prevenção capazes de reproduzir e quantificar com precisão falhas indesejáveis ao produto final, pois quando se fala em melhoria de produtos, se refere a conceber projetos que reduzam cada vez mais custos de fabricação, porém sem comprometimento do desempenho esperado pelo cliente quanto à funcionalidade e durabilidade do produto.

Para análise de Engenharia define-se a confiabilidade como uma probabilidade. Assim, estar-se-á utilizando o conceito de confiabilidade como sendo a probabilidade de um produto, sistema, máquina ou equipamento operar sem falhas, dentro das 
especificações para as quais foi projetado e construído, por um período de tempo determinado.

Para analisar a confiabilidade de um processo ou produto é de fundamental importância saber a clara definição das falhas e dos mecanismos que levam a elas. A definição de um critério de falha é de fundamental importância, pois o mesmo possibilita determinar a partir de que momento o produto ou equipamento sob análise é considerado com o desempenho abaixo daquele considerado aceitável. Como exemplos de critérios de falha, pode-se citar o vazamento de óleo do motor pelo retentor, quebra de eixo de uma máquina e uma lâmpada queimada.

Segundo Lafraia (2001), falha funcional é a incapacidade de qualquer item atingir o padrão de desempenho esperado.

O modo de falha pode ser definido como o mecanismo pelo qual o item falha $e$ normalmente tem-se mais de um modo de falha para os produtos. O modo de falha dos componentes é função das solicitações a que o mesmo será submetido durante sua operação. Entretanto, é possível que haja alterações neste modo de falha se as solicitações limites previstas no projeto forem ultrapassadas.

Adicionalmente, o ambiente de operação deve ser bem caracterizado, sendo um aspecto complexo, pois não só inclui o meio físico, mas as ações de manutenção e operação. Finalmente, deve-se especificar o tempo de utilização, o qual pode expressar a severidade de uso imposta ao produto.

A confiabilidade é uma grandeza mensurável a partir da análise estatística da ocorrência do evento falha. Sua observação e tratamento estatístico são relevantes, pois a partir desta análise pode-se obter a probabilidade citada na definição de confiabilidade.

Segundo Ebel (1998), na década de 60 houve um grande crescimento da chamada Confiabilidade Física que visa analisar o processo de falha através de estudo do mecanismo físico ou químico desencadeador da falha. Esta tendência nasceu na RADC (Rome Air Development Center) em Nova York nos Estados Unidos. Em 1961 a RADC iniciou um programa denominado Física da Falha (Physics of Failure). Atualmente importantes pesquisas são desenvolvidas em Física da Falha, principalmente em institutos como o CALCE (Center for Advanced Life Cycle Engineering) da Universidade de Maryland, Estados Unidos.

A partir do final de década de 70, a confiabilidade passou a ser empregada no projeto de sistemas complexos, cuja falha normalmente causa prejuízos elevados, 
quer sejam de natureza ambiental, financeira ou econômica, além de poder levar a perda de vidas humanas.

2.1.1 Definição e tratamento matemático da confiabilidade

Para a conceituação matemática utiliza-se a seguinte definição de confiabilidade: "a probabilidade de que um sistema ou equipamento sobreviva por um período de tempo específico".

Expressando esta probabilidade em termos da variável aleatória $t$, o tempo até ocorrer a falha, e da correspondente função densidade de probabilidade (fdp) de ocorrência de falha $f(t)$, tem-se que a probabilidade de falha, em um intervalo de tempo específico, pode ser definida pela relação:

$$
f(t) \Delta t=\mathrm{P}\{t<t<t+\Delta t\}
$$

Sendo $F(t)$ a função de distribuição acumulada, vem:

$$
F(t)=\mathrm{P}\{\boldsymbol{t}<t\}
$$

ou seja, $F(t)$ expressa a probabilidade de ocorrer falha até um tempo $t$.

E por conceito lógico, esta função $F(t)$ é crescente com o tempo, atingindo um valor unitário quando $t$ tende a $\infty$, tal como indicado na Figura 1.

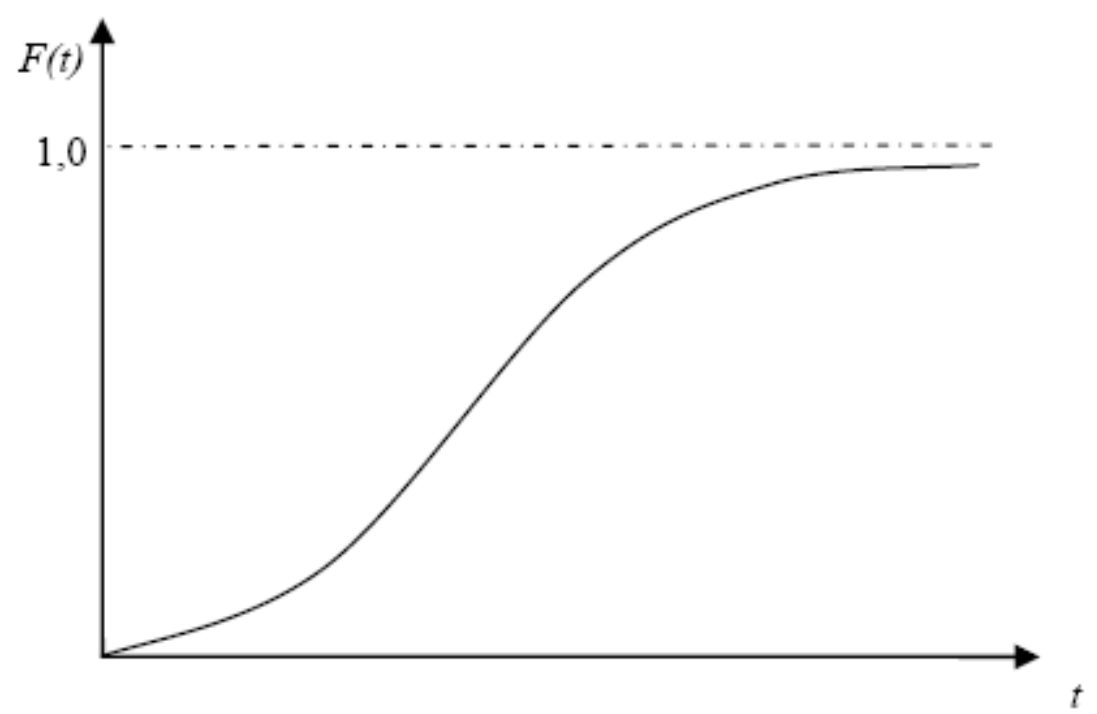

Figura 1 - Função de Probabilidade Acumulada F(t). (Leitch,1995). 
Como, sob o ponto de vista da lógica de sua operação, um componente ou equipamento ou está operando adequadamente, conforme previsto no projeto, ou está no estado de falha, portanto eventos mutuamente excludentes, a confiabilidade, $R(t)$, pode ser expressa pela relação:

$$
R(\mathrm{t})=P\{\boldsymbol{t}>t\}
$$

ou seja,

$$
R(t)=1-F(t)
$$

A Função de Confiabilidade está mostrada na Figura 2.

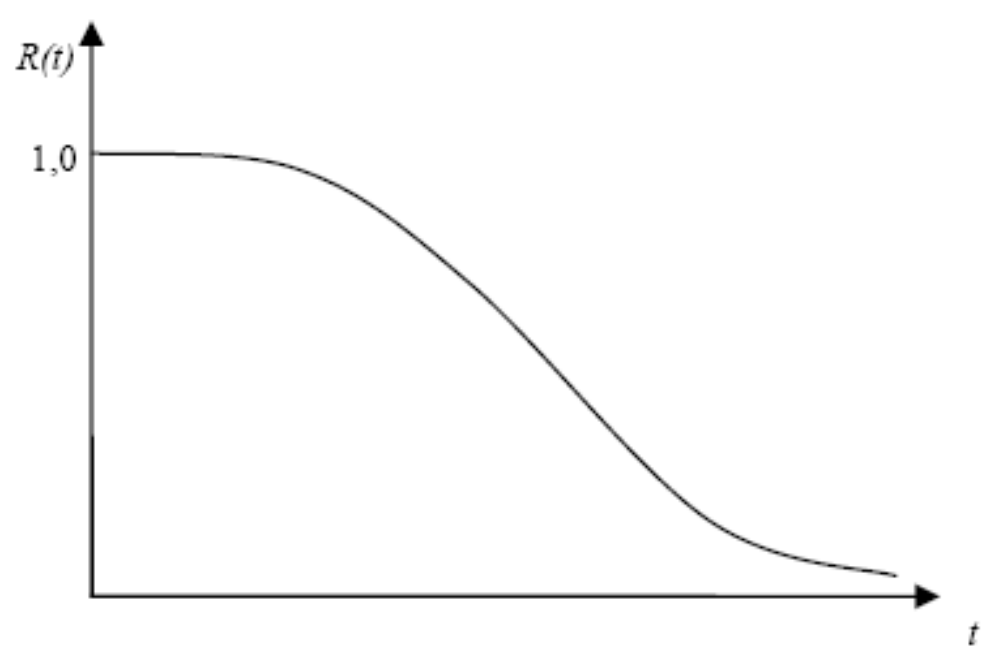

Figura 2 - Função de Confiabilidade R(t). (Leitch, 1995).

Como decorrência da própria definição da função distribuição acumulada, tem-se:

$$
\begin{aligned}
& R(t=0)=1 \\
& R(t=\infty)=0
\end{aligned}
$$

A partir do gráfico apresentado na Figura 2 verifica-se, portanto, que a confiabilidade de um produto ou sistema apenas decai ao longo do tempo, ou seja, quanto maior o tempo de operação do mesmo maior será a probabilidade deste apresentar falha. Portanto, apenas no instante em que o equipamento é colocado em operação, sua confiabilidade é de $100 \%$. Adicionalmente, pode-se afirmar que a confiabilidade não é restaurada, ou seja, não aumenta ao longo da vida operacional. 
Segundo Souza (2003) a taxa de falha $\lambda(t)$ pode ser definida em termos da própria confiabilidade, como segue: " $\lambda(t) \Delta t$ é a probabilidade de que o sistema falhará em um tempo de apreciação $t<t+\Delta t$, dado que ainda não falhou até o tempo em $t=t$ ". Tem-se que $\lambda(\mathrm{t}) \Delta \mathrm{t}$ é a probabilidade condicional indicada na equação (2.7):

$$
\lambda(\mathrm{t}) \Delta t=\mathrm{P}(t<t+\Delta t \mid t>t)
$$

Assim, com base na definição de probabilidade condicional, tem-se:

$$
P(t<t+\Delta t \mid t>t)=\mathrm{P}\{(\boldsymbol{t}>t) \cap(t<t+\Delta t)\} / \mathrm{P}(\boldsymbol{t}>t)
$$

Como o numerador da Equação (2.8) é a própria $f(t) \Delta t$ e o denominador é $R(t)$, a taxa de falhas instantânea é expressa pela relação:

$$
\lambda(\mathrm{t})=f(t) / R(t)
$$

O comportamento da taxa de falha, $\lambda(t)$, em relação ao tempo $t$ é um indicador das causas de falha. A curva da banheira ("bathtub curve"), mostrada na Figura 3, representa graficamente esta relação para sistemas ou componentes sem redundância.

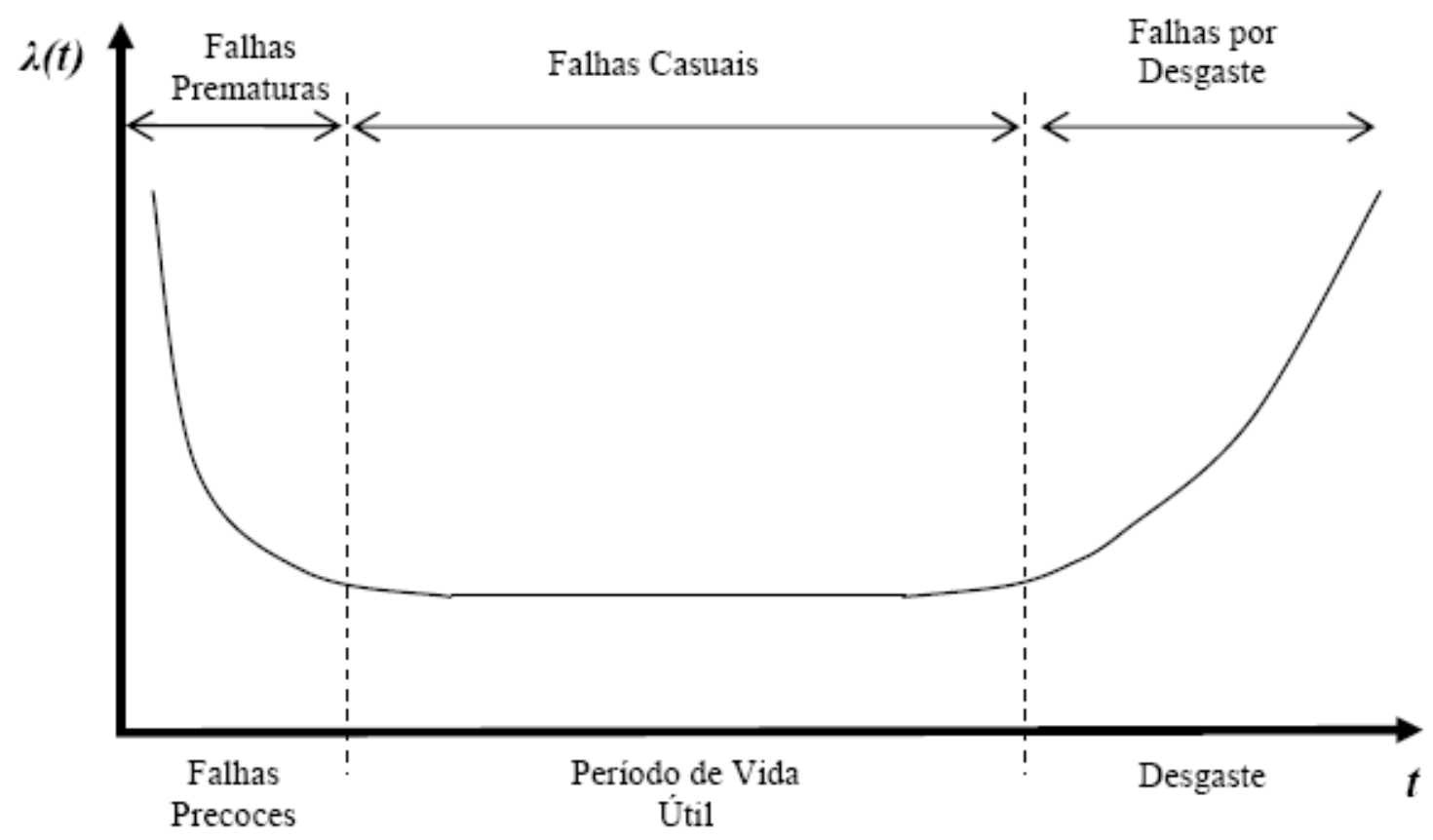

Figura 3 - Representação da Curva da Banheira (Lafraia, 2001).

O curto intervalo de tempo indicado na primeira região do gráfico indica taxas de falha que decrescem a partir de $t=0$. 
Esta região denomina-se de falhas precoces ("early failures"). As falhas, neste período, são causadas por problemas associados aos processos de fabricação e montagem ou mesmo com o material empregado na fabricação do componente. Estes problemas são não usuais, ou seja, ocorrem esporadicamente, pois sua ocorrência deve ser controlada por ações de Engenharia da Qualidade. No caso de montagem, é bastante comum a falha estar relacionada a algum erro humano do operador, por exemplo, no caso da montagem de um retentor na aplicação final de uma caixa de transmissão, podem ocorrer problemas de montagem como 0 desalinhamento do selo em relação ao alojamento ou do selo em relação ao eixo de aplicação. Muitas vezes o problema da falha precoce é contornado através da especificação de um período de tempo durante o qual o equipamento realiza um préteste. Durante este tempo o carregamento e utilização do produto são controlados de tal maneira que problemas são detectados e componentes são reparados antes da entrega do produto ao cliente final.

A região intermediária da curva da banheira contém as aproximadamente constantes e menores taxas de falha, sendo preferencialmente o período de operação do produto. As falhas que ocorrem durante esta fase são denominadas falhas aleatórias e normalmente originam-se de carregamentos inevitáveis e inesperados e menos comumente devido a defeitos inerentes ao produto em si. Podem-se citar como exemplos de causas de falha na região intermediária da curva da banheira: terremotos, surtos de energia, vibrações excessivas, impactos mecânicos, flutuações de temperatura e de umidade inesperados.

$\mathrm{Na}$ última região, mais à direita da curva da banheira, observa-se que a taxa de falha é crescente, em função do próprio desgaste do produto, na fase final de sua vida útil. Nesta fase, as falhas tendem a estar relacionadas com fenômenos físicos de natureza cumulativa tais como corrosão, trincas de fadiga, desgaste por atrito, dentre outros. $\mathrm{O}$ aumento muito rápido da taxa de falha normalmente fundamenta o critério de quando peças devem ser substituídas e também determina a vida útil do produto ou sistema.

A curva da banheira representada na Figura 3 pode ser considerada genérica, uma vez que cada categoria de produto apresenta uma curva característica.

Quando são medidos os tempos até a falha de componentes ou sistemas e são calculados as funções $f(t)$ ou $F(t)$, está se trabalhando com distribuições estatísticas de tempo de vida. 
Um parâmetro importante de qualquer distribuição estatística é o seu valor médio. 0 valor médio associado a uma função densidade de probabilidade $f(t)$ é calculado como indicado na equação 2.10

$$
\mathrm{m}_{\mathrm{T}}=\int_{0}^{\infty} t \cdot f(t) d t
$$

O valor médio é chamado de Tempo Médio até a Falha, ou MTTF, do inglês "Mean Time to Failure".

\subsubsection{Análise de Tempo de Falha}

Análise de Tempo de Falha, conforme Freitas e Colosimo (1997, p.65), é a análise de dados de durabilidade provenientes tanto de campo quanto de testes de vida acelerados para se obter parâmetros de interesse, como o tempo médio até a falha (MTTF), a fração esperada de falhas no período de garantia, entre outros.

Segundo Fiedler e Knoblauch (2003), os parâmetros mais utilizados são nesse tipo de análise:

- Função confiabilidade $R(t)$ : fração esperada de unidades em operação após um tempo $t$.

- Função de Distribuição Acumulada $F(t)$ : fração de unidades que falharam após um tempo t.

- Função de Densidade de Probabilidade (fdp) $f(t)$ : fração da população original que falha entre um tempo $t$ e $t+d t$.

- Taxa de Falha $\lambda(t)$ : fração da população restante em um tempo t que falha entre $t$ e $t+d t$

Das definições observadas no tópico acima, pode-se considerar como dados:

$R(t)=1 \rightarrow 0, t=0 \rightarrow \infty$

$f(t)=d F(t) / d t$

$F(t)=1-R(t)$

$F(t)=0 \rightarrow 1, t=0 \rightarrow \infty$

$\lambda(t)=f(t) / R(t)$

Segundo Billinton e Allan (1987), e conforme observado acima, estes parâmetros são descritos por distribuições de probabilidades. Todos os componentes falharão em diferentes tempos no futuro, pois esses tempos de falha obedecem a 
distribuições de probabilidade que podem ou não ser conhecidas, e que descrevem a probabilidade de um item falhar ou a sobrevivência do mesmo num determinado intervalo de tempo. Se um processo de manufatura sofre alterações, conseqüentemente a distribuição que descreve os tempos de falha do componente também pode se alterar, resultando em outros valores de probabilidade de falha dentro de um período de tempo.

Tais distribuições não podem ser determinadas a partir do conhecimento do material e geometria do componente ou processo de fabricação do mesmo e sim através de ensaios com amostras ou informações de dados de tempo até a falha de componentes em operação.

As distribuições de probabilidade ou modelos probabilísticos mais empregados são Exponencial, Weibull, Gauss ou Normal e Log-normal, e só após a seleção de uma destas distribuições, que melhor descreva o comportamento da distribuição do tempo de falha do produto sob teste, é possível estimar os parâmetros de interesse, como a confiabilidade, taxa de falhas, porcentagens de falhas até um tempo de operação específico.

Segundo Freitas e Colosimo (1997), os modelos probabilísticos são caracterizados por valores, chamados de parâmetros, tais como de forma, escala e posicionamento no caso da distribuição de Weibull, e que conferem a identidade do comportamento da distribuição dos dados em análise, sendo então possível responder às perguntas de interesse. Os modelos Normal e Lognormal são caracterizados por dois parâmetros, o exponencial por apenas um, e o modelo de Weibull por 2 ou 3 parâmetros. Para estimação destes parâmetros utilizam-se os métodos como o dos mínimos quadrados e o da máxima verossimilhança.

Como apresentado, falhas são caracterizadas como eventos indesejáveis no produto, sendo então necessário, em um estudo de confiabilidade, a correta definição do que vem a ser falha em um componente e uma unidade de medida, como por exemplo, horas, ciclos, quilômetros, para caracterizar o tempo de uso do componente no instante da falha.

As falhas podem vir de dados completos onde se conhece o valor exato do tempo da falha ou dados agrupados onde se conhece o intervalo limitado em que se encontra o valor do tempo da falha. 


\subsection{ENSAIO ACELERADO DE VIDA}

A maioria dos produtos, senão sua totalidade, é projetada para operar por longos períodos de tempo sem falhar. Assim, não é novidade que poucas unidades falhem em um ensaio realizado nas condições normais de uso, logo, é particularmente difícil estimar a distribuição dos tempos até a falha ou o desempenho ao longo do tempo de componentes de produtos de alta confiabilidade a partir da execução de ensaios de confiabilidade com solicitações correspondentes às condições normais de uso, quer seja pela necessidade de longa duração do ensaio ou pela observação de um reduzido número de falhas, fato que aumenta a incerteza na estimativa da confiabilidade.

Em um ensaio acelerado de vida, busca-se reduzir o tempo de ocorrência de falhas do equipamento ou produto, sem se alterar os modos de falha. A partir dos resultados destes ensaios, e empregando-se técnicas de extrapolação de resultados, baseadas não só em modelos matemáticos, mas também nos fenômenos físicos associados aos modos de falha, pode-se definir a confiabilidade do equipamento na sua condição normal de uso.

Os ensaios acelerados de vida são largamente utilizados para produtos onde o tempo disponível para realização de ensaios é muito curto em relação ao tempo de vida útil para que este produto foi projetado. Estes ensaios são particularmente utilizados para se obter informações da confiabilidade de componentes, proporcionando a possibilidade de uma identificação e remoção antecipada dos modos de falha, melhorando assim a confiabilidade ainda na fase de desenvolvimento do produto. Neste ponto existem dificuldades práticas e questões estatísticas envolvidas na aceleração da ocorrência da falha, especialmente para produtos mais complexos, que podem falhar de diferentes maneiras.

Segundo Nelson (2005), ensaio acelerado de vida consiste em um ensaio de elevada solicitação que encurta a vida do produto, ou acelera a degradação do desempenho de um produto. O termo "solicitação" é usado de forma a representar uma variável acelerada. O propósito destes ensaios é, normalmente, estimar a vida ou a degradação do produto sob solicitações de menor magnitude, representando as 
condições normais de uso, a partir de ensaios com solicitações de maior magnitude e, portanto com menor tempo de execução.

Ensaios acelerados também são utilizados com o objetivo de estimar a garantia do componente em teste, pois permite a extrapolação de dados de tempo de falha em diferentes níveis de solicitação, possibilitando assim o cálculo da garantia estimada. As vantagens dos ensaios acelerados, além do tempo de execução e custo reduzido (pois tem-se um menor tempo utilização do equipamento de teste se comparado ao tempo de utilização necessário para a realização de um teste de vida), são a comodidade da coleta dos dados, pois os ensaios são realizados em laboratório, e a certeza de que amostras podem ser submetidas comparativamente às mesmas condições de solicitação, o que é muito difícil de garantir quando e ensaio é baseado na análise do desempenho em campo.

Para tanto, um planejamento torna-se necessário, identificando quais são as variáveis de solicitação (ex.:temperatura), quantos e quais níveis (ex.:200/250 e $300^{\circ}$ ) e qual a forma de aplicação da solicitação (constante, tipo degrau, progressivo e cíclico). Além disso, é necessário determinar o tamanho da amostra a ser alocada por nível de solicitação.

Entretanto, embora extremamente atraentes sob o ponto de vista de reduzir o tempo de desenvolvimento de um produto, a utilização de ensaios acelerados envolve um complexo estudo de definição dos modos de falha dos componentes e das maneiras pelas quais os mesmos podem ter sua freqüência de ocorrência acelerada, em função da alteração das condições de operação do produto.

De acordo com Nelson (2005) o primeiro plano de ensaios acelerados foi desenvolvido na década de 60 por Chernoff. Este plano envolvia somente distribuições exponenciais e apenas duas condições aceleradas e trabalhava principalmente com dados censurados. Na década de 70, Wayne Nelson e seus colaboradores, como por exemplo, Meeker, publicaram diversos trabalhos, nos quais foram desenvolvidos planos de ensaios para distribuições lognormais e de Weibull, tais como os citados na obra "Optimum accelerated life tests for Weibull and extreme value distribution and censored data" [Meeker e Nelson (1975)]

Os resultados destes ensaios acelerados de vida são usados no processo do projeto para avaliar ou demonstrar a confiabilidade de componentes e/ou subsistemas, para certificar componentes, detectar modos de falha não previstos no projeto e comparar a qualidade de diferentes fabricantes de um mesmo produto, da maneira mais rápida 
possível. Os ensaios acelerados de vida têm se tornado mais importantes em função da rapidez das mudanças tecnológicas, produtos mais complexos e com mais componentes, pressão pela rápida introdução de novos produtos no mercado, e pela expectativa dos consumidores por produtos com maior melhor confiabilidade.

Existem principalmente duas razões para execução dos ensaios acelerados. São elas:

(a) Estimativa de vida;

(b) Identificação, correção ou confirmação de problemas e fragilidades;

As diferenças entre estas razões, apesar de sutis, podem ter um impacto muito significativo sobre as hipóteses sobre as quais o ensaio é baseado.

O ensaio acelerado de vida é um ensaio pelo qual a duração da vida de um produto novo pode ser estimada e posteriormente, através de um procedimento de extrapolação, determina-se a vida nas condições normais de uso. Aqui o foco primário é a estimativa da vida de um item sob as condições normais de operação, baseado em informações obtidas em ensaios realizados sob condições mais severas.

Neste caso, o mecanismo de falha esperado para o produto é usualmente documentado e estudado e busca-se a aceleração do tempo de desenvolvimento do mesmo. Assim, problemas de identificação e correção de falhas não esperadas são de importância secundária, considerando correto o projeto do produto.

Ensaios acelerados de seleção ("screening") são empregados para detectar falhas no produto, tendo em vista problemas de projeto, do processo de fabricação, montagem ou dos materiais e componentes utilizados neste produto. Nestes ensaios aplica-se uma combinação de solicitações, de magnitude superior às previstas na operação normal do produto, de forma a precipitar a ocorrência de falhas. Neste ensaio não se busca a redução do tempo para ocorrência de uma falha específica, mas sim verificar, através do aumento da solicitação, a ocorrência de falhas inesperadas no produto, as quais estão associadas com o processo de desenvolvimento do mesmo. A detecção destas falhas, ainda na fase de produção de protótipos, permite a correção das mesmas antes do produto ter uma produção normal para o mercado consumidor, aumentando, portanto, a sua confiabilidade.

Os ensaios acelerados de vida são empregados para adquirir mais informações sobre a confiabilidade obtida do estudo das falhas ocorridas em um dado tempo de ensaio, usando um ambiente que é mais severo que o experimentado durante o uso 
normal do equipamento. Contudo, segundo a norma militar US MILHDBK-338 (1998):

“Ensaios acelerados sempre devem ser abordados com o devido cuidado. Existem limitações básicas para a técnica. Toda aplicação de ensaio acelerado é única. Sutis diferenças na aplicação podem invalidar totalmente as informações adquiridas durante o ensaio ou as conclusões alcançadas pelo ensaio."

Os ensaios acelerados em laboratório reduzem o tempo de desenvolvimento e gastos na obtenção das informações, porém, segundo Rai e Singh (2003), sozinhos não fornecem uma completa confiança sobre o desempenho de campo, pois podese observar que os dados de campo provém de informações mais confiáveis sobre a distribuição de vida, já que combinam exposições ambientais, de difícil simulação em laboratório.

Oh e Bai (2001) seguem esse pensamento e propõem um método de estimação da distribuição do tempo de vida a partir da análise de dados de ensaios e dados de falhas de campo durante o período de garantia.

Outros autores, como Majeske (2003) e Coit e Dey (1999), também propõem métodos de análise de confiabilidade utilizando dados de garantia, porém o grande problema reside na coleta das informações, pois nem sempre estas são devidamente registradas, sendo que quando o período de garantia é superado, já não há um acompanhamento da vida do produto.

\subsubsection{Métodos de Aceleração}

Nos ensaios acelerados, a extrapolação dos dados para a condição de uso normal do equipamento deve ser baseada em um bom conhecimento do fenômeno físico que está sendo acelerado, a fim de que possa ser explorada toda a capacidade deste tipo de ensaio.

Um cuidado especial a ser observado quando da execução deste ensaio consiste na correta seleção do fator de aceleração, de forma a reduzir o período para ocorrência de um dado modo de falha específico, evitando a ocorrência de outro modo de falha 
que não seja objeto do estudo, ou seja, aqueles que não são esperados nas condições normais de uso do produto ou componente.

A escolha deste fator de aceleração depende muito do conhecimento que o projetista tem sobre o modo de falha em estudo.

Nos ensaios acelerados de vida é fundamental que se conheça o modelo que relaciona a vida nas condições aceleradas com a mesma nas condições normais de operação do sistema. Assim, estes ensaios requerem $\square$ um entendimento antecipado do mecanismo de falha e um conhecimento da magnitude da aceleração deste mecanismo de falha, como função da solicitação acelerada.

$\mathrm{Na}$ maioria dos casos, fatores de aceleração apropriados podem ser obtidos através de um estudo da literatura, mas em alguns casos novos modelos devem ser desenvolvidos.

Segundo Meeker e Escobar (1999), a faixa de validade do modelo de aceleração não pode ser excedida e a aceleração de um esforço não pode alterar o mecanismo de falha. Se um ensaio acelerado introduzir um novo mecanismo de falha que não é experimentado nas condições normais de uso, este fato pode levar a conclusões falsas e implicar em mudanças desnecessárias de projeto. Por este motivo é altamente recomendável que se continue o ensaio acelerado até pelo menos um número mínimo de falhas ocorrer. Análises post mortem irão verificar qual o mecanismo de falha que realmente está ocorrendo, e se não há um novo mecanismo de falha introduzido pela aceleração.

Segundo Souza (2003), os três principais métodos de aceleração empregados na execução de ensaios acelerados são:

a) Aumento da Taxa de Uso

Neste tipo de ensaio, opera-se o equipamento a uma taxa de uso maior que a prevista para sua utilização normal. Entende-se por taxa de uso o número de vezes que o produto é utilizado ao longo de um intervalo de tempo. Entende-se como aceleração o aumento da taxa de utilização do produto em um dado intervalo de tempo, reduzindo o tempo necessário para executar-se um dado número de acionamentos. Para aplicação deste ensaio, deve-se ter completo domínio do mecanismo de falha a ser acelerado, e que o mesmo dependa apenas da taxa de uso. Nota-se que neste ensaio aplicam-se as cargas encontradas na condição normal de uso do produto ou componente.

b) Aumento da Taxa de Envelhecimento (Degradação) 
Intensificam-se as solicitações como, por exemplo, temperatura e umidade, através do aumento da magnitude destas variáveis aplicadas no ensaio, o que faz com que ocorra uma aceleração do processo físico-químico associado ao modo de degradação considerado para o equipamento. Entende-se por degradação a perda da capacidade operacional do componente ou sistema, apresentando um desempenho abaixo de um nível mínimo desejado.

A maior dificuldade deste ensaio é extrapolar o resultado para a condição normal de uso do componente, ou seja, relacionar um dado tempo de ensaio com a vida esperada do componente. Para tanto se necessita de um profundo conhecimento do fenômeno em estudo, incluindo conhecimento sobre o comportamento do material empregado na fabricação do componente.

c) Aumento do Carregamento

Através do aumento da magnitude do carregamento (tensão elétrica, pressão, solicitação mecânica) precipita-se a ocorrência de um dado mecanismo de falha do equipamento ou componente, ou seja, a falha ocorre em um tempo reduzido, em comparação com o tempo necessário para a ocorrência da mesma na condição normal de operação.

Em um ensaio acelerado com o emprego do aumento da magnitude do carregamento pode-se utilizar uma combinação de vários métodos de aceleração, desde que os efeitos das acelerações sejam independentes e muito bem controlados.

A dificuldade de extrapolação dos resultados é a mesma citada no caso do aumento da taxa de envelhecimento.

2.2.2 Análise de Resultados de um Ensaio Acelerado de Vida

Para extrapolar os resultados é necessário definir uma relação que permita associar os resultados experimentais, na condição acelerada, com os resultados a serem obtidos como estimativa daqueles relativos às condições normais de uso.

- Relações Baseadas no Conhecimento do Problema Físico

Para alguns mecanismos, conhecendo-se a modelagem teórica físico-química que rege o fenômeno de falha em estudo, pode-se obter uma relação entre os dados 
experimentais, ao longo de toda a faixa de aceleração, o que permite definir, para a condição de uso, o MTTF, a confiabilidade e outros parâmetros. Um exemplo clássico deste tipo de lei é a denominada Lei de Arrhenius, a qual representa o efeito da temperatura sobre um fenômeno químico, tal como o efeito da temperatura sobre a taxa de corrosão de um material. Com o emprego desta lei, pode-se extrapolar os dados experimentais, obtidos na condição acelerada, diretamente para a condição de uso.

\section{- Relações Empíricas}

A partir dos resultados experimentais é necessário definir relações empíricas que expressem a variação da confiabilidade, e do MTTF em função da aceleração de uma variável. Normalmente esta técnica é empregada para analisar fenômenos dos quais não se tem um perfeito domínio das características físicas ou químicas.

A definição dos valores de interesse para a condição normal de uso é baseada na realização de ensaios com grupos de componentes sendo que cada grupo é submetido a uma dada condição de solicitação acelerada. Estes ensaios, usualmente, não são censurados, observando-se o tempo de falha de todos os elementos da amostra.

\subsubsection{Procedimento de Análise}

O procedimento de análise, para ensaios acelerados onde não se conhece a lei que rege a aceleração do fenômeno físico associado a um dado modo de falha, deve ser baseado na utilização de diversas condições de ensaio. Com esses ensaios obtém se os tempos até a falha, e então se determina a distribuição de probabilidade que melhor se adapta aos dados. Subseqüentemente, constroem-se as funções densidade de probabilidade para cada uma das condições aceleradas.

A partir das distribuições podem ser determinados os tempos até a falha para o produto com vários níveis de confiança nas diversas condições aceleradas. A Figura 4 apresenta esses níveis de confiança para 5\%, 95\% e 50\%.

Determinam-se então as funções matemáticas que melhor se adaptam aos correspondentes níveis de confiança dos tempos até a falha. Estas funções são utilizadas para a determinação dos mesmos níveis de confiança nas condições 
normais de uso, ou seja, o tempo até a falha, com um dado nível de confiança, nas condições normais de uso.

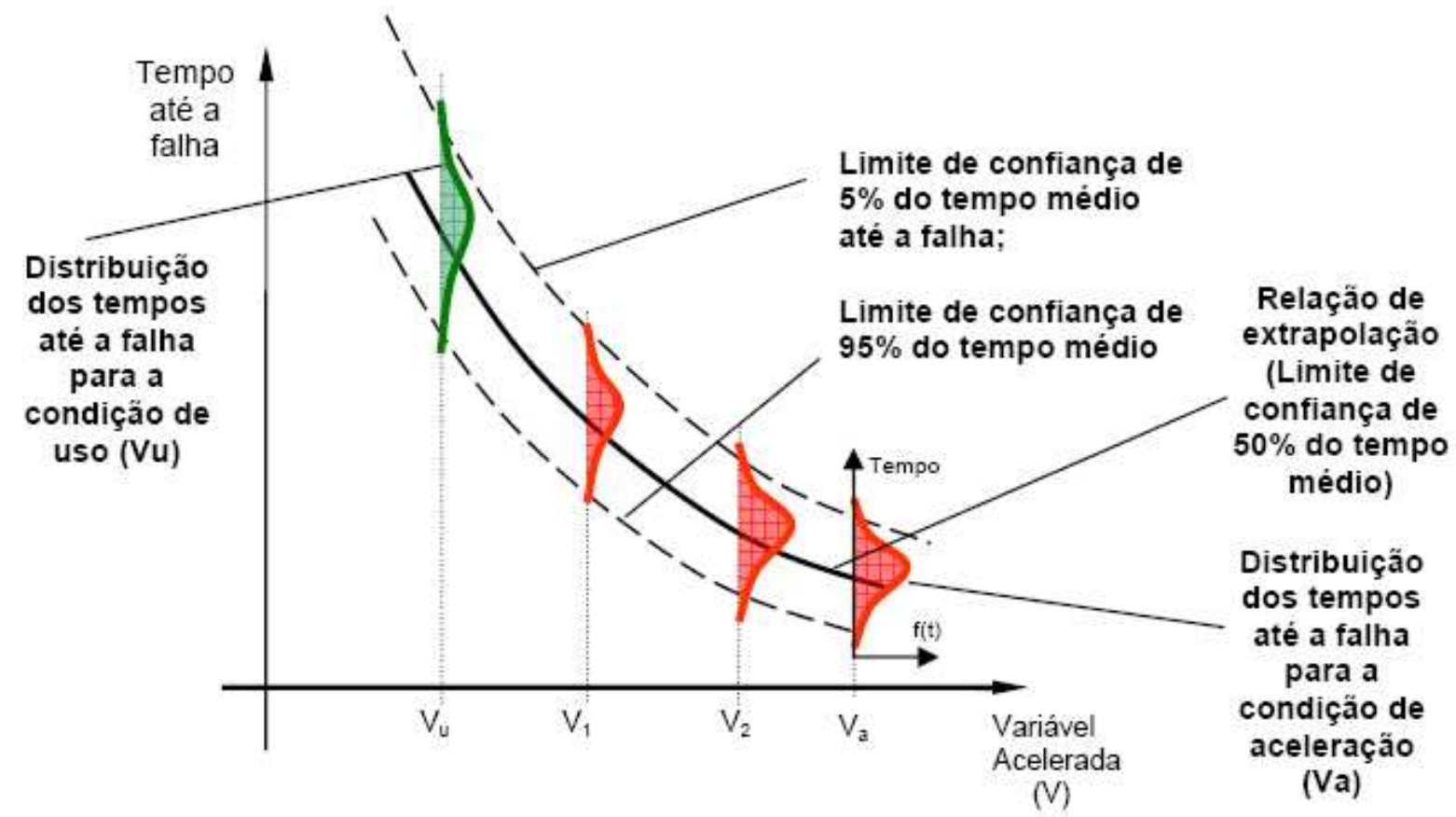

Figura 4 - Procedimento de Análise do Ensaio de Vida Acelerado. (SOUZA, 2003)

\subsection{DADOS DE GARANTIA}

Segundo Rai e Singh (2003), os dados de garantia são uma rica fonte para determinação da confiabilidade do produto, pois apenas os testes acelerados em adição ou não aos testes de vida em laboratório não são suficientes para prever com total confiança o desempenho do produto em campo. Porém, estes dados, como informações de tempo e kilometragem de vida do produto, quando da ocorrência da falha, estão restritos apenas ao período coberto pela garantia, ou seja, constituem dados incompletos, pois não se sabe o comportamento do produto após este período.

Outro fato que chama atenção é que, segundo Guida e Pulcini (2002, p.129), grande parte das estimações realizadas nas indústrias usa apenas dados observados em testes de laboratório e ignoram o conhecimento de retorno de garantia de produtos anteriores similares ao desenvolvimento atual. No entanto, conforme observado no capítulo introdutório, muitos dos produtos na indústria automotiva são evolucionários 
e não revolucionários, o que facilitaria a avaliação da confiabilidade utilizando-se de dados do histórico de produtos conhecidos, ou seja, em uso.

Os dados obtidos dentro do período de garantia, por sua vez, também podem apresentar valores inexatos de tempo, para ocorrência das falhas e descrição de falhas vagas, pois a aquisição dessas informações é realizada, em grande parte dos casos, por pessoas que realizam outras funções e a aquisição dessas informações se torna uma obrigação secundária e de menor valor, o que prejudica substancialmente o estudo da confiabilidade, pois trabalhar com dados nesta situação pode conduzir a estimações não precisas de taxa de falhas em campo.

No caso de dados incompletos, Rai e Singh (2003) realizaram delineamentos de experimentos comparando 3 métodos para estimação e 3 níveis de dados incompletos. Uma simulação foi realizada através de números randômicos para gerar uma distribuição normal, a qual serviu de parâmetro de comparação. Mais três curvas foram estimadas, porém cada qual com uma certa porcentagem de valores censurados diferentes, ou seja, incompletos. Ao final, concluiu-se que não há diferenças significativas entre os métodos, porém, quanto maior a quantidade de dados censurados, maior será a diferença entre a curva estimada e a curva de referência, onde não há dados censurados.

Rai e Singh (2003) propuseram uma metodologia com 5 passos, restrita apenas a componentes com distribuição de tempo até a falha modeladas por distribuição normal ou log-normal, onde primeiramente é realizada uma seleção de dados de garantia com a quilometragem mínima de falha, retirando dados onde o produto foi removido por falha de outro componente, selecionando apenas dados os referentes à qualidade do produto manufaturado. Estima-se os parâmetros da população utilizando-se também os dados incompletos. Exclui-se os valores que estão fora dos 99\% dos limites estatísticos, pois são dados não claros. Verifica-se se a distribuição é normal ou lognormal, e, por fim, estima-se a taxa de falhas para falhas de campo. Coit e Dey (1999), já haviam proposto um método para análise de dados de campo e também mencionam a dificuldade de se obter dados confiáveis sobre os tempos exatos de ocorrência da falha.

Já em Finkelstein (2002), é proposto um método de modelagem de tempo de vida de produtos com idade inicial desconhecida, através de uma variável randômica, pois, em aplicações de engenharia, um item que falhou pode, eventualmente, ser substituído por outro usado, sobre o qual desconhece-se o histórico. 
Majeske (2003), propôs um modelo misto para dados de garantia automotiva, incluindo parâmetros de desempenho do produto em campo, em fabricação, no processo de montagem no cliente final, etc, de maneira a estimar qual a taxa de falha que poderá ocorrer em campo referente a essas situações mencionadas. No estudo, utilizou-se uma população de 9532 carros de luxo, representando um mês de produção, para demonstrar a metodologia. Foram analisados dados de uma porção de veículos que superaram o período normal de garantia, 2 anos após a montagem dos mesmos. Foi possível separar os dados de falhas prematuras provenientes de falhas de montagem do produto (qualidade de fabricação), das falhas inerentes ao projeto, de maneira a avaliar a capacidade de detecção de falhas na linha de produção da empresa, pois os dados foram separados em 2 modos de falhas que seguiram uma distribuição de Weibull.

Guida e Pulcini (2002), propuseram um procedimento para avaliação da confiabilidade automotiva, baseada em dados do histórico e do conhecimento técnico, uma vez que não se pode ignorá-los durante o desenvolvimento de novos produtos, podendo economizar tempo e custos em testes demasiados e retrabalho.

Em Zou et al. (2002), tem-se um método para análise da confiabilidade do sistema de porta do corpo do veículo, com relação a uma das mais importantes qualidades, a energia de fechamento da porta. Esta deve ser a menor possível, porém sem comprometer a segurança de fechamento da porta, de modo que através de experimentações foi possível delinear a região segura de trabalho.

Eisele et al. (1996), desenvolveram um método para avaliação da segurança dos projetos automobilísticos, onde, através do estudo da base de dados sobre acidentes do estado da Virgínia (USA), foi possível identificar tipos de acidentes e quantidade, de modo a construir uma árvore de falhas e a probabilidade de ocorrência do evento de topo. Como resultado do método, pontos críticos no automóveis podem ser avaliados e projetos de melhorias implementados.

\subsection{ANÁLISE DO VALOR}

É um processo sistemático de análise de um produto, projeto, sistema ou serviço sob a ótica das funções a que se destina, de maneira a estimular a busca de 
alternativas que cumpram estas funções com menores custos de investimento e operação.

O processo se realiza criativamente por uma equipe multidisciplinar, desenvolvendo alternativas e orientações precisas para implementá-las.

A engenharia de valor tem como objetivo estabelecer um equilíbrio de rendimento, qualidade e funcionalidade do projeto, com os mais baixos custos de construção, operação e manutenção.

Uma situação que pode exemplificar bem a definição acima, onde se salienta a engenharia do valor como uma ferramenta que analisa o problema com o foco na solução e não no problema, pode ser observada no programa da NASA visando o lançamento de astronautas onde se tinha um problema a ser solucionado referente ao fato de que as canetas não funcionavam na gravidade zero.

Os Estados Unidos trabalharam com o foco no problema e contataram a Andersen Consulting (Accenture), empregaram uma década de pesquisas, com um custo de aproximadamente 12 milhões de dólares, conseguindo desenvolver uma caneta que escrevesse com gravidade zero, de ponta cabeça, debaixo d'água, em praticamente qualquer superfície incluindo cristal e em variações de temperatura desde abaixo de zero até mais de 300 graus Celsius.

Já os russos trabalharam com o foco na solução e utilizaram um lápis.

Uma definição complementar de Engenharia do Valor que não pode ser ignorada, intimamente relacionada com custos, segundo Csillag (1995, p.25), é "constitui uma abordagem muito original para reduzir custos de produção de bens e serviços e aumentar o valor para o usuário. Consiste basicamente em identificar as funções de determinado produto, avaliá-las e inicialmente propor uma forma alternativa de desempenhá-las de maneira mais conveniente do que a conhecida. Trata-se de uma ferramenta potente que origina reduções de custos da ordem de até $60 \%$ em média". A metodologia foi desenvolvida por Lawrence D. Miles para a empresa General Eletric Company em 1947 e tinha como foco analisar as funções desempenhadas pelos produtos através de seus componentes, objetivando reduzir custos e substituir materiais raros após os longos anos de conflito da 2a Guerra Mundial. O sucesso foi tão grande que a metodologia vem se espalhando para outros países até os dias atuais, sendo que melhorias na aplicação da metodologia foram acrescentadas pelos seus seguidores. 
A fundação da SAVE (Sociedade Americana de Engenharia do Valor) em 1959, nos Estados Unidos, foi um marco importante para a divulgação da metodologia para outros países, sendo que no Brasil, a ABEAV (Associação Brasileira de Engenharia do Valor) foi criada em 1984.

No Brasil, a divulgação desta metodologia teve início com alguns seminários na década de 60, tendo como importante marco a publicação do livro "Análise do Valor" por João Mário Csillag em 1985. O autor posteriormente, em 1988, foi premiado como o melhor trabalho do ano, no Congresso Internacional da SAVE com a apresentação do método "COMPARE" (Comparar Parâmetros), de sua autoria.

Análise do valor, engenharia do valor e gerenciamento do valor são sinônimos quanto ao objetivo final, o que muda é apenas o foco, pois o termo Análise do Valor se refere à melhoria em produtos já existentes, Engenharia do Valor se refere a novos desenvolvimentos de produtos, e Gerenciamento do Valor é aplicado à administração. Mas todos apresentam a mesma metodologia e técnica de aplicação. A metodologia do valor é constituída de 3 elementos fundamentais, segundo Csillag (1995, p.60):

- Função: característica de um bem ou serviço que atenda a exigência do cliente. Ex.: um relógio de pulso pode ter como funções: "mostrar horas", "mostrar datas", "cronometrar tempo", "embelezar cliente", "permitir porte", etc. A função pode ser básica (função do projeto, "mostrar horas"), essencial (função necessária para o desempenho da função básica, "armazenagem de energia”) e de suporte (não é essencial para o desempenho da função básica, influência a decisão de compra e satisfação do cliente, "estética”). Deve ser descrita apenas por um verbo e um substantivo

- Valor: medida monetária atribuída a bens e serviços. Pode ser classificado de acordo com vários critérios, como por exemplo, uso, estima, além do próprio custo monetário.

- Desempenho: grau de atendimento da função, conjunto de habilidades específicas funcionais do produto que o fazem adequado ao mercado e vendável. Pode se traduzir em qualidade, confiabilidade, intercambiabilidade, aparência, facilidade de manutenção, etc.

O objetivo principal da metodologia é determinar onde termina o desempenho satisfatório e onde começa o excesso de desempenho, pois este certamente aumenta o custo do bem ou serviço. $O$ foco é a análise de funções, pois estimula o 
pensamento criativo removendo bloqueios mentais que estão associados à forma física de produtos ou coisas conhecidas. Toda função deve ser representada por verbo seguido de substantivo, sendo hierarquizada. Para estimular a criatividade o nome da função deve se referir ao objeto da ação e não à própria ação, neste caso usamos "por que?". Ex.: Por que "parafusar placa"? Para "prender placa". E por que "prender placa"? Para "identificar máquina". "Identificar máquina" é mais aberto, amplo, e constitui a real necessidade desejada, que pode ou não ser realizada de uma outra forma com o mesmo desempenho esperado e por um custo inferior.

Para a mente humana a resolução de problemas fechados é mais cômoda, pois os limites são fixados durante a fase da solução do problema e a resposta é mais fácil de ser obtida. Porém, esta nem sempre é a mais adequada. Ao contrário, os problemas abertos apresentam caminhos diversos que podem conduzir a soluções revolucionárias. É preciso encontrar um meio termo e trabalhar com as duas situações durante a elaboração do plano de trabalho.

Foram desenvolvidas uma grande quantidade de técnicas aplicadas à metodologia pelos seguidores de Miles. Porém, por mais simples que seja a técnica, faz-se necessária a elaboração de um planejamento de trabalho, com levantamento das informações do produto em estudo, como requisitos (funções) e custos confiáveis de fontes idôneas, e a ação de uma equipe multidisciplinar.

A metodologia não visa apenas a redução de custos, e sim, aumento de valor agregado, pois, em alguns casos, pode-se até aumentar os recursos consumidos quando estes estão abaixo das necessidades relativas, desde que o cliente perceba a função e isto gere incremento nas vendas.

É uma ferramenta que possui as mais diversificadas aplicações, podendo ser utilizada em: estudos para projetos de construção civil, estudos para empreendimentos diversos, estudos para obras em andamento (com o objetivo de aproveitar as oportunidades que acontecem durante a execução dos mesmos), estudos de produtos (para aprimorar os padrões de itens de engenharia e reduzir custos de produção), estudos de processos de fabricação entre outros estudos que se destinam a algum tipo de melhoria com análise de custos.

O estudo deve iniciar com a definição do problema e a formação da uma equipe que deve possuir número impar de elementos a fim de se evitar possibilidade de empate em uma possível votação, assim como é necessário que os fatores abaixo sejam observados: 
- Líder treinado e com experiência

- 5 a 7 membros na equipe para garantir sinergia

- Equipe multidisciplinar, com experiência técnica

- Experiência relacionada com o escopo do projeto

- Treinamento em EV desejável, mas não obrigatório

- Disposição adequada para participação como membro de equipe sob o controle do líder

- Pode incluir a participação dos projetistas e dos parceiros do projeto, assim como do usuário

O fluxograma indicado na Figura 5 exemplifica o encademento da atividade que pode ser utilizado como base para a aplicação da metodologia.

Para a análise de valor do produto retentor, utiliza-se uma equipe multidisciplinar formada por engenheiros de desenvolvimento de produto, qualidade e processos, assim como técnicos responsáveis pela análise dimensional de peças novas, e também pela análise de peças substituídas no período de garantia.

Não foi utilizado nenhum representante do usuário, visto que o objetivo é que o mesmo perceba o valor agregado de todo o estudo através da redução do índice de retorno de peças em campo durante o período de garantia.

Das análises de falhas em garantia da peça selecionada será selecionada a característica que deverá ser melhorada no retentor, e esse será o dado a ser utilizado para o início no estudo de análise do valor.

Como resultado da análise de valor, pretende-se obter os elementos que deverão ser modificados no retentor a fim de se observar melhoria na característica utilizada no início do estudo e oriunda das análises de retorno em garantia. 


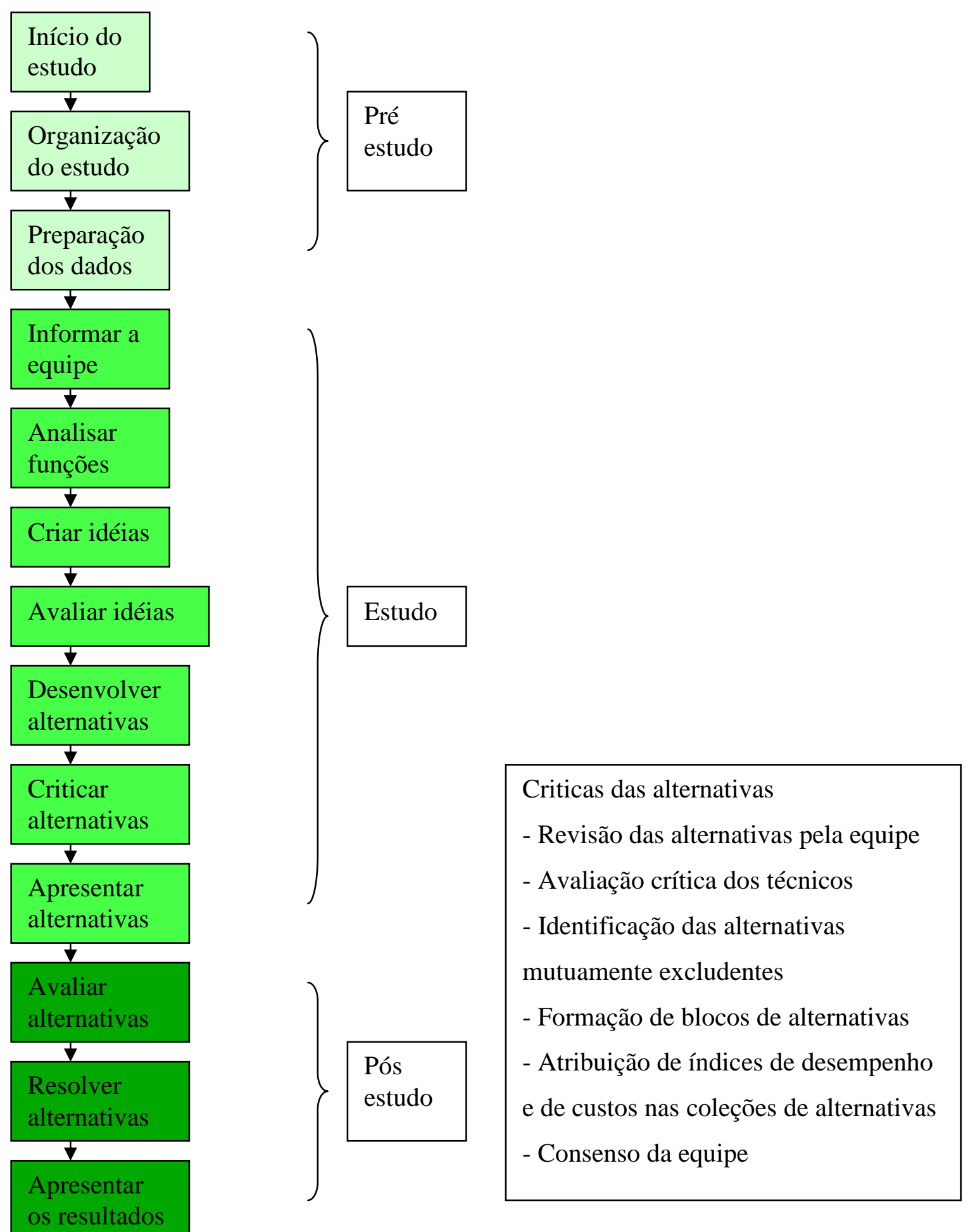

Figura 5 - Fluxo a ser utilizado para a aplicação da metodologia da análise do valor (Csillag, 1991) 


\section{CONCEITOS DO RETENTOR}

Retentores são utilizados para a vedação de eixos rotativos, especialmente na construção de máquinas, bem como na indústria automobilística.

De acordo com a norma NBR 12906/1993 (ABNT 1993), retentor pode ser definido com um "Anel composto basicamente de uma ou mais membranas elastoméricas ou plásticas em forma de lábios, podendo ser associada(s) a uma ou mais estrutura(s) rígida(s) (revestida(s) ou não), destinado basicamente à vedação de fluidos em eixos e alojamentos com movimentos relativos, assim como à vedação de agentes externos ao conjunto onde está instalado, para evitar seu acesso ao lábio de vedação do fluido, denominado lábio de vedação principal"

Além da exigência principal, para um bom efeito de vedação, exige-se mais para os retentores:

- Segurança de funcionamento;

- Longa vida útil;

- Montagem simples;

- Compatibilidade com os produtos a serem vedados;

- Pouco atrito.

Os produtos a serem vedados podem ser pastosos, líquidos ou, em casos excepcionais, gasosos. Trata-se, principalmente, de produtos de lubrificação, como óleos e graxas de lubrificação e também líquidos de trabalho como óleos hidráulicos (conforme DIN 51524), líquidos de pressão dificilmente inflamáveis (conforme VDMA 24317 e 24320) e até óleos de silicone, com poucas características de lubrificação.

Em casos excepcionais, também devem ser vedados produtos agressivos com baixa característica de lubrificação como, por exemplo, solventes orgânicos ou produtos químicos agressivos como ácidos e lixívias.

A base da padronização do projeto do retentor é a norma DIN 3760 que possui como pontos principais:

1. Área de validade;

2. Medidas, descrições;

3. Matéria-prima e proteção de superfície;

4. Marcação; 
5. Emprego;

6. Diretrizes para montagem;

7. Explicações.

Pode-se separar o retentor em partes funcionais e nomeá-las de acordo com a Figura 6.

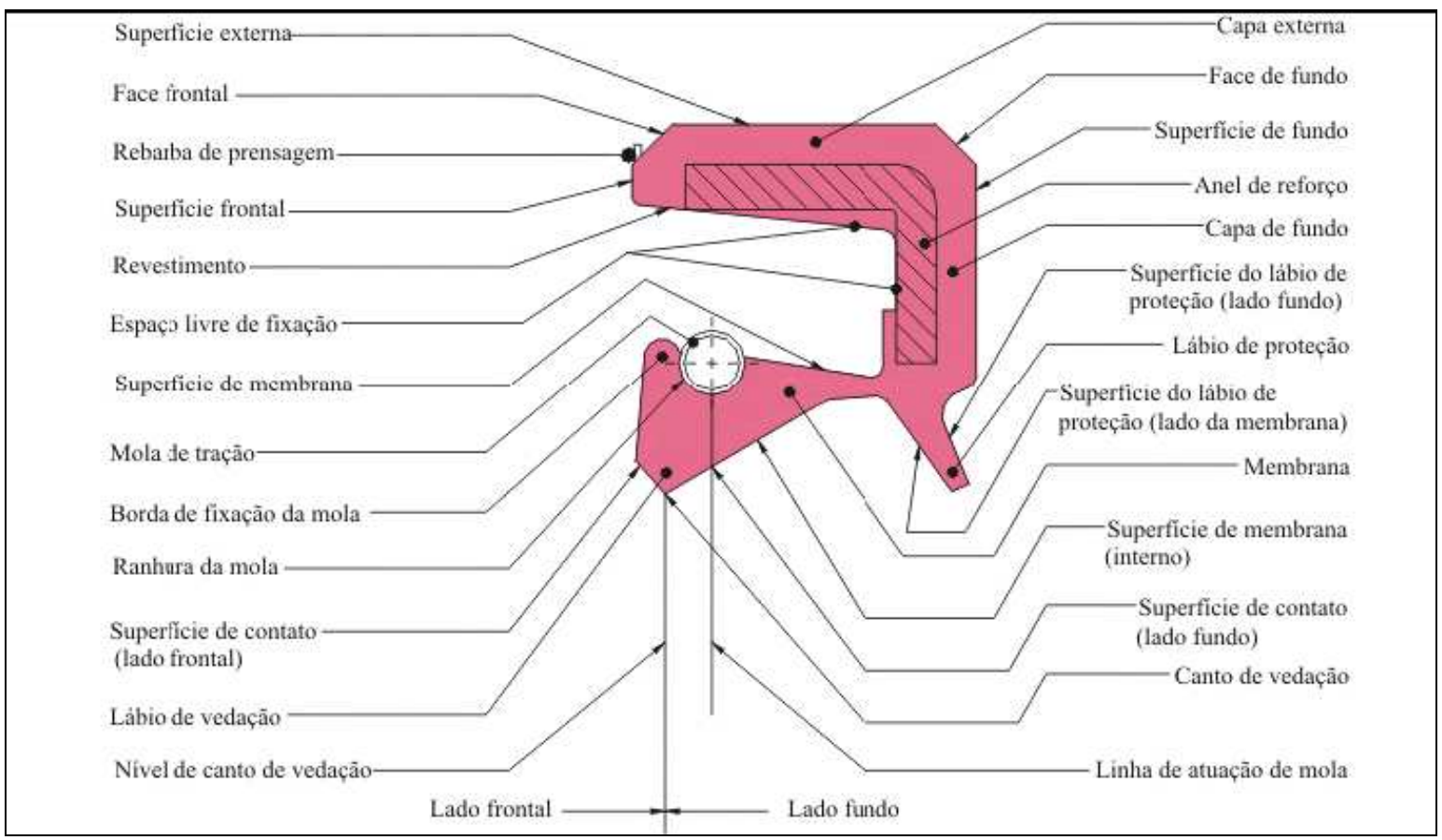

Figura 6 - Retentor divido de acordo com suas partes e respectivos nomes [CBV VEDAÇÕES Catálogo Técnico]

As principais características do retentor são discutidas na seqüência deste capítulo.

\section{1 - EXTERNO CILÍNDRICO DE ELASTÔMERO OU DE METAL}

Existem formas construtivas com chapa externa metálica como mostra a Figura 7, formas c) e d) que podem ser fornecidas estampadas (com revestimento para auxiliar na vedação externa, absorvendo variações de matéria prima e processo na estampagem) ou retificadas na circunferência externa. Já as formas construtivas 
com a capa externa de elastômero são constituídas com uma chapa metálica de reforço, como mostra a Figura 7, formas a) e b).

Os diâmetros com capa externa de elastômero liso (Figura 7 construção a), são usados para aplicação em alojamentos de materiais ferrosos, com tolerâncias de diâmetro H8. Já os diâmetros ondulados (Figura 7 construção b) são usados para aplicação em alojamentos de materiais metálicos não-ferrosos, e plásticos, cujos coeficientes de dilatação são maiores que o dos materiais ferrosos, ou quando a tolerância destes diâmetros nos materiais ferrosos for maior que H8

Nestes casos, determina-se uma interferência entre o diâmetro externo do retentor e o diâmetro do alojamento, maior que a interferência determinada para os diâmetros externos lisos, de modo a garantir, em ambos os casos, uma correta fixação e adequada vedação entre o retentor e o alojamento.

Existe também a construção mostrada na forma e) da Figura 7, que possui diâmetro externo parcialmente recoberto de elastômero, essa construção possui a união das características apresentadas para as peças com construção somente de metal e somente de borracha, mas seu custo de fabricação é mais elevado se comparado as demais construções devido a sua maior complexidade de projeto e execução de ferramental para fabricação da carcaça metálica, assim como maior custo de projeto e execução dos moldes de injeção para garantir o recobrimento parcial de elastômero. Outro fator que aumenta o custo de fabricação do tipo construção na forma e) da Figura 7, é o fato de o mesmo necessitar de maior controle de variáveis do processo produtivo como, volume de elastômero a ser injetado, temperaturas e pressões do processo de vulcanização a fim de manter baixos os níveis de refugo. 


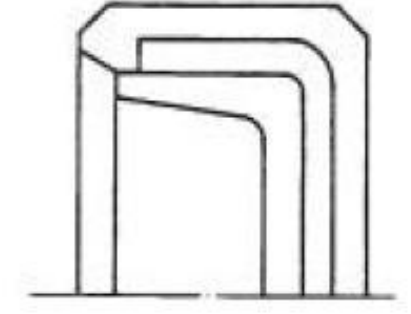

a) Construção com membrana de elastomero na forma lisa

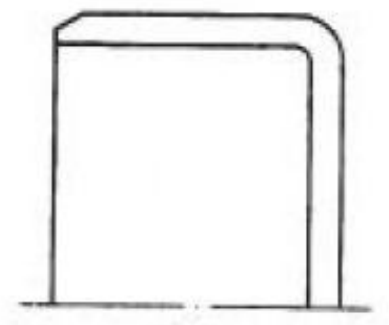

c) Construçẫo de capa externa metálica

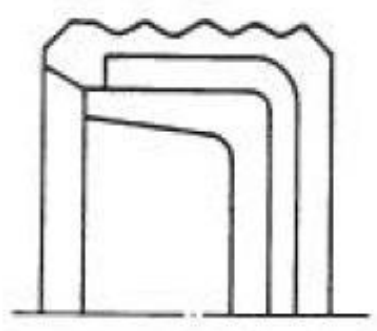

b) Construção com membrana de elastomero na forma ondulada

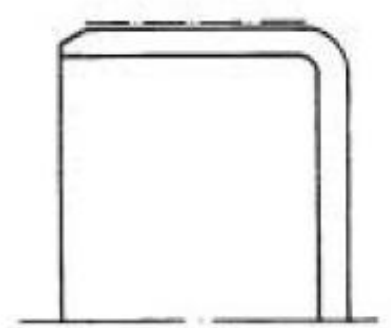

d) Construçẫo de capa externa metálica revestida

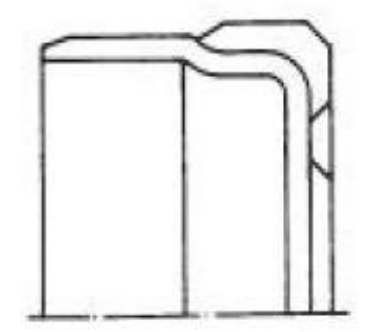

e) Construçẫo de capa externa semi-recoberta por membrana de elastomero

Figura 7 - Exemplos de construção externa para o retentor [DIN 3760]

\section{2 - CONSTRUÇÕES GERAIS}

Quanto ao tipo de construção geral, os retentores podem ser normais ou especiais. Na Figura 8, pode-se observar exemplos de construção dos retentores tipo normais. 

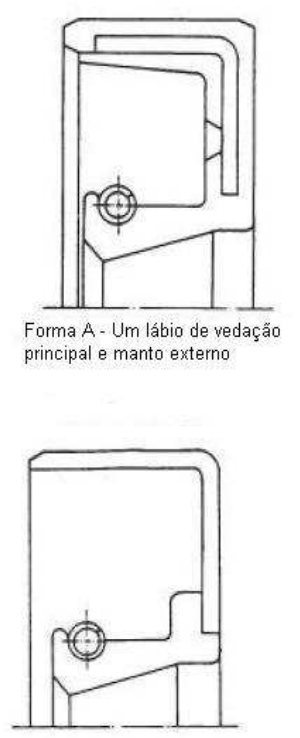

Forma B - Um lábio de vedaçã̃o principal e superfície externa metálica

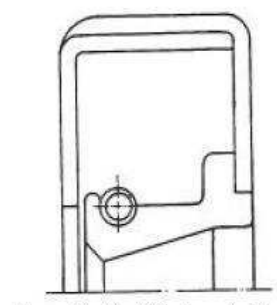

Forma C - Um lábio de vedaçẫo principal e reforço estrutural interno

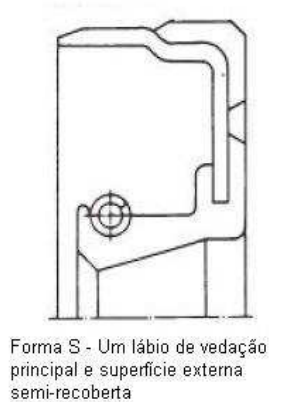

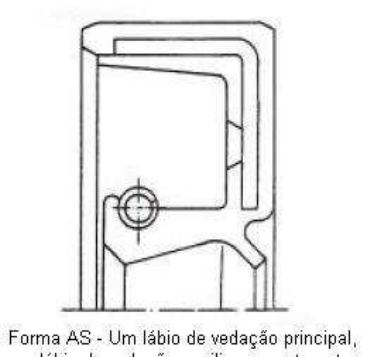

um lábio de vedação auxiliar e manto extern

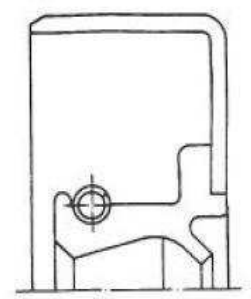

Forma BS - Um lábio de vedaçẫo principal, um lábio de vedaçắo auxiliar e superfície externa metálica
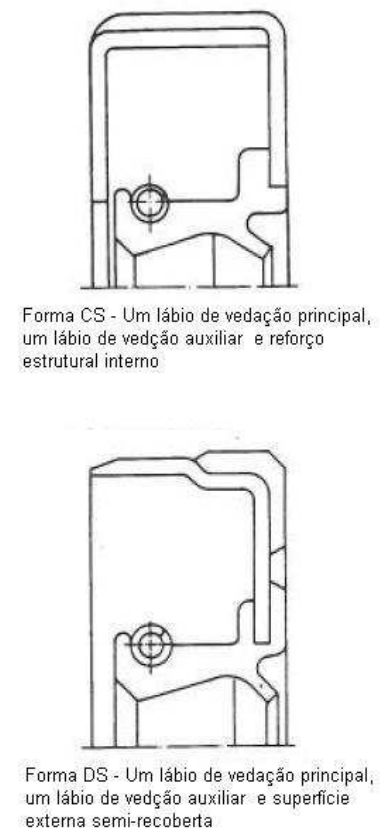

Figura 8 - Exemplos de construção dos retentores tipo normais [DIN 3760]

Na forma A, os retentores tem um recobrimento elastomérico na face posterior e um manto externo de borracha, que recobre o diâmetro na sua altura total.

A forma AS tem as mesmas características da forma $A$, porém conta ainda com um lábio de vedação auxiliar, contra contaminantes externos.

Em ambas as formas, o manto do diâmetro externo pode ser liso ou ter forma ondulada 
Por ter cobertura de material elastômero em todo o diâmetro externo, as formas $\mathrm{A} \mathrm{e}$ AS são preferidas para locais onde a vedação no diâmetro externo é uma característica mais critica do que a fixação e montagem do retentor no conjunto.

As formas $A$ e $B$, respectivamente sem e com lábio de vedação auxiliar, tem a carcaça (reforço estrutural) sem recobrimento elastomérico, sendo o diâmetro externo determinado pela própria carcaça. A exatidão dimensional do diâmetro externo pode ser obtida por calibragem mecânica ou usinagem fina. São formas preferidas quando o elastômero é de custo elevado e/ou a vedação não é de grande dificuldade (fluidos de viscosidade elevada - exemplo: óleos SAE 90, SAE 140), e a temperatura não é muito elevada.

As formas D e DS, respectivamente sem e com lábio auxiliar de vedação, reúnem ótima fixação e vedação através do diâmetro externo do retentor, o qual é constituído parte diretamente pela chapa e parte diretamente pela cobertura de borracha. É uma construção eficiente e normalmente de maior custo que as anteriores

As formas C e CS, respectivamente sem e com lábio auxiliar de vedação, tem 0 diâmetro externo em chapa e constam ainda com um reforço estrutural interno a mais (carcaça), para maior rigidez. Para obtenção desta maior rigidez, contrapõemse o maior custo, a maior dificuldade de montagem e a maior fuga dos limites de circularidade.

As formas B, BS, C e CS podem ainda contar com um revestimento fino selante no diâmetro externo, para melhorar a vedação que, nestas formas, não é tão eficiente como nas formas com manto externo de borracha (no diâmetro externo)

Além das formas básicas, listadas acima, existe ainda uma grande quantidade de formas especiais obtidas da conjugação das formas básicas já apresentadas, e de outros elementos necessários a funções especificas, a serem combinadas entre clientes e fornecedores, e correspondem apenas a exemplos de outras formas também utilizadas em aplicações especificas, como indicado na Figura 9. São típicos, por exemplo, para uso em eixos de movimento deslizante axial, como em amortecedores de suspensão de veículos automotores, os retentores mostrados na Figura 9 formas i) e j). Por isso, estes têm o perfil mais encorpado, e a carcaça é reforçada para fixação rígida, e não apenas por interferência mecânica no diâmetro externo como nas formas B, BS, C, CS, D e DS. 


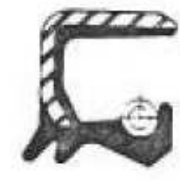

a) Multipla vedaçẫo auxiliar

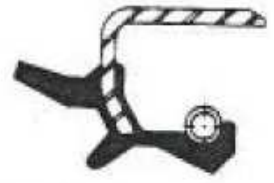

b) Vedaçẫo auxiliar atuando sobre defletor metalico

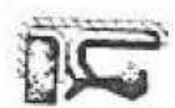

c) Vedaçẫo auxiliar adicional em feltro, contra agentes externos de grande porte

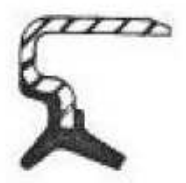

d) Vedaçẩo principal sem o auxílio de mola

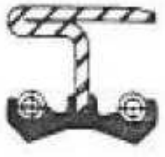

e) Vedaçẩo principal dupla para vedar fluidos em ambos os lados

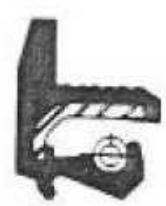

g) Com aba de vedaçã̃o no diâmetro externo

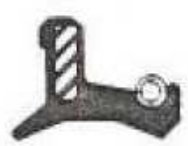

i) Vedaçẳo em eixos com movimento axial

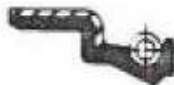

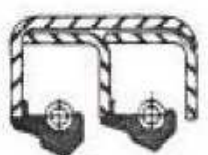

f) Vedação principal dupla para vedar fluidos em apenas um lado

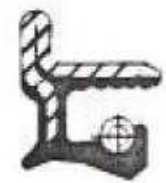

h) Com aba de apoio no diâmetro externo

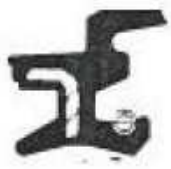

j) Vedaçẫo em eixos com movimento axial, diametro externo com auxilar de fechamento do sistema, e contruçấo interna para operar dispositivo de alivio de pressão na aplicação

k) Retentores de vedação em eixos com movimento axial e necessidade de permitir pelicula de lubrificante para evitar travamento dos eixos

Figura 9 - Exemplos de construção dos retentores tipo especiais [DIN 3760] - Continua 
eixos rotativos

de grande excentricidade

dinâmica e/ou movimento

angular
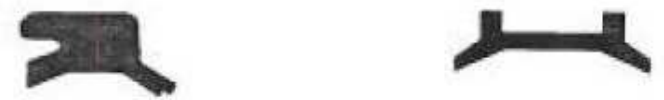

m) Retentores sem reforço estrutural (carcaça), para aplicaçôes com movimentos lentos ou nulos do eixo e/ou alojamento
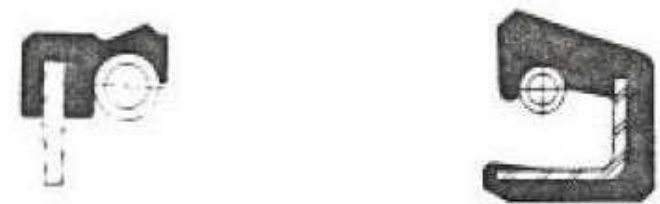

n) Vedaçã̃o sobre 0 alojamento e nẫo sobre o eixo. Utilizam molas de expansẫo e nẫo de contraçẫo
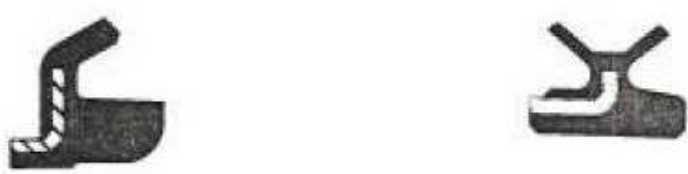

o) Vedaçẫo sobre o alojamento e nẫo sobre o eixo. Sem a utilizaçẫo de molas

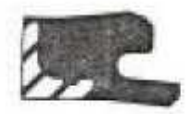

p) Vedaçẫo com utilizaçẫo de calço de anel plásico, para extremas pressốes de fluido

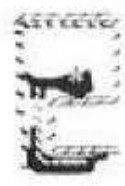

q) Vedaçôes principal e auxiliar apoiadas sobre pista própria

Figura 9 - Exemplos de construção dos retentores tipo especiais [DIN 3760] (continuação) 
A forma dos chanfros e a das curvaturas anterior e posterior deve obedecer primordialmente a exigências de montagem e é produto de acordo entre cliente e fabricante.

Quando necessário, um lábio de proteção adicional, para evitar a penetração externa de poeira e sujeira, é adicionado ao retentor. A forma do lábio de vedação auxiliar pode determinar sua interferência ou não com o eixo onde se deve aplicar o retentor, dependendo primordialmente das exigências de sua atuação contra agentes contaminantes externos.

\section{3 - LÁBIO DE VEDAÇÃO PRINCIPAL COM CARGA DE MOLA}

Tem a tarefa de garantir a vedação dinâmica e estática contra o eixo girando ou parado. A forma do lábio de vedação principal pode ser obtida tanto por moldagem como por usinagem da superfície anterior do lábio de vedação principal. As formas geométricas em alto-relevo no lábio de vedação principal e/ou auxiliar tem a finalidade de aumentar e eficiência de vedação do fluido e são chamadas de estrias hidrodinâmicas, ribs ou vedação hidrodinâmica. Pode-se observar a representação de algumas estrias hidrodinâmicas típicas associadas ao respectivo sentido de rotação do eixo na Figura 10. 

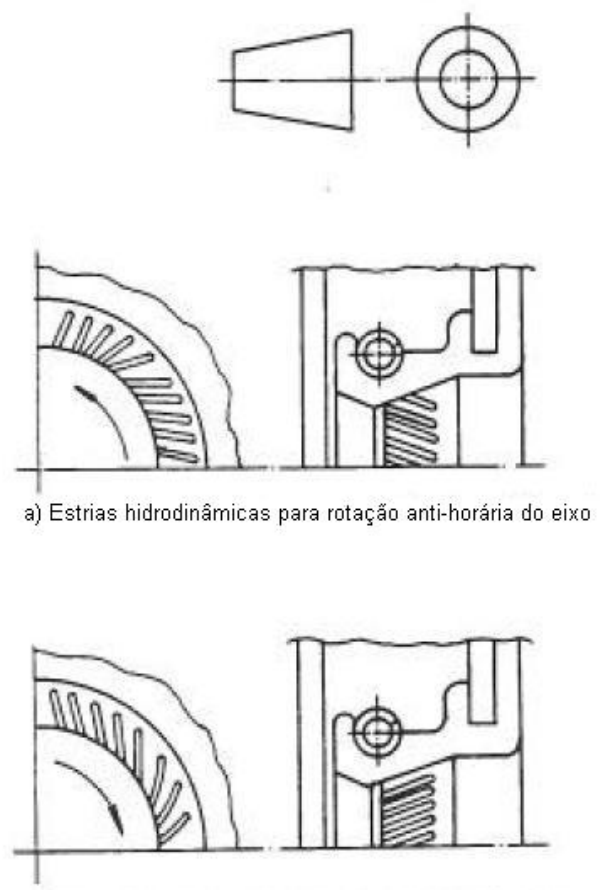

b) Estrias hidrodinâmicas para rotaçã̃o horária do eixo

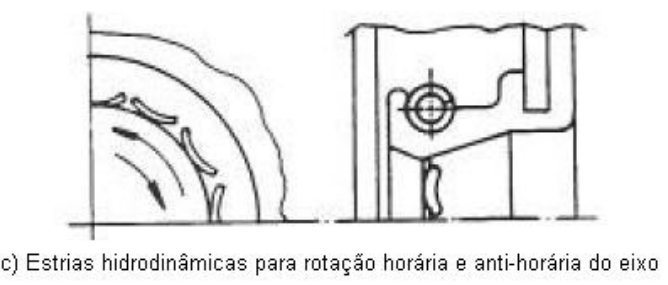

* A observaçã̃o do sentido de rotaçẫo do eixo é feita a partir do lado posterior do vedador de fluidos

Figura 10 - Exemplificação da construção das estrias hidrodinâmicas [DIN 3760]

\section{$3.4-$ MOLA}

A carga radial do retentor é determinada pelo perfil do retentor, borracha utilizada e pela mola utilizada.

A mola presente nos retentores pode ter a característica de ser compressiva ou expansiva de acordo com necessidade de sua aplicação, ou seja, se a vedação principal esta localizada sobre o eixo (utiliza-se molas compressivas) e se a vedação principal está localizada sobre o alojamento (utiliza-se molas expansivas).

A mola possui a função de manter a força radial do retentor na região de vedação principal ao longo do tempo compensando e efeito da degradação da borracha. 
Deve ser especificada através do tipo de arame utilizado em sua construção e com as características mostradas na Figura 11.
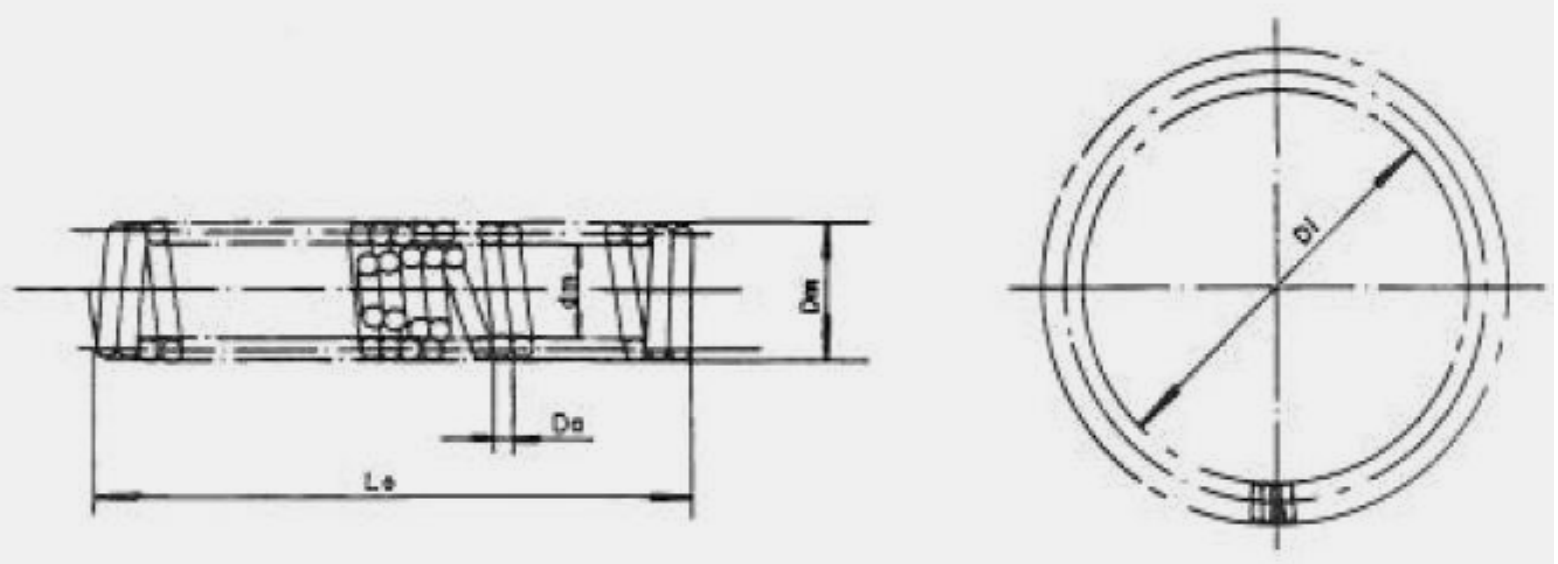

$\mathrm{Dm}=$ diámetro da mola

$\mathrm{Da}=$ diämetro do arame

Lo $=$ comprimento da mola (sem incluir as eineo espiras fechadas para montagem)

$\mathrm{Di}=$ diămetro interno da mola fechada

$\mathrm{dm}=$ diametro interno da mola

Figura 11 - Características básicas da mola [DIN 3760]

\section{5 - SELEÇÃO DO ELASTÔMERO}

Para o desenvolvimento de um retentor deve-se ter conhecimento de suas condições de operação conforme os pontos abaixo:

- Produtos a serem vedados;

- Velocidade na circunferência (obtida através da informação de rotação ou velocidade da superfície a ser vedada);

- Temperatura de trabalho;

- Pressão imposta ao retentor;

- Carga de sujeira externa.

O produto a ser vedado é que determina principalmente a seleção do composto do elastômero que irá constituir o retentor. De influência decisiva também são os efeitos químicos dos produtos sobre os compostos. Como em todas as reações químicas, estes processos também são acelerados por temperaturas elevadas. As matérias- 
primas de vedação podem amolecer ou endurecer sobre influência dos produtos a serem vedados.

Pode-se citar como fator de endurecimento a temperatura de aplicação mais alta à qual o material pode resistir. Já como fator de amolecimento pode-se citar o inchamento causado pelo produto a serem vedado.

O nível do produto a ser vedado determina as condições da retirada de calor e, desta forma, a temperatura na superfície de vedação, região onde há o contato com a parte em movimento (normalmente o eixo). Na Figura 12, pode-se observar a relação entre as variáveis nível do produto a ser vedado (em relação à linha de centro) e a temperatura observada na superfície de vedação. Os valores da curva de limite inferior foram averiguados para um produto a ser vedado com eixo totalmente coberto pelo fluido a ser vedado, e a curva de limite superior, mostra os valores observados quando temos um eixo com apenas $25 \%$ de sua área transversal coberta pelo produto a ser vedado. A faixa entre a curva do limite superior e inferior mostra possíveis relações de temperatura na superfície de vedação e como serão geradas sob a influência de diferentes produtos de retiradas de calor. É de grande influência sobre a vida útil de um retentor a sua temperatura diretamente no canto de vedação. Isso depende das condições de retirada de calor em cada lugar de emprego.

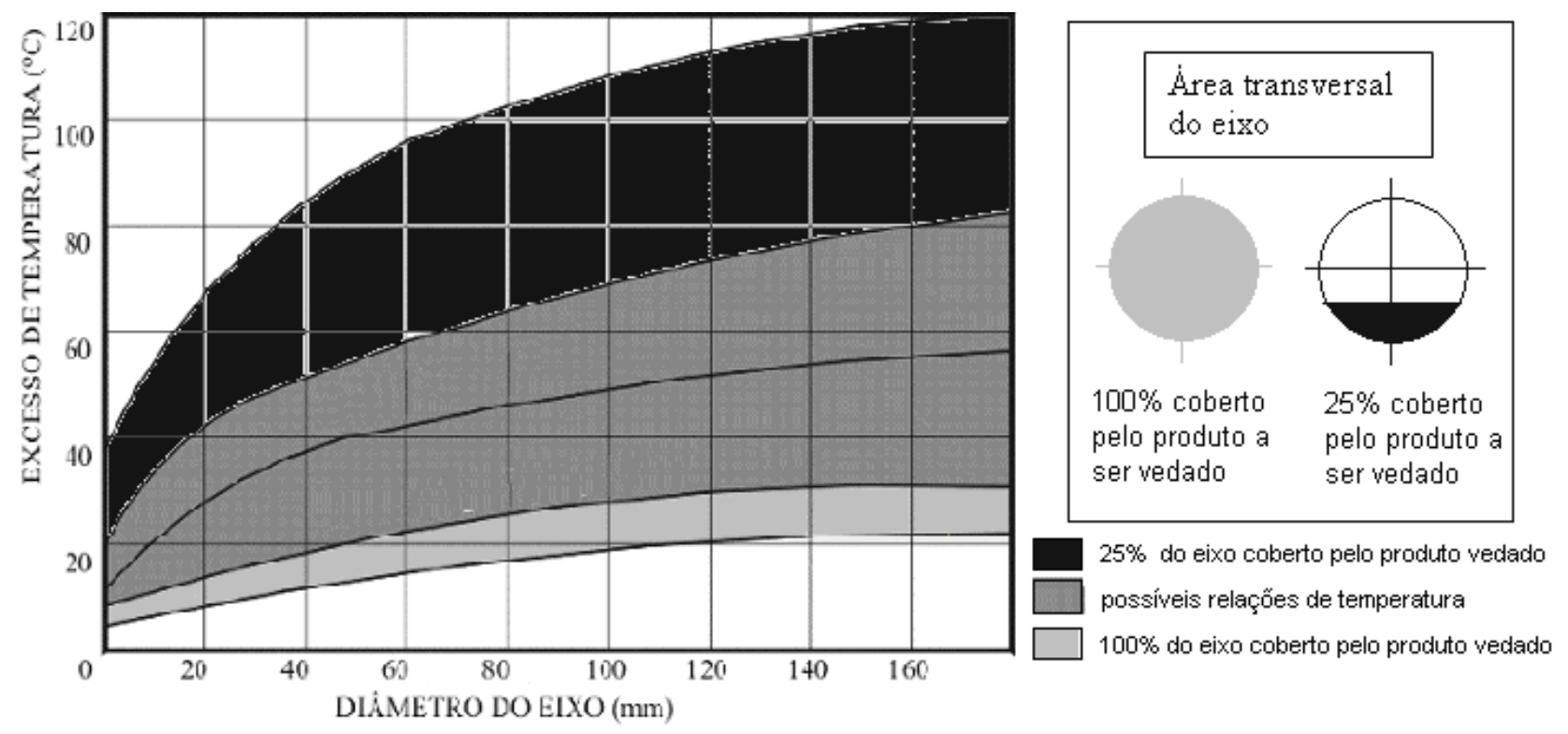

Temperatura do banho de óleo $100^{\circ} \mathrm{C}$.

Rotação 3000 RPM.

Figura 12 - Temperatura no ponto de vedação de um retentor na vedação de diferentes produtos. 
Quando existe pressão sobre o ponto de vedação, o lábio de vedação será pressionado adicionalmente sobre o eixo. Por isso serão gerados atritos maiores e uma temperatura mais elevada no canto de vedação do retentor. Valores de referência para as possibilidades de emprego com vedação de pressão de retentores feitos de NBR 70 Sh constam na Figura 13.

Esses valores somente são válidos para sistemas com eixos $100 \%$ cobertos pelo produto a ser vedado, e com boa retirada de calor através do produto a ser vedado. Em caso de pressão negativa temporária no ponto de vedação, pode ser necessário montar um segundo retentor com lábio de vedação direcionado para o lado do ar. Todos os retentores submetidos à pressão devem ser protegidos, no lado contrário da pressão, para evitar deformação do perfil de elastômero, possibilitando assim uma falha.

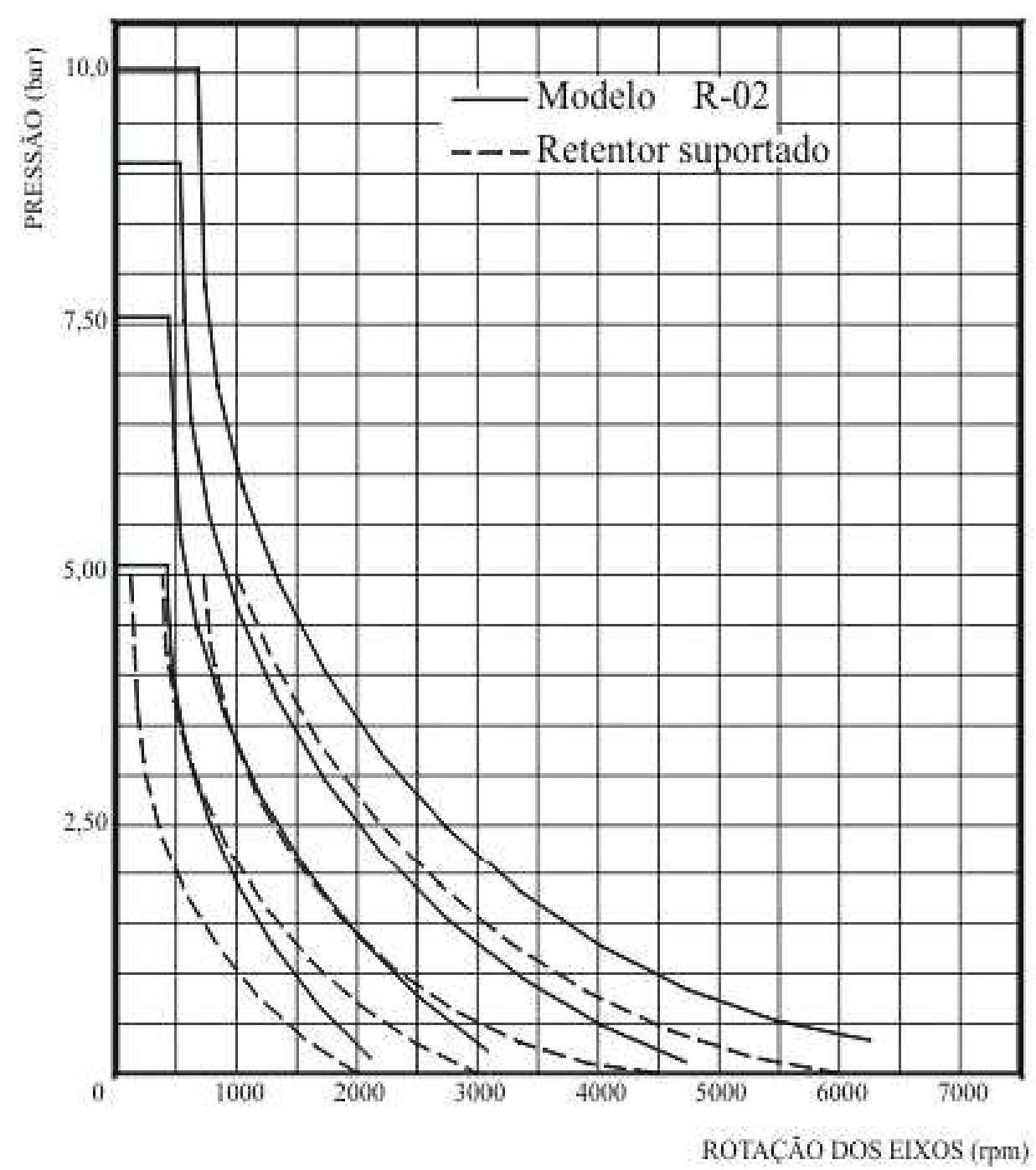

Figura 13 - Pressão permitida do produto a ser vedado para retentores [SABÓ - Catálogo Técnico] 
Quando existir a formação de sujeira ou umidade no lado externo, recomenda-se a montagem de retentores com lábio de proteção. O espaço entre os lábios de proteção e a vedação deve ser preenchido com graxa antes da montagem. Essa graxa não é somente necessária para a lubrificação adicional do lábio de proteção, mas, também, para a proteção do eixo contra corrosão produzida pela umidade.

Em casos de geração de sujeira extremamente forte, recomenda-se a montagem, um atrás do outro, de dois retentores ou o emprego de modelos especiais.

\section{6 - RECOMENDAÇÕES QUANTO A APLICAÇÃO DO RETENTOR}

Na Figura 14, podem ser observadas as informações referentes ás dimensões básicas do retentor sobre o eixo e local de montagem. 

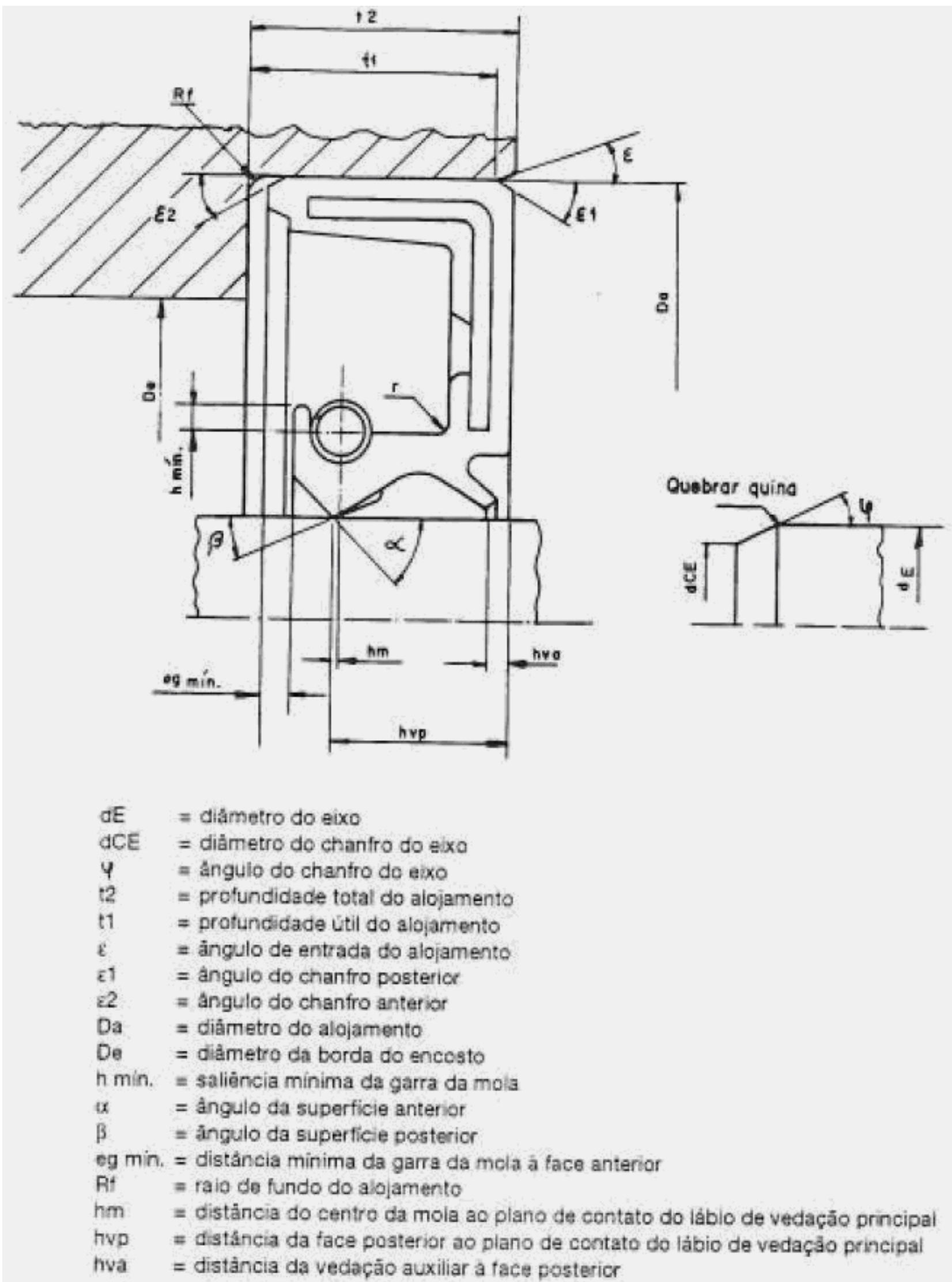

Figura 14 - Informações de dimensões básicas [SABÓ - Catálogo Técnico] 
De acordo com a norma NBR 12906 (ABNT 1993), pode-se observar divergências permissíveis para as principais dimensões básicas do vedador instalado no eixo e no alojamento, sendo os valores para essas divergências observados nas Figuras 15 e 16.

Unid: $\mathrm{mm}$

\begin{tabular}{|c|c|c|}
\hline Dimensão & Divergència & Referència \\
\hline $\begin{array}{l}\text { hvp } \\
\text { Para hwp } \leq S \\
\text { Para hvp }>5<10 \\
\text { Para hwp }>10<15\end{array}$ & $\begin{array}{l} \pm 0,30 \\
\pm 0,40 \\
\pm 0,45\end{array}$ & DIN $3761 / 2$ \\
\hline $\begin{array}{c}\text { hm } \\
\text { Para mvp } \leq 5 \\
\text { Para hvp }>5<10 \\
\text { Para hwp }>10<15\end{array}$ & $\begin{array}{l} \pm 0,25 \\
\pm 0,35 \\
\pm 0,45\end{array}$ & DIN 37 ба $1 / 2$ \\
\hline $\begin{array}{l}\text { hva } \\
a \\
\alpha \\
\beta\end{array}$ & $\begin{array}{l} \pm 0,30 \\
\pm 8^{\circ} \text { usinado } \\
\pm 5^{\prime} \text { moldado } \\
\pm 5^{\circ}\end{array}$ & DiN $3761 / 2$ \\
\hline
\end{tabular}

Figura 15 - Informações de divergências permissíveis no alojamento [DIN 3760]

Tabela 4 - Divergencias máximas para circularidade de eixos

\begin{tabular}{|c|c|c|c|}
\hline $\begin{array}{c}\text { Diâmetro } \\
\text { (mm) }\end{array}$ & $\begin{array}{c}\text { Tolerância } \\
\langle\mu\rangle\end{array}$ & $\begin{array}{l}\text { Diàmetro } \\
(\mathrm{mm})\end{array}$ & $\begin{array}{c}\text { Toleráneia } \\
\text { (Hi) }\end{array}$ \\
\hline 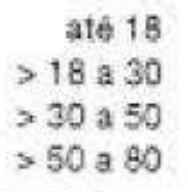 & $\begin{array}{l}4 \\
5 \\
6 \\
8\end{array}$ & $\begin{array}{l}>80 \text { a } 120 \\
>120 \text { a } 180 \\
>180 \text { a } 250\end{array}$ & $\begin{array}{l}10 \\
13 \\
15\end{array}$ \\
\hline
\end{tabular}

Figura 16 - Informações de divergências permissíveis na circularidade do eixo [DIN 3760]

Com relação ao alojamento, a seguir são descritas as recomendações que se aplicam a todos os tipos de retentores:

- A tolerância H8, conforme NBR 6407 (ABNT 1993), deve ser cumprida para o diâmetro onde o retentor será alojado, para um boa fixação e vedação

- A rugosidade de superfície, conforme NBR 6405 (ABNT 1993), deve atender ao descrito a seguir, para a correta vedação estática: 
a) vedador formas $A, A S, D, D S: R t=25 \mu m$

b) vedador formas $B, B S, C, C S: R t=16 \mu m$

c) vedador formas $B, B S, C, C S: R t=25 \mu m$ (com revestimento de borracha no diametro externo)

Para fixação segura, os seguintes valores devem ser seguidos independentes da forma do retentor: $\mathrm{Ra}=0,8 \mathrm{u}$ a $3,2 \mathrm{u} ; \mathrm{Rz}=6,3 \mu \mathrm{m}$ a $16 \mu \mathrm{m}$

- O chanfro dever ter ângulo de entrada de 5 a 15 graus, liso, sem danos, rebarbas ou outros defeitos

- A profundidade mínima deve ser 0,3 $\mathrm{mm}$ maior que a altura do retentor, exceto quando a profundidade de montagem do retentor for determinada pelo seu encosto na superfície de fundo do alojamento

- Para o diâmetro do furo do alojamento deve ser prevista a tolerância ISO H8. A vedação geralmente é retida no alojamento por interferência entre os diâmetros do alojamento e o externo da peça. Os valores recomendados para esta interferência, bem como as tolerâncias dos diâmetros de alojamento e retentor, devem seguir a norma DIN 3761 (DIN 1983), estão mostrados na Tabela 1 abaixo (consultar Figura 17 para verificar as nomenclaturas)

Tabela 1 - Tolerâncias para os diâmetros de eixo, alojamento, externo da peça [CBV Vedações Catálogo Técnico]

\begin{tabular}{|c|c|c|c|c|c|}
\hline \multicolumn{6}{|c|}{ Tolerância de DF e DR e Interferência Resultante } \\
\hline \multirow[b]{2}{*}{$\varnothing D N$} & \multirow[b]{2}{*}{$\begin{array}{c}\text { Tol. DF } \\
\text { (H8) }\end{array}$} & \multicolumn{2}{|c|}{ Retentor tipo R-05 } & \multicolumn{2}{|c|}{ Retentor tipo B-05 ou A-05 } \\
\hline & & $\begin{array}{l}\text { Tol. } \\
\text { DR }\end{array}$ & $\begin{array}{l}\text { Interferência } \\
\text { Resultante }\end{array}$ & $\begin{array}{l}\text { Tol. } \\
\text { DR }\end{array}$ & $\begin{array}{l}\text { Interferência } \\
\text { Resultante }\end{array}$ \\
\hline de 10 a 18 & $\begin{array}{c}0 \\
+0,027\end{array}$ & $\begin{array}{l}+0,30 \\
+0,15\end{array}$ & $\begin{array}{l}+0,300 \\
+0,123\end{array}$ & $\begin{array}{l}+0,20 \\
+0,10\end{array}$ & $\begin{array}{l}+0,200 \\
+0,073\end{array}$ \\
\hline de 18 a 30 & $\begin{array}{c}0 \\
+0,033\end{array}$ & $\begin{array}{l}+0,30 \\
+0,15\end{array}$ & $\begin{array}{l}+0,300 \\
+0,117\end{array}$ & $\begin{array}{l}+0,20 \\
+0,10\end{array}$ & $\begin{array}{l}+0,200 \\
+0,067\end{array}$ \\
\hline de 30 a 50 & $\begin{array}{c}0 \\
+0,039 \\
\end{array}$ & $\begin{array}{l}+0,30 \\
+0,15 \\
\end{array}$ & $\begin{array}{l}+0,300 \\
+0,111 \\
\end{array}$ & $\begin{array}{l}+0,20 \\
+0,10 \\
\end{array}$ & $\begin{array}{l}+0,200 \\
+0,061\end{array}$ \\
\hline de 50 a 80 & $\begin{array}{c}0 \\
+0,046\end{array}$ & $\begin{array}{l}+0,35 \\
+0,20\end{array}$ & $\begin{array}{l}+0,350 \\
+0,154\end{array}$ & $\begin{array}{l}+0,23 \\
+0,13\end{array}$ & $\begin{array}{l}+0,230 \\
+0,084\end{array}$ \\
\hline de 80 a 120 & $\begin{array}{c}0 \\
+0,054\end{array}$ & $\begin{array}{l}+0,35 \\
+0,20\end{array}$ & $\begin{array}{l}+0,350 \\
+0,146\end{array}$ & $\begin{array}{l}+0,25 \\
+0,15\end{array}$ & $\begin{array}{l}+0,250 \\
+0,096\end{array}$ \\
\hline de 120 a 180 & $\begin{array}{c}0 \\
+0,063 \\
\end{array}$ & $\begin{array}{l}+0,45 \\
+0,25\end{array}$ & $\begin{array}{l}+0,450 \\
+0,187\end{array}$ & $\begin{array}{l}+0,28 \\
+0,18\end{array}$ & $\begin{array}{l}+0,280 \\
+0,117\end{array}$ \\
\hline de 180 a 300 & $\begin{array}{c}0 \\
+0,072\end{array}$ & $\begin{array}{l}+0,45 \\
+0,25\end{array}$ & $\begin{array}{l}+0,450 \\
+0,178\end{array}$ & $\begin{array}{l}+0,30 \\
+0,20\end{array}$ & $\begin{array}{l}+0,300 \\
+0,128\end{array}$ \\
\hline
\end{tabular}




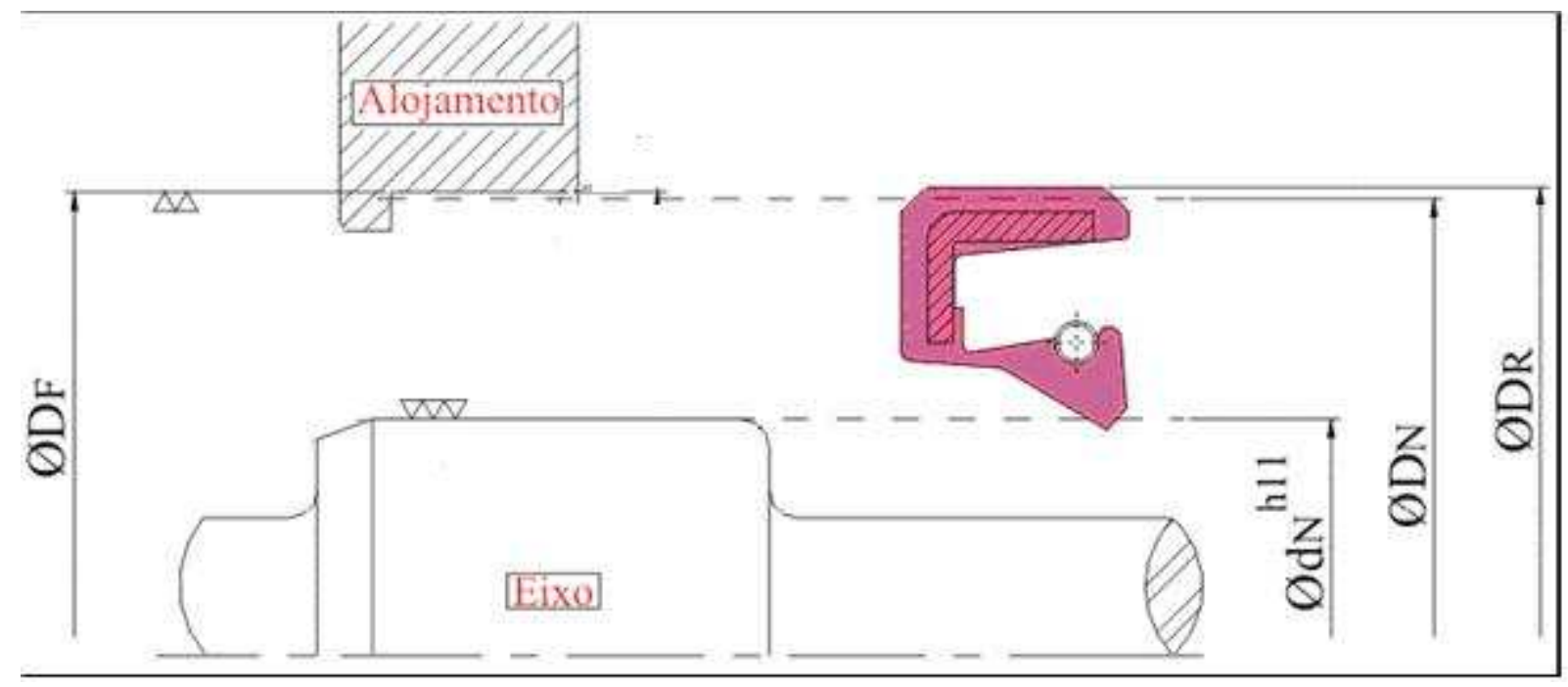

Figura 17 - Informações das nomenclaturas utilizadas na Tabela 1 [CBV Vedações - Catálogo Técnico]

Para os cálculos, deve-se seguir a ordem abaixo:

1) Cálculo de DF $=\varnothing D N+$ Tol. DF

2) Cálculo de $\mathrm{DR}=\varnothing \mathrm{DN}+$ Tol. $\mathrm{DR}$

3) Cálculo da Interferência Resultante: Int. máx = DR máx - DF mín

Int. mín = DR mín - DF máx

Para se obter uma boa condição de montagem do retentor, deve ser previsto um chanfro de entrada no início do alojamento, com inclinação da ordem de $5^{\circ}$ a $15^{\circ}$, numa profundidade de $0,8 \mathrm{~mm}$ mínimo. Os cantos desta superfície devem estar livres de rebarbas de usinagem.

Para o diâmetro do eixo dN deverá ser prevista a tolerância conforme recomendação da norma DIN 3761, ou seja, a tolerância ISO h11.,

Com o objetivo de conferir uma boa durabilidade e eficiência de trabalho ao retentor, a superfície do eixo onde trabalha o lábio deverá atender as seguintes exigências:

- Adotar tolerância geral de fabricação h11 para o diâmetro, conforme NBR 6407.

- Obter rugosidade da superfície para eixos rotativos, preferencialmente por operação de retifica de topo, ou seja, aquela em que a ferramenta abrasiva se aproxima e se afasta do eixo perpendicularmente à sua linha de centro, de modo a não deixar marcas de usinagem em forma de hélice. Este cuidado evita que o fluido a ser vedado possa ser bombeado pela rotação do eixo através das hélices de usinagem. 
- O valor da rugosidade para eixos rotativos deve estar conforme NBR 6405, conforme as seguintes faixas de valores: Ra $0,2 \mu \mathrm{m}$ a $0,5 \mu \mathrm{m}$; Rt $1,6 \mu \mathrm{m}$ a $4,0 \mu \mathrm{m}$; $R z 1,2 \mu \mathrm{m}$ a $2,8 \mu \mathrm{m}$, onde todos os tipos de rugosidade ( $R a, R t$ e $R z$ ) devem ser verificados. Valores menores que o mínimo tendem a não manter o filme de óleo sob o lábio de vedação principal, necessário à sua lubrificação. Já valores maiores que o máximo reduzem a vida útil do retentor.

- Se ultrapassado o valor Rt, pode ocorrer vazamento com o conjunto parado.

- Para movimentos axiais e grande força radial do lábio de vedação principal, também se deve usar rugosidade menor. Por exemplo: $\mathrm{Ra}=0,03 \mu \mathrm{m}$ a 0,09 $\mu \mathrm{m}$, para hastes de amortecedores, da suspensão de veículos.

- As superfícies devem ser isentas de imperfeições, como batidas, cortes, arranhões, oxidação.

- A dureza da superfície do eixo para altas rotações e com alguma incidência de impureza no fluido ou impureza externa, que atinja o lábio de vedação principal, deve ser de 55Rc mín., pois, caso contrário, há formação de canaleta sobre o eixo pela ação do lábio de vedação principal do retentor. Para baixas rotações, boa lubrificação e baixas temperaturas, este valor pode ser reduzido para até 28Rc.

- As quinas dos eixos devem ser chanfradas ou arredondadas de modo a facilitar a montagem do eixo no retentor ou vice-versa, evitando sua danificação.

- Para a maioria dos casos, os chanfros devem ter 15 a 25 graus e os arredondamentos, 0,6 a 1,0 mm de raio. Ambos devem ser lisos e isentos de rebarbas ou marcas. Durante a montagem, o eixo deve ser lubrificado com o próprio fluido da aplicação, para facilitar a penetração do retentor.

Devido as inevitáveis variações de superfície usinada do alojamento e do mancal, é previsto que haja uma certa excentricidade entre os mesmos. Em outras palavras, a linha de centro geométrico do alojamento do retentor não coincide exatamente com a linha de centro efetiva do giro do eixo, conforme pode ser observado na Figura 18. À essa característica aplica-se o nome de excentricidade estática. 


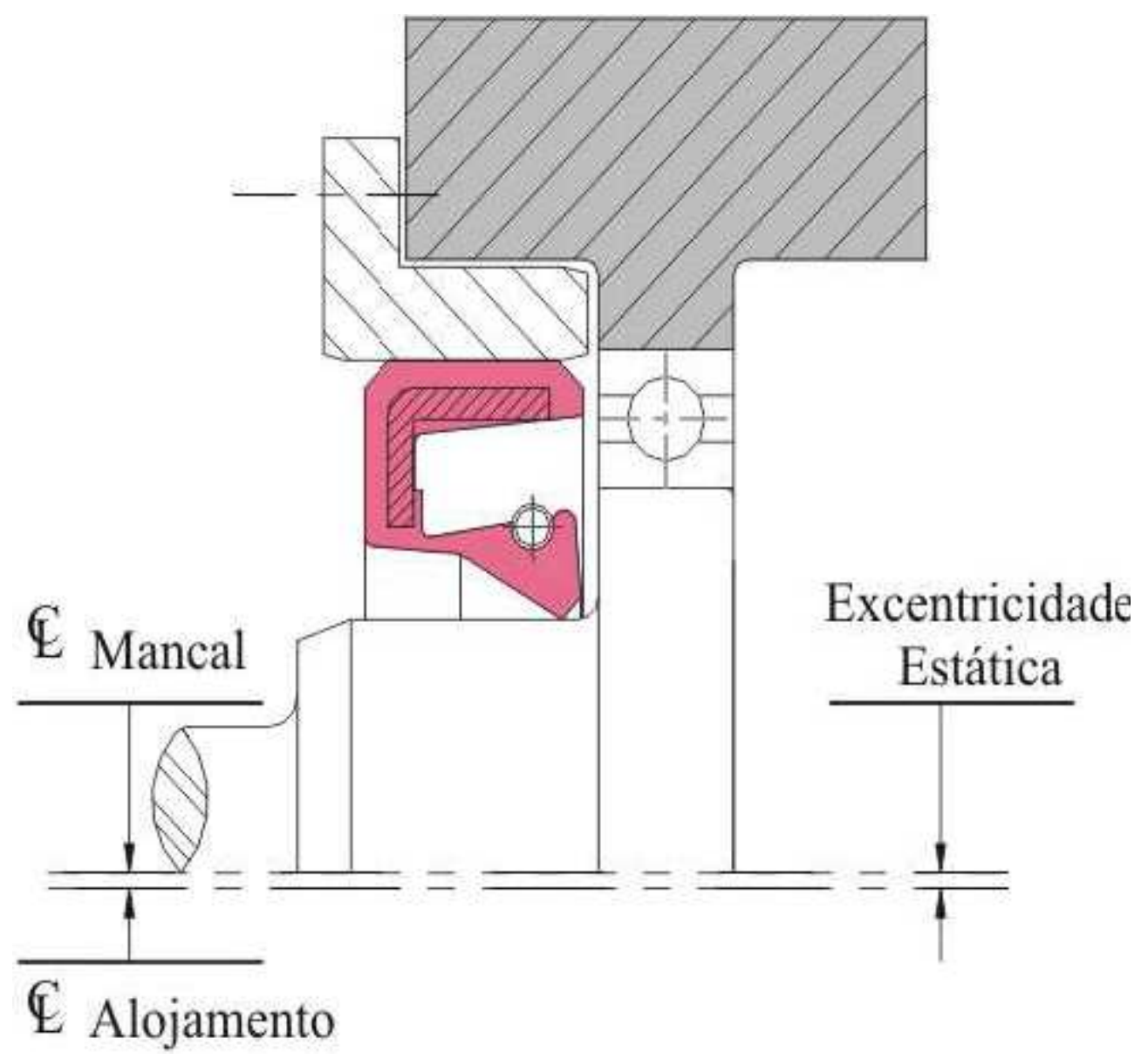

Figura 18 - Exemplificação da excentricidade estática que o retentor é submetido. [CBV Vedações Catálogo Técnico]

À distância entre as duas linhas de centros, definida como excentricidade estática, deverá ser mantida dentro dos limites estreitos indicados na Figura 19

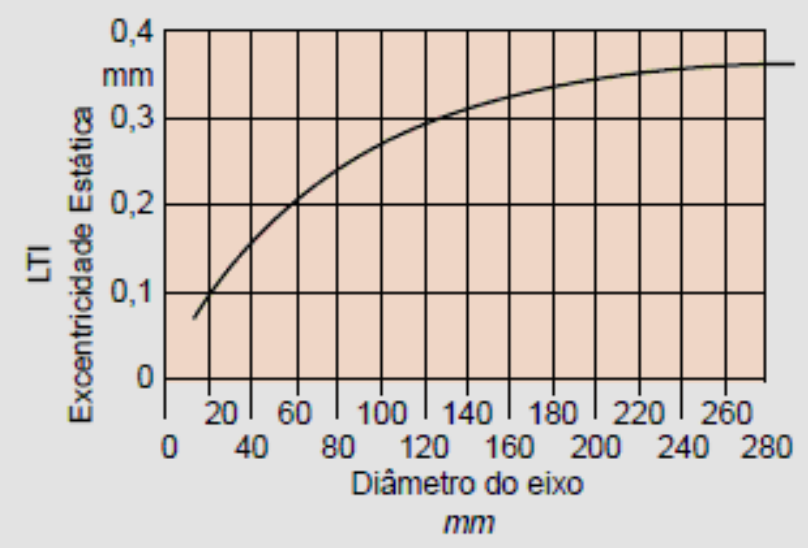

Figura 19 - Limite do excentricidade estática suportada pelo retentor [SABÓ - Catálogo Técnico]

Igualmente é previsto que na usinagem do eixo haja uma excentricidade entre a linha de centro efetiva de giro do eixo e a linha de centro do diâmetro da pista de 
trabalho do retentor, conforme mostrado na Figura 20. À essa característica aplicase o nome de excentricidade dinâmica.

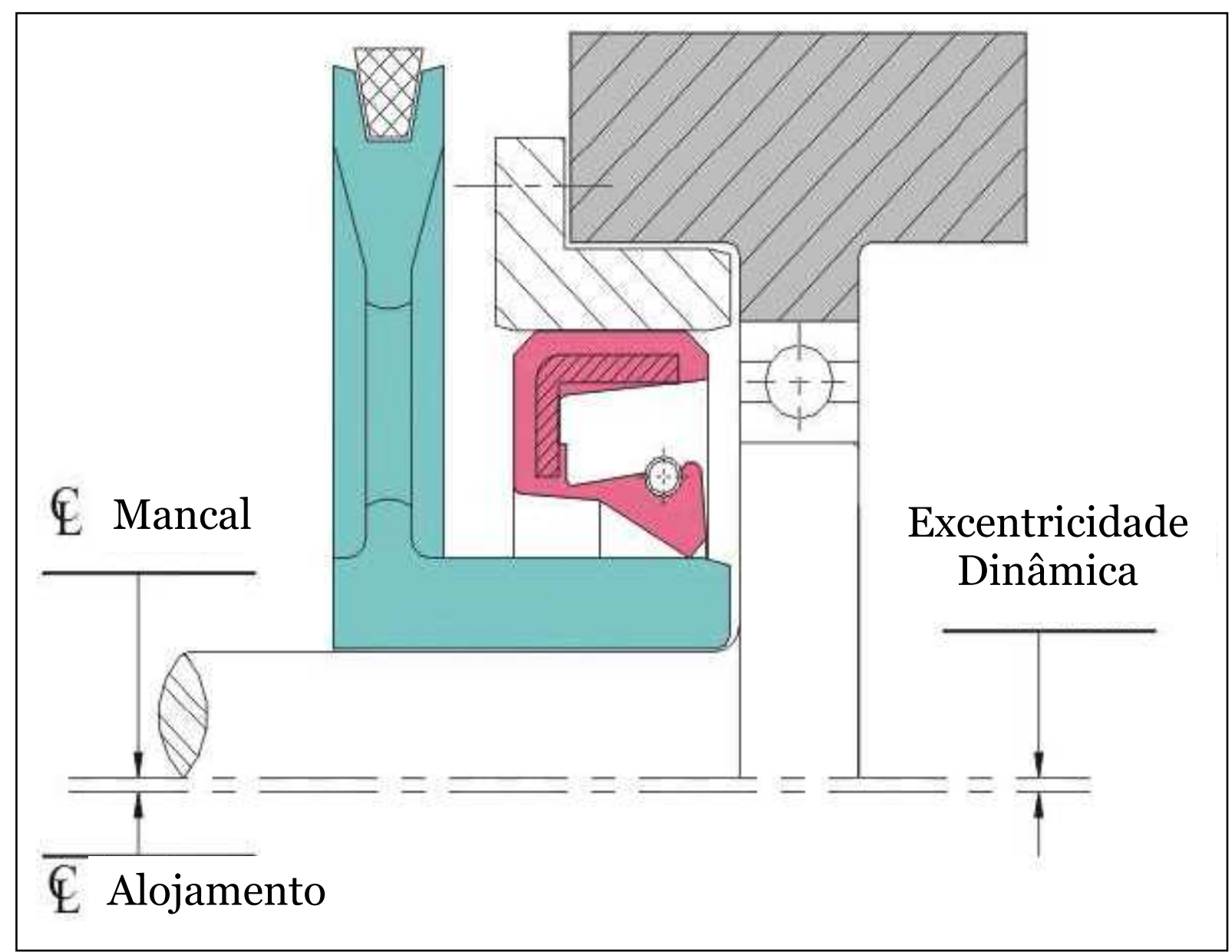

Figura 20 - Exemplificação da excentricidade dinâmica que o retentor é submetido. [CBV Vedações Catálogo Técnico]

Essa excentricidade dinâmica deverá estar contida dentro dos valores recomendados na Figura 21. Para valores muito acima dos recomendados, haverá o risco do lábio de vedação, devido à sua inércia, não conseguir manter o contato com o eixo, principalmente no caso de elevadas velocidades angulares. 


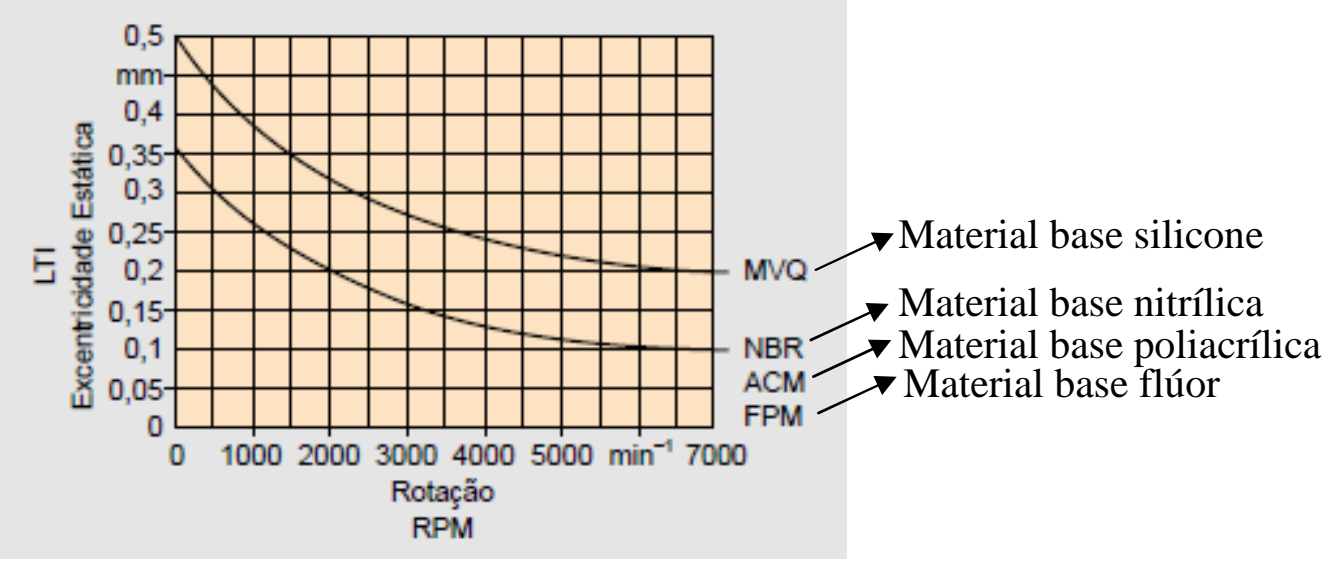

Figura 21 - Limite de excentricidade dinâmica suportada pelo retentor. [CBV Vedações - Catálogo Técnico]

Os retentores devem ser colocados tão perto dos mancais quanto possível, para evitar maiores perdas da coaxialidade e da concêntricidade.

Retentores do tipo especial, que apresentam lábios de vedação mais flexíveis e de maior comprimento, permitem maiores divergências que as mostradas.

Para a montagem do retentor no alojamento deve-se utilizar um dispositivo apropriado que tenha a superfície de apoio no retentor o mais próximo possível do diâmetro externo do retentor, de modo a evitar deformações no ato da prensagem. $\mathrm{Na}$ Figura 22, podem ser observados alguns tipos de dispositivos usualmente empregados 

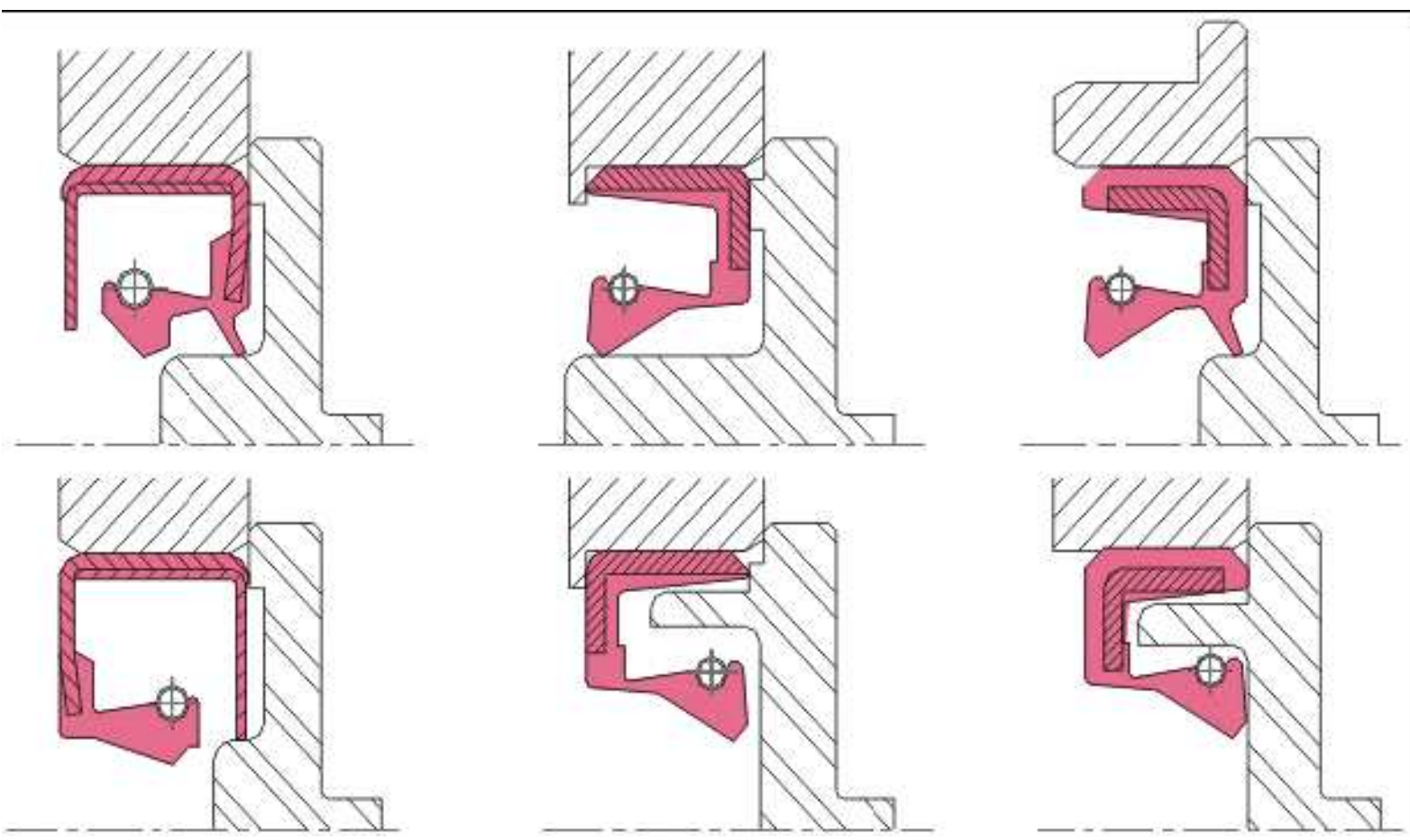

Figura 22 - Exemplos de dispositivos para montar o retentor no alojamento. [CBV Vedações Catálogo Técnico]

Durante a montagem do retentor no eixo de trabalho, não havendo possibilidade de chanfrar ou arredondar as superfícies do eixo sobre as quais deve ser introduzido o retentor, ou então, no caso do retentor ter que passar obrigatoriamente por uma região irregular, como entalhados ou rasgos de chaveta, recomenda-se o uso de uma luva de proteção para o lábio, conforme ilustrado na Figura 23, observando que o diâmetro da luva não deve deformar o lábio. Podem ser fabricadas de qualquer material que permita que estas luvas estejam com as superfícies externas (por onde passa o lábio do retentor) bem polidas, perfeitamente limpas e livres de danos superficiais ou arestas vivas, provocadas por batidas durante o seu manuseio, sendo que normalmente são executas em plástico.

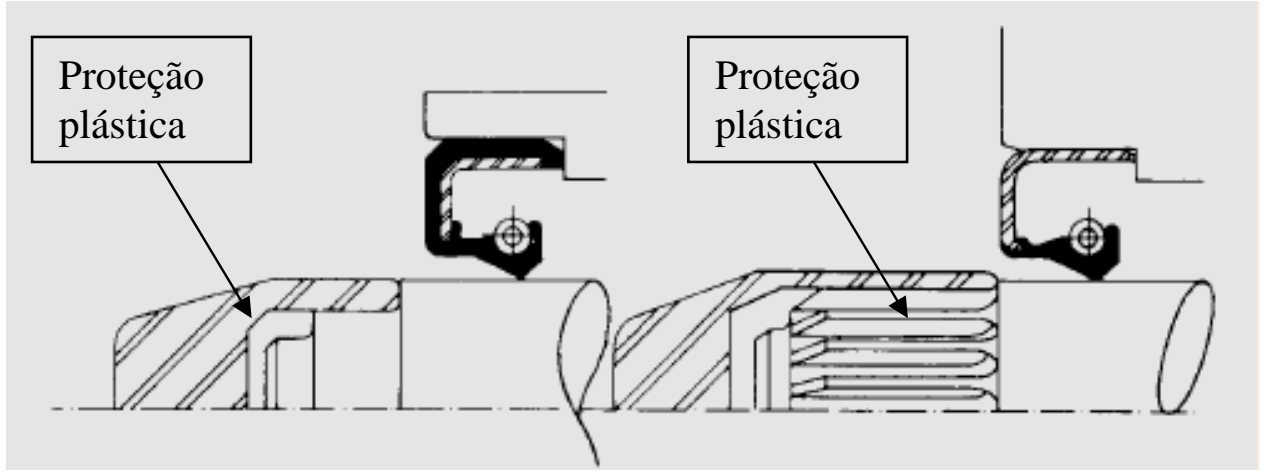

Figura 23 - Exemplos de proteção para vedação do retentor em relação ao eixo [CBV Vedações Catálogo Técnico] 


\section{7 - TIPOS DE FALHAS}

Retentores têm diversos modos de falhas, e sua taxa de falha pode ser caracterizada pela curva da banheira apresentada na Figura 3, ou seja, observa-se falhas prematuras, falhas casuais e falhas por desgaste.

Falhas prematuras podem ser exemplificadas pela montagem errada ou inadequada onde se pode originar dano na região de vedação, perda da mola durante a montagem, dano no diâmetro externo do retentor ou danificação na vedação auxiliar. Outros exemplos de falhas casuais seriam os defeitos de fabricação e as danificações no eixo e/ou no alojamento da aplicação.

Observa-se também falha por desgaste acelerado, caracterizadas por seleções inadequadas no projeto, podem ser exemplificadas por vazamentos devido à seleção de material incompatível com o óleo ou temperatura da aplicação, fazendo com que o elastômero amoleça ou endureça. Temos também a seleção de perfil incompatível com a aplicação, originado problemas de dificuldade de bombeamento, ou vedação auxiliar ineficiente para as condições de contaminantes da aplicação, originando assim um desgaste agressivo na região de vedação, oriundo do atrito de contaminantes com o eixo e o retentor. Outro exemplo é a seleção de mola incompatível com o perfil, originando desgaste prematuro na forma plana na região de vedação ou ineficiência de bombeamento devido à dificuldade de manter 0 contato do perfil com o eixo.

Falhas por desgaste são caracterizadas pelo desgaste do elastômero durante sua utilização, onde se observa um desgaste plano na região de vedação. 


\section{MÉTODO DE TRABALHO}

O método proposto pode servir de modelo para desenvolvimento de novos produtos que utilizem um ou mais itens semelhantes ao de outro produto já em produção, ou pode ser utilizado visando a melhoria de produtos já existentes.

No fluxograma constante da Figura 24 podem-se observar os passos a ser seguidos para a aplicação do método.

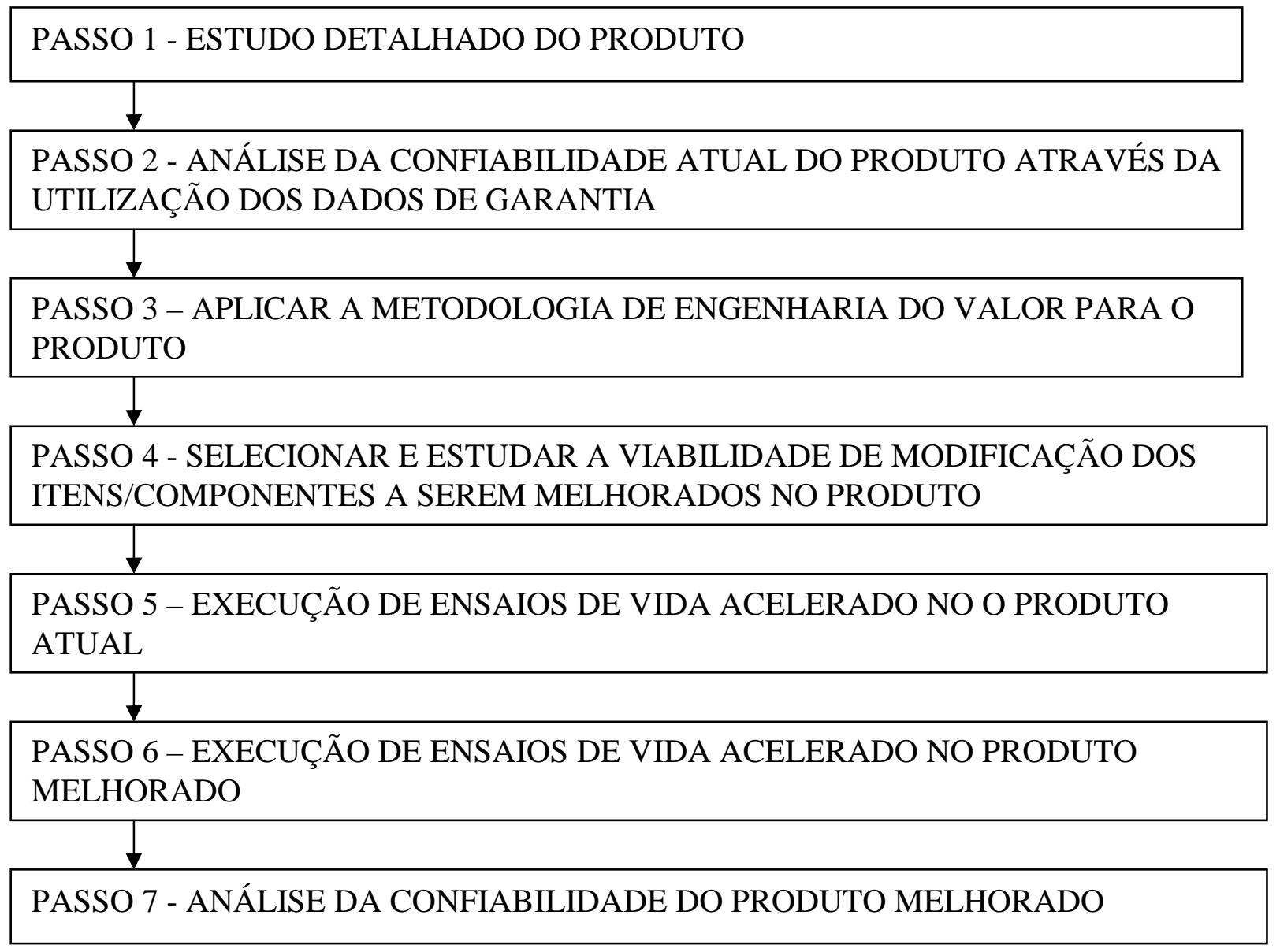

Figura 24 - Fluxograma representando o método proposto neste texto.

Na seqüência abaixo, pode-se observar a descrição, explicação e justificativa dos passos apresentados:

Passo 1 - Estudo detalhado do produto.

Nesse passo, o objetivo é estudar o produto, sua função no conjunto, assim como a de seus componentes. Esse estudo deve possuir como base normas técnicas, 
informações detalhadas da aplicação onde o produto é utilizado, se possível, memórias de cálculos e escolhas realizadas durante o desenvolvimento do produto em estudo. Todas essas informações devem ser coletadas de maneira detalhada e minuciosa, pois devem conter a maior quantidade de informações possíveis e confiáveis, a fim de cercar as variáveis que podem ser melhoradas, assim como fornecer dados para auxiliar na localização da variável que será melhorada.

Passo 2 - Análise da confiabilidade atual do produto através da utilização dos dados de garantia.

Executar a análise de confiabilidade do produto atual para caracterizar com dados técnicos a situação presente do produto. Os dados para o estudo de confiabilidade devem ser oriundos das análises de peças garantia, e deve-se observar o período de garantia coberto, assim como período de fabricação das peças analisadas e separação por tipo de defeito apresentado, assim como o tempo que acorreu a falha. O objetivo desse passo é fornecer dados que serão utilizados para a comparação com os resultados de peças atuais submetidas à ensaio acelerado, a fim de se obter relação entre o ensaio acelerado aplicado e o desempenho da peça na aplicação. Tem-se também o objetivo de estabelecer comparação com o produto melhorado, a fim de se observar se a melhoria realizada no produto foi realmente eficaz.

Passo 3 - Aplicar a metodologia de engenharia do valor para o produto.

Nesse passo deve-se aplicar a metodologia de engenharia do valor para o produto selecionado a fim de se selecionar a característica a ser melhorada no mesmo. A utilização dessa metodologia foi apresentada no Capítulo 2, Item 2.4, e como característica básica apresentada, o grupo encarregado da análise deve ser multidisciplinar formado por número ímpar de pessoas a fim de evitar possibilidade de empate em uma possível votação. Como resultado da aplicação da metodologia de engenharia do valor, pode-se obter mais de uma característica a ser modificada, cabendo ao líder do grupo de pesquisa expor a opinião do grupo com relação à importância de cada característica assim como sua importância na melhoria no produto final.

Passo 4 - Selecionar e estudar a viabilidade de modificação dos itens/componentes a serem melhorados no produto.

Nesse passo devem-se selecionar os itens que foram direcionados pelo estudo de engenharia do valor e realizar uma verificação do impacto da melhoria proposta no projeto, fabricação e controle de qualidade do mesmo. 
Para essa verificação deve-se observar quais serão os impactos da alteração proposta em todos os setores produtivos, assim como o impacto que a mesma pode acarretar na aplicação. Deve-se observar tanto os impactos positivos como os negativos, para que se possa fundamentar a decisão da alteração proposta.

Considerando que o produto estudado é um item de produção corrente, o objetivo desse passo é selecionar e organizar as características originadas da aplicação da engenharia do valor, analisando a implementação da mesma, viabilidade de execução no processo produtivo e de controle de qualidade.

Passo 5 - Execução de ensaios de vida acelerado para o produto atual

Nesse passo será selecionada a ciclagem do teste que será utilizado através do tipo de aceleração que o produto deverá sofrer. A seleção dessa ciclagem deverá ser realizada apoiada em normas e poderá sofrer influência dos dados oriundos do conhecimento das condições de aplicação do produto. Nesse passo também, será selecionada a quantidade de peças que serão ensaiadas e, finalmente, nesse passo serão realizado os ensaios acelerados de vida acelerado no produto atual. $O$ objetivo desse passo é fornecer dados para se obter uma relação entre o ensaio acelerado realizado e o comportamento do produto na aplicação, para que se possa estimar a confiabilidade do produto melhorado na aplicação através da aplicação do mesmo tipo de ensaio acelerado.

Passo 6 - Execução de ensaios de acelerados vida no produto melhorado Nesse passo serão executados ensaios acelerados de vida no produto melhorado. $O$ tipo de ensaio a ser aplicado deverá ser o mesmo que foi aplicado no produto atual, definido no passo anterior. O objetivo desse passo é fornecer dados para que se possa estimar a confiabilidade do produto melhorado durante sua utilização na aplicação.

Passo 7 - Análise de confiabilidade do produto melhorado

Com as informações obtidas nos passos anteriores deverá ser realizado estudo para estimar a confiabilidade do produto melhorado durante sua aplicação. Para esse estudo, deverá ser utilizada a relação obtida entre ensaio acelerado de vida com a peça atual e estudo de confiabilidade da peça atual, assim como os resultados dos ensaios acelerados de vida, realizados com a peça melhorada. Como objetivo da execução desse passo deverá ser verificada a eficiência da melhoria proposta. 


\section{CASO EXEMPLO: METODOLOGIA PROPOSTA APLICADA A UM RETENTOR}

Aplica-se o método de trabalho apresentado na capitulo anterior à um retentor automotivo utilizado em uma caixa de câmbio para caminhão, a fim de elucidar o método como um todo.

Dentro de um universo de mais de 3000 retentores candidatos a ser objeto do estudo, foram realizados alguns filtros para que seja selecionado o melhor item no escopo do estudo.

A fim de que se tenha uma melhor rastreabilidade dos dados das peças de garantia, primeiramente foram eliminados os itens que não possuem nenhum tipo de identificação de data ou período de fabricação, em seguida foram eliminados os itens produzidos em grandes volumes (subentenda-se por grande volume uma quantidade maior que 50 mil peças por mês), e também foram eliminados os itens vendidos à mais de uma planta ou cliente. Na seqüência, a fim de se obter dados com alta credibilidade, foram verificados os dados no banco de dados de garantia, assim como nos relatórios de análise e foram eliminados os itens com informações incompletas ou inconsistentes sobre a análise de garantia. Por último, foram eliminados os itens para os quais não se possuía grande quantidade de informações de sua aplicação, seja por serem itens antigos ou apenas pela razão de o cliente não informar.

Com a aplicação desses filtros, saiu-se de um universo de aproximadamente 3000 itens para aproximadamente 50 itens. E por fim, realizou-se uma escolha aleatória dentre esses itens restantes, selecionando 0 item que por motivo de sigilo profissional chamaremos de X, o qual pode ser identificado pela Figura 25. 


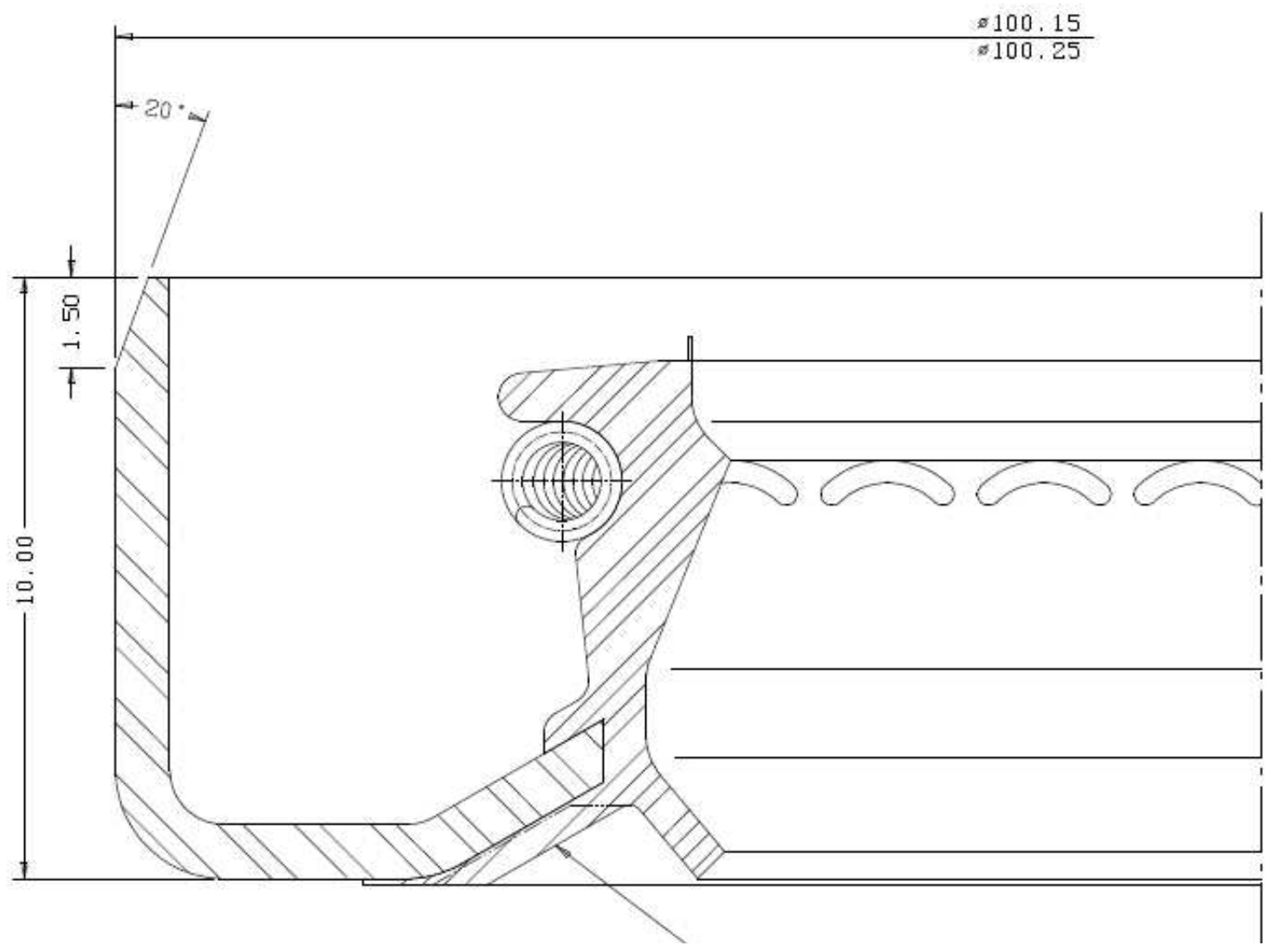

Figura 25 - Item X, retentor que estará sendo utilizado no estudo.

5.1. ESTUDO DETALHADO SOBRE O ITEM X, DE SUA FUNÇÃO NO CONJUNTO, E DE SEUS COMPOMENTES.

Esse tópico se refere ao Passo 1 apresentado no método do trabalho e foi concluído no capitulo 3.

Do estudo realizado pode-se alocar o retentor estudado na forma construtiva de externo metálico, conforme Figura 7 tipo c) e de construção geral tipo BS, conforme Figura 8.

5.2. ANÁLISE DOS DADOS DE GARANTIA E CÁLCULO DA CONFIABILIDADE DO ITEM X. 
Esse tópico se refere ao Passo 2 apresentado no método de trabalho.

O item X, mostrado na Figura 25 acima, é utilizado como retentor de saída da caixa de transmissão de caminhões pesado, principalmente os utilizados no transporte nas regiões canavieiras.

São utilizadas duas peças em cada caixa de transmissão, uma peça para cada lado da saída, conforme Figura 26 abaixo. A caixa de transmissão possui um volume de utilização anual de aproximadamente 6500 peças. Logo, tem-se um volume anual de aproximadamente 13000 peças do item $X$.

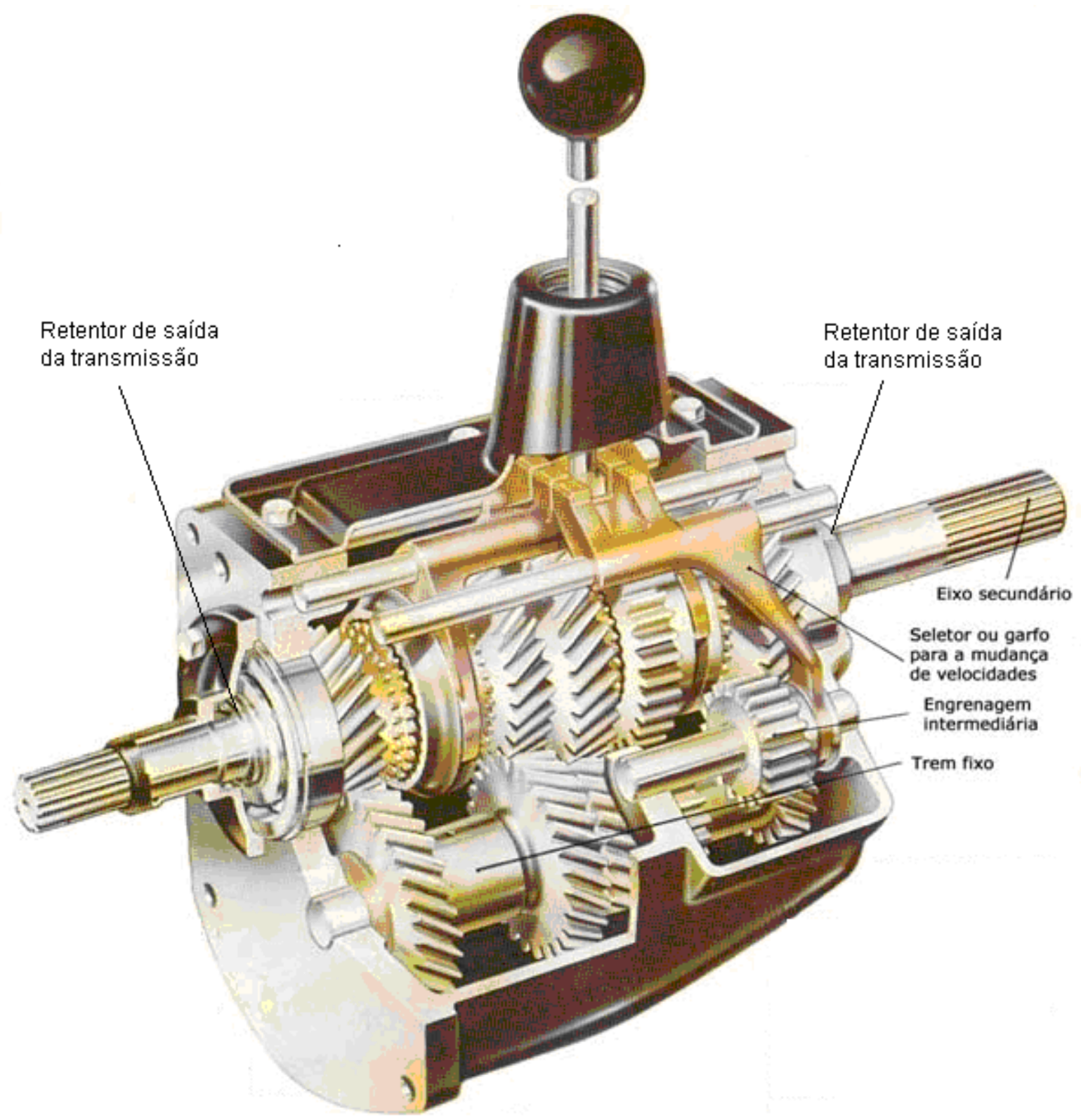

Figura 26 - Localização do retentor na aplicação 
Em sua gravação, o retentor possui dois caracteres na forma de letras que codificam os dois últimos dígitos do ano de fabricação conforme Tabela 2

Tabela 2 - Identificação de rastreabilidade gravada na peça

\begin{tabular}{|l|l|}
\hline 1 & $\mathrm{~A}$ \\
\hline 2 & $\mathrm{~B}$ \\
\hline 3 & $\mathrm{C}$ \\
\hline 4 & $\mathrm{D}$ \\
\hline 5 & $\mathrm{E}$ \\
\hline 6 & $\mathrm{~F}$ \\
\hline 7 & $\mathrm{G}$ \\
\hline 8 & $\mathrm{H}$ \\
\hline 9 & $\mathrm{I}$ \\
\hline 0 & $\mathrm{~J}$ \\
\hline
\end{tabular}

Logo, para as peças produzidas no ano 2007, ano que será estudado, analisam-se as peças que apresentam os caracteres "JG" em sua gravação.

Para o estudo proposto estar-se-á utilizando os dados do ano de 2007, onde se teve uma utilização de 11818 peças e um retorno de 211 peças em garantia, com motivos mostrados na Tabela 3.

Tabela 3 - Informações da analise de retorno

\begin{tabular}{|c|l|}
\hline Quantidade & \multicolumn{1}{|c|}{ Análise do retorno } \\
\hline 76 & Montagem inadequada \\
\hline 57 & danificadas na desmontagem impossibilitado sua análise \\
\hline 27 & Impurezas na área de vedação \\
\hline 27 & $\begin{array}{l}\text { Não apresentaram problemas que justificasse o } \\
\text { vazamento }\end{array}$ \\
\hline 12 & deformações e riscos na vedação \\
\hline 8 & desgaste acentuado \\
\hline 4 & descolagem \\
\hline 211 & Total \\
\hline
\end{tabular}

Na Figura 27 pode-se observar a distribuição percentual dos motivos de retorno das peças analisadas, assim como pode-se visualizar facilmente os maiores índices de retorno de garantia. 


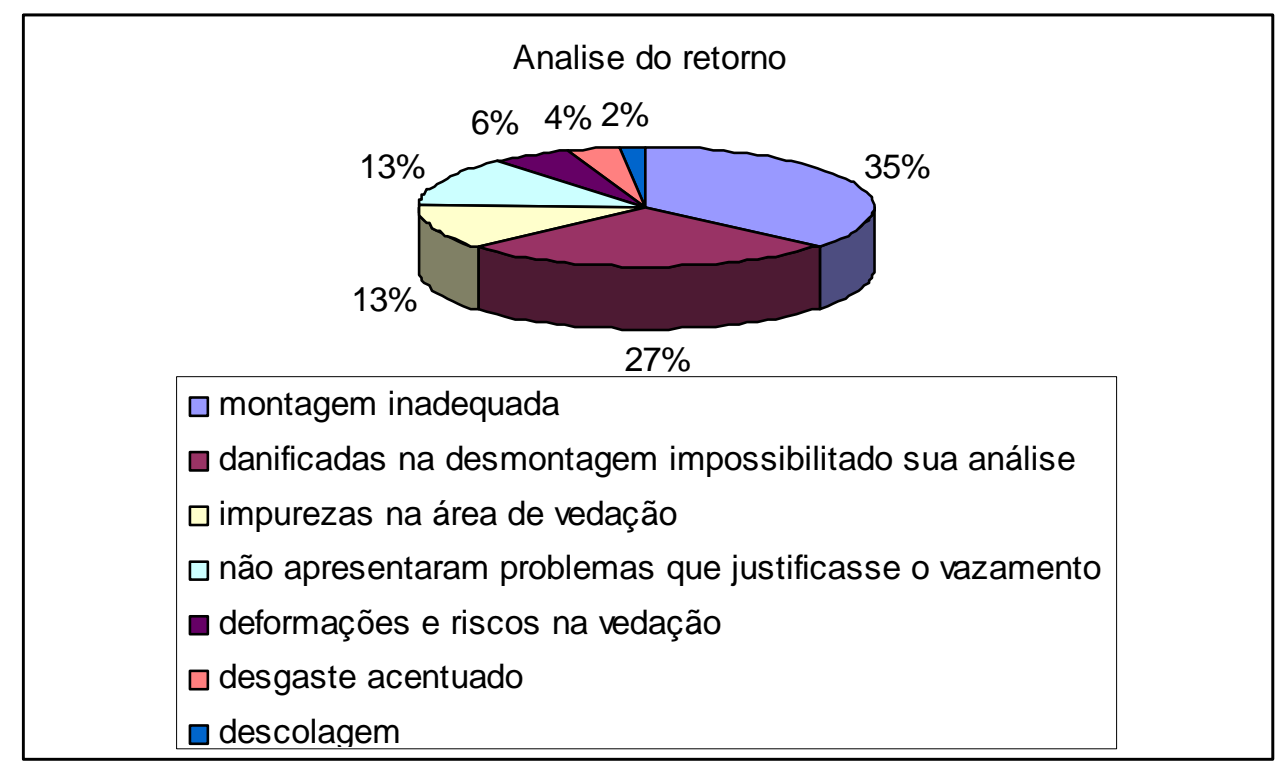

Figura 27 - Diagrama de "Pizza" com as informações da analise de retorno

Das informações constantes nos relatórios e no banco de dados de garantia selecionou-se as mais relevantes para o estudo, na seqüência, montou-se uma tabela para auxílio no cálculo de confiabilidade de peça na condição atual, a qual pode ser consultada no Apêndice A. Na Tabela 4 tem-se um extrato da tabela do Apêndice $A$ onde se observa o cabeçalho e as seis primeiras linhas da mesma para que se possa facilmente visualizar as informações selecionadas do banco de dados de garantia.

Tabela 4: Modos de falha dos dados de retorno

\begin{tabular}{|c|c|c|c|c|c|c|c|}
\hline peça\# & $\begin{array}{l}\text { Data do } \\
\text { retorno }\end{array}$ & Relatorio\# & $\begin{array}{l}\text { Nota fiscal } \\
\text { recebida\# }\end{array}$ & $\begin{array}{l}\text { quant.peças } \\
\text { recebidas } \\
\text { para analise }\end{array}$ & Cód & Conclusão & $\mathrm{KM}$ \\
\hline 1 & Jan & 6 & 510 & 2 & 4 & Desgaste acentuado & 963 \\
\hline 2 & Jan & 6 & 510 & 2 & 7 & $\begin{array}{l}\text { não apresentaram } \\
\text { problemas que } \\
\text { justificasse o } \\
\text { vazamento }\end{array}$ & 772 \\
\hline 3 & Fev & 15 & 733 & 6 & 1 & Descolagem & 1437 \\
\hline 4 & Fev & 15 & 733 & 6 & 5 & $\begin{array}{l}\text { impurezas na área de } \\
\text { vedação }\end{array}$ & 1424 \\
\hline 5 & Fev & 15 & 733 & 6 & 6 & montagem inadequada & 1001 \\
\hline 6 & Fev & 15 & 733 & 6 & 7 & $\begin{array}{l}\text { não apresentaram } \\
\text { problemas que } \\
\text { justificasse o } \\
\text { vazamento }\end{array}$ & 1001 \\
\hline
\end{tabular}


$\mathrm{Na}$ Figura 28 pode-se observar uma foto representativa de peça que retorna da garantia avaliada com falha devido ao desgaste acentuado.

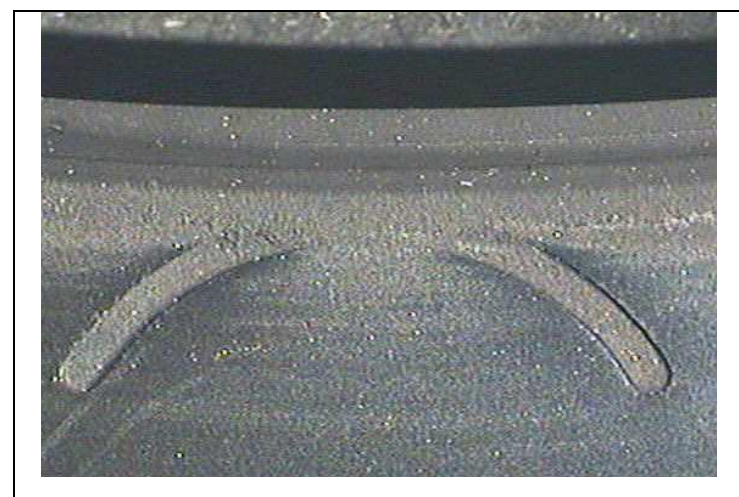

Figura 28 - Foto representativa das peças que retornaram de campo com laudo de falha por desgaste acentuado

Com base nos dados constantes no Apêndice A se calculou a confiabilidade do retentor na condição atual.

Primeiramente utilizaram-se dois estimadores não paramétricos, a tabela de vida e o estimador de Kaplan-Meier.

Em ambos estimadores, necessita-se dividir os dados em grupos, e para essa divisão utilizou-se a STURGES' RULE (MIL-HDBK-338, 1950) conforme equação (11).

$$
k=1+3,3 \log N
$$

onde:

$\mathrm{N}>$ é o numero de dados de falha existentes no banco de dados

$\mathrm{k}>$ quantidade de grupos que serão gerados.

Assim, aplicando a STURGES' RULE para $\mathrm{N}=211$ chega-se a uma divisão de 9 grupos com intervalos conforme a Tabela 5.

Tabela 5: Divisão de intervalos para os dados de retorno

\begin{tabular}{|l|}
\hline Intervalo \\
\hline 0 à 22500 \\
\hline 22501 à 45000 \\
\hline 45001 á 67500 \\
\hline 67501 à 90000 \\
\hline 90001 à 112500 \\
\hline 112501 à 135000 \\
\hline 135001 à 157500 \\
\hline 157501 à 180000 \\
\hline 180001 à 202500 \\
\hline
\end{tabular}


Com esses dados, foi possível calcular a tabela de vida, Tabela 6. Na tabela de vida utiliza-se a divisão de intervalos da Tabela 5 e calcula-se a probabilidade de um item falhar no intervalo em questão $\left({ }^{\wedge} q\right)$, sabendo que ele não falou até o início do intervalo. Calcula-se também essa probabilidade percentualmente $\left({ }^{\wedge} \mathrm{q} \%\right)$

Tabela 6 : Tabela de vida para o retentor corrente

\begin{tabular}{|c|c|c|c|c|c|}
\hline Intervalo & $\begin{array}{l}\text { No. sob } \\
\text { risco }\end{array}$ & No.Falhas & $\begin{array}{l}\text { Probabilidade de } \\
\text { um item falhar no } \\
\text { intervalo } \\
\wedge \mathrm{a}\end{array}$ & $\begin{array}{l}\text { Probabilidade } \\
\text { percentual de um item } \\
\text { falhar no intervalo } \\
\wedge \text { ( }(\%)\end{array}$ & $\begin{array}{l}\text { Confiabilidade(\%) } \\
R(t)\end{array}$ \\
\hline 0 à 22500 & 11818 & 89 & 0,0075 & 0,7530 & 100 \\
\hline 22501 à 45000 & 11729 & 35 & 0,0029 & 0,2984 & 99,2469 \\
\hline 45001 á 67500 & 11694 & 25 & 0,0021 & 0,2137 & 98,9507 \\
\hline 67501 à 90000 & 11669 & 21 & 0,0018 & 0,1799 & 98,7392 \\
\hline 90001 à 112500 & 11648 & 15 & 0,0013 & 0,1288 & 98,5615 \\
\hline 112501 à 135000 & 11633 & 1 & 0,00008 & 0,0086 & 98,4345 \\
\hline 135001 à 157500 & 11632 & 13 & 0,0011 & 0,1117 & 98,4261 \\
\hline 15701 à 180000 & 11619 & 5 & 0,0004 & 0,0430 & 98,3161 \\
\hline 18001 à 202500 & 11614 & 7 & 0,0006 & 0,0602 & 98,2738 \\
\hline
\end{tabular}

Da tabela de vida acima, pode-se observar que o retentor atual possui confiabilidade de 98,27\%, para o período de garantia que é de 1 ano.

Para o cálculo do estimador de Kaplan-Meier, cria-se uma tabela com todos os dados gerados a qual, pode ser consultada no Apêndice A e um extrato desta é apresentado na Tabela 7. Nesta, observa-se o cabeçalho, as seis primeiras e as duas últimas linhas da mesma para que se possa visualizar as informações geradas no cálculo do estimador de Kaplan-Meier.

Tabela 7 : Tabela para cálculo do estimador de Kaplan-Meier

\begin{tabular}{|r|r|r|l|}
\hline \multicolumn{1}{|l|}{} & $\mathrm{d}$ & $\mathrm{N}$ & $\begin{array}{l}\text { Confiabilidade } \\
\mathrm{R}(\mathrm{t})\end{array}$ \\
\hline 0 & 0 & 11818 & 1 \\
\hline 772 & 1 & 11817 & 0,999915376 \\
\hline 963 & 1 & 11816 & 0,999830752 \\
\hline 1001 & 1 & 11815 & 0,999746128 \\
\hline 1001 & 1 & 11814 & 0,999661505 \\
\hline 1048 & 1 & 11813 & 0,999576881 \\
\hline 195725 & 1 & 11608 & 0,982228992 \\
\hline 198352 & 1 & 11607 & 0,982144368 \\
\hline & & & \\
\hline
\end{tabular} 2 últimas linhas

Observa-se que os dois estimadores apresentaram dados próximos para a confiabilidade ao final do período de garantia, tem-se a tabela de vida com $98,27 \%$ e 
Kaplan-Meier com 98,21\%, pode-se atribuir essa diferença ao número de intervalos utilizado para o cálculo. O estimador de Kaplan-Meier possui o número de intervalos igual ao número de falhas, já para a construção da tabela de vida, utiliza-se a Sturges' rule para calcular a quantidade de intervalos a ser utilizado na análise, o que fez com que número de intervalos fosse menor se comparado ao número de intervalos utilizado pelo estimador de Kaplan-Meier.

Com isso concluí-se que a tabela de vida é sensível à quantidade de intervalos utilizados, e por isso não se deve escolher a quantidade de intervalos aleatoriamente.

Os dados analisados refletem a quantidade de peças que retornaram para a análise de garantia no período de 1 ano.

A empresa que fabrica o retentor em questão apresenta como meta a confiabilidade de 99,99\%. Essa confiabilidade foi selecionada de acordo com histórico de dados de outros itens ao longo dos anos, mas para alguns produtos específicos, o cliente pode solicitar a confiabilidade que deseja em seu item.

\subsection{APLICAÇÃO DA METODOLOGIA DE ENGENHARIA DO VALOR PARA O ITEM $\mathrm{X}$.}

Esse tópico se refere ao Passo 3 apresentado no método de trabalho.

Para a análise de qual característica da peça que deveria ser melhorada, selecionou-se o item que originou a maior quantidade de peças retornadas.

Para a análise desejada no trabalho exposto, a equipe é composta por membros da indústria de autopeças conforme discriminado abaixo:

- Engenheiro de desenvolvimento de produtos com mais de 30 anos de experiência

- Coordenador de projetos de moldes de injeção de borracha com mais de 20 anos de experiência

- Engenheira de desenvolvimento de produtos e qualidade com 7 anos de experiência e com treinamento na técnica de análise do valor, que terá a função de líder no grupo

- Engenheiro de qualidade no desenvolvimento de produtos com 5 anos de experiência 
- Laboratorista responsável pelo dimensionamento de produtos novos com 15 anos de experiência

- Laboratorista responsável pela análise de peças de garantia com 20 anos de experiência.

Descartaram-se as 76 peças que retornaram por montagem inadequada na aplicação, pois esse tipo de característica está diretamente relacionada com o fator humano na montagem do retentor na aplicação. Por motivos óbvios, descartaram-se também as 57 peças danificadas na desmontagem.

Descartaram-se as 27 peças com impurezas na área de vedação, pois essa característica não demonstra falha por vazamento, de acordo com a sistemática de análise das peças de garantia utilizada pela empresa essas peças são trocadas pois demonstram que em um futuro essas impurezas irão gerar desgaste acentuado devido ao atrito das mesmas com a borracha de vedação, fazendo com que se caracterize o vazamento.

$\mathrm{Na}$ seqüência descartaram-se, por motivos óbvios, as 27 peças que não apresentaram problemas que justificasse o vazamento.

E finalmente descartaram-se as 12 peças com deformações e riscos na vedação, devido ao fato de essas características estarem vinculas ao dispositivo de montagem utilizado, assim como as condições de limpeza e isenção de danificações.

Chegando-se assim na caracteriza que se deve melhorar, ou seja, o sexto maior índice de retorno, as 8 peças com desgaste acentuado.

O desgaste acentuado observado nas peças de garantia está relacionado ao atrito de contaminantes externos com a borracha do vedador, e é caracterizado como indicado na Figura 28. Portanto se deve estudar como melhorar a característica de proteção contra contaminates externos.

$\mathrm{Na}$ seqüência aplicou-se a técnica de engenharia do valor, a fim de se determinar quais as funções do retentor que estão relacionadas com a característica de proteção contra contaminantes externos em um retentor.

A seqüência abaixo mostra o estudo realizado, o qual é iniciado pela construção da Tabela 8 onde se observa o produto retentor, seus componentes e funções. 
Tabela 8: Tabela com relação de componentes do retentor e suas funções

1- Relaçã̃o dos componentes e funçốes

\begin{tabular}{|c|c|c|}
\hline Parte & Nome & Funçẫo \\
\hline \multirow[b]{5}{*}{1} & \multirow[t]{5}{*}{ Superficie externa } & vedar estaticamente \\
\hline & & garantir montagem \\
\hline & & fixar peça \\
\hline & & expulsar peça \\
\hline & & dificultar montagem \\
\hline \multirow[b]{2}{*}{2} & \multirow[t]{2}{*}{ Chanfro anterior } & auxiliar montagem \\
\hline & & \\
\hline \multirow[b]{2}{*}{3} & \multirow[t]{2}{*}{ Face anterior } & finalizar curso de montagem \\
\hline & & protegar perfil (empilhamento) \\
\hline 4 & Ranhuras & fixar carcaça (fabricação) \\
\hline \multirow[b]{2}{*}{5} & \multirow[t]{2}{*}{ Superficie interna do labio } & estabilizar perfil \\
\hline & & absower excentricidade \\
\hline \multirow[b]{2}{*}{6} & \multirow[t]{2}{*}{ Mola } & garantir força radial \\
\hline & & garantir vedaçẫo \\
\hline 7 & Garra da mola & segurar mola \\
\hline \multirow[b]{2}{*}{8} & \multirow[t]{2}{*}{ Alojamento da mola } & segurar mola \\
\hline & & posicionar mola \\
\hline \multirow[b]{2}{*}{9} & \multirow{2}{*}{$\begin{array}{l}\text { Superficie anterior do labio de } \\
\text { vedaçẫo principal (ângulo óleo) }\end{array}$} & estabilizar perfil \\
\hline & & auxiliar vedaçã̃o \\
\hline \multirow[b]{2}{*}{10} & \multirow{2}{*}{ Lábio de vedação principal } & vedar dinamicamente \\
\hline & & evitar vazamento \\
\hline 11 & Chanfro posterior & auxiliar montagem \\
\hline \multirow[b]{3}{*}{12} & \multirow[t]{3}{*}{ Face posterior } & identificar peça \\
\hline & & unir extremidades \\
\hline & & auxiliar montagem \\
\hline \multirow[b]{2}{*}{13} & \multirow[t]{2}{*}{ Carcaça (reforço estrutural) } & reforçar selo \\
\hline & & promover adesấo (borracha) \\
\hline \multirow[b]{2}{*}{14} & \multirow[t]{2}{*}{ Regiao de flexăo do labio } & estabilizar perfil \\
\hline & & absorver excentricidade \\
\hline 15 & Lábio de vedação auxiliar & vedar contaminaçẫo externa \\
\hline \multirow[b]{2}{*}{16} & \multirow{2}{*}{$\begin{array}{l}\text { Superficie posterior do labio de } \\
\text { vedação principal }\end{array}$} & estabilizar perfil \\
\hline & & evitar vazamento \\
\hline
\end{tabular}

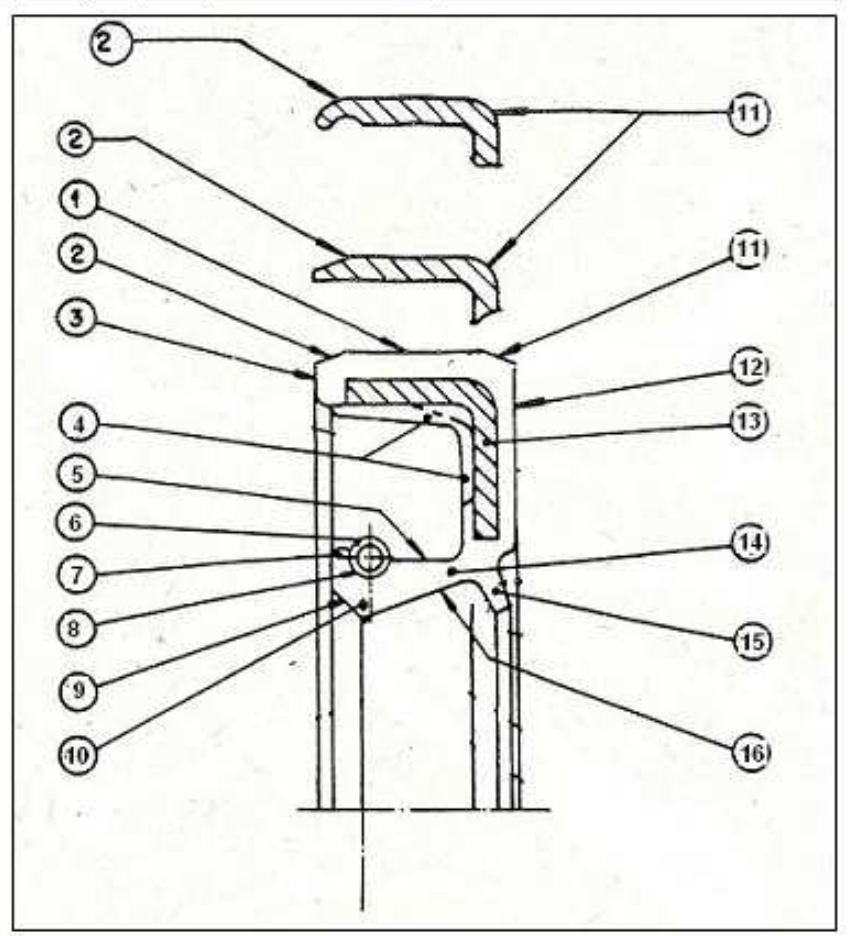


Como seqüência de estudo, tal como apresentado no Capítulo 2, Item 2.4, foi elaborada a Tabela 9 que apresenta apenas as funções dos componentes. Essa tabela foi elaborada para que se possa classificar estas funções.

Tabela 9 : Funções dos componentes

\begin{tabular}{|l|}
\hline Função \\
\hline vedar estaticamente \\
\hline fixar peça \\
\hline expulsar peça \\
\hline auxiliar montagem \\
\hline finalizar curso de montagem \\
\hline proteger perfil (empilhamento) \\
\hline fixar carcaça (fabricação) \\
\hline estabilizar perfil \\
\hline absorver excentricidade \\
\hline garantir força radial \\
\hline garantir vedação \\
\hline segurar mola \\
\hline posicionar mola \\
\hline auxiliar vedação \\
\hline vedar dinamicamente \\
\hline evitar vazamento \\
\hline identificar peça \\
\hline unir extremidades \\
\hline reforçar selo \\
\hline promover adesão (borracha) \\
\hline vedar contaminação externa \\
\hline
\end{tabular}

$\mathrm{Na}$ Tabela 10, pode-se observar a classificação das funções apresentadas na Tabela 8 conforme o critério sugerido por Cisllag (1991):

- Identificadora (I) / Agregada (A)

- Relevante (R) / Irrelevante (IR) / Indesejável (IN)

- Uso (U) / Estima (E) 
Tabela 10 : Tabela com classificação das funções

\begin{tabular}{|c|c|c|c|}
\hline \multicolumn{4}{|c|}{ Classificação } \\
\hline $\mathrm{I} / \mathrm{A}$ & $\mathrm{R} / \mathrm{I} / \mathrm{IN}$ & $\mathrm{U} / \mathrm{E}$ & Funções \\
\hline 1 & $\mathrm{R}$ & $\mathrm{U}$ & vedar estaticamente \\
\hline A & $\mathrm{R}$ & $\mathrm{U}$ & fixar peca \\
\hline A & IN & $U$ & expulsar peça \\
\hline A & $\mathrm{IN}$ & $\mathrm{E}$ & dificultar montagem \\
\hline A & $\mathrm{I}$ & $E$ & auxiliar montagem \\
\hline A & IR & $\mathrm{E}$ & finalizar curso de montagem \\
\hline A & IR & $\mathrm{E}$ & proteger perfil (empilhamento) \\
\hline A & IR & $U$ & fixar carcaça (fabricação) \\
\hline A & $\mathrm{R}$ & $\mathrm{U}$ & estabilizar perfil \\
\hline A & $\mathrm{R}$ & $\mathrm{U}$ & absorver excentricidade \\
\hline A & $\mathrm{R}$ & $\mathrm{U}$ & garantir força radial \\
\hline A & $\mathrm{R}$ & $\mathrm{U}$ & garantir vedação \\
\hline A & $\mathrm{R}$ & $\bar{U}$ & segurar mola \\
\hline A & $\mathrm{R}$ & $\mathrm{U}$ & posicionar mola \\
\hline A & $\mathrm{R}$ & $\mathrm{U}$ & auxiliar vedação \\
\hline $\mathrm{I}$ & $\mathrm{R}$ & $\bar{U}$ & vedar dinamicamente \\
\hline A & IN & $U$ & evitar vazamento \\
\hline A & IR & $E$ & identificar peça \\
\hline A & $\mathrm{R}$ & $E$ & unir extremidades \\
\hline A & $\mathrm{R}$ & $\mathrm{U}$ & reforçar selo \\
\hline A & $\mathrm{R}$ & $\mathrm{U}$ & promover adesão (borracha) \\
\hline A & $\mathrm{R}$ & $\mathrm{E}$ & variar custo \\
\hline A & $\mathrm{R}$ & $\mathrm{U}$ & vedar contaminação externa \\
\hline
\end{tabular}

Para o estudo em questão, não foi realizada a valoração das funções, pois de acordo com o método proposto no Capítulo 4, o objetivo da utilização desta ferramenta é de investigar e selecionar um ou mais componentes para ser objeto de modificação de acordo com a melhoria da função desejada.

Com o exposto pode-se observar que a característica a ser modificada será a vedação auxiliar, sendo esse o único elemento responsável pela função vedação contaminação externa.

Conclui-se que a metodologia atingiu o objetivo esperado, auxiliando a selecionar qual componente deverá ser modificado para conseguir que o item tenha um desempenho maior na função selecionada.

\subsection{SELEÇÃO E ESTUDO DOS ITENS / COMPONENTES A SEREM MELHORADOS NO ITEM X}


Esse tópico se refere ao Passo 4 apresentado no método de trabalho.

Com base no estudo de engenharia do valor, pode-se observar que a característica a ser melhorada no retentor esta relacionada à vedação auxiliar. Com isso sugere-se um aumento da interferência da vedação auxiliar da peça em estudo com o eixo da aplicação.

Esse aumento de interferência será realizado de maneira a garantir que na pior condição de montagem, onde pode-se observar a maior excentricidade entre eixo e sede, todo o perímetro da vedação auxiliar tenha contato com o eixo

Na Figura 29, pode-se observar, dentro do círculo, o detalhe da alteração proposta.

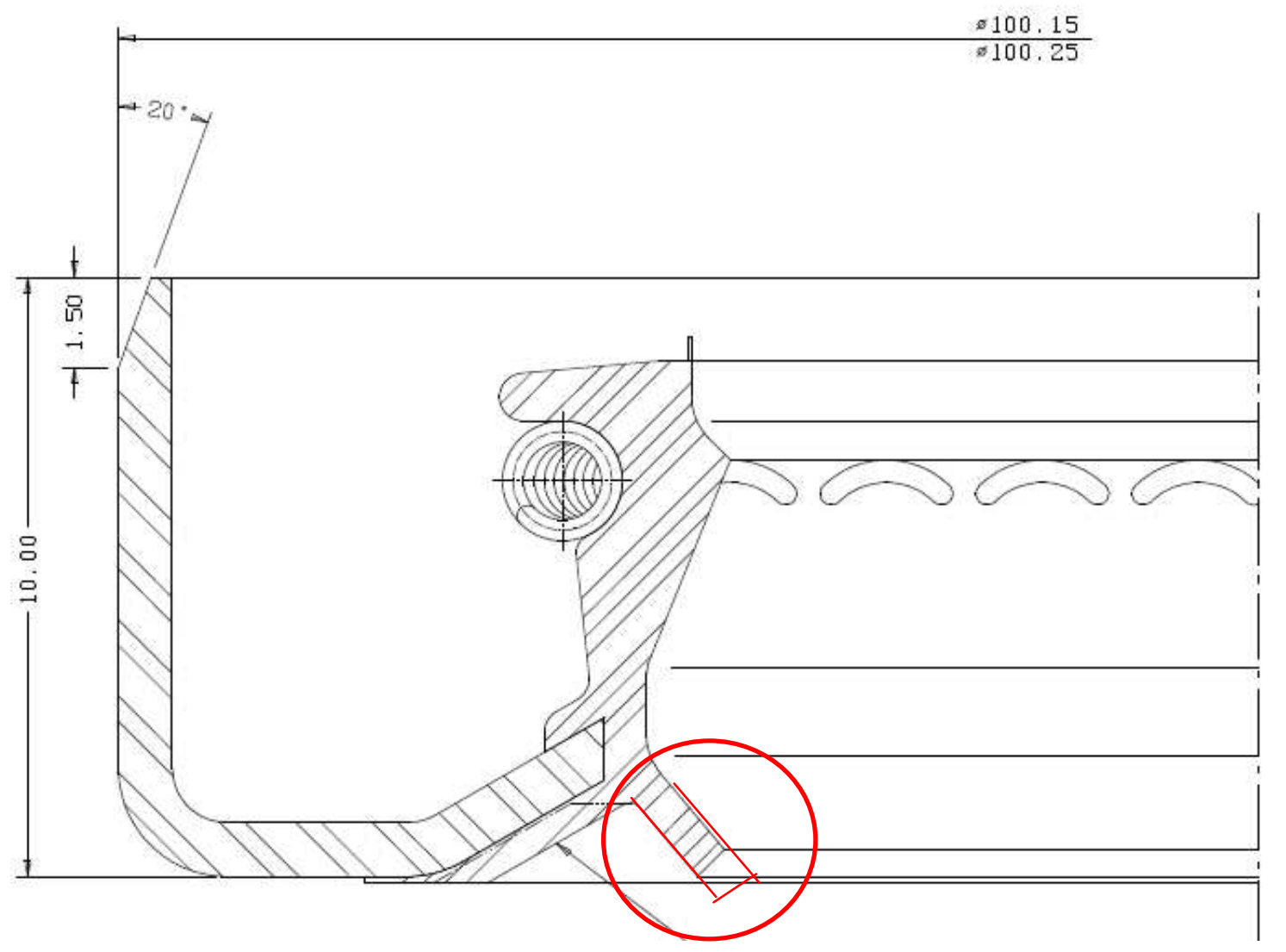

Figura 29 - Detalhe da alteração proposta

5.5. EXECUÇÃO DE ESNSAIOS DE VIDA ACELERADO NO PRODUTO ATUAL.

Esse tópico se refere ao Passo 5 apresentado no método de trabalho.

$\mathrm{Na}$ Figura 30 pode-se observar uma foto da máquina de teste utilizada. 
Esse tipo de equipamento está de acordo com a norma NBR12906/19893. Entre outras características exigidas na norma, permite o controle de rotação do eixo, assim como o sentido de rotação. Permite também o controle de temperatura do fluido a ser vedado, regulagem das excentricidades do eixo e do alojamento, assim como pressão do fluido ou do depósito do fluido.

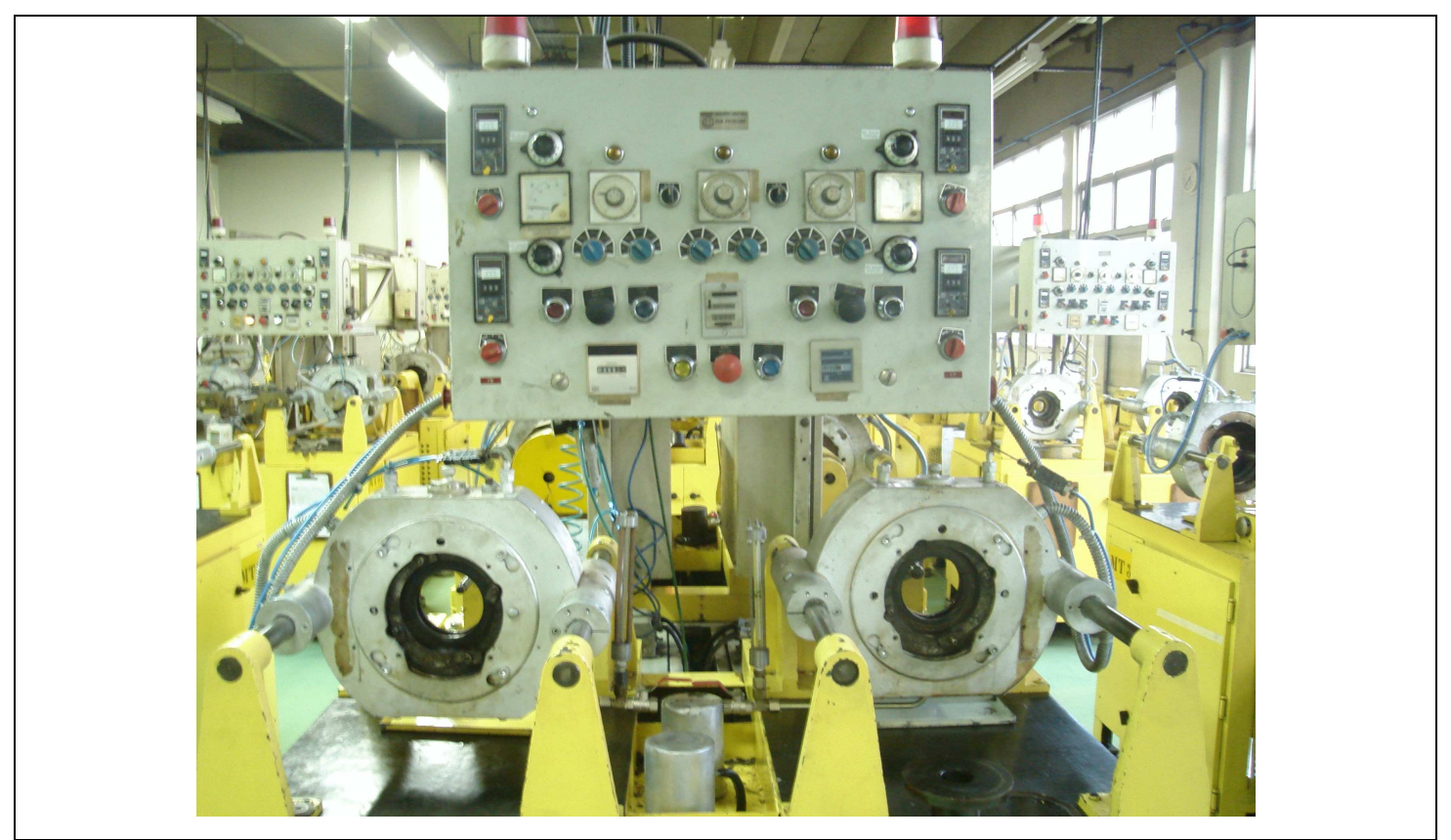

Figura 30 - Foto da maquina de teste utilizada

Na Figura 31 pode-se observar o dispositivo utilizado para simular a condição de contaminação externa no retentor.

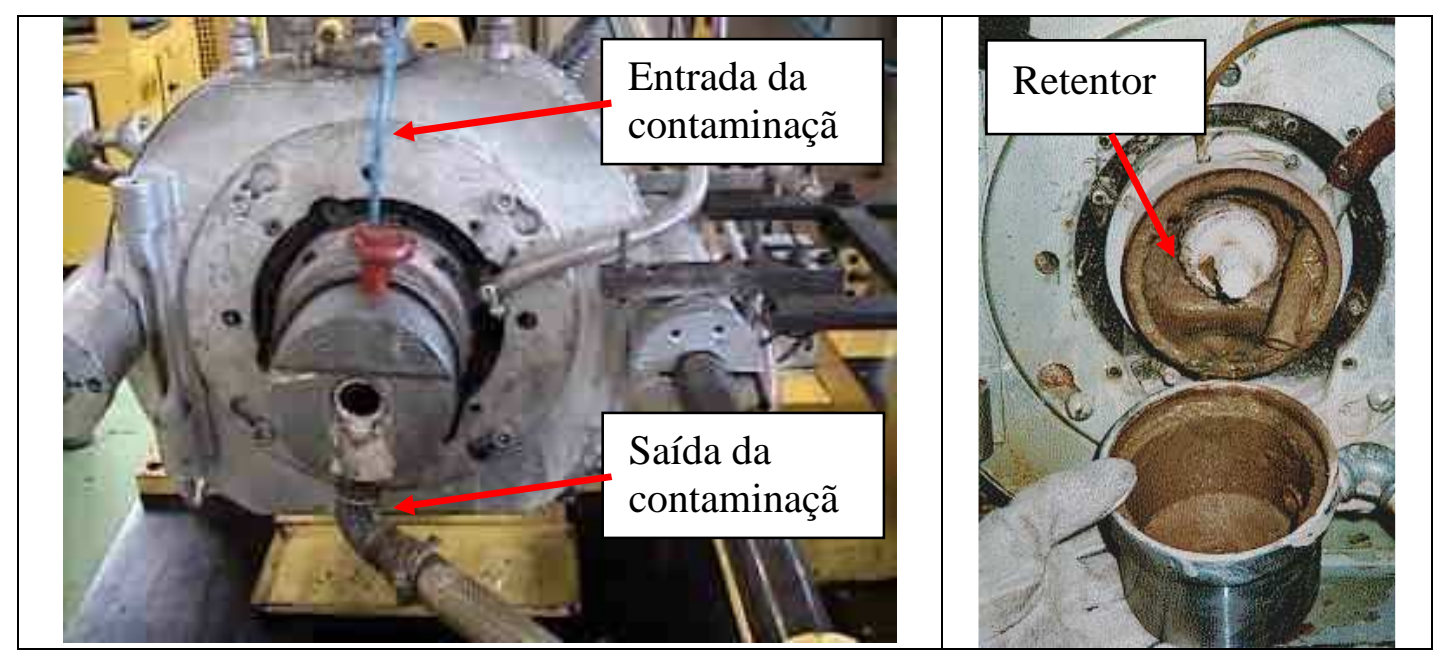

Figura 31 - Foto do dispositivo de simulação de contaminação externa 
Essa simulação foi realizada utilizando o bombeamento de lama contra o retentor. A composição da lama foi de 1 parte ISO 12103-1 A2 pó fino para 10 partes de água potável em peso.

\subsubsection{Condições de teste para ensaio de contaminação externa na peça corrente}

Para a execução dos testes foi utilizado o óleo SPIRAX 90 HD, no nível de linha de centro da peça, conforme ilustrado na Figura 32. Essa condição foi utilizada pois simula a condição da peça em uso real, onde o óleo exerce a função de lubrificação e refrigeração do sistema de troca de marchas, funções essas de vital importância para o funcionamento e durabilidade do sistema.

Figura 32 - Foto exemplificando condição de nível de centro do óleo

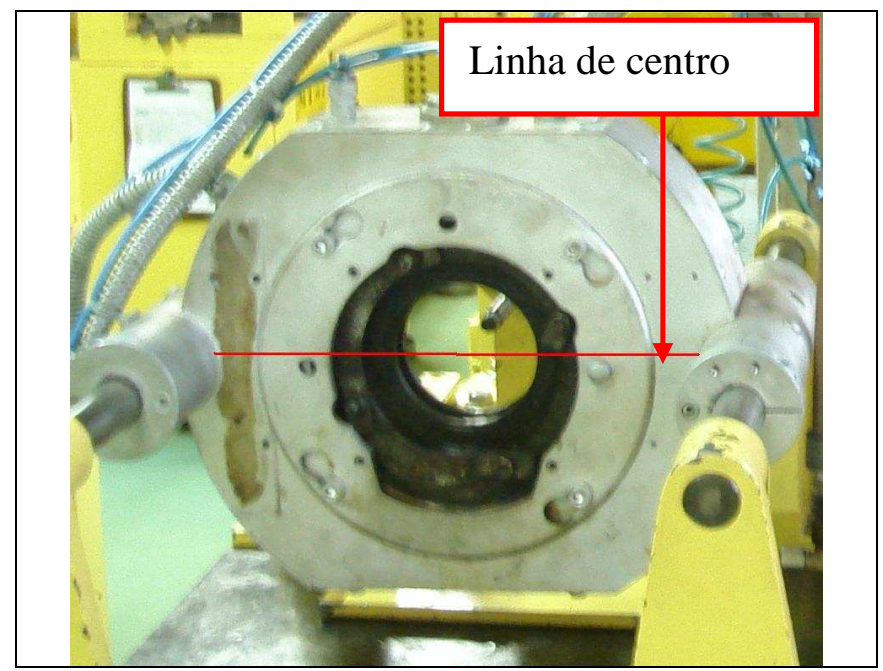

Durante a execução do teste foi utilizado o ciclo com variação de tempo, temperatura e rotação constante na Tabela 11.

O ciclo foi montado de acordo com a norma DIN3761 parte 10 onde se solicita:

14 horas em temperatura de exigência e número de rotações máximo

6 horas em temperatura e número de rotações máximo

4 horas em imobilização com resfriamento para a temperatura ambiente de $15^{\circ} \mathrm{C}$ até $35^{\circ} \mathrm{C}$ conforme norma DIN 50014 
Tabela 11: Ciclo de solicitação utilizada no teste

\begin{tabular}{|l|l|l|}
\hline Tempo & Temperatura & Rotação \\
\hline 14 horas & $80^{\circ} \mathrm{C}$ & 2200 RPM \\
\hline 6 horas & $110^{\circ} \mathrm{C}$ & 2200 RPM \\
\hline 4 horas & $25^{\circ} \mathrm{C}$ & 0 RPM \\
\hline
\end{tabular}

O ciclo citado na tabela foi realizado até se observar a falha do retentor, ou seja, o vazamento do mesmo caracterizado pela passagem do óleo para a lama ou de lama para o óleo.

A peça a ser testada foi montada com excentricidade de $0,25 \mathrm{~mm}$ em relação ao eixo, e de 0,1 mm em relação ao alojamento, condições essas máximas permitidas na aplicação da peça.

5.5.2. Resultados no teste de lama com a peça corrente

$\mathrm{Na}$ Tabela 12 observam-se os resultados dos testes

Tabela 12: Tabela com resultados obtidos em teste de lama da peça corrente

\begin{tabular}{|l|l|l|l|}
\hline Teste $\#$ & Inicio & Término & Duração \\
\hline 1 & $04 / \mathrm{ago} / 08$ & $05 / \mathrm{ago} / 08$ & $24 \mathrm{hrs}$ \\
\hline 2 & $06 / \mathrm{ago} / 08$ & $07 / \mathrm{ago} / 08$ & $12 \mathrm{hrs}$ \\
\hline 3 & $11 / \mathrm{ago} / 08$ & $12 / \mathrm{ago} / 08$ & $15 \mathrm{hrs}$ \\
\hline 4 & $12 / \mathrm{ago} / 08$ & $13 / \mathrm{ago} / 08$ & $17 \mathrm{hrs}$ \\
\hline 5 & $18 / \mathrm{ago} / 08$ & $19 / \mathrm{ago} / 08$ & $26 \mathrm{hrs}$ \\
\hline 6 & $20 / \mathrm{ago} / 08$ & $22 / \mathrm{ago} / 08$ & $32 \mathrm{hrs}$ \\
\hline
\end{tabular}

Para a aquisição de dado de durabilidade procedeu-se da seguinte maneira:

- Montagem do teste;

- Marcação de hora de início do ciclo;

- Realizar leitura de vazamento a cada 12 horas a partir da hora marcada de início de ciclo.

Com isso têm-se dados agrupados em intervalos de 12 horas, não sendo possível identificar o instante exato da falha. 
5.5.3. Análise das peças corrente testadas em lama

Pode-se observar que todas as peças apresentaram o mesmo modo de falha que as peças analisadas de retorno em garantia, ou seja, vazamento devido ao desgaste excessivo da vedação principal pela interação com contaminantes externos em excesso.

Nas fotos constantes das Figuras 33 a 38 pode-se verificar as condições da vedação principal após o teste, assim como o desgaste na mesma. Pode-se também observar a condição da vedação antes do teste, para que se possa ter visão comparativa da condição de desgaste excessivo observado.

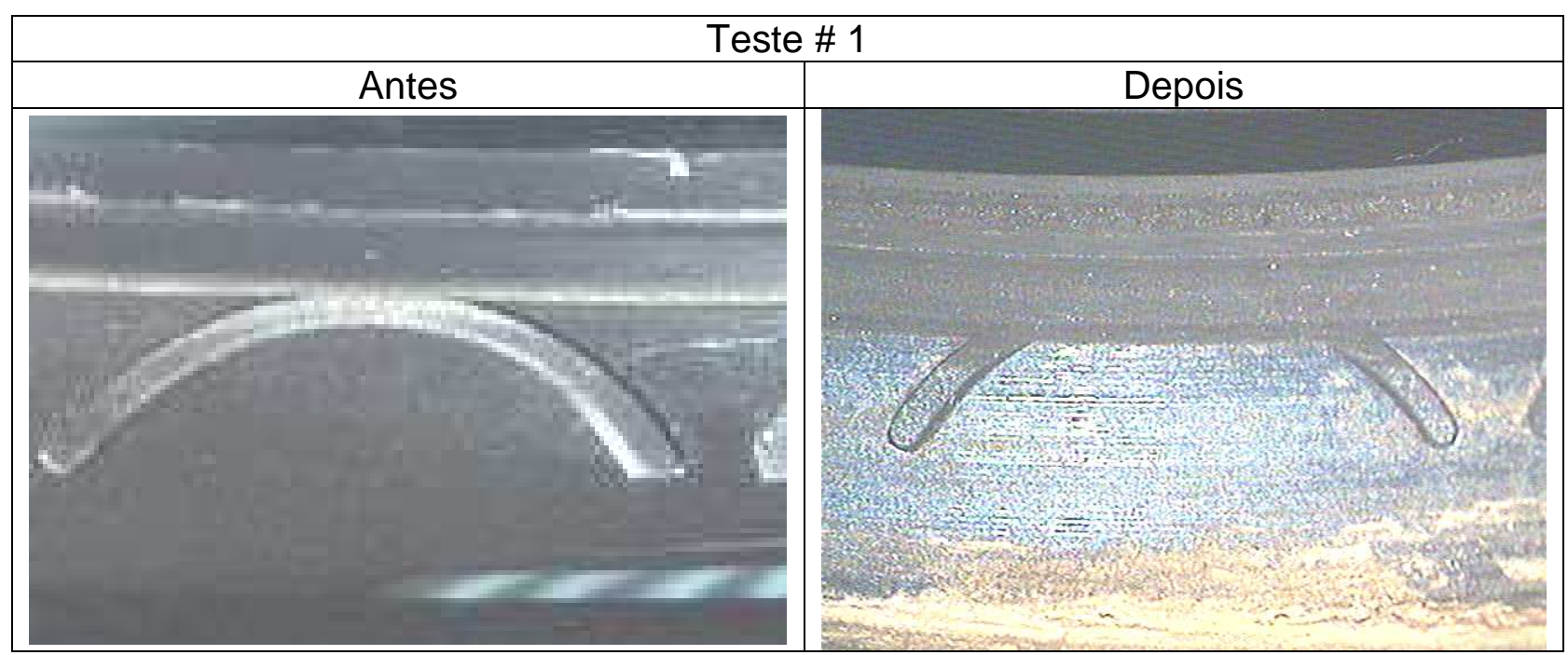

Figura 33 - Detalhe do comparativo em desgaste na região dos ribs na peça do teste \# 1

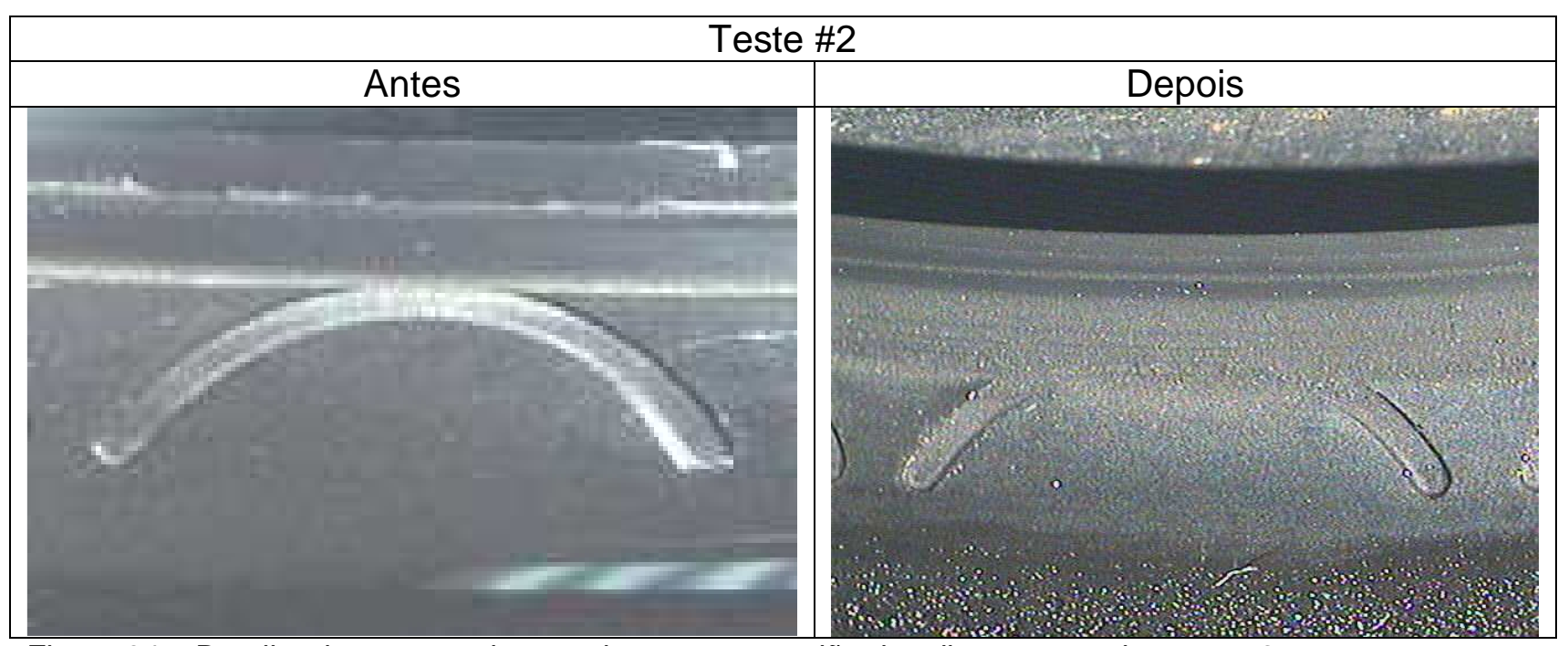

Figura 34 - Detalhe do comparativo em desgaste na região dos ribs na peça do teste \# 2 


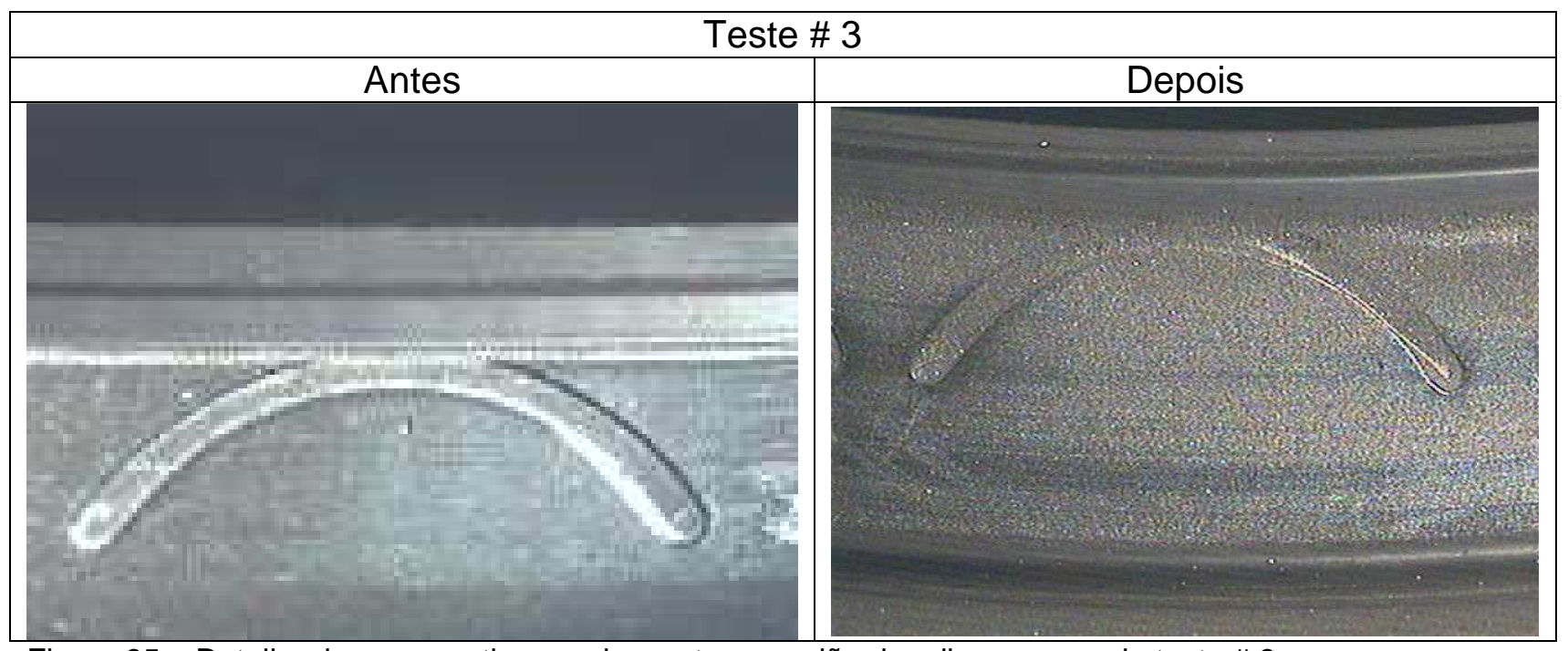

Figura 35 - Detalhe do comparativo em desgaste na região dos ribs na peça do teste \# 3

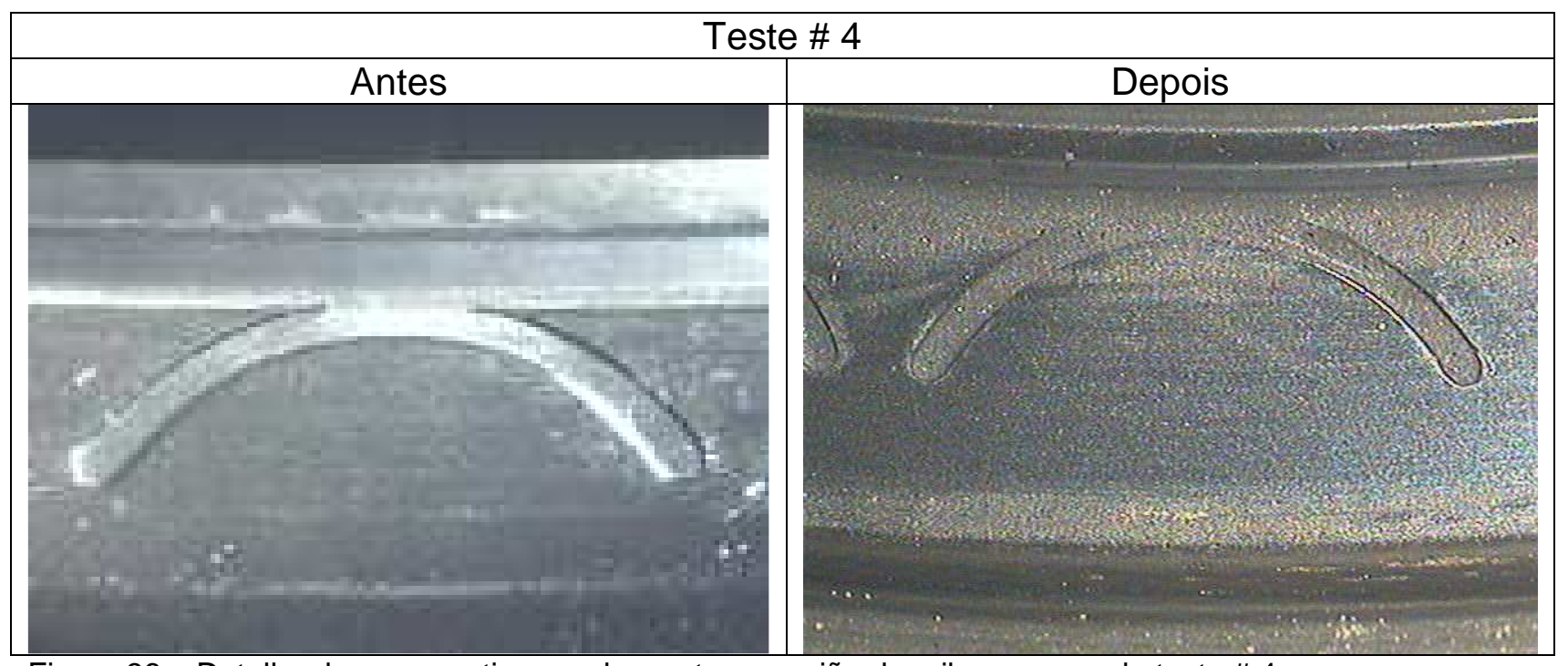

Figura 36 - Detalhe do comparativo em desgaste na região dos ribs na peça do teste \# 4 


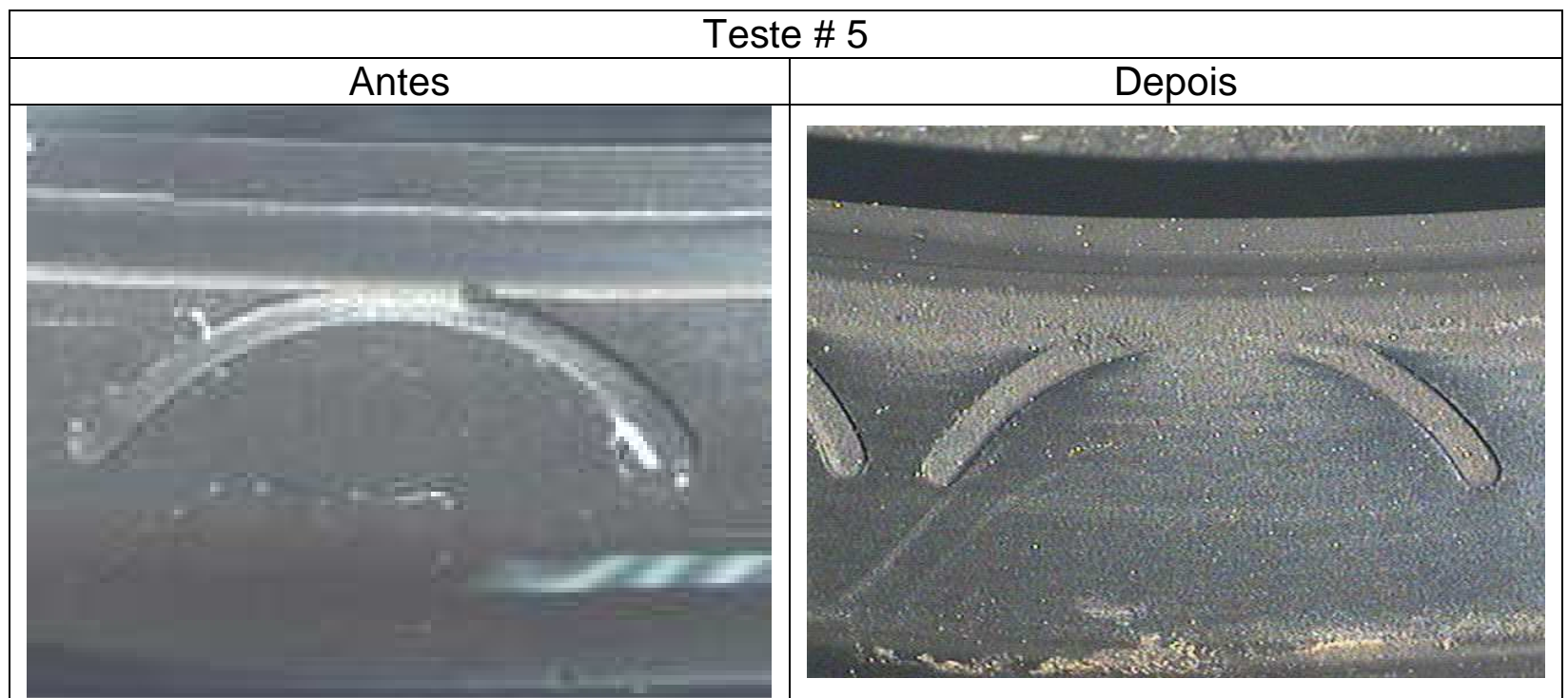

Figura 37 - Detalhe do comparativo em desgaste na região dos ribs na peça do teste \# 5

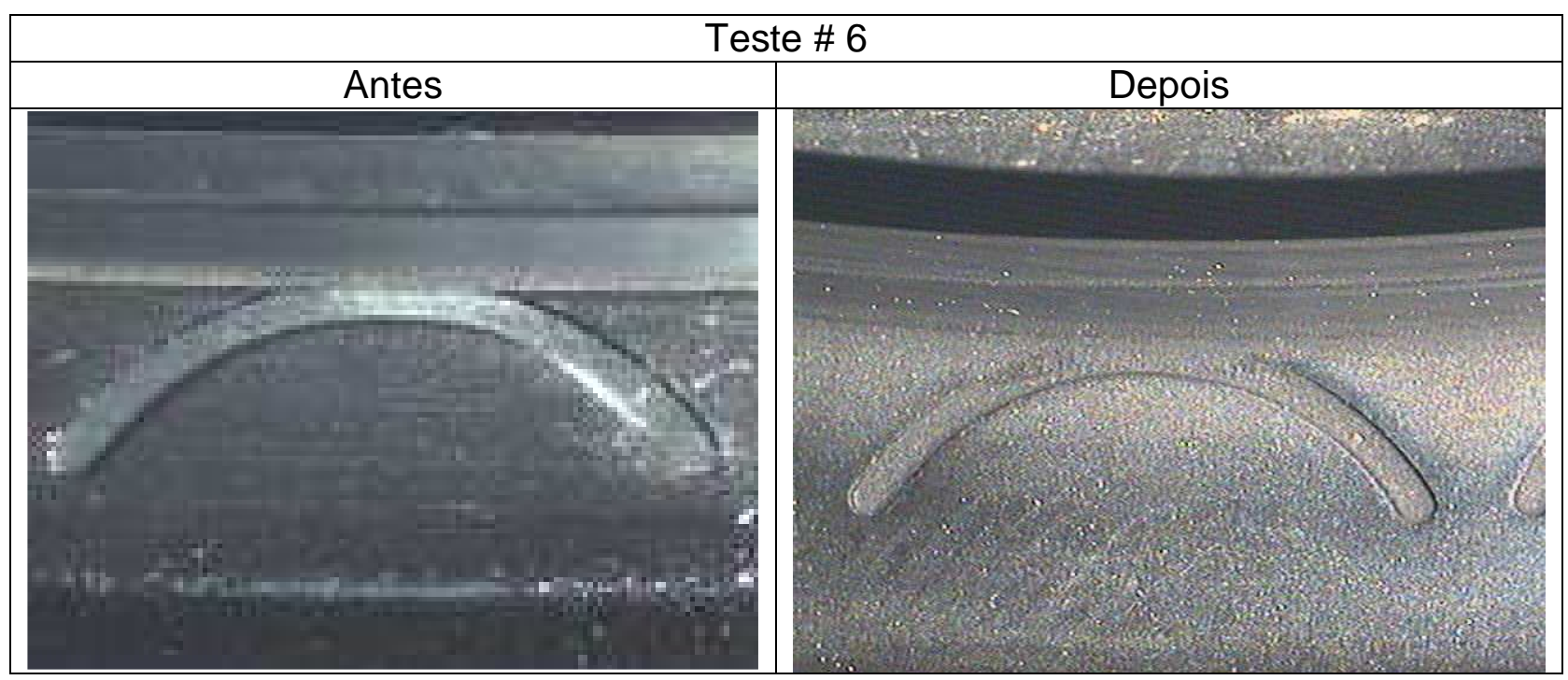

Figura 38 - Detalhe do comparativo em desgaste na região dos ribs na peça do teste \# 6 
5.5.4. Execução de ensaios de vida acelerado na peça corrente - Teste de durabilidade acelerado

Para a realização do teste de durabilidade acelerado fui utilizada a mesma máquina utilizada para a realização do teste de lama, conforme Figura 30. Excetuando-se pela utilização do dispositivo de simulação de contaminação externa que não se faz necessário nesse tipo de teste,

5.5.5. Condições de teste para ensaio de durabilidade acelerado para peça corrente

Para a execução dos testes foi utilizado o óleo SPIRAX 90 HD, no nível de linha de centro da peça, mesma condição utilizada no teste de contaminação externa, conforme Figura 32.

Durante a execução do teste foi utilizado o ciclo da Tabela 13 abaixo.

O ciclo foi montado de acordo com a norma DIN3761 parte 10 onde se solicita:

14 horas em temperatura de exigência e número de rotações máximo

6 horas em temperatura e número de rotações máximo

4 horas em imobilização com resfriamento para a temperatura ambiente de $15^{\circ} \mathrm{C}$ até $35^{\circ} \mathrm{C}$ conforme norma DIN 50014

Tabela 13: Tabela com ciclagem utilizada nos testes de durabilidade acelerada

\begin{tabular}{|l|l|l|}
\hline Tempo & Temperatura & Rotação \\
\hline 14 horas & $80^{\circ} \mathrm{C}$ & 2200 RPM \\
\hline 6 horas & $110^{\circ} \mathrm{C}$ & 2200 RPM \\
\hline 4 horas & $25^{\circ} \mathrm{C}$ & 0 RPM \\
\hline
\end{tabular}

O ciclo citado na tabela foi realizado até observar a falha do retentor, ou seja o vazamento do mesmo caracterizado pela passagem do óleo para a lama ou de lama para o óleo.

A peça a ser testada foi montada com excentricidade de $0,25 \mathrm{~mm}$ em relação ao eixo, e de $0,1 \mathrm{~mm}$ em relação ao alojamento, condições essas máximas permitidas na aplicação da peça. 
5.5.6. Resultados no teste de durabilidade acelerado com a peça corrente

$\mathrm{Na}$ Tabela 14 abaixo podemos observar os resultados dos testes

Tabela 14: Tabela com resultados da peça corrente em teste de durabilidade acelerada

\begin{tabular}{|l|l|l|l|}
\hline Teste \# & Inicio & Término & Duração \\
\hline 7 & $6 /$ out $/ 08$ & $8 /$ out $/ 08$ & 62 hrs. \\
\hline 8 & $9 /$ out $/ 08$ & $13 /$ out $/ 08$ & $98 \mathrm{hrs}$. \\
\hline 9 & $14 /$ out $/ 08$ & $19 /$ out $/ 08$ & $112 \mathrm{hrs}$. \\
\hline 10 & $20 /$ out $/ 08$ & $27 /$ out $/ 08$ & $160 \mathrm{hrs}$. \\
\hline 11 & $28 /$ out $/ 08$ & $3 /$ nov $/ 08$ & $156 \mathrm{hrs}$. \\
\hline 12 & $4 /$ nov $/ 08$ & $12 /$ nov $/ 08$ & $184 \mathrm{hrs}$. \\
\hline
\end{tabular}

5.5.7. Análise das peças corrente testadas em durabilidade acelerada

Nas fotos abaixo pode-se verificar as condições da vedação principal após o teste, assim como o desgaste na mesma

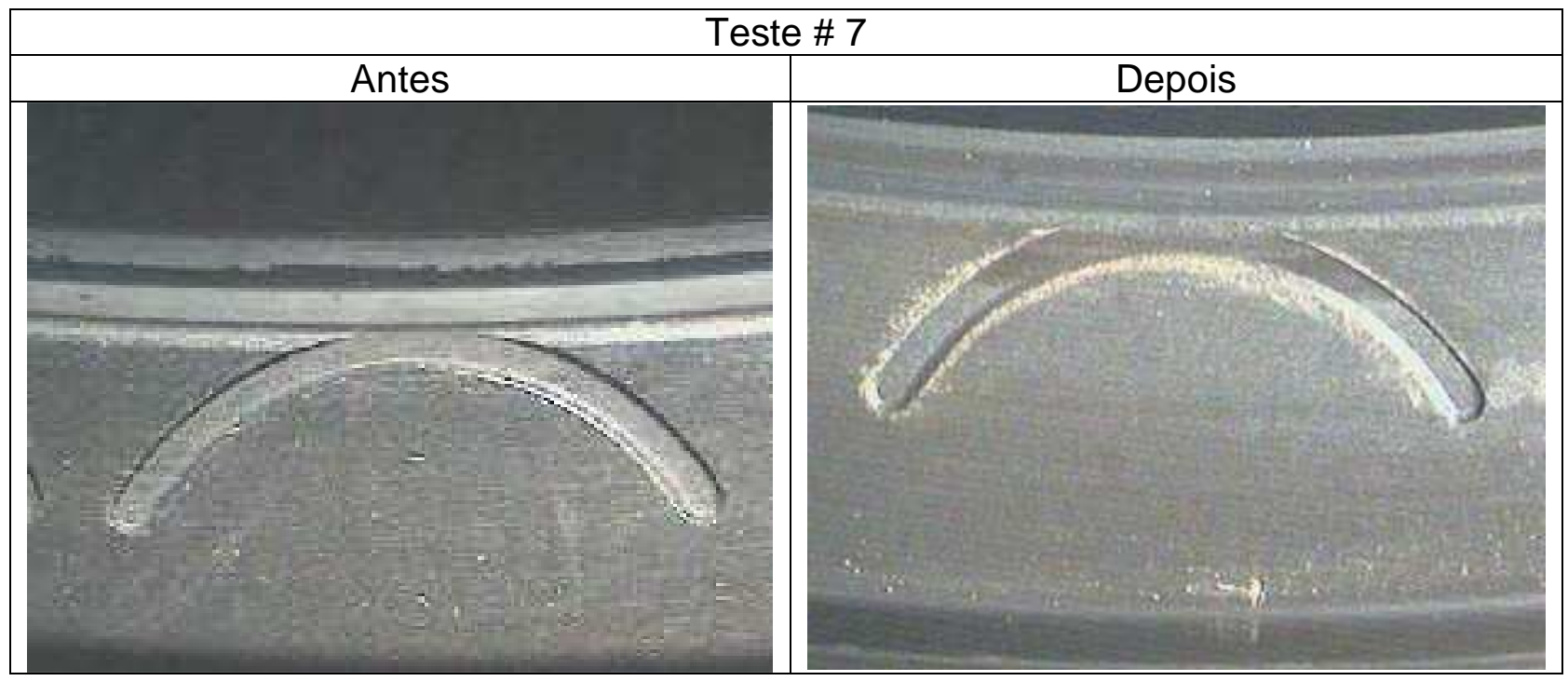

Figura 39 - Detalhe do comparativo em desgaste na região dos ribs na peça do teste \# 7 


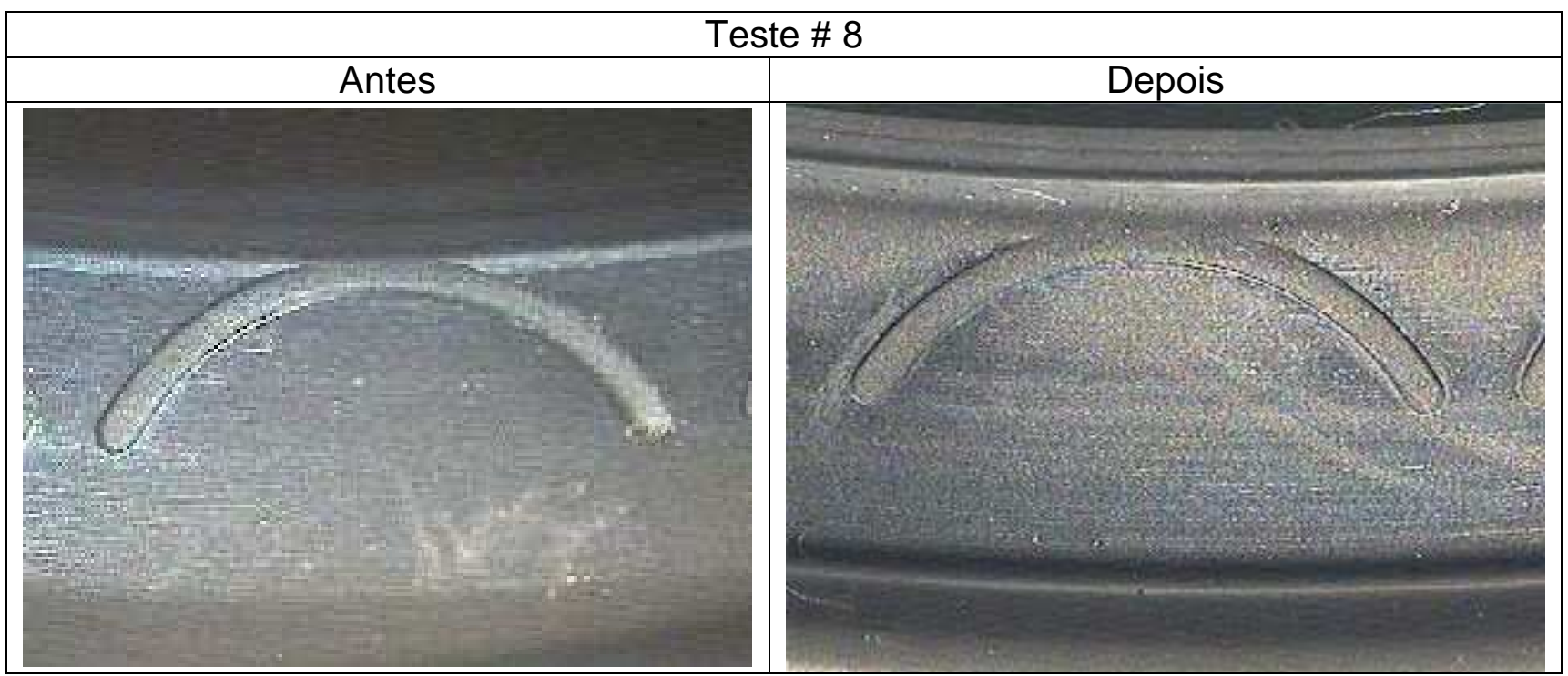

Figura 40 - Detalhe do comparativo em desgaste na região dos ribs na peça do teste \# 8

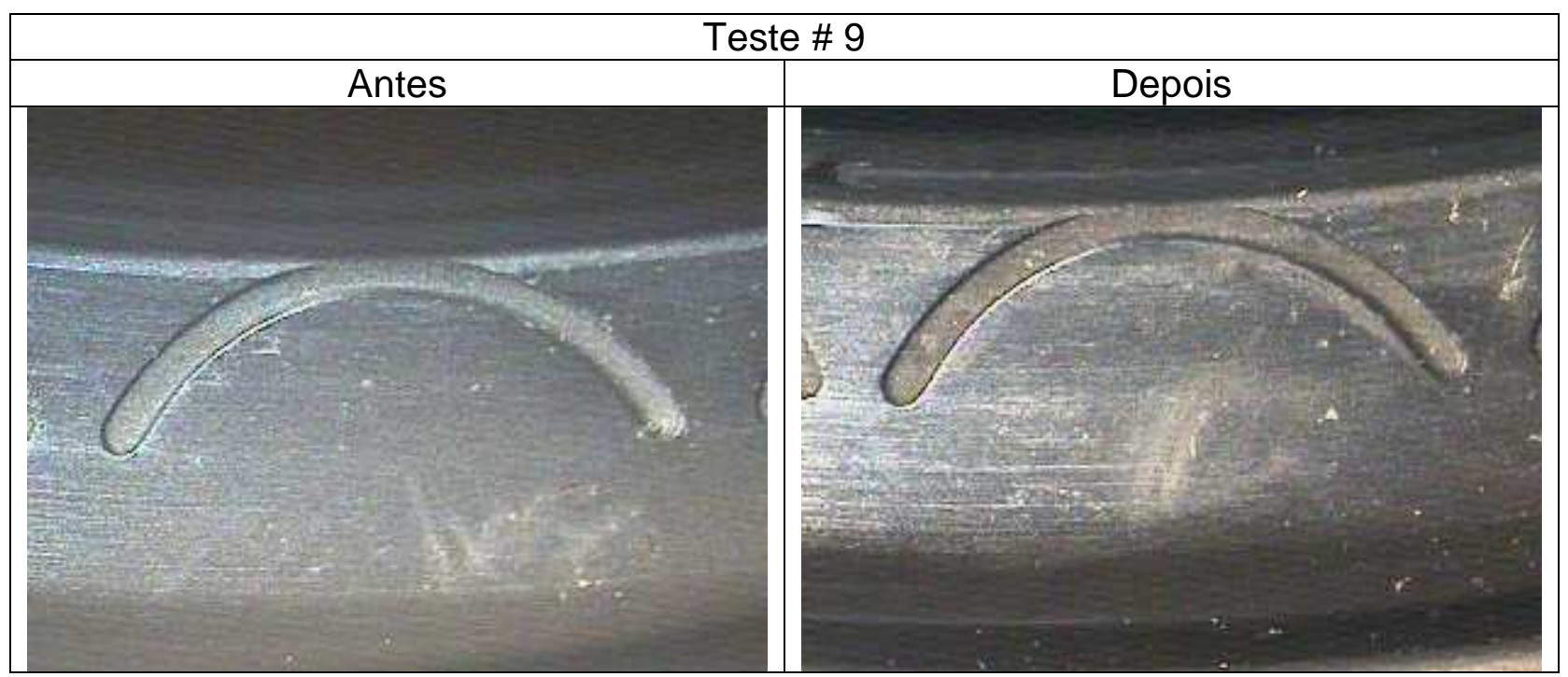

Figura 41 - Detalhe do comparativo em desgaste na região dos ribs na peça do teste \# 9 


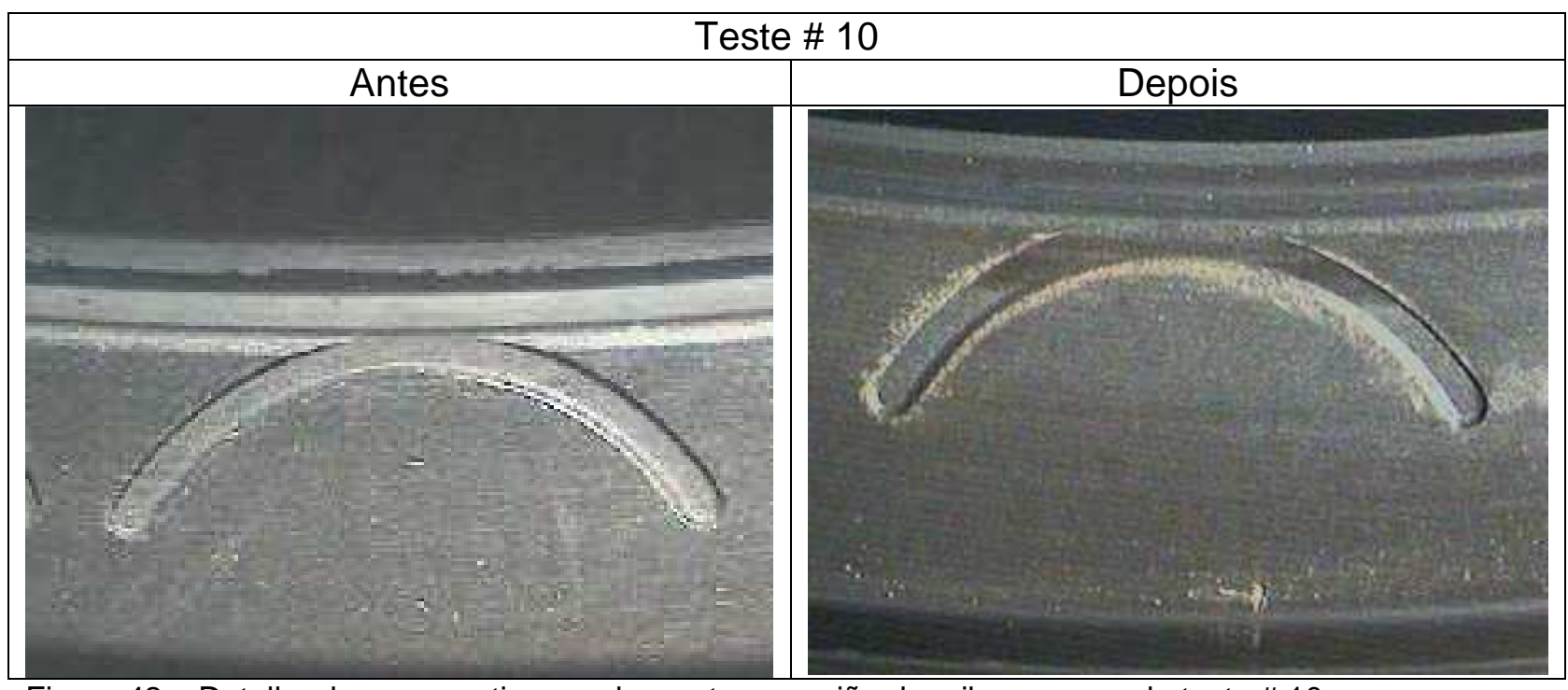

Figura 42 - Detalhe do comparativo em desgaste na região dos ribs na peça do teste \# 10

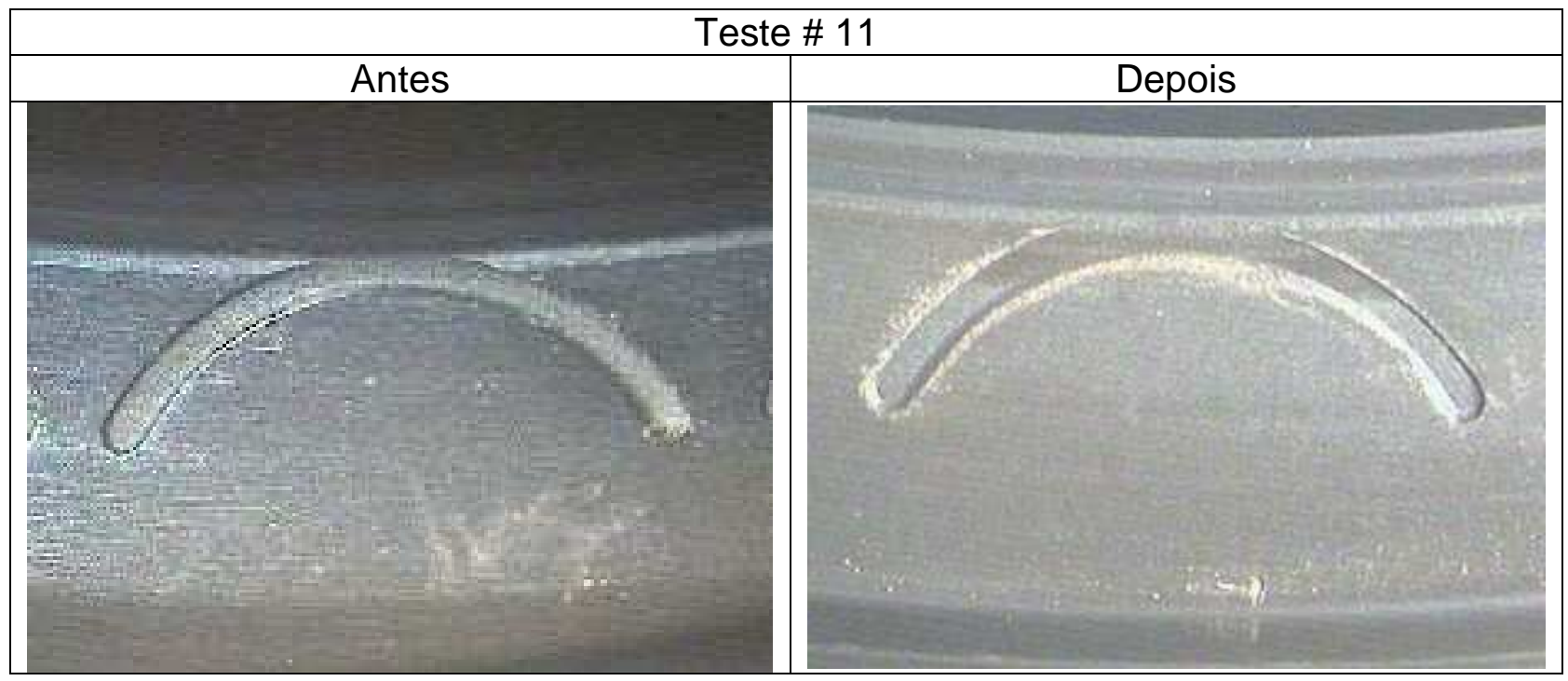

Figura 43 - Detalhe do comparativo em desgaste na região dos ribs na peça do teste \# 11 


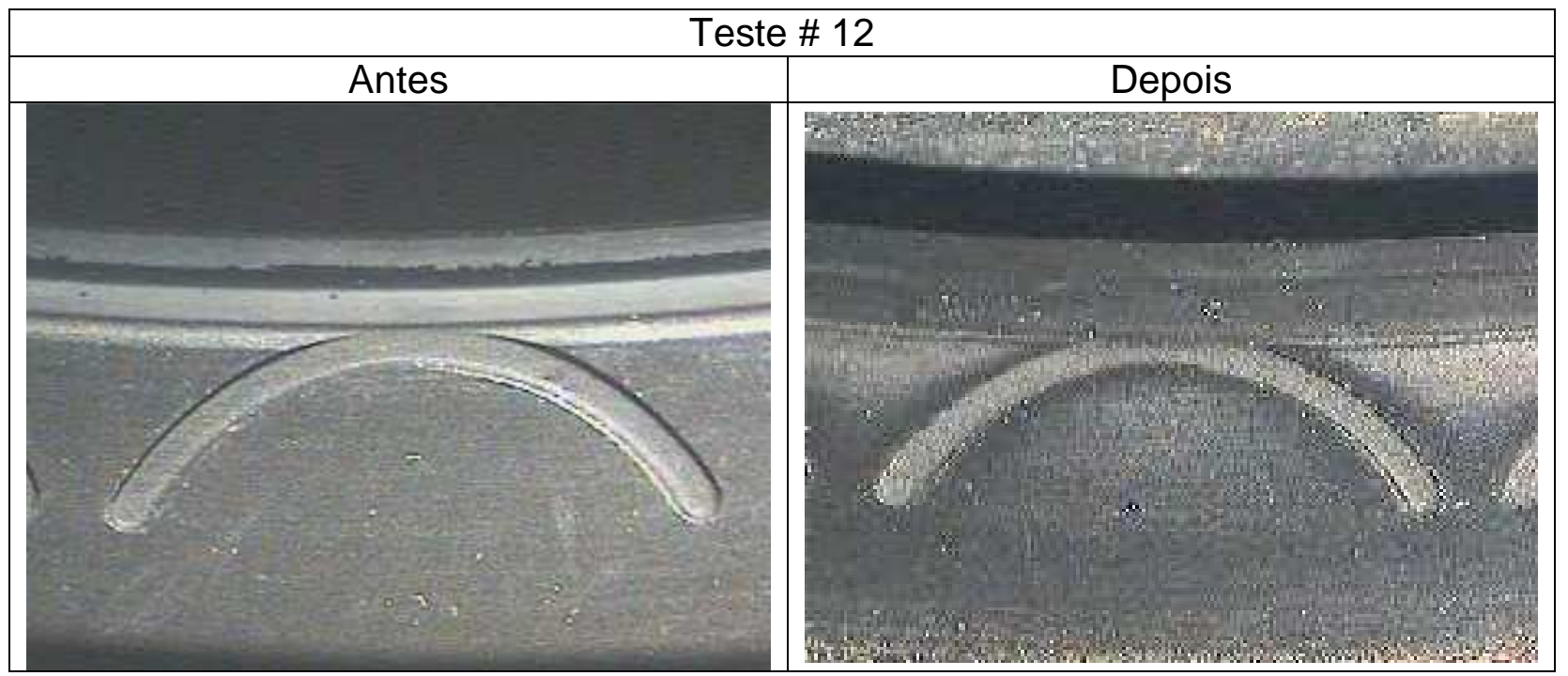

Figura 44 - Detalhe do comparativo em desgaste na região dos ribs na peça do teste \# 12

\subsection{EXECUÇÃO DE ENSAIOS DE VIDA ACELERADO NO PRODUTO MELHORADO.}

Esse tópico se refere ao Passo 6 apresentado no método de trabalho.

Os ensaios realizados, assim como os equipamentos utilizados e métodos de aceleração, verificação e análise de falha são mesmos realizados no produto atual e mostrados no item 5.5 .

5.6.1. Condições de teste para ensaio de contaminação externa no produto alterado

Para a execução dos testes de contaminação externa no produto alterado foram utilizadas as mesmas condições de teste utilizada na execução dos ensaios de contaminação acelerada na peça corrente, essas condições podem ser observadas no item 5.5.1.

5.6.2. Resultados no teste de lama com a peça alterada

Na Tabela 15 observa-se os resultados dos testes. 
Tabela 15: tabela com resultados obtidos em teste de lama da peça alterada

\begin{tabular}{|l|l|l|l|}
\hline Teste \# & Inicio & Término & Duração \\
\hline 13 & $10 / \mathrm{ago} / 09$ & $12 / \mathrm{ago} / 09$ & $42 \mathrm{hrs}$ \\
\hline 14 & $17 / \mathrm{ago} / 09$ & $19 / \mathrm{ago} / 09$ & $51 \mathrm{hrs}$ \\
\hline 15 & $24 / \mathrm{ago} / 09$ & $27 / \mathrm{ago} / 09$ & $39 \mathrm{hrs}$ \\
\hline 16 & $31 / \mathrm{ago} / 09$ & $02 / \mathrm{set} / 09$ & $48 \mathrm{hrs}$ \\
\hline 17 & $08 / \mathrm{set} / 09$ & $10 / \mathrm{set} / 09$ & $45 \mathrm{hrs}$ \\
\hline 18 & $14 / \mathrm{set} / 09$ & $16 / \mathrm{set} / 09$ & $53 \mathrm{hrs}$ \\
\hline
\end{tabular}

Para a aquisição de dado de duração procedeu-se da mesma maneira que a utilizada no teste de lama com a peça corrente (item 5.5.1). Logo, também observam-se dados agrupados em intervalos de 12 horas, não sendo possível identificar o instante exato da falha.

5.6.3. Análise das peças alteradas testadas em lama

Pode-se observar que todas as peças apresentaram o mesmo modo de falha que as peças analisadas no retorno em garantia e que as peças correntes submetidas a ensaio de contaminação externa, ou seja, vazamento devido ao desgaste excessivo da vedação principal pela interação com contaminantes externos em excesso.

Nas fotos constantes das Figuras 44 a 49 pode-se verificar as condições da vedação principal após o teste, assim como o desgaste na mesma. Pode-se também observar a condição da vedação antes do teste, para que se possa ter visão comparativa da condição de desgaste excessivo observado. 


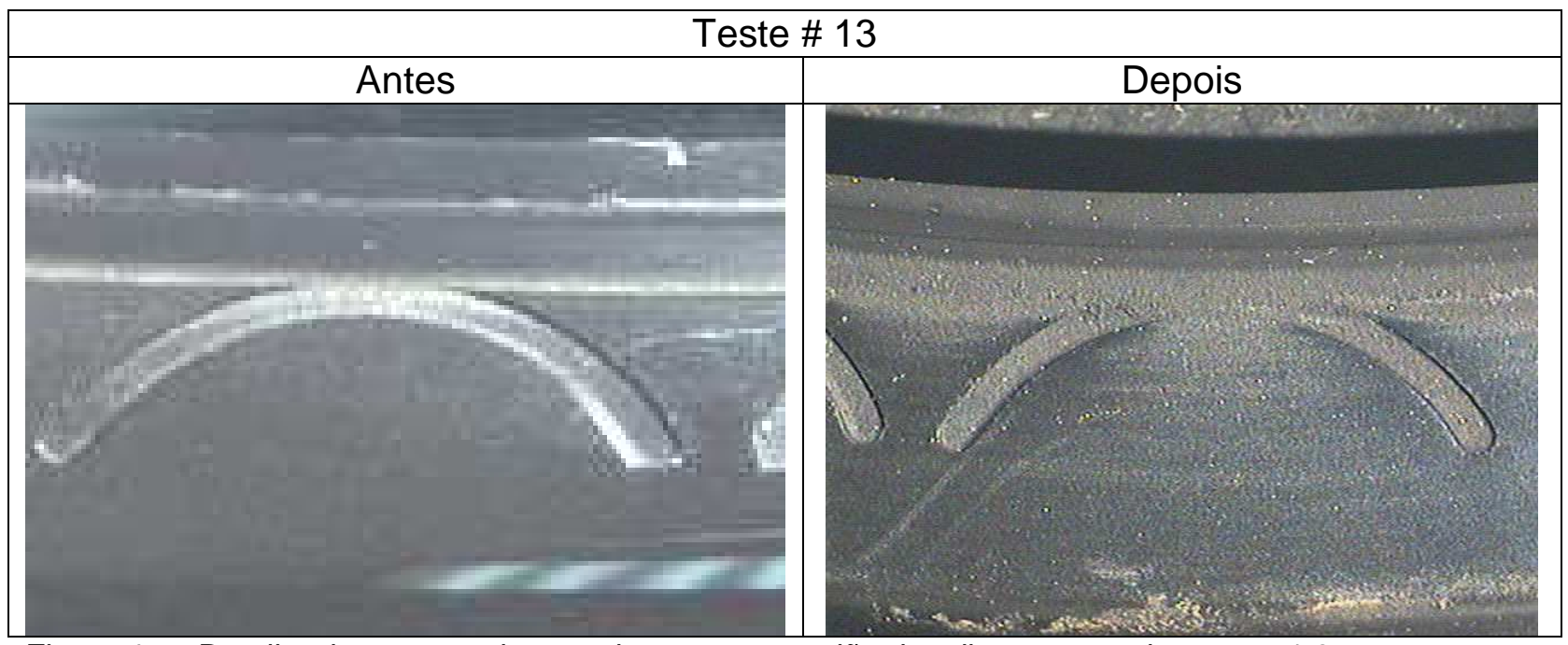

Figura 45 - Detalhe do comparativo em desgaste na região dos ribs na peça do teste \# 13

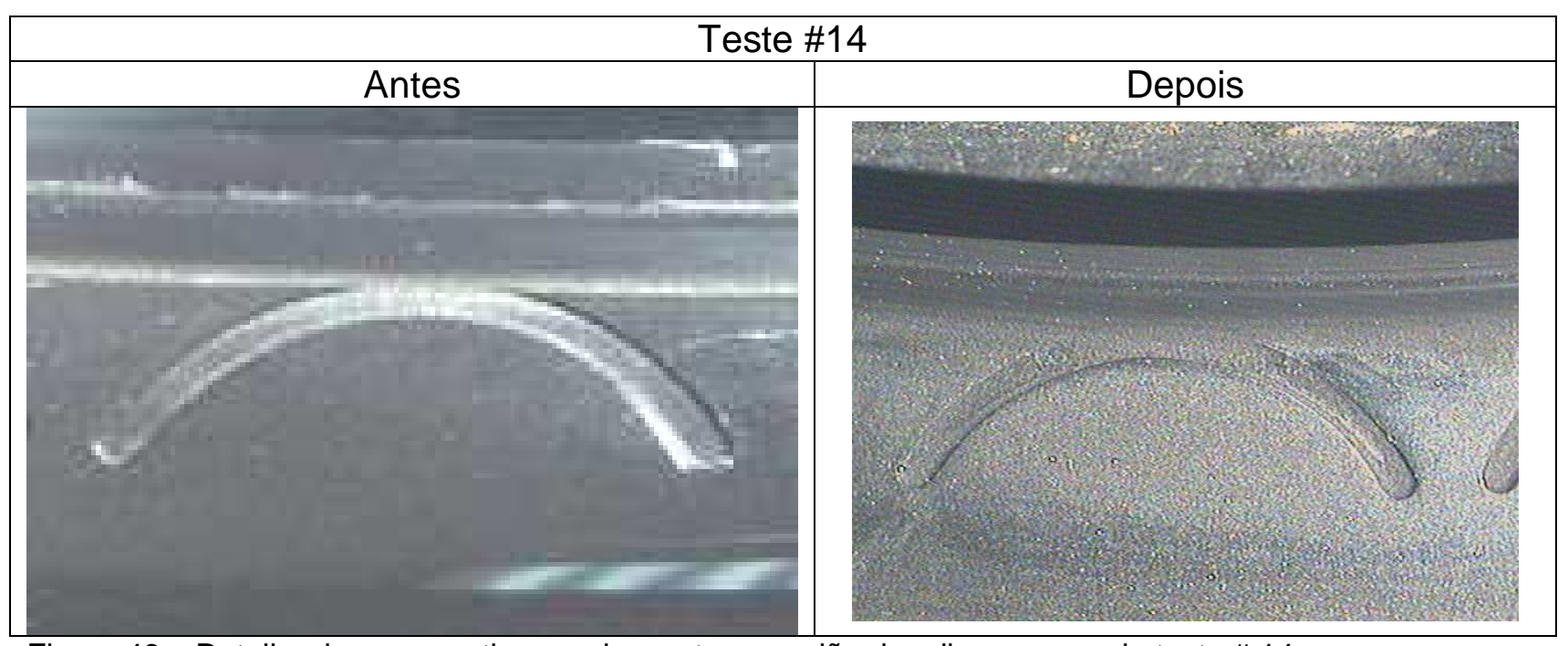

Figura 46 - Detalhe do comparativo em desgaste na região dos ribs na peça do teste \# 14 


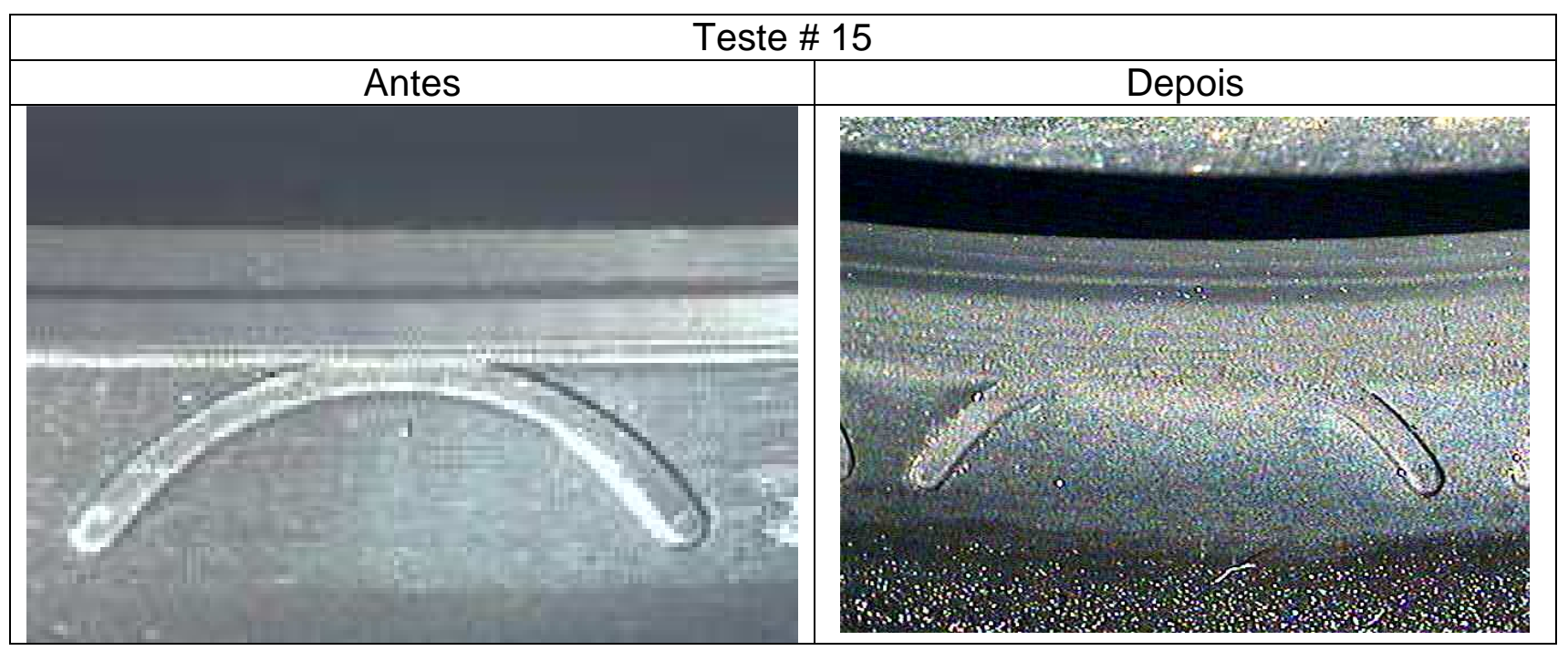

Figura 47 - Detalhe do comparativo em desgaste na região dos ribs na peça do teste \# 15

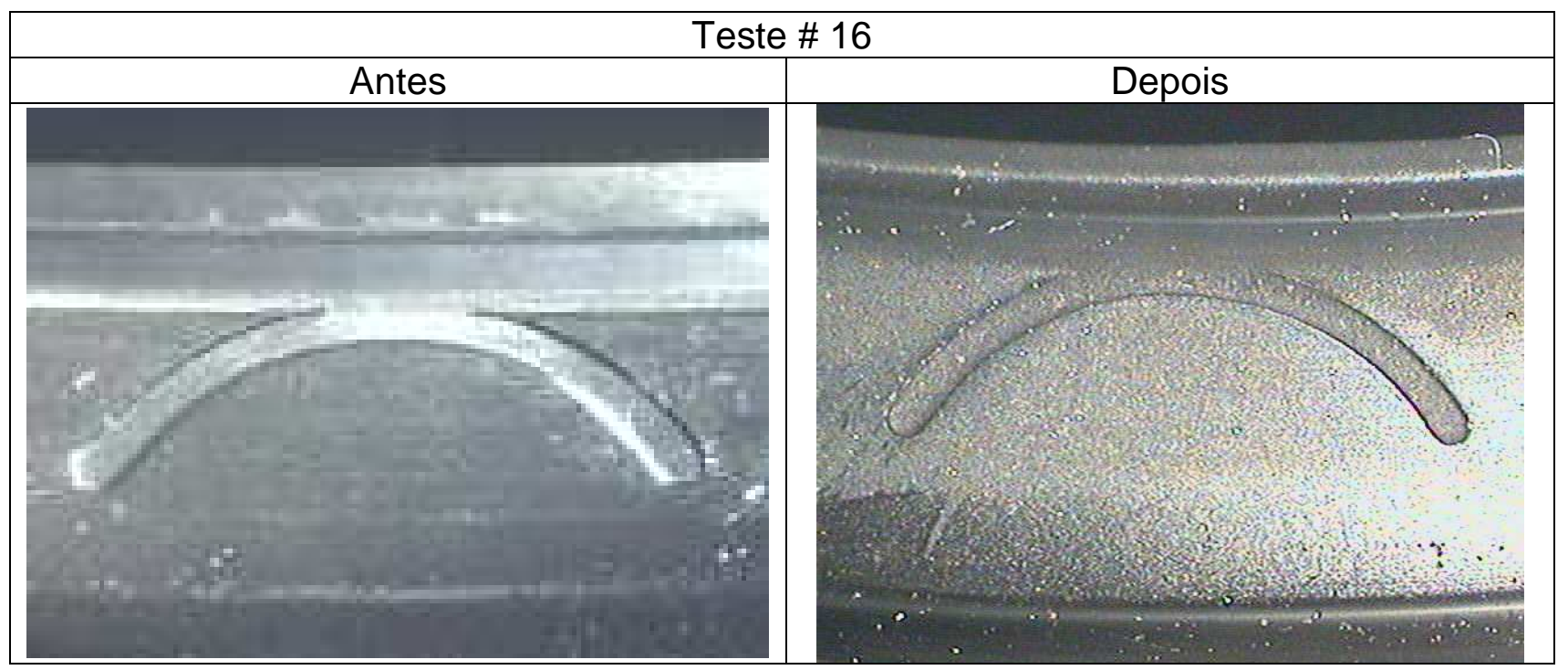

Figura 48 - Detalhe do comparativo em desgaste na região dos ribs na peça do teste \# 16 


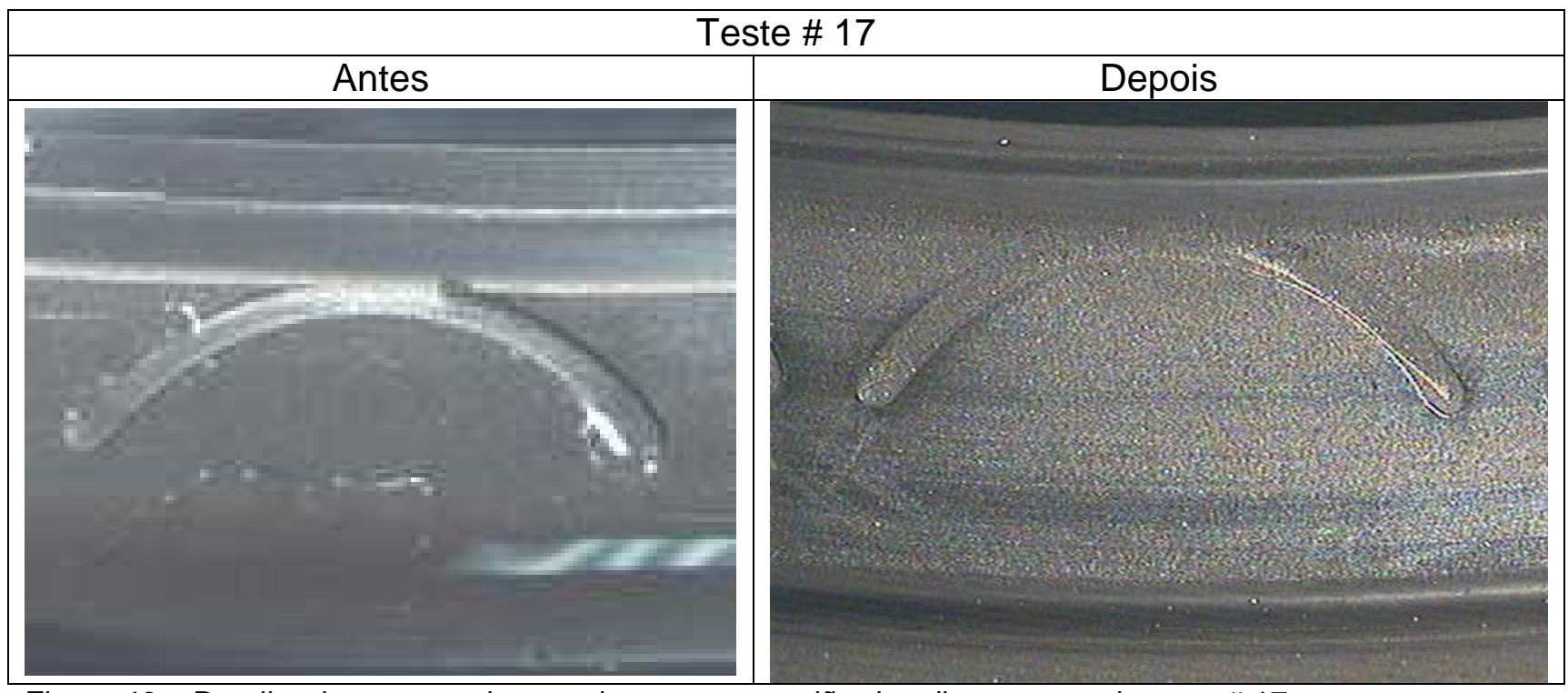

Figura 49 - Detalhe do comparativo em desgaste na região dos ribs na peça do teste \# 17

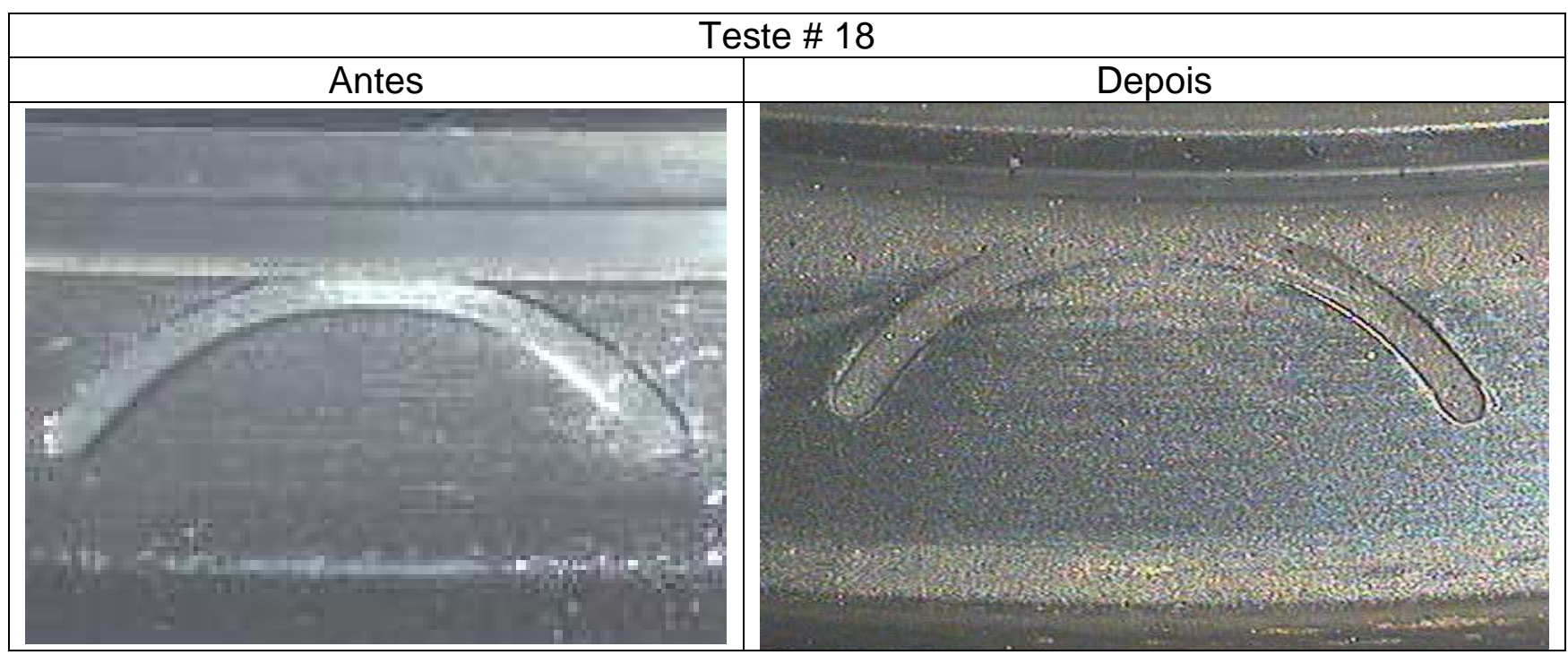

Figura 50 - Detalhe do comparativo em desgaste na região dos ribs na peça do teste \# 18 
5.6.4. Execução de ensaios de vida acelerado no produto alterado - Teste de durabilidade acelerado

Para a realização do teste de durabilidade acelerado fui utilizada a mesma máquina utilizada para a realização do teste de lama, conforme Figura 29. Excetuando-se pela utilização do dispositivo de simulação de contaminação externa que não se faz necessário nesse tipo de teste, assim como foi realizado no ensaio de vida do produto atual (item 5.5.4)

5.6.5. Condições de teste para ensaio de durabilidade acelerado no produto alterado

Para a realização do teste de durabilidade acelerado foram utilizadas as mesmas condições de teste utilizada na execução dos ensaios de contaminação acelerada na peça corrente, essas condições podem ser observadas no item 5.5.5.

5.6.6. Resultados no teste de durabilidade acelerado com a peça alterada

$\mathrm{Na}$ Tabela 16 abaixo podemos observar os resultados dos testes

Tabela 16: Tabela com resultados da peça alterada em teste de durabilidade acelerada

\begin{tabular}{|l|l|l|l|}
\hline Teste \# & Inicio & Término & Duração \\
\hline 19 & $03 / \mathrm{aug} / 09$ & $12 / \mathrm{aug} / 09$ & $126 \mathrm{hrs}$. \\
\hline 20 & $06 / \mathrm{aug} / 09$ & $14 / \mathrm{aug} / 09$ & $110 \mathrm{hrs}$. \\
\hline 21 & $11 / \mathrm{aug} / 09$ & $21 / \mathrm{aug} / 09$ & $168 \mathrm{hrs}$. \\
\hline 22 & $17 / \mathrm{aug} / 09$ & $25 / \mathrm{aug} / 09$ & $115 \mathrm{hrs}$. \\
\hline 23 & $19 / \mathrm{aug} / 09$ & $02 / \mathrm{set} / 09$ & $179 \mathrm{hrs}$. \\
\hline 24 & $24 / \mathrm{aug} / 09$ & $03 / \mathrm{set} / 09$ & $158 \mathrm{hrs}$. \\
\hline
\end{tabular}

5.6.7. Análise das peças alteradas testadas em durabilidade acelerada 
Nas fotos abaixo pode-se verificar as condições da vedação principal após o teste, assim como o desgaste na mesma.

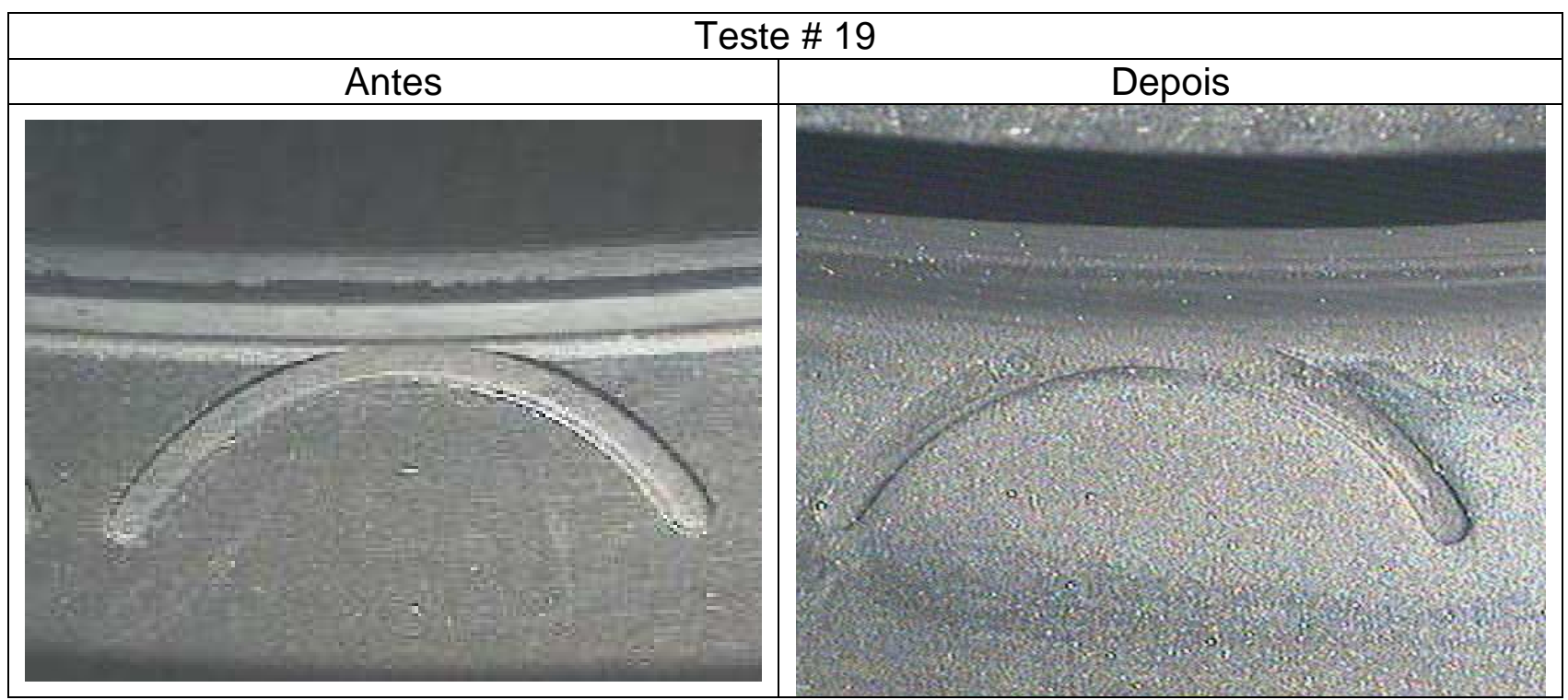

Figura 51 - Detalhe do comparativo em desgaste na região dos ribs na peça do teste \# 19

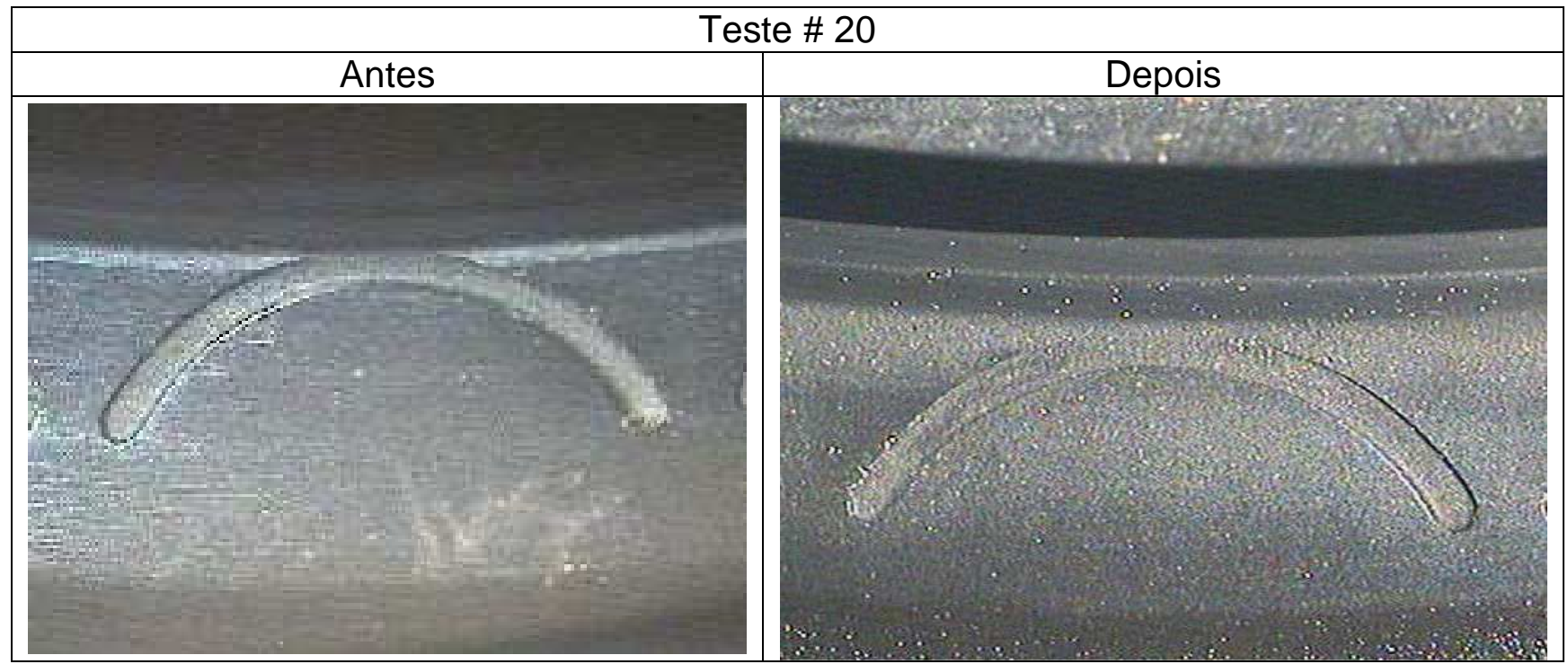

Figura 52 - Detalhe do comparativo em desgaste na região dos ribs na peça do teste \# 20 


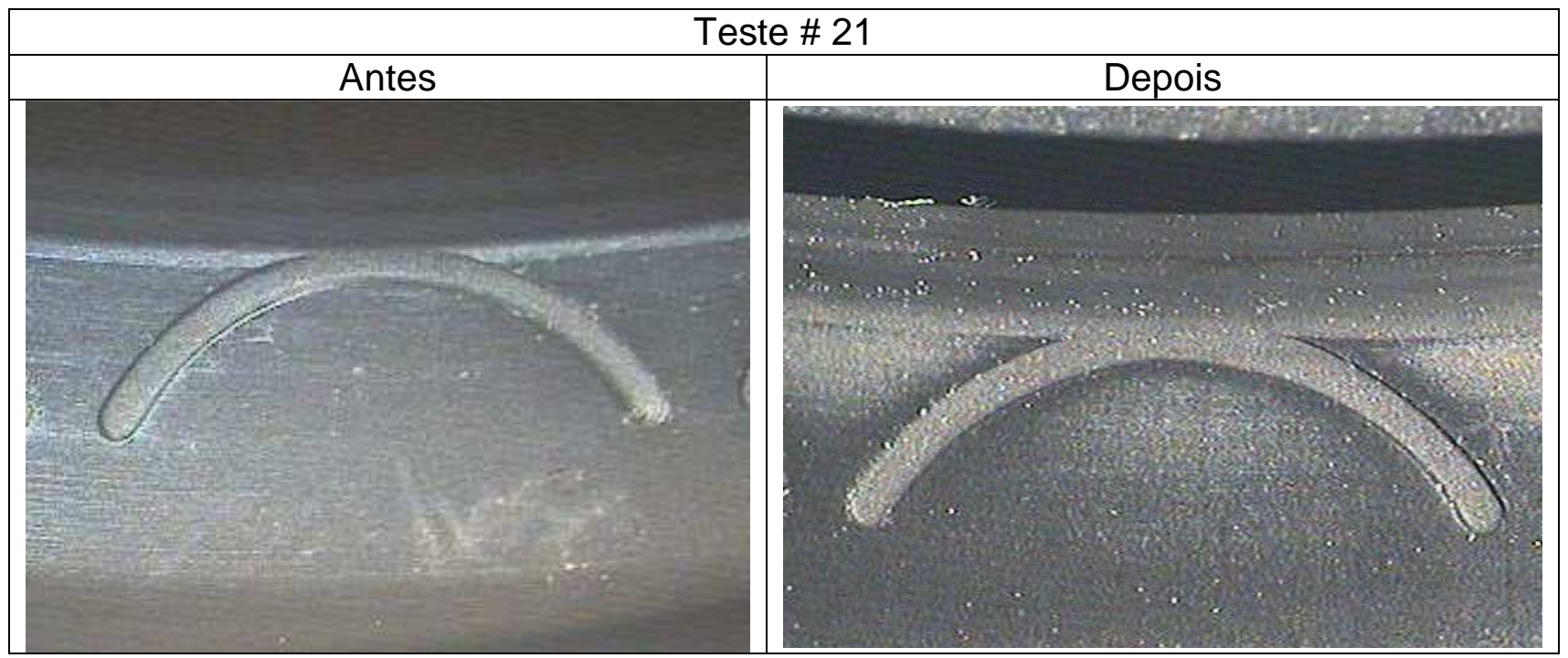

Figura 53 - Detalhe do comparativo em desgaste na região dos ribs na peça do teste \# 21

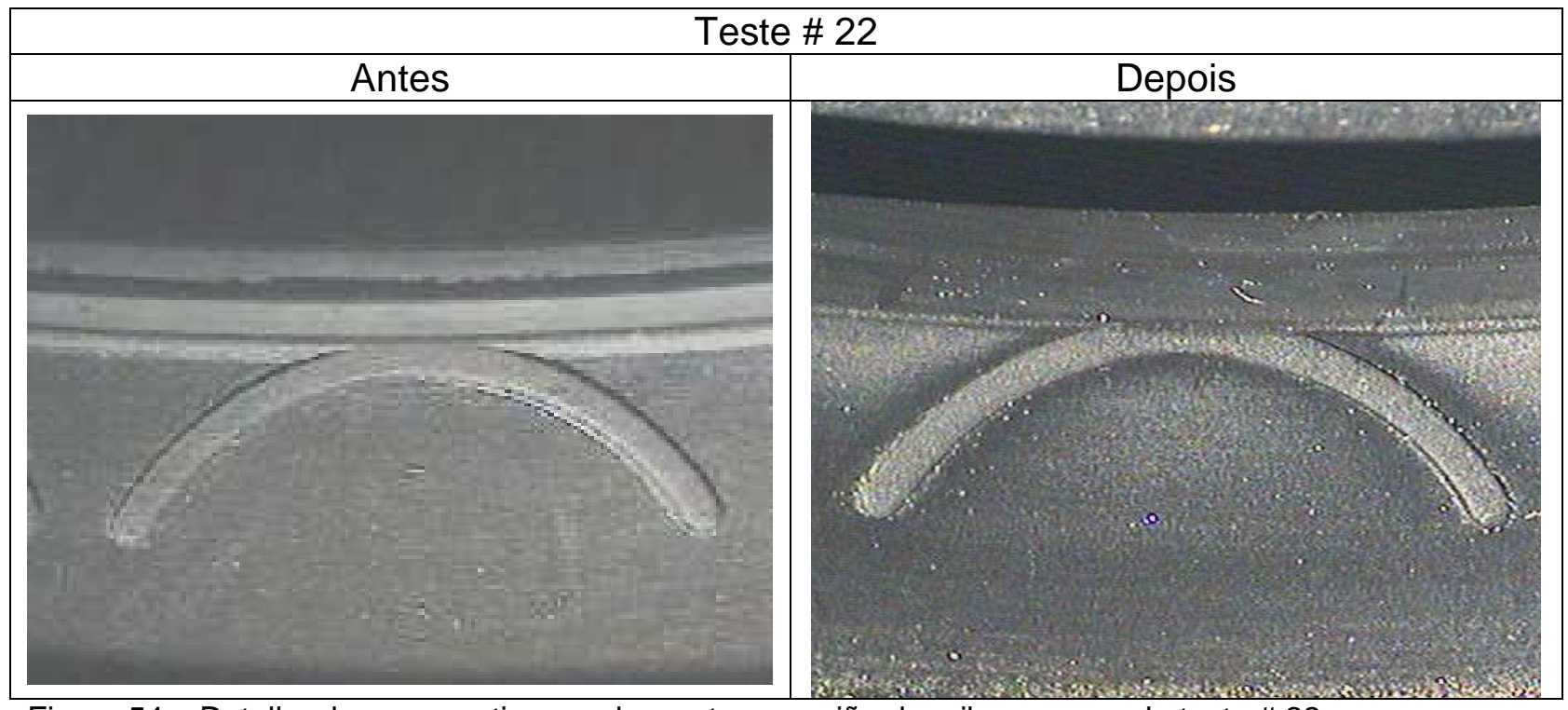

Figura 54 - Detalhe do comparativo em desgaste na região dos ribs na peça do teste \# 22 


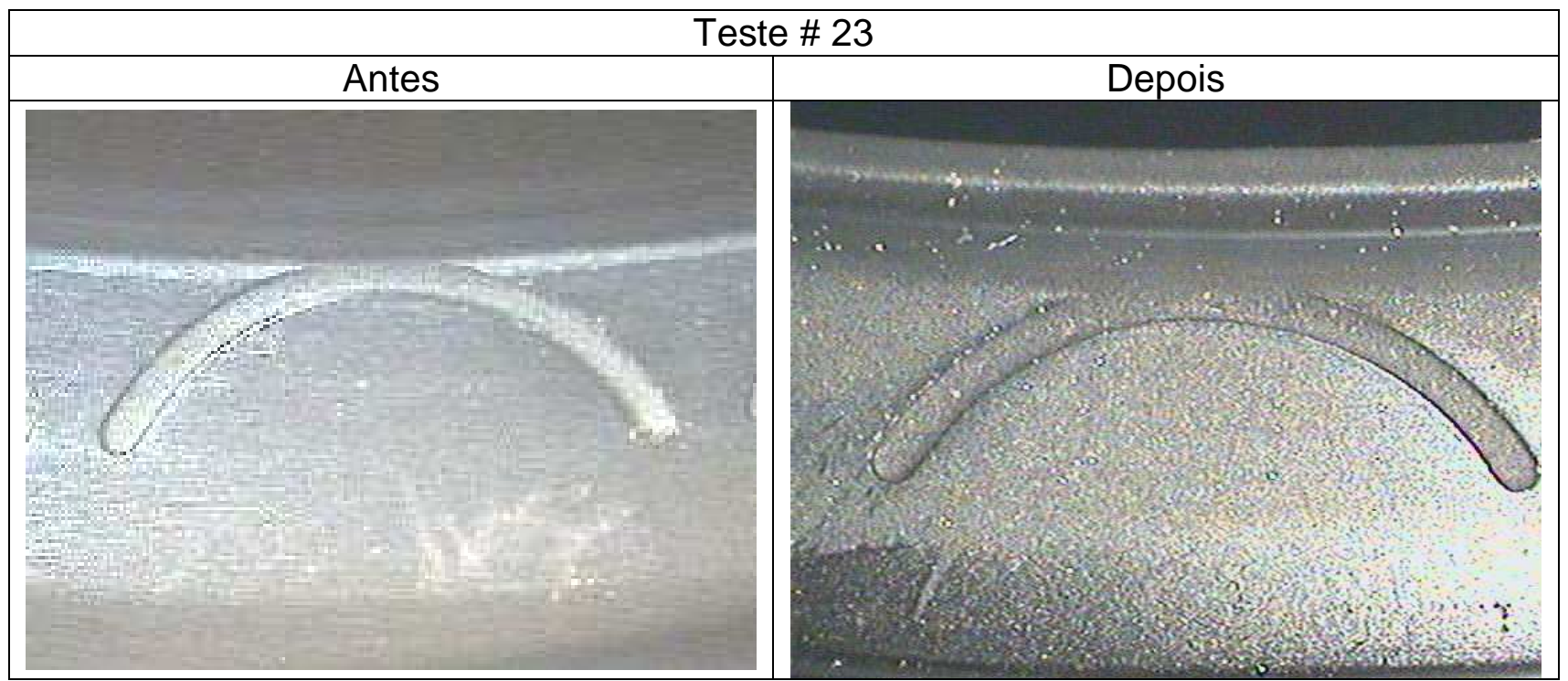

Figura 55 - Detalhe do comparativo em desgaste na região dos ribs na peça do teste \# 23

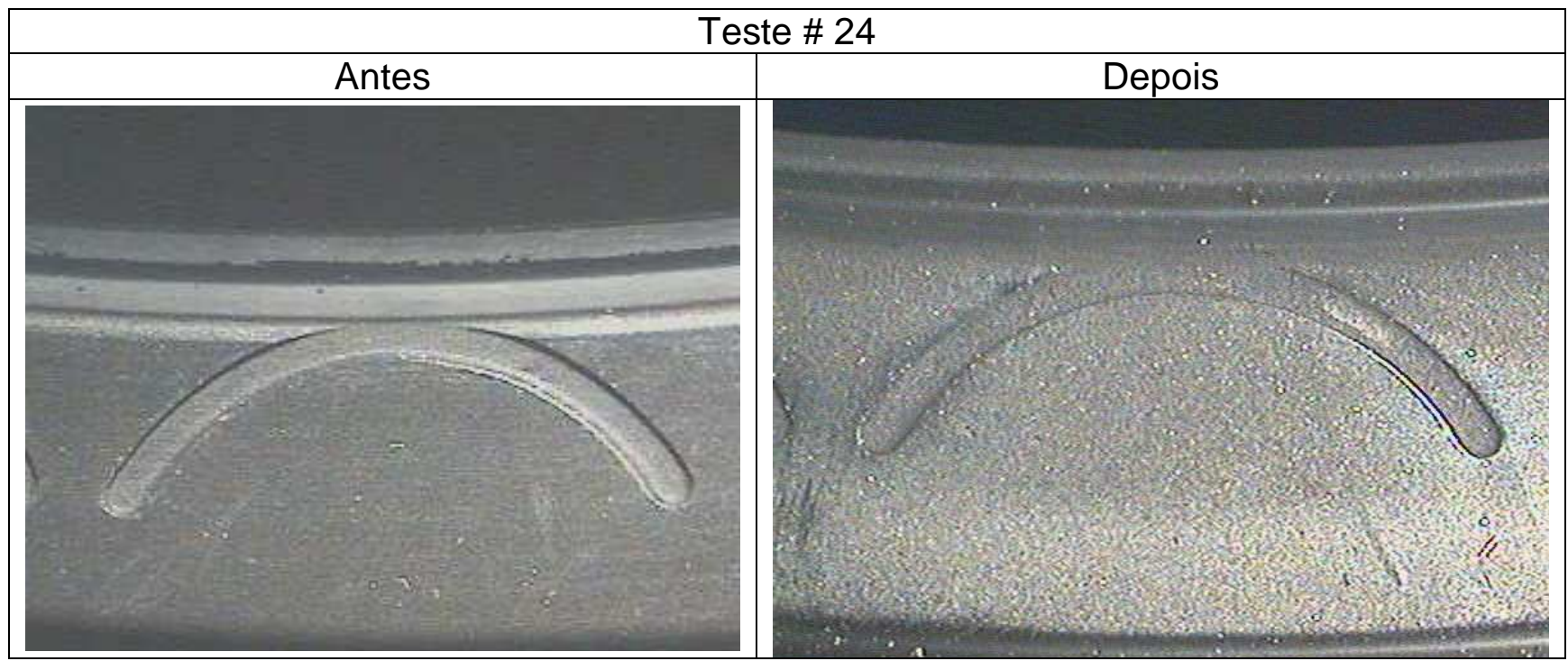

Figura 56 - Detalhe do comparativo em desgaste na região dos ribs na peça do teste \# 24

\subsection{ESTUDO DE CONFIABILIDADE}

Esse tópico se refere ao Passo 7 apresentado no método de trabalho. Nele estar-seá realizando análise de confiabilidade do produto atual através dos dados de garantia e relacionando o resultado com o estudo de confiabilidade realizado através dos testes de vida acelerado para a versão atual. Essa relação será realizada pela verificação do fator de aceleração. 
Estar-se-á também realizando um estudo de confiabilidade dos testes de vida acelerado das peças com nova versão e, através da relação alcançada acima, buscar-se-á a confiabilidade em campo da nova versão.

Á comparação acima será realizada pela utilização do fator de aceleração encontrada na análise entre peças de garantia e testes de vida acelerado para a versão de produto atual.

Para a seleção da distribuição que melhor represente os dados originados, utilizarse-á os softwares Weibull++7 e Alta 7 Pro, através da inserção dos dados em sua tabela da cálculo, são obtidos os gráficos da caracterização da curva confiabilidade, conforme observa-se nos itens abaixo.

5.7.1 Estudo de confiabilidade da peça atual através dos dados de garantia

A tabela de vida para os dados de garantia foi calculada e apresentada na Tabela 6. Para o estudo de confiabilidade da peça atual através dos dados de garantia, inseriu-se os dados de quilometragem em que os produtos falharam por desgaste acelerado no software Weibull++7.

$\mathrm{Na}$ Figura 57, pode-se observar a tela onde os valores são inseridos no software Weibull++7. 


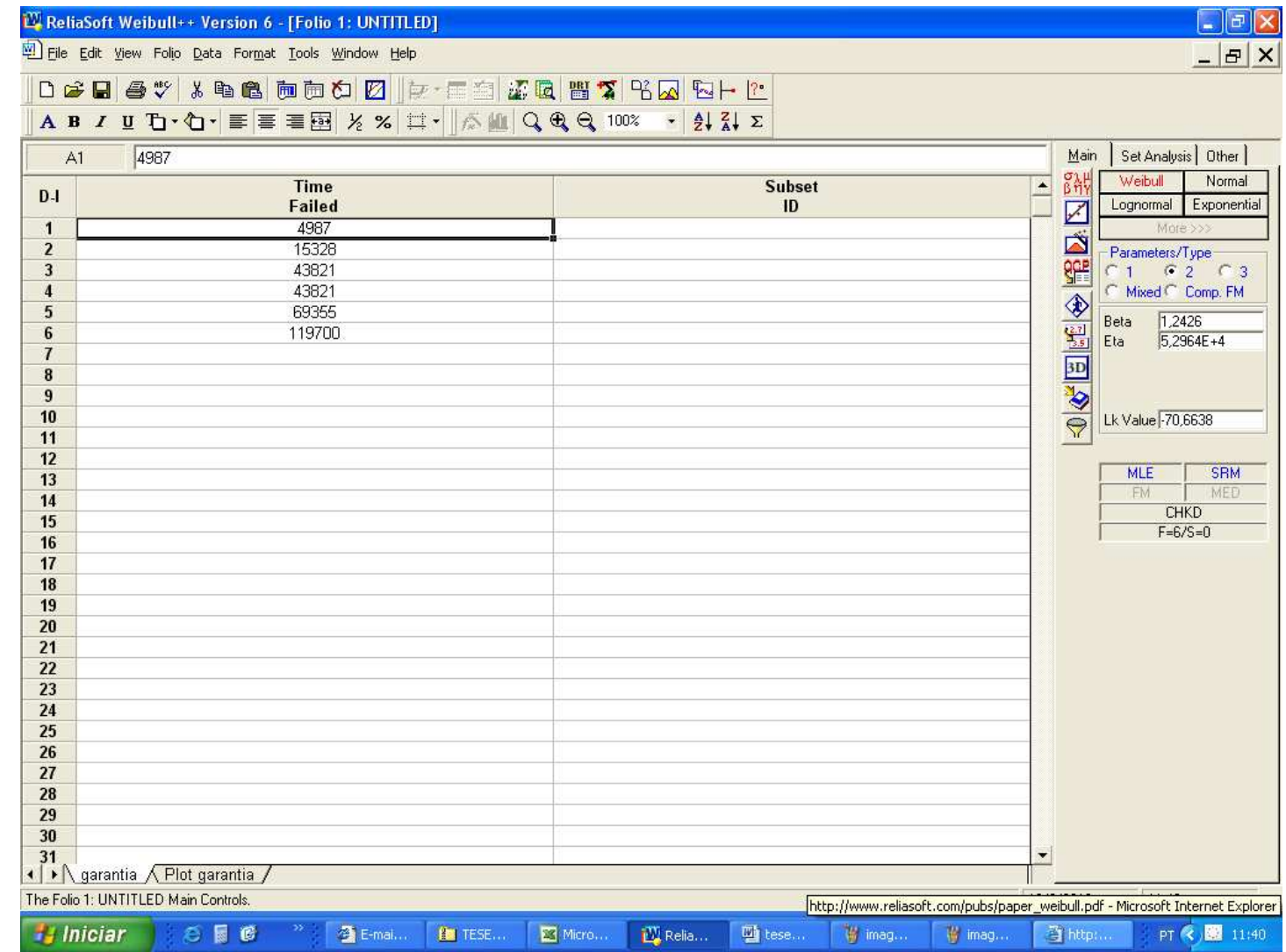

Figura 57 - Tabela de inserção de valores no software.

$\mathrm{Na}$ seqüência selecionou-se o método de análise dos dados, ou seja, para determinar os parâmetros de uma função de distribuição de probabilidade que modele o problema em análise. Como se verifica na Figura 58, foi selecionado o método da Máxima Verossimilhança, este método foi introduzido por R. A. Fisher (1912) e foi selecionado por ser baseado em determinar estimativas que tenham a maior eficiência incorporando as censuras, assim como selecionou-se o método de Kaplan-Meier para a ordenação das curvas calculadas, como verifica-se na Figura 58. 


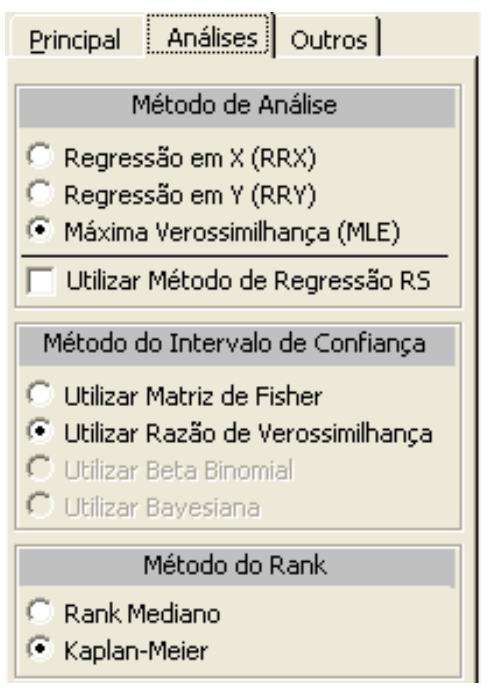

Figura 58 - Seleção de parâmetros para calculo de confiabilidade.

Após realizados os cálculos para todas as curvas, realizou-se o teste de aderência e como verifica-se na Figura 59, a curva que mais se adequou aos dados de garantia foi a Weibull com dois ou três parâmetros.

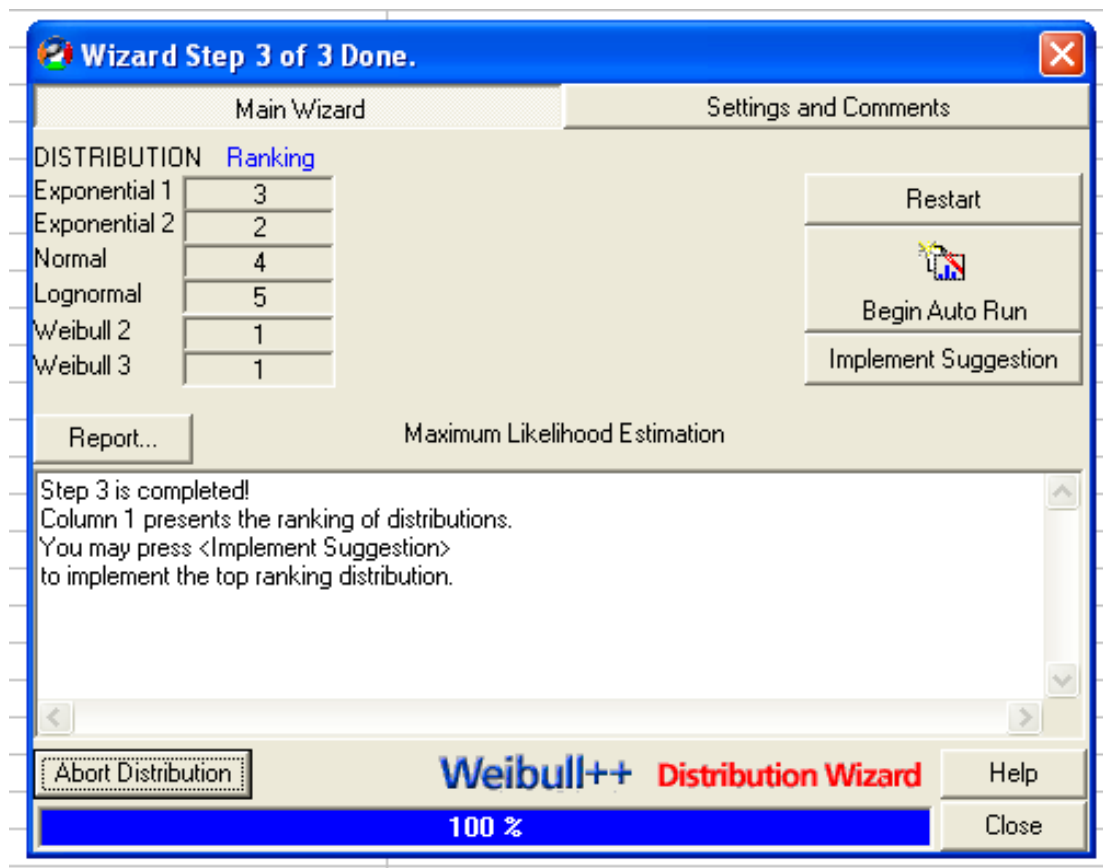

Figura 59 - Organização das curvas do resultado do teste de aderência para as curvas no calculo de confiabilidade.

Na Figura 60 observam-se os resultados dos três parâmetros que o programa utiliza para realizar o teste de aderência, onde cada parâmetro verifica [RELIASOFT. User's guide ReliaSoft's Weibull++(1997)]: 
- AVGOF > verifica o ajuste dos dados em relação às distribuições, valores baixos indicam bons ajustes.

- AVPLOT > verifica medida normalizada dos dados em relação às curvas das distribuições

- $\quad L K V>$ verifica a função de verossimilhança e os parâmetros.

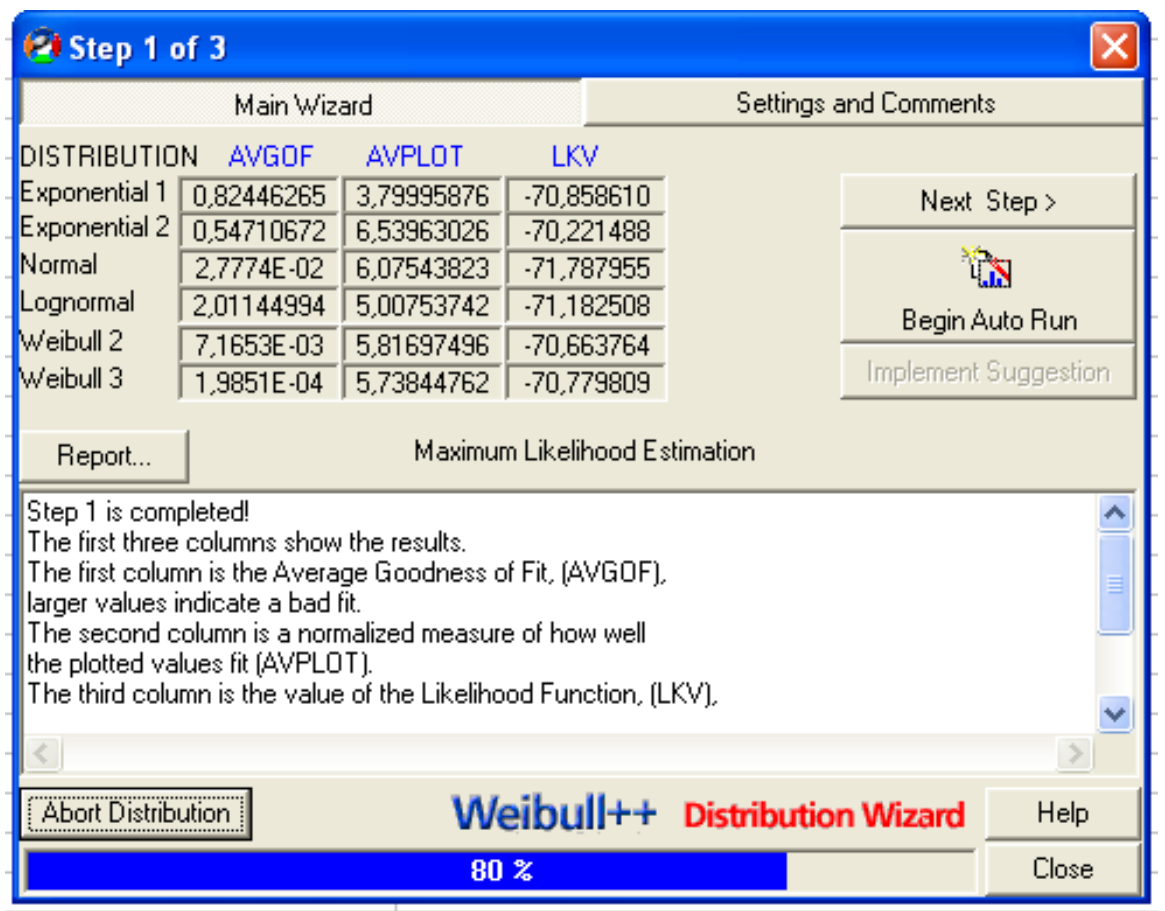

Figura 60 - Parâmetros do resultado do teste de aderência para as distribuições.

Na Figura 61 observam-se os resultados ponderados através da variável DESV. Essa ordenação é realizada através da atribuição de pesos aos parâmetros AVGOF, AVPLOT e LKV, originando respectivamente RAVGOF, RAVPLOT e RLKV. 


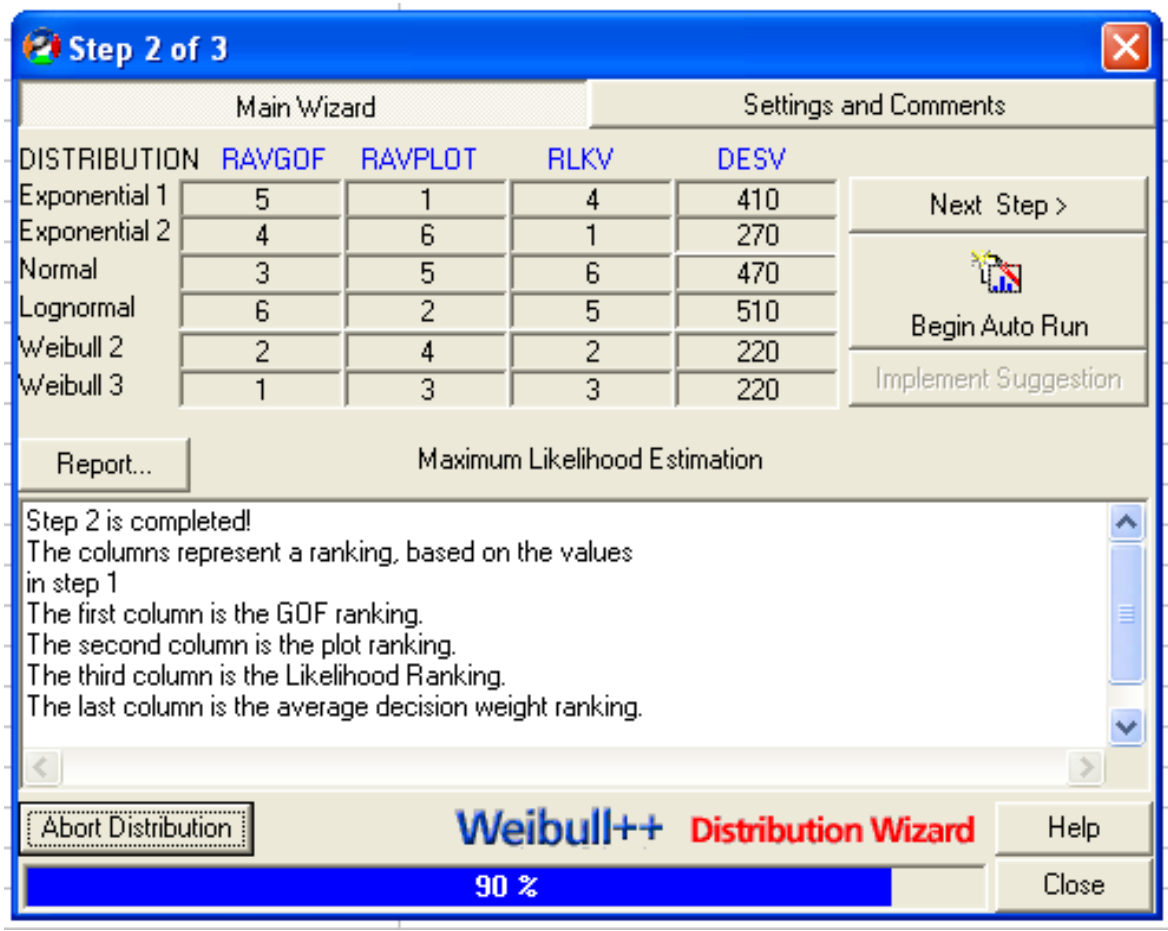

Figura 61 - Resultados ordenados para o teste de aderência para as distribuições.

Observa-se também na Figura 61 o cálculo da variável DESV, que é o resultado de união ponderada das variáveis RAVGOF, RAVPLOT e RLKV, para todas as distribuições.

Os valores das variáveis RAVGOF, RAVPLOT e RLKV são ordenados e a curva que apresenta melhor aderência é possui menores valores para as variáveis.

Os pesos utilizados para as ponderações, são os mesmos da configuração inicial do programa e conforme Figura 62 [RELIASOFT. User's guide ReliaSoft's Weibull++(1997)]. 


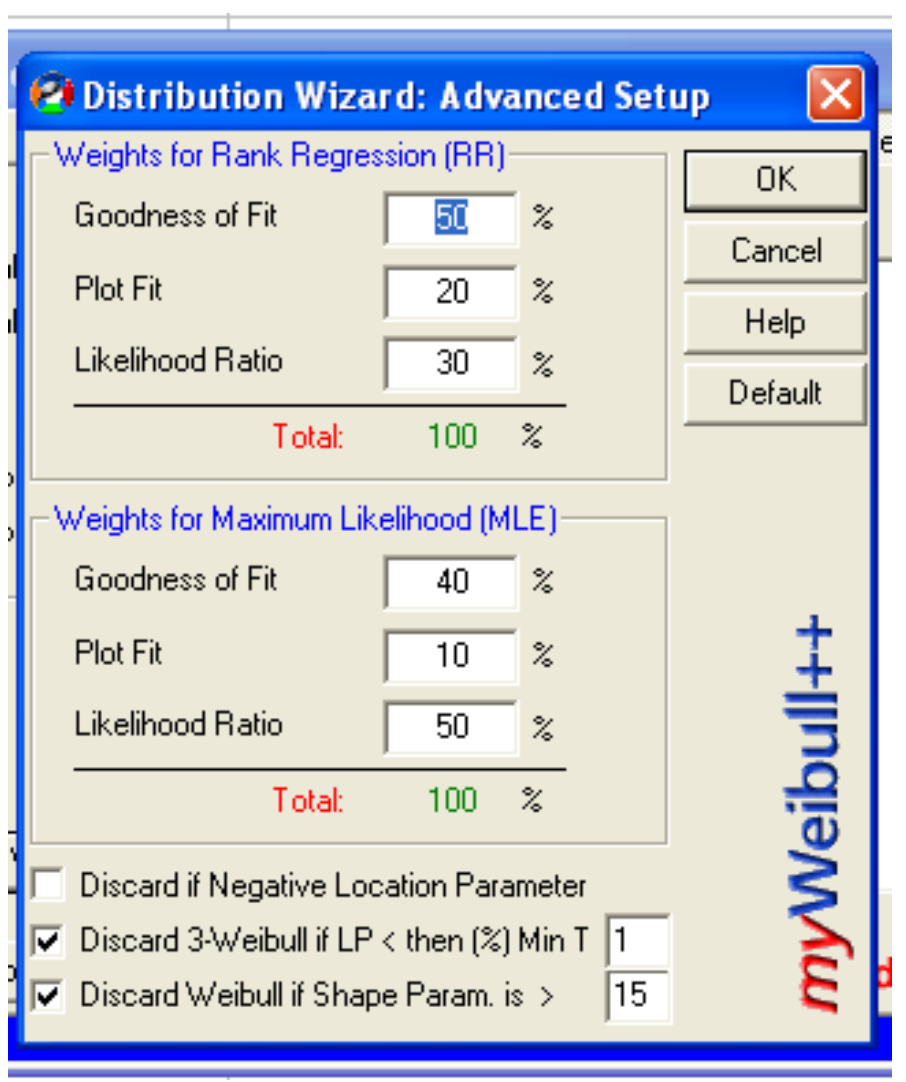

Figura 62 - Pesos utilizados nas ponderações de acordo com simulações de Monte Carlo.

Logo, utiliza-se a distribuição de Weibull com dois parâmetros para representar os dados de garantia, com valores de forma e escala conforme apresentados na Figura 63. 


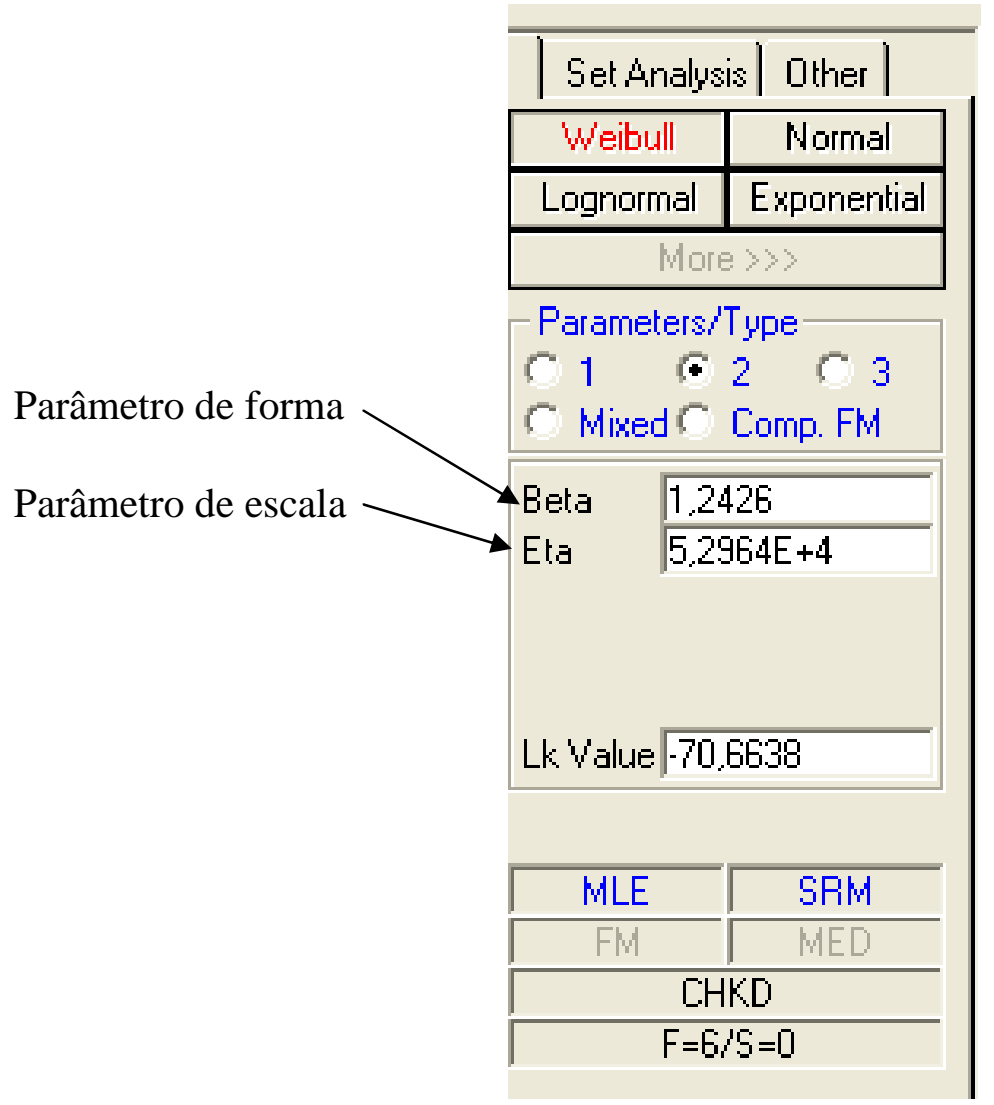

Figura 63 - Valores para as variáveis da curva de Weibull para os dados de garantia.

Essa distribuição tem a função densidade de probabilidade descrita pela equação (12).

$$
f(x, \beta, \eta)=\frac{\beta}{\eta}\left(\frac{x}{\eta}\right)^{\beta-1} e^{-(x / \eta)^{\beta}}
$$

Na Figura 64, observa-se a curva de probabilidade em papel probabilístico para os dados de garantia representada pela distribuição Weibull com os parâmetros calculados na Figura 63. 


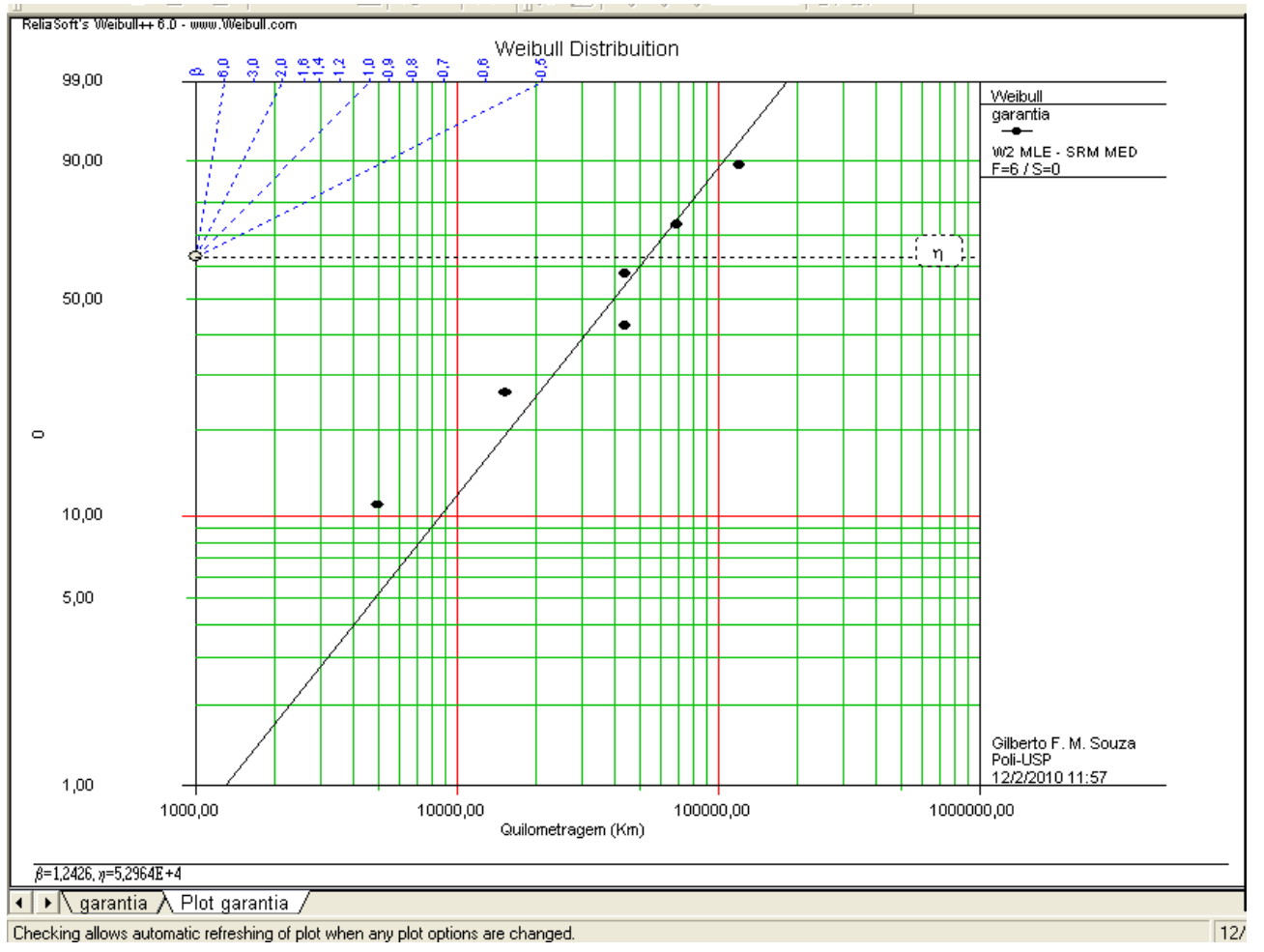

Figura 64 - Curva de probabilidade para os dados de garantia.

Na Figura 65, observa-se o gráfico de confiabilidade em função da quilometragem.

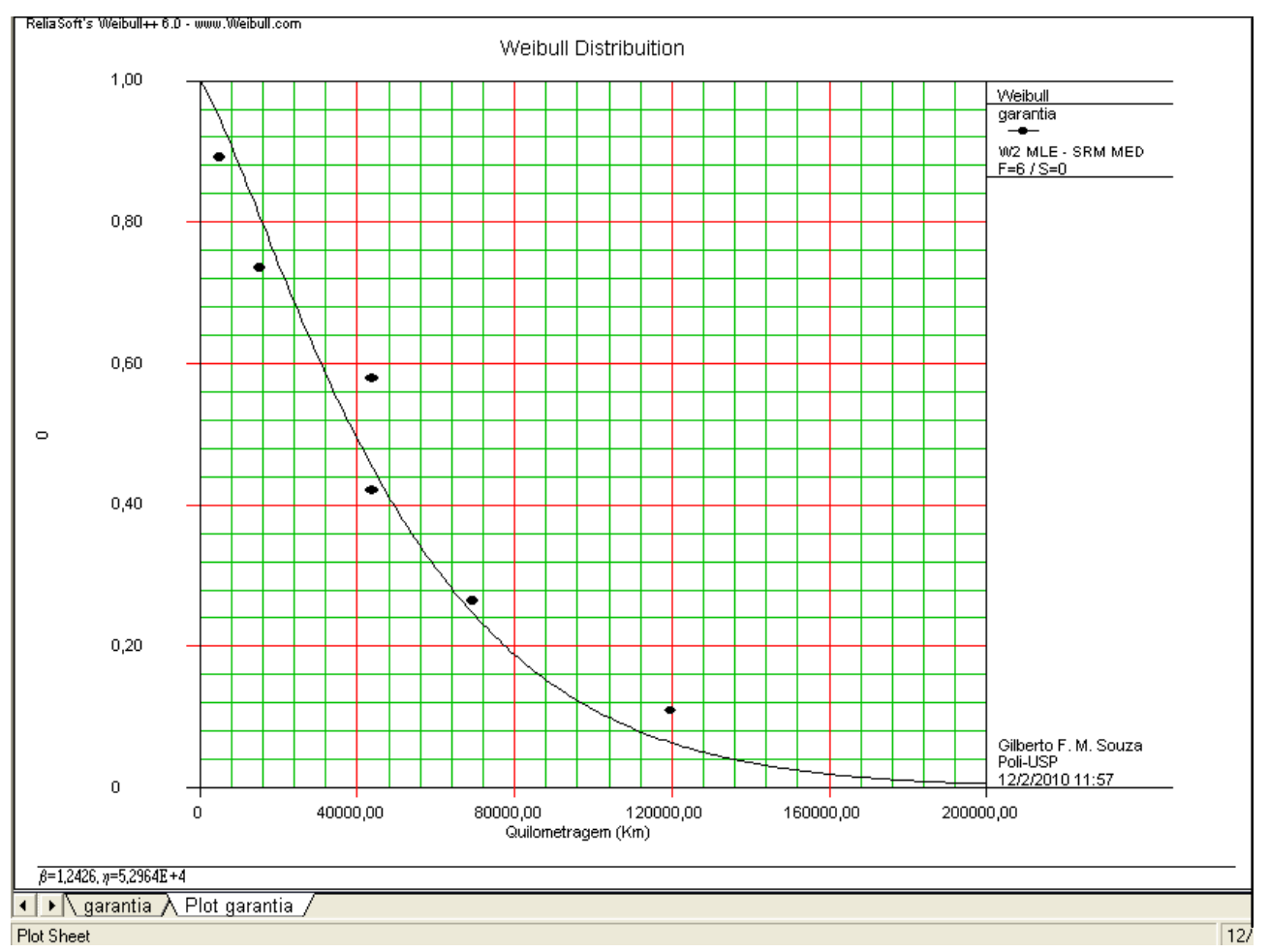

Figura 65 - Gráfico de confiabilidade para os dados de garantia. 
Na Figura 66, observa-se o gráfico da probabilidade de falha com o incremento da quilometragem.

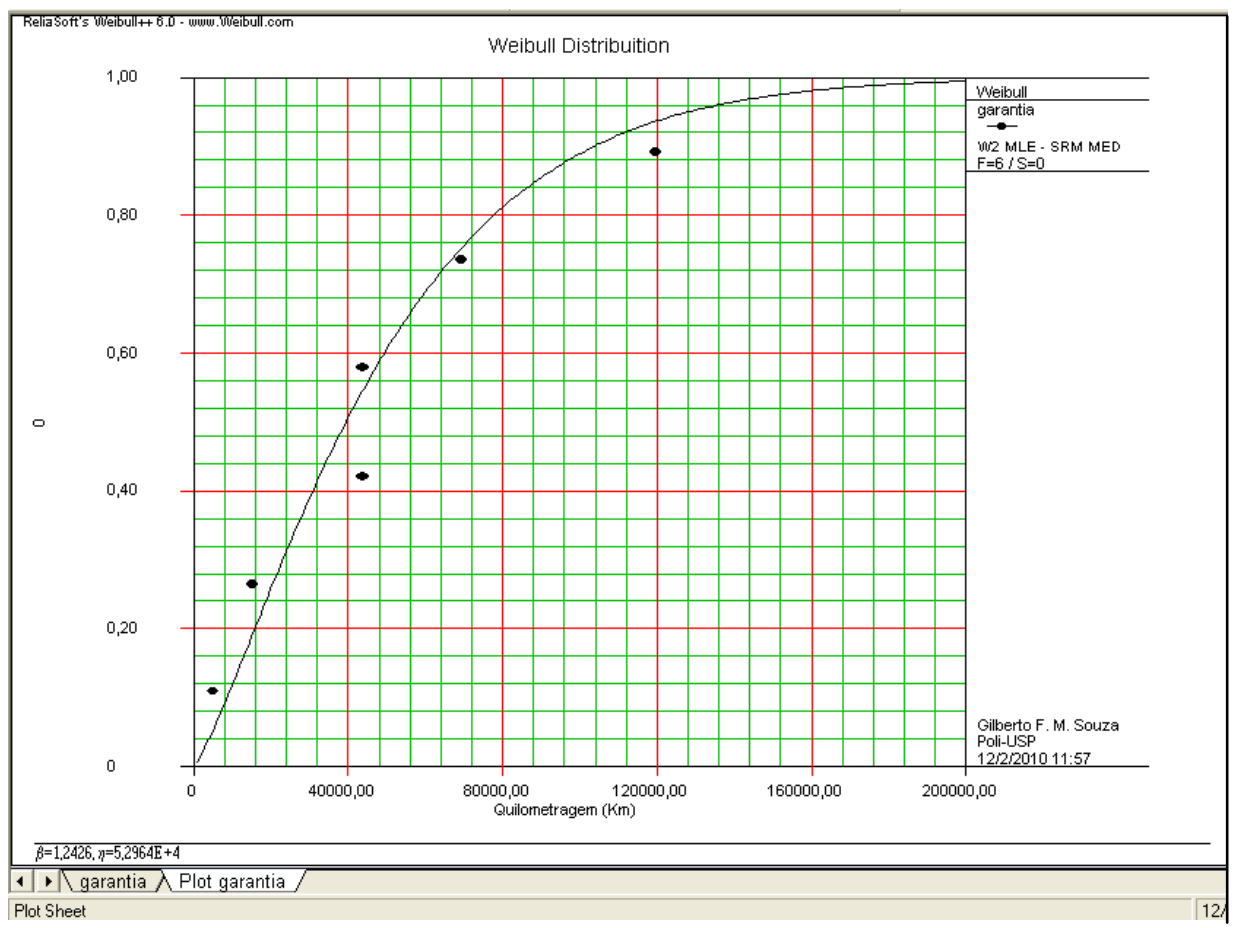

Figura 66 - Gráfico de probabilidade de falha para os dados de garantia.

Na Figura 67, observa-se o gráfico da função densidade de probabilidade.

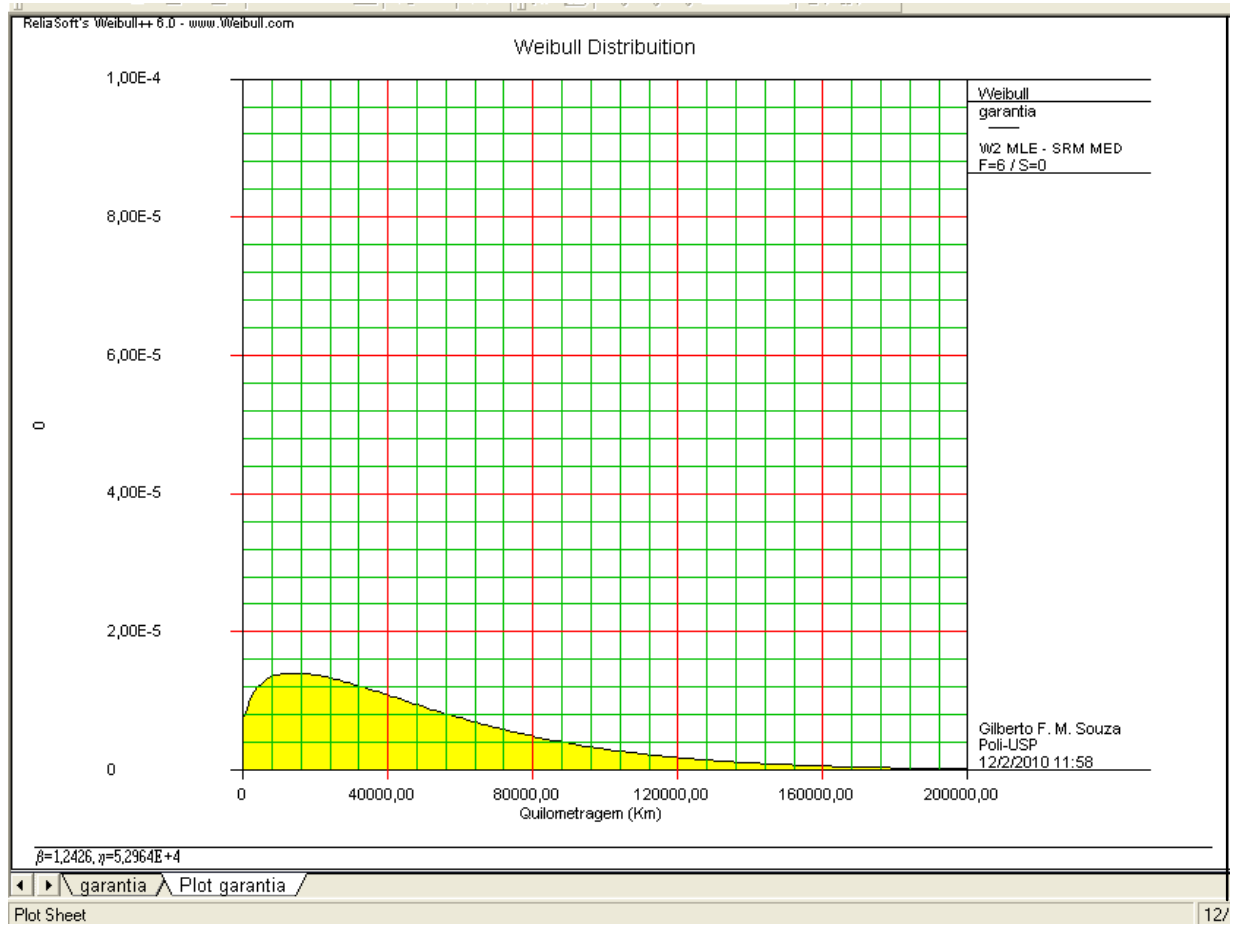

Figura 67 - Gráfico da função densidade de probabilidade para os dados de garantia. 
Na Figura 68, observa-se o gráfico da taxa de falha no tempo.

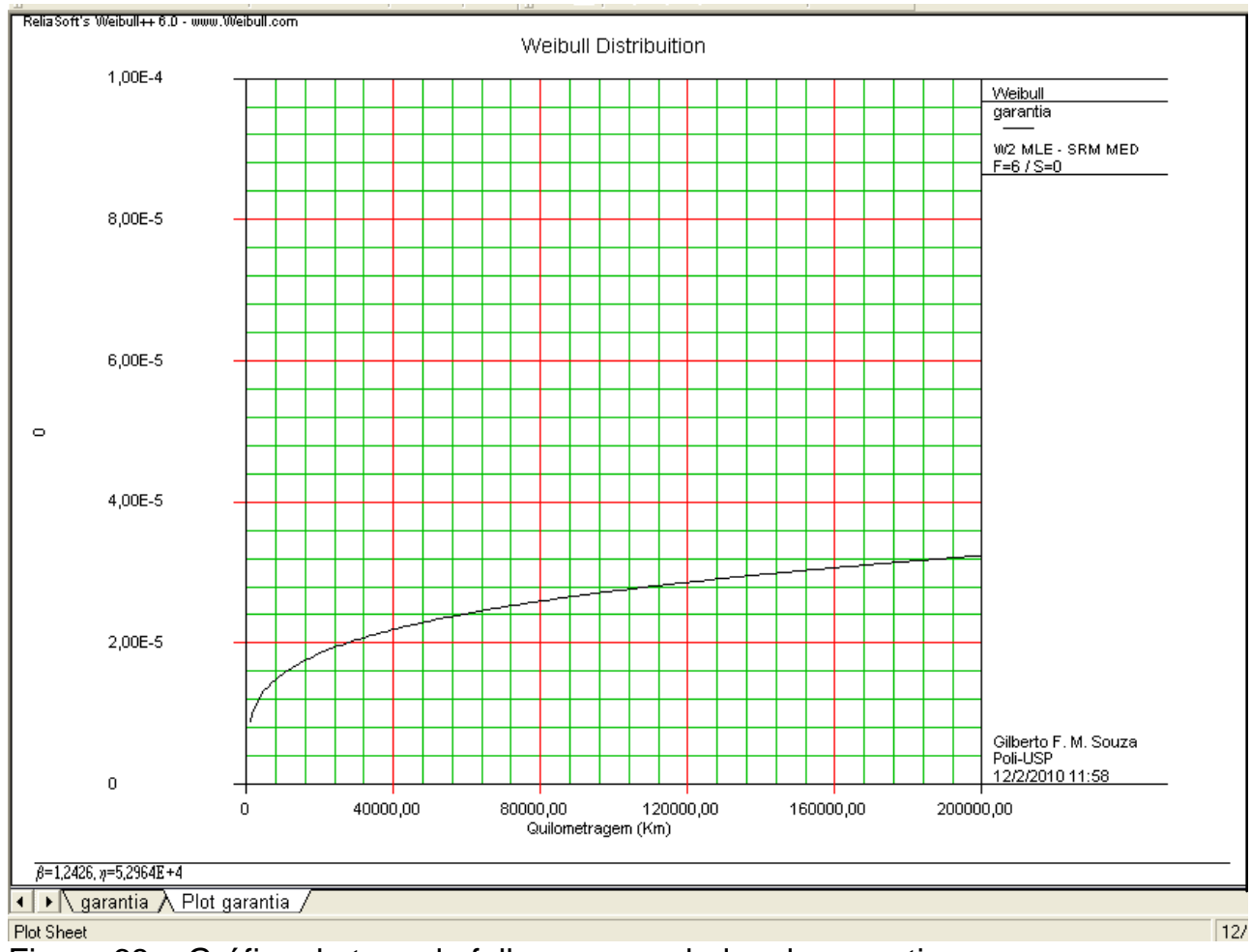

Figura 68 - Gráfico da taxa de falha para os dados de garantia.

Segundo Pinto e Xavier (2001) o significado do parâmetro de forma encontrado para os dados de garantia ( $\beta=1,2426$ ), ou seja, maior que 1 , demonstra que observam-se falhas dependentes do tempo de uso, como era de se esperar visto que estamos estudando dados de garantia.

5.7.2 Estudo de confiabilidade da peça atual submetida à ensaio de vida acelerado

Para o estudo de confiabilidade da peça atual através dos dados de ensaio de vida acelerado, inseriu-se os dados tempo de falha observados nos itens 5.5.1 e 5.5.2 no software Alta 7 Pro. Esse software é especificamente utilizado para analise de dados oriundos de ensaios acelerados.

Foram utilizados os dados dos itens 5.5.1 e 5.5.2, ou seja, ensaio acelerado por lama e durabilidade acelerado, pois os mesmos representam dois níveis de solicitação acelerada, ou seja, com lama e sem lama.

Na Figura 69, pode-se observar a tela onde os valores são inseridos. 


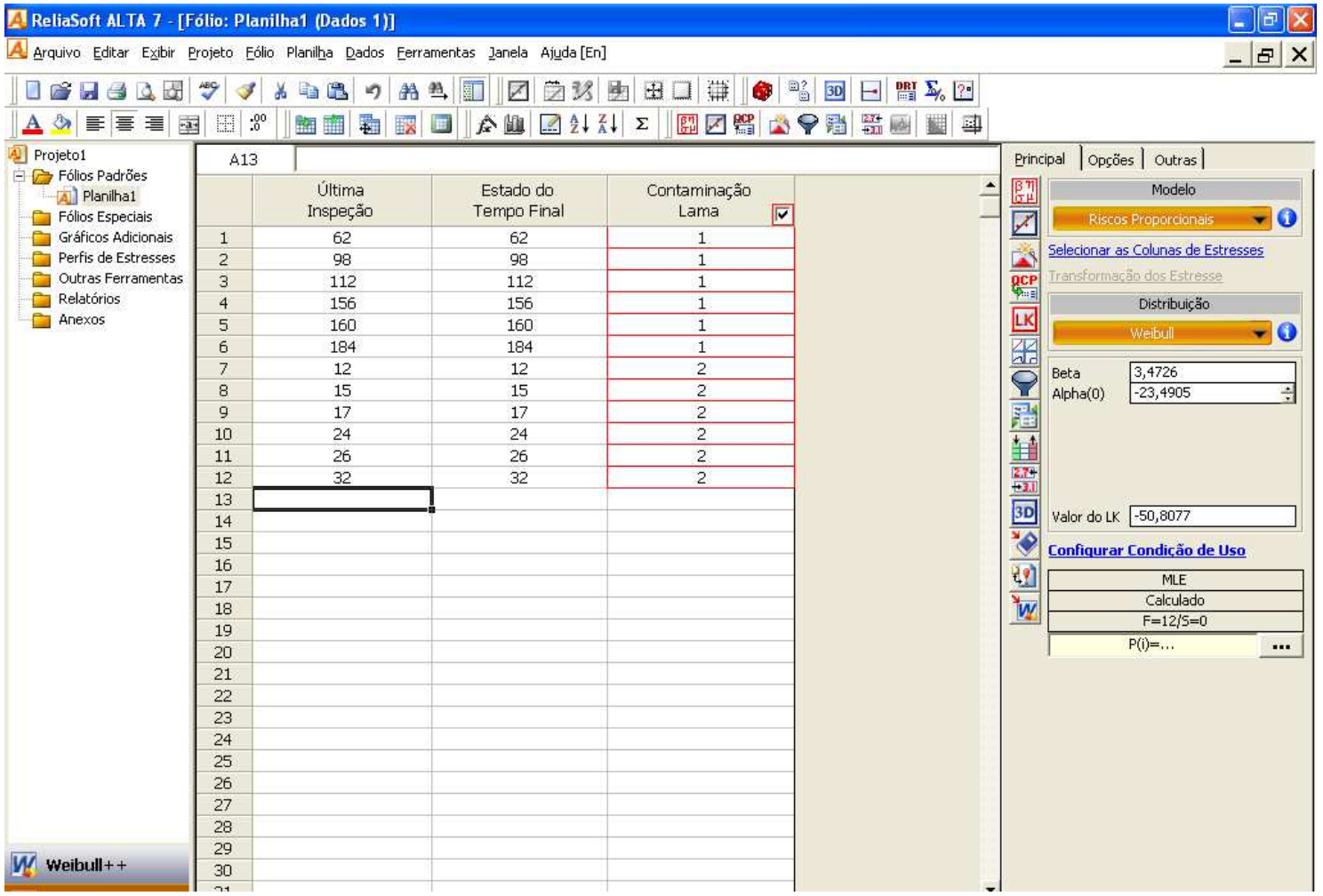

Figura 69 - Tabela onde os resultados dos ensaios com a peça atual são inseridos.

Após realizados os cálculos para todas as curvas, realizou-se o teste de aderência e como verifica-se na Figura 70, a curva que mais se adequou aos dados foi a Weibull.

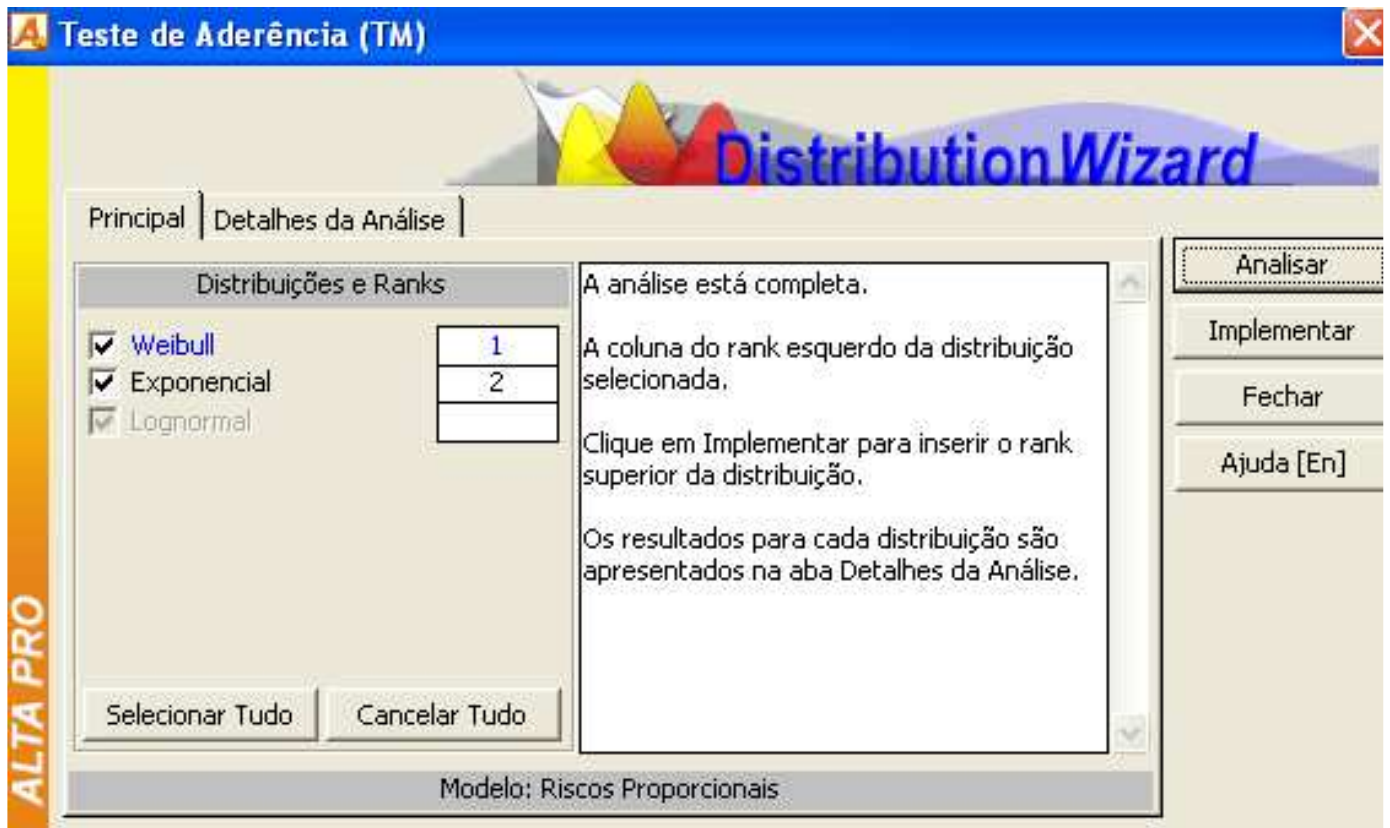

Figura 70 - Ordenação resultante do teste de aderência para os dados de ensaio com a peça atual. 
Observa-se na Figura 71 os resultados obtidos pelo o teste de aderência.

O parâmetro Alpha(1) representa ETA ( $\eta$ ), semelhantemente a variável apresentada pelo programa Weibull++, conforme mostrado para o cálculo com dados de garantia na Figura 63.

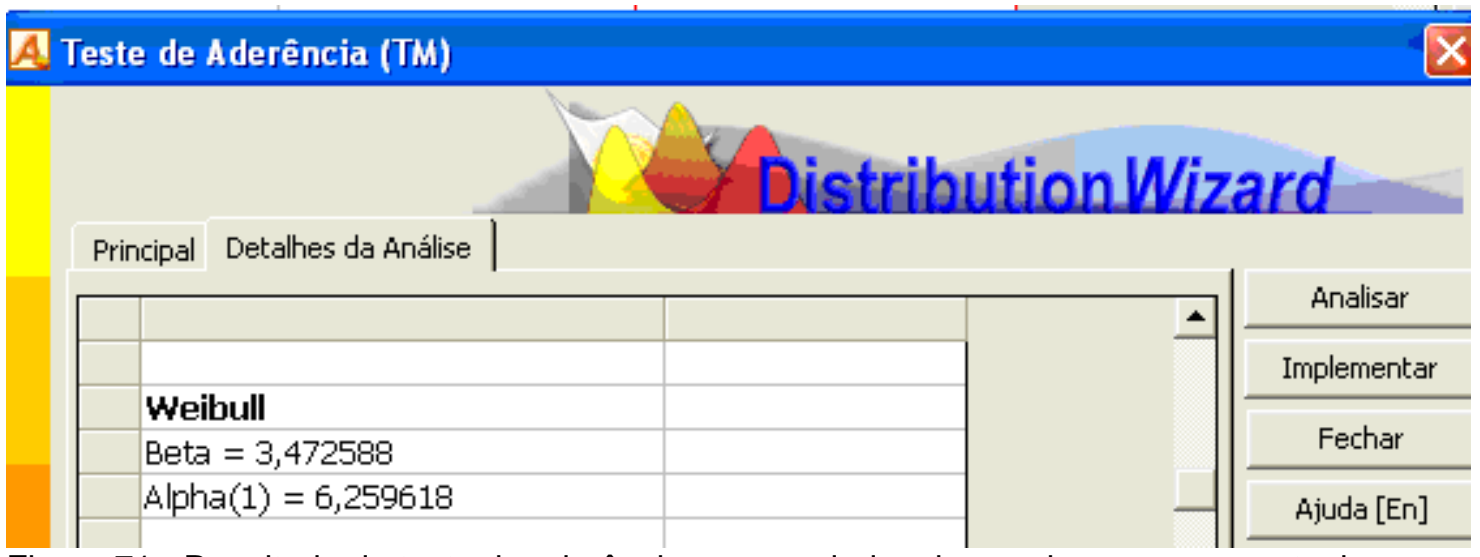

Figura 71 - Resultado do teste de aderência para os dados de ensaio com a peça atual.

Logo, para os dados de ensaio acelerado com lama realizados no produto atual verifica-se uma curva de Weibull com os parâmetros indicados na Figura 72.

Conforme mencionado anteriormente, o parâmetro Alpha(1) representa Eta (n) ou seja, o parâmetro de escala da distribuição.

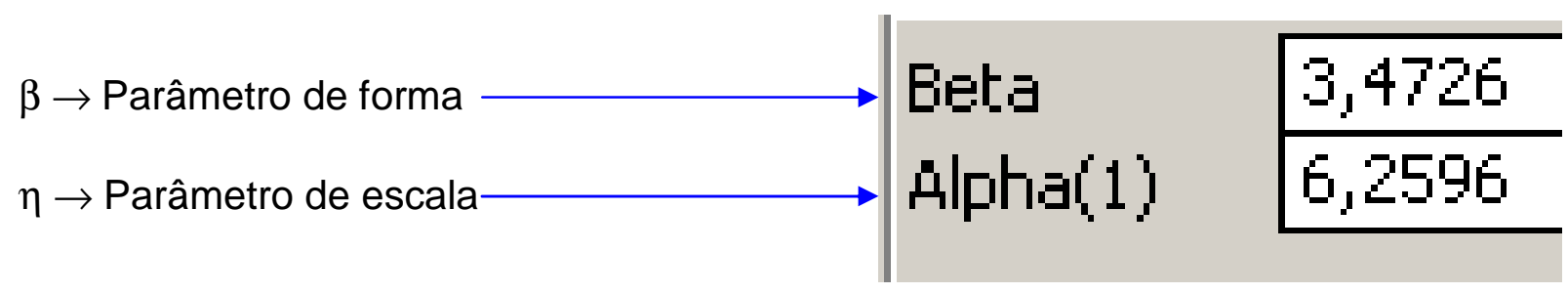

Figura 72 - Valores para as variáveis da curva de Weibull que representa os resultados de ensaios com a peça atual.

Na Figura 73, observa-se a curva de probabilidade em papel probabilístico para os dados de ensaio acelerado com lama representada pelo tipo Weibull com as variáveis acima. 


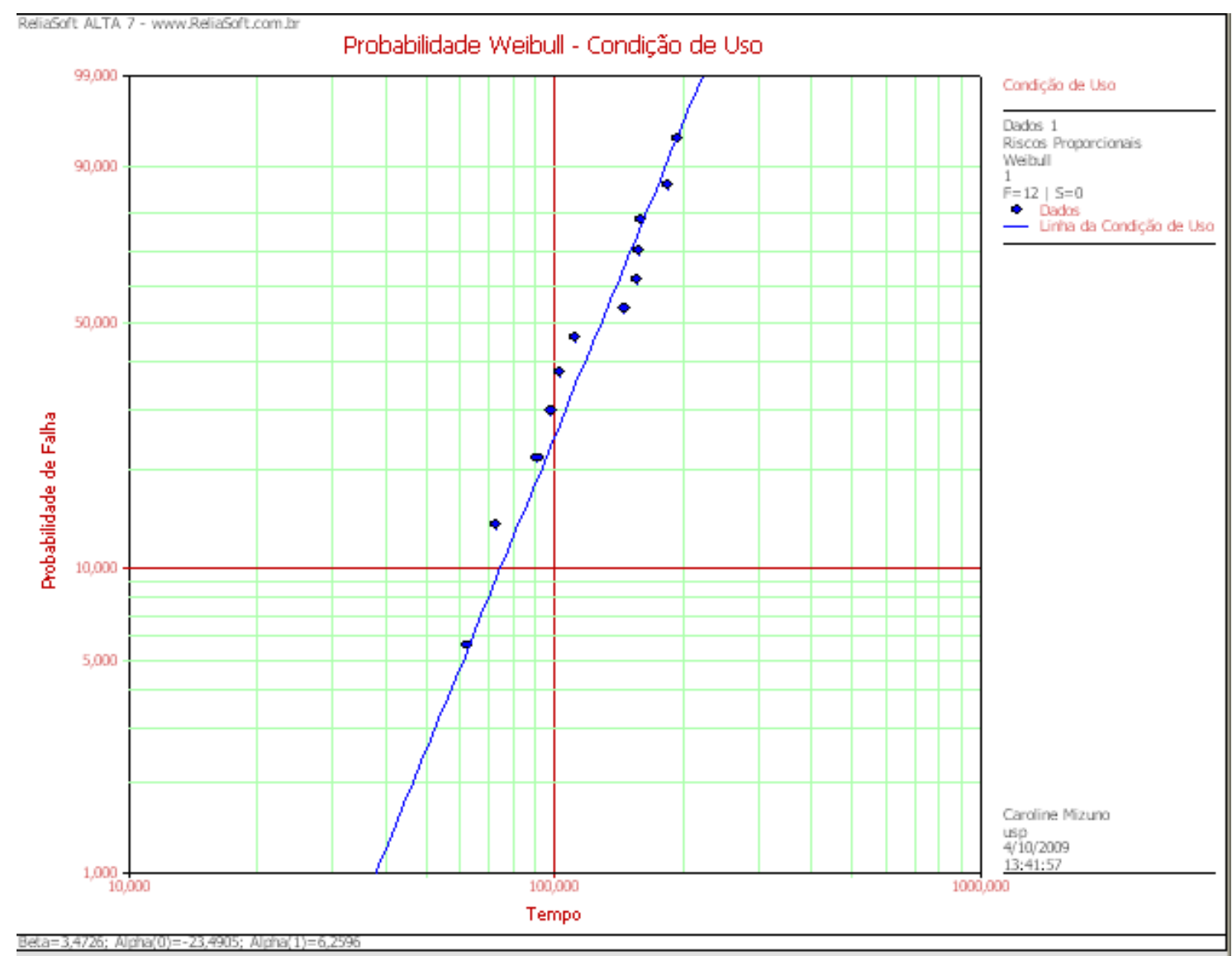

Figura 73 - Curva de probabilidade para a peça atual.

Na Figura 74, observa-se a curva de confiabilidade no tempo para os dados de ensaio acelerado realizados na peça atual. 


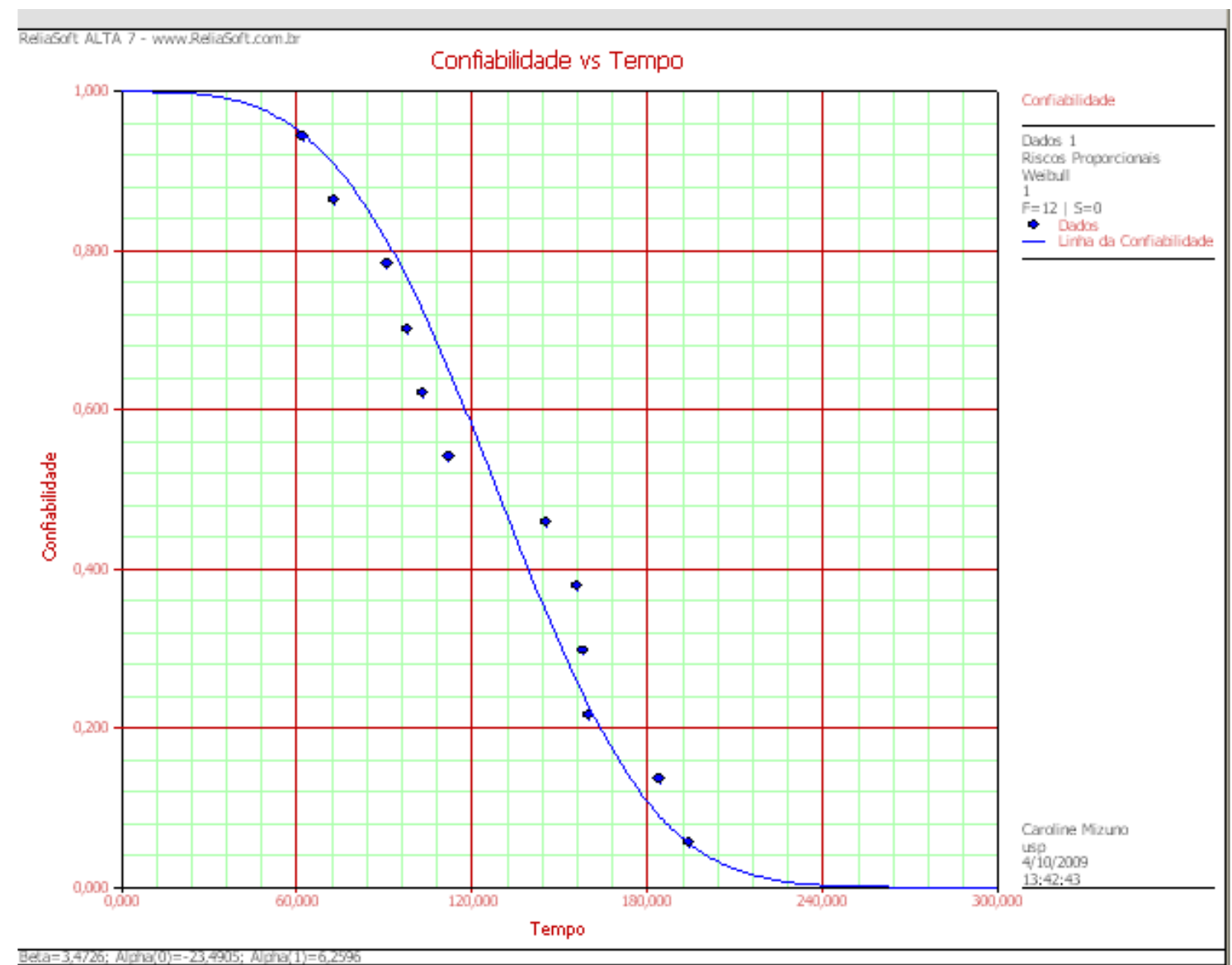

Figura 74 - Curva de confiabilidade para a peça atual.

Na Figura 75, observa-se a curva de probabilidade de falha no tempo para os dados de ensaio acelerado realizados na peça atual. 


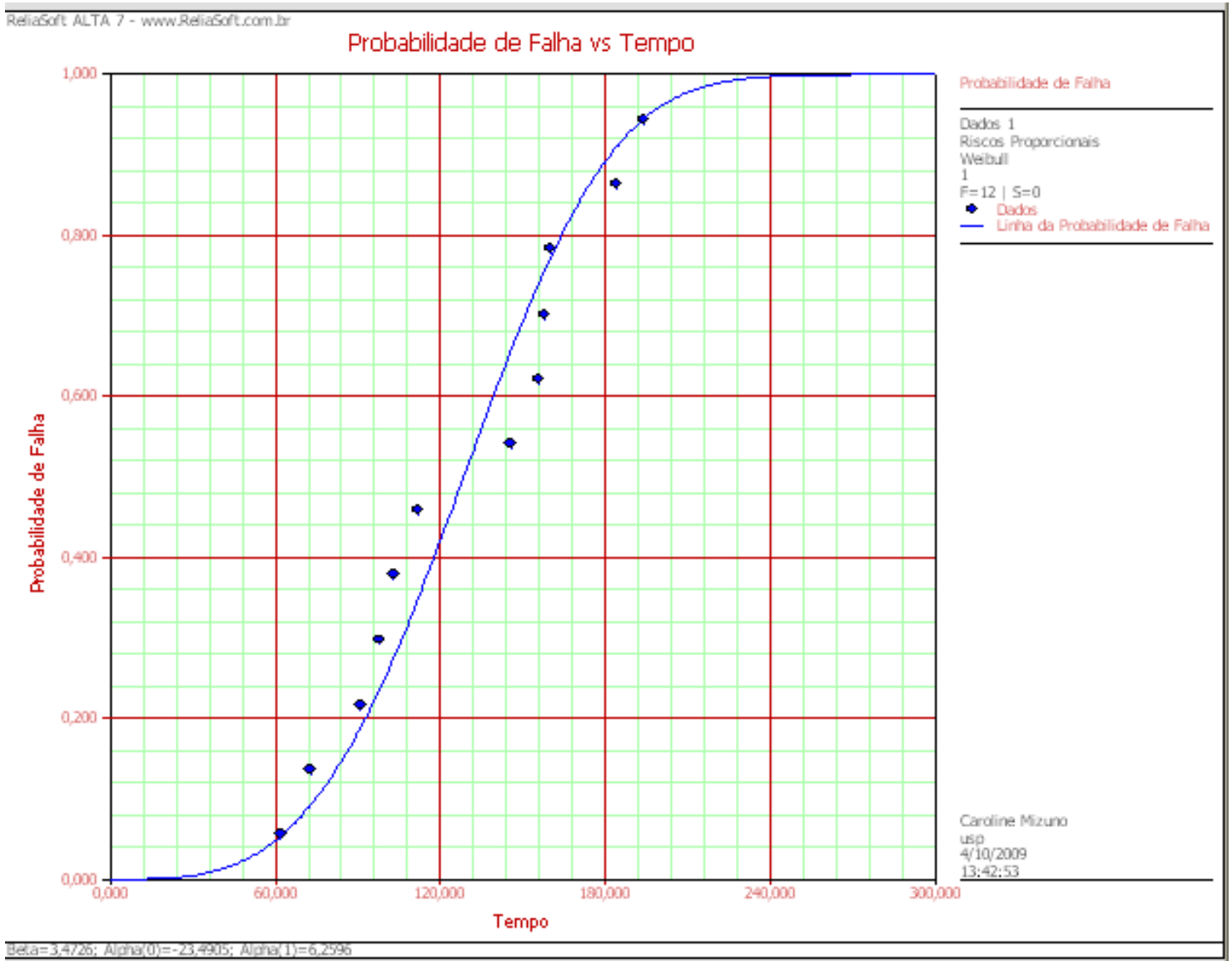

Figura 75 - Curva de probabilidade para a peça atual.

Na Figura 76, observa-se a curva de função densidade de probabilidade. 


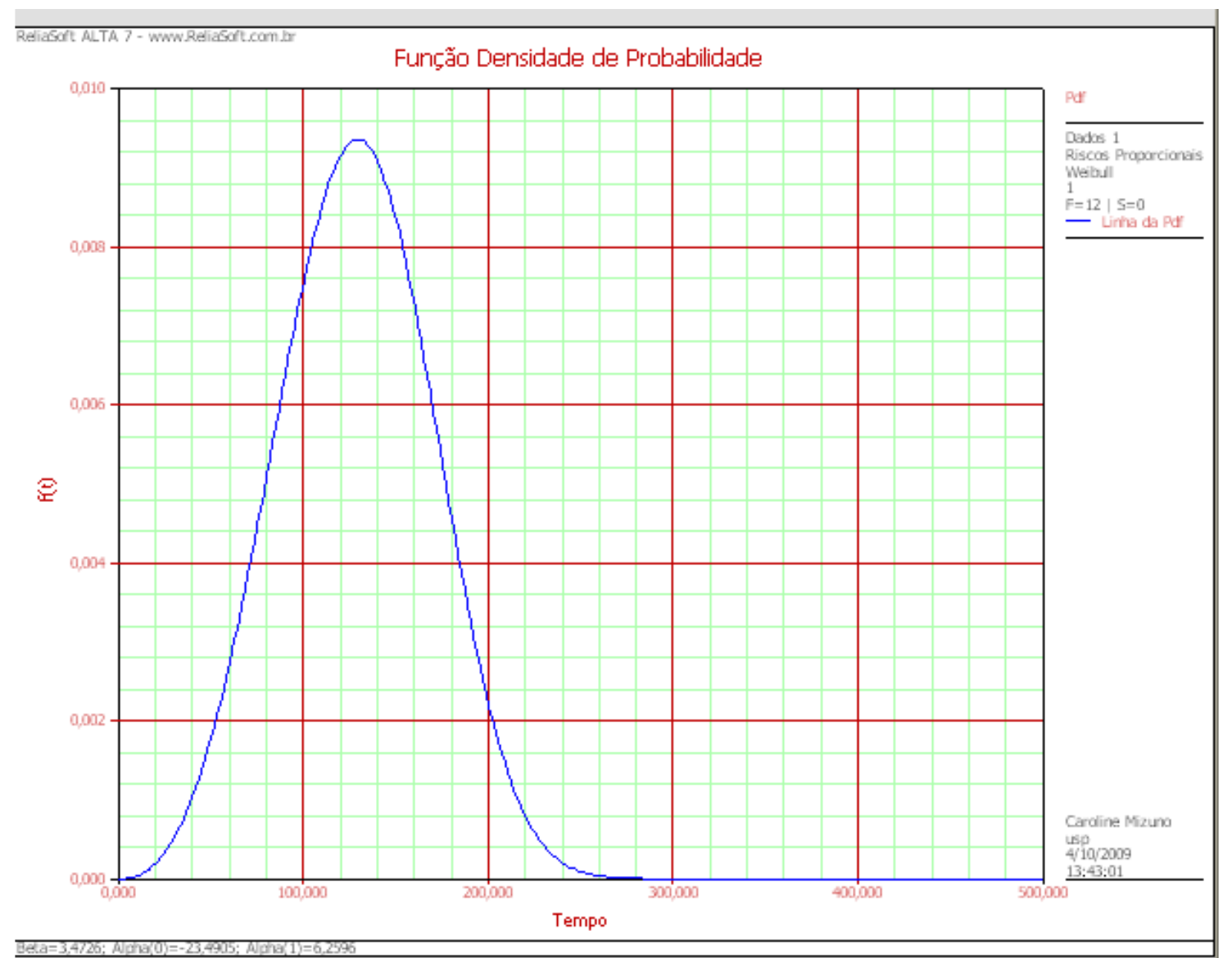

Figura 76 - Curva da função densidade de probabilidade para a peça atual.

Na Figura 77, observa-se a taxa de falha no tempo. 


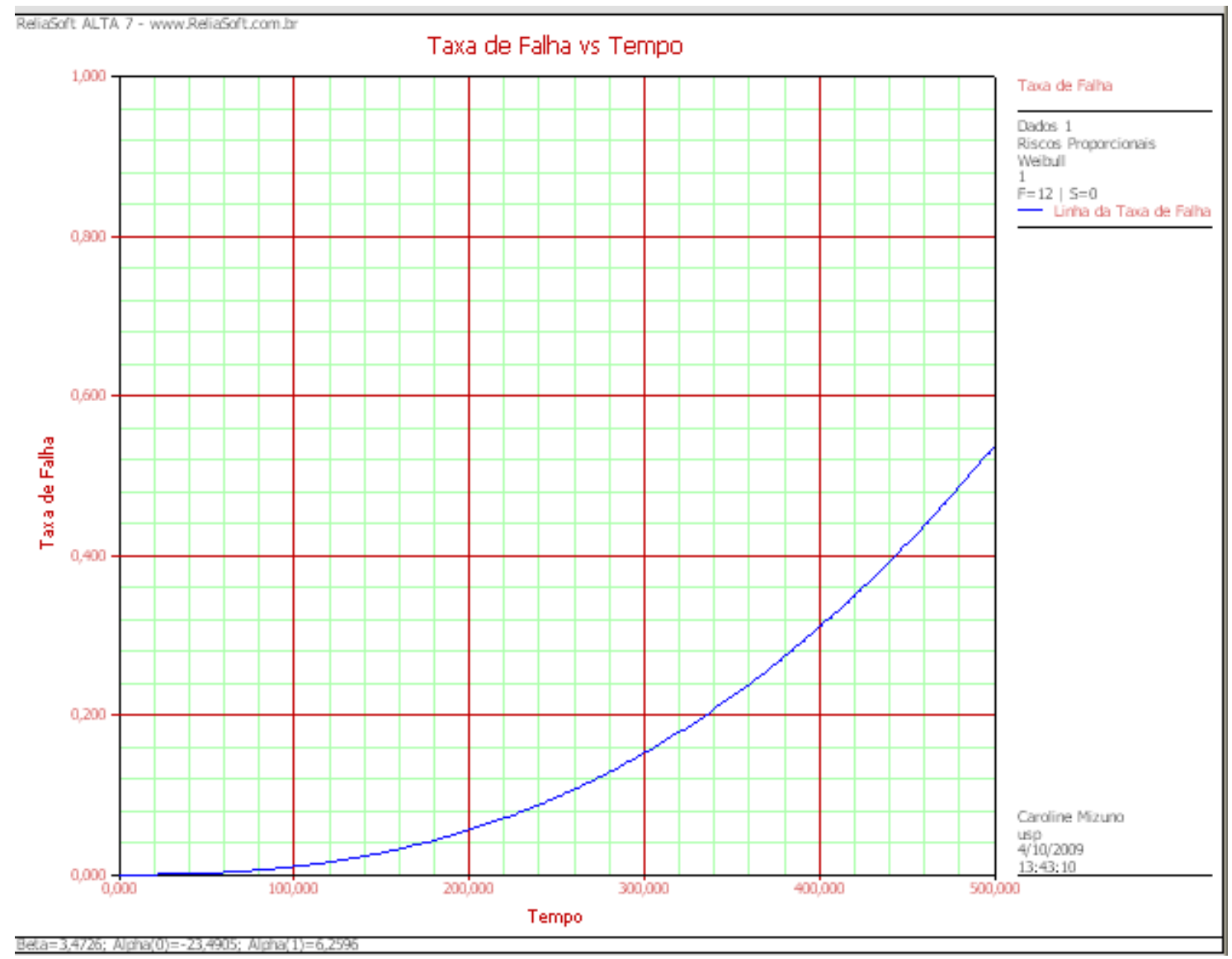

Figura 77 - Taxa de falha para a peça atual.

Na Figura 78, observa-se o fator de aceleração originado pela solicitação de maior magnitude. 


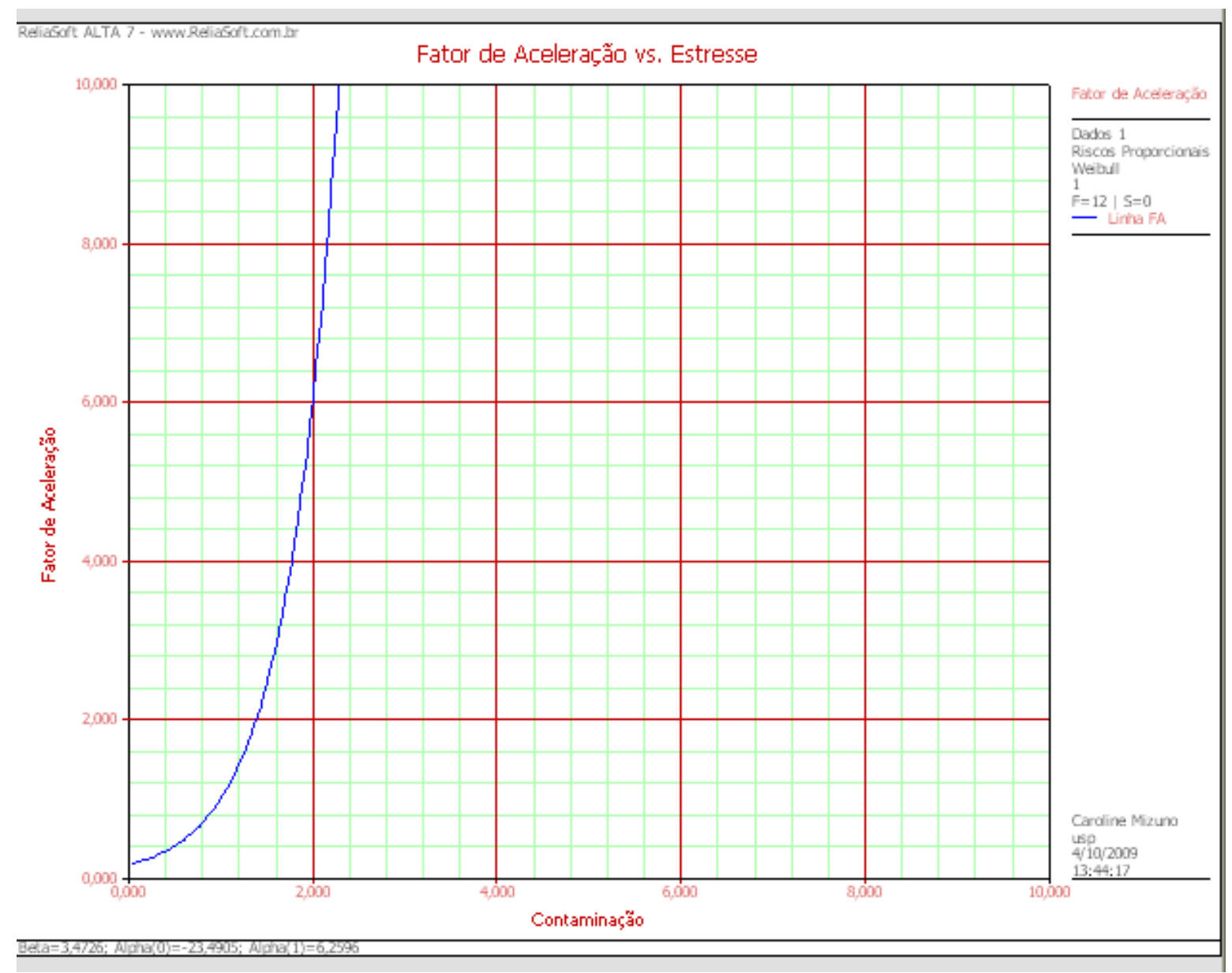

Figura 78 - Fator de aceleração.

5.7.3 Estudo de confiabilidade da peça modificada submetida à ensaio de vida acelerado

Para o estudo de confiabilidade da peça modificada através dos de ensaio acelerado, inseriu-se os dados tempo de falha observados nos itens 5.5 .3 e 5.5 .4 no software Alta 7, esse software é especificamente utilizado para analise de dados oriundos de ensaios acelerados.

Foram utilizados os dados dos itens 5.5 .3 e 5.5.4, ou seja, ensaio acelerado por lama e durabilidade acelerado pois os mesmos representam dois níveis de solicitação, ou seja, com lama e sem lama.

Na Figura 79, pode-se observar a tela onde os valores são inseridos. 


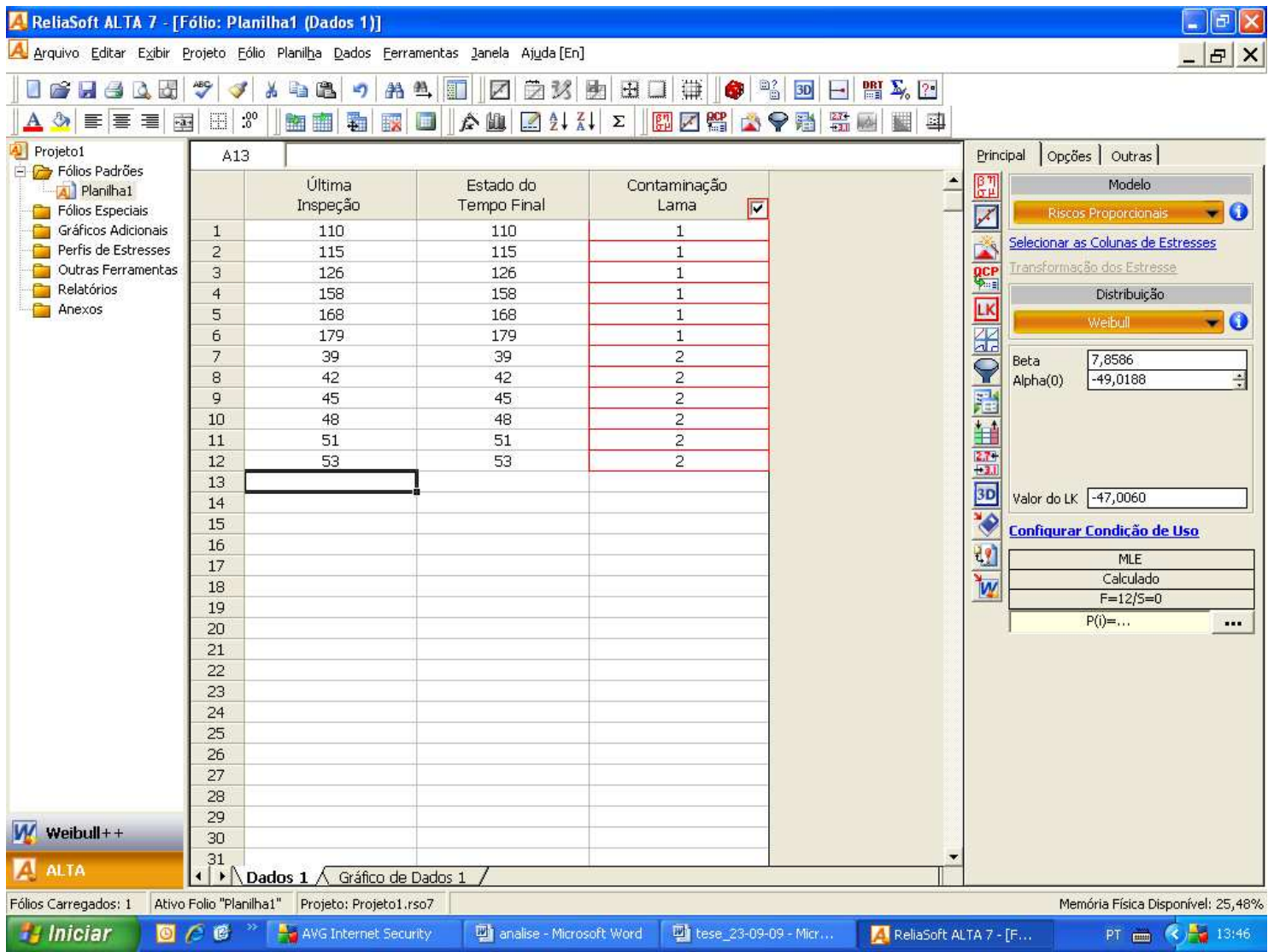

Figura 79 - Tabela onde são inseridos os resultados dos testes com a peça modificada.

Após realizados os cálculos para todas as curvas, realizou-se o teste de aderência e como pode-se verificar na Figura 80, a curva que mais se adequou aos dados foi a Weibull. 


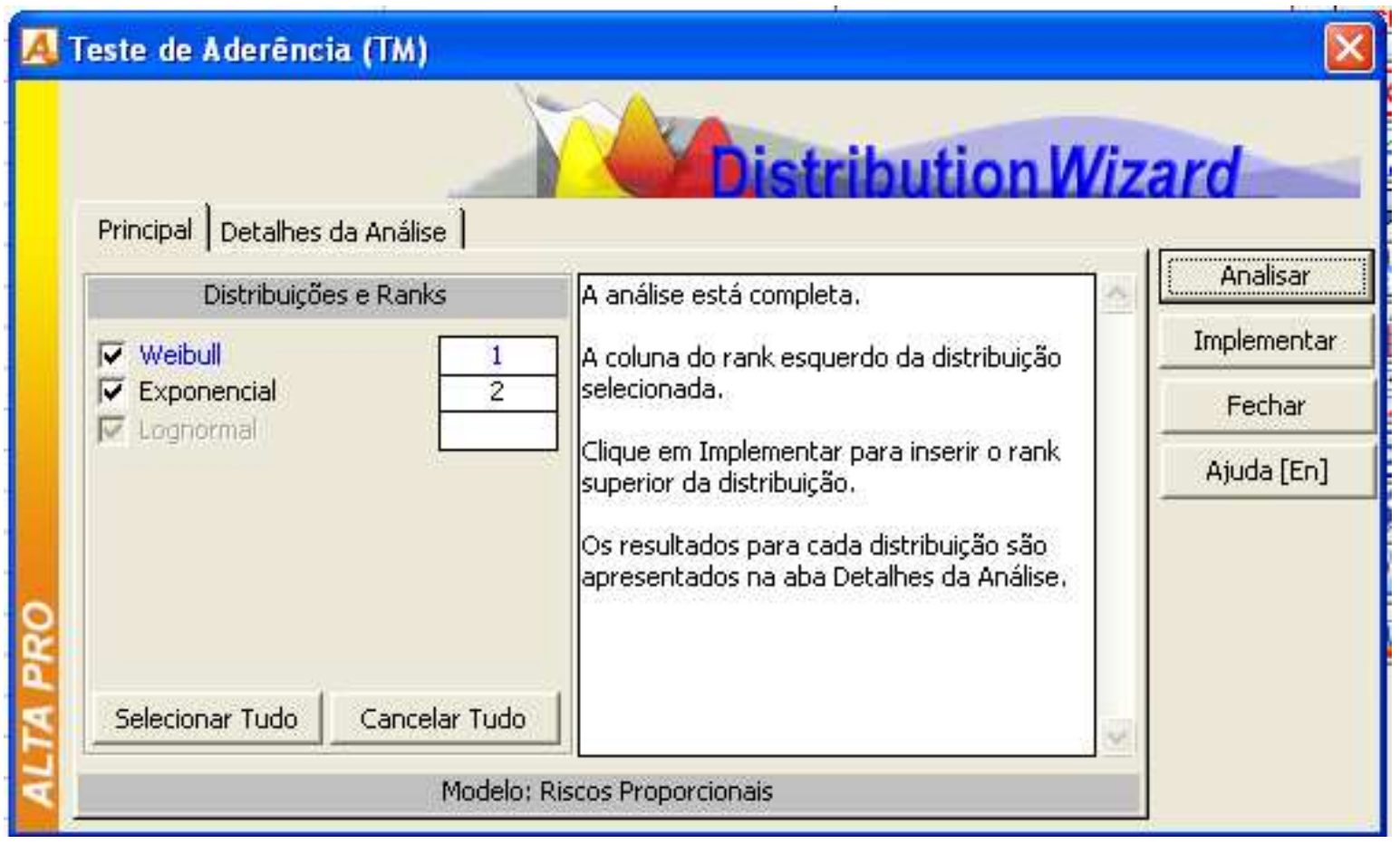

Figura 80 - Ordenação do resultado do testes de aderência.

Pode-se observar na Figura 81 os resultados obtidos pelo o teste de aderência.

O parâmetro Alpha(1) representa ETA ( $\eta)$, semelhantemente a variável apresentada pelo programa Weibull++, conforme mostrado para o cálculo com dados de garantia na Figura 63

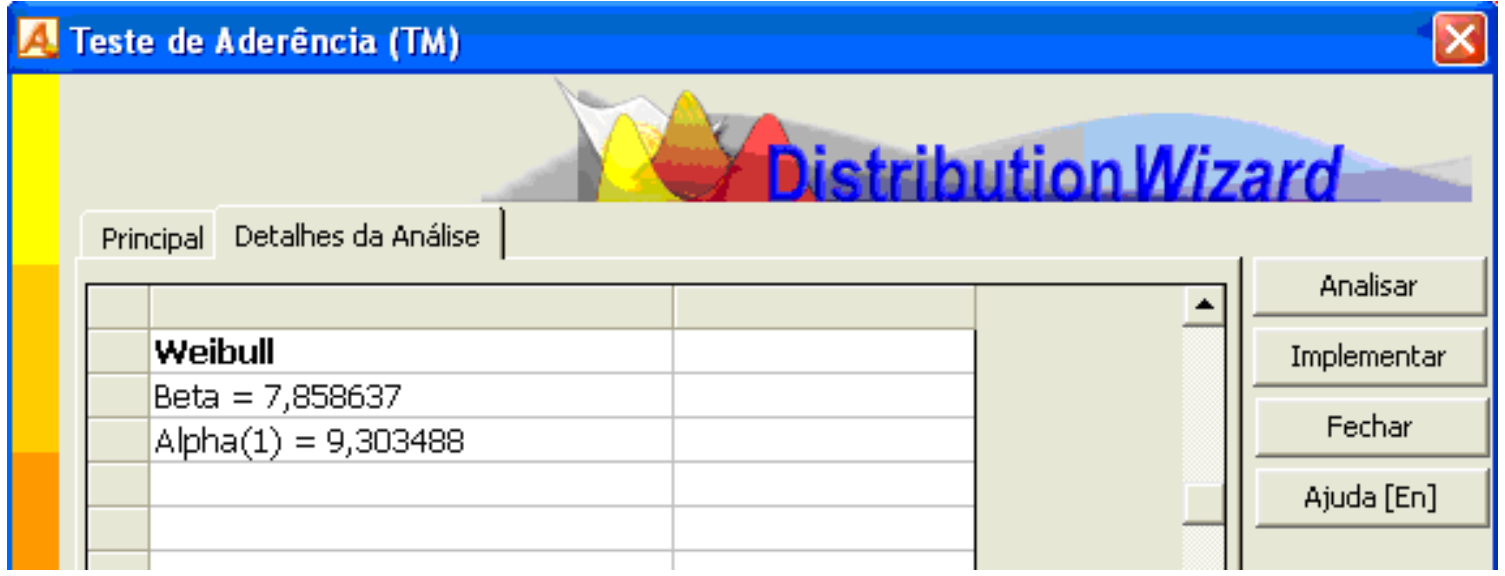

Figura 81 - Resultado do teste de aderência. 
Logo, para os dados de ensaio acelerado com lama realizados no produto modificado teremos uma curva de Weibull com os seguintes valores variáveis que a descrevem.

Conforme mencionado anteriormente, o parâmetro Alpha(1) representa Eta (n) ou seja, o parâmetro de escala da distribuição.

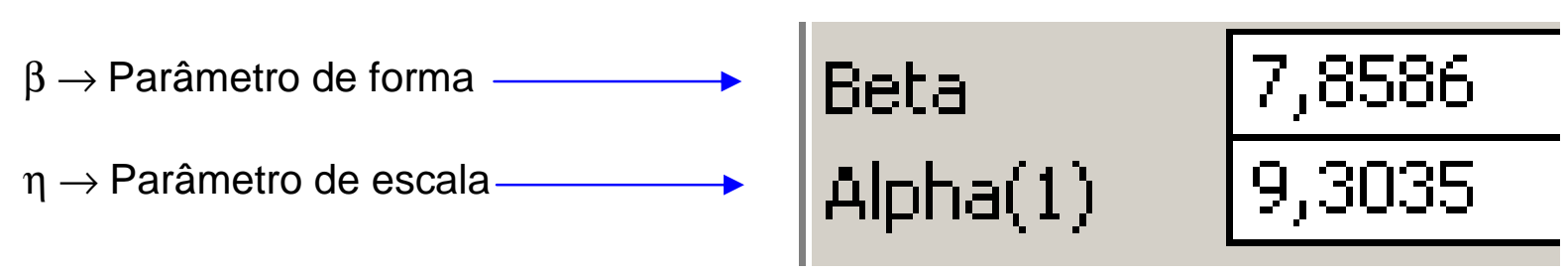

Figura 82 - Valores para as variáveis da curva de Weibull que representa os resultados de ensaios com a peça modificada.

$\mathrm{Na}$ Figura 83, podemos observar a curva de probabilidade em papel probabilístico para os dados de ensaio acelerado com lama representada pelo tipo Weibull com as variáveis acima. 


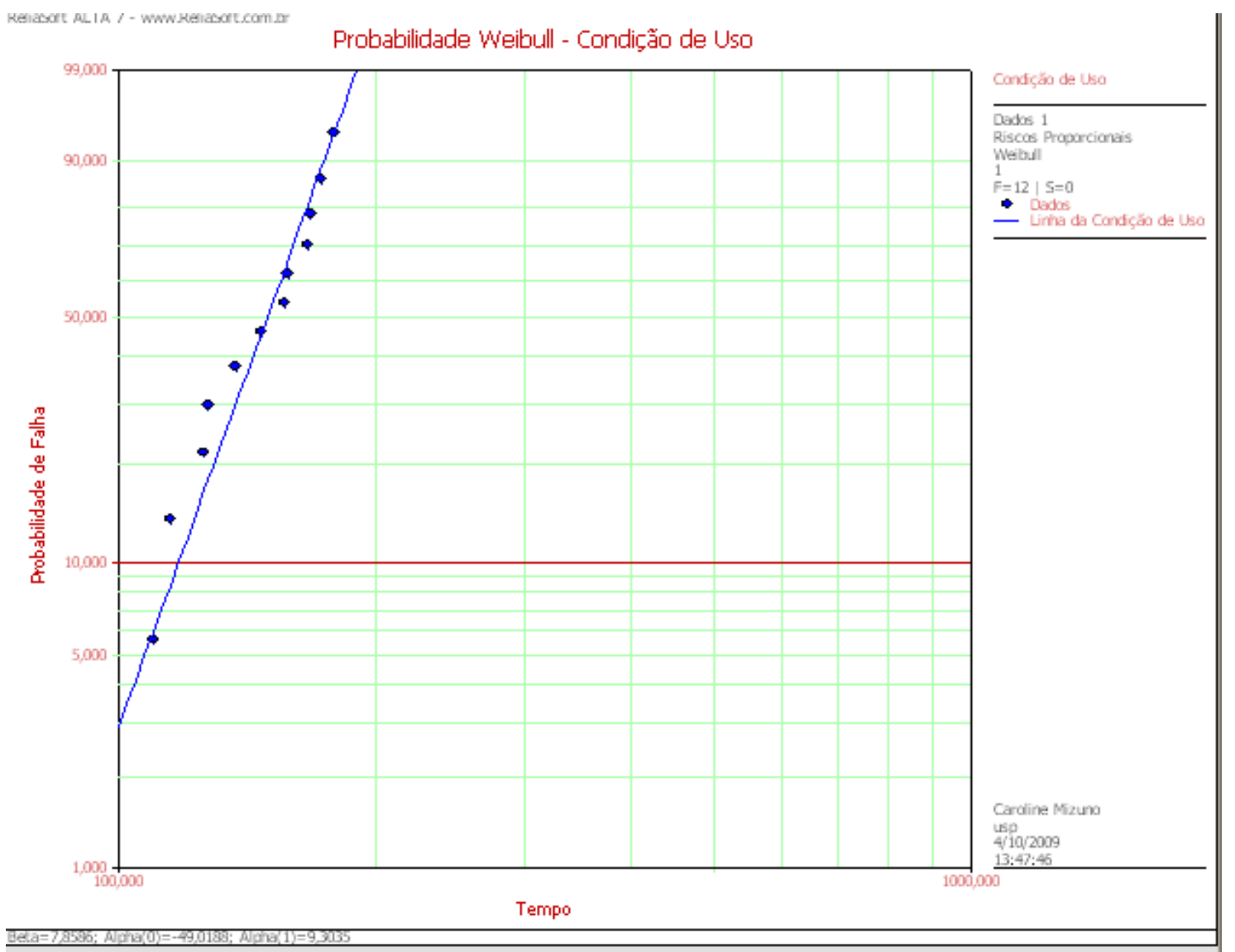

Figura 83 - Curva de probabilidade para a peça modificada.

$\mathrm{Na}$ Figura 84, observa-se a curva de confiabilidade no tempo para os dados de ensaio acelerado realizados na peça modificada. 


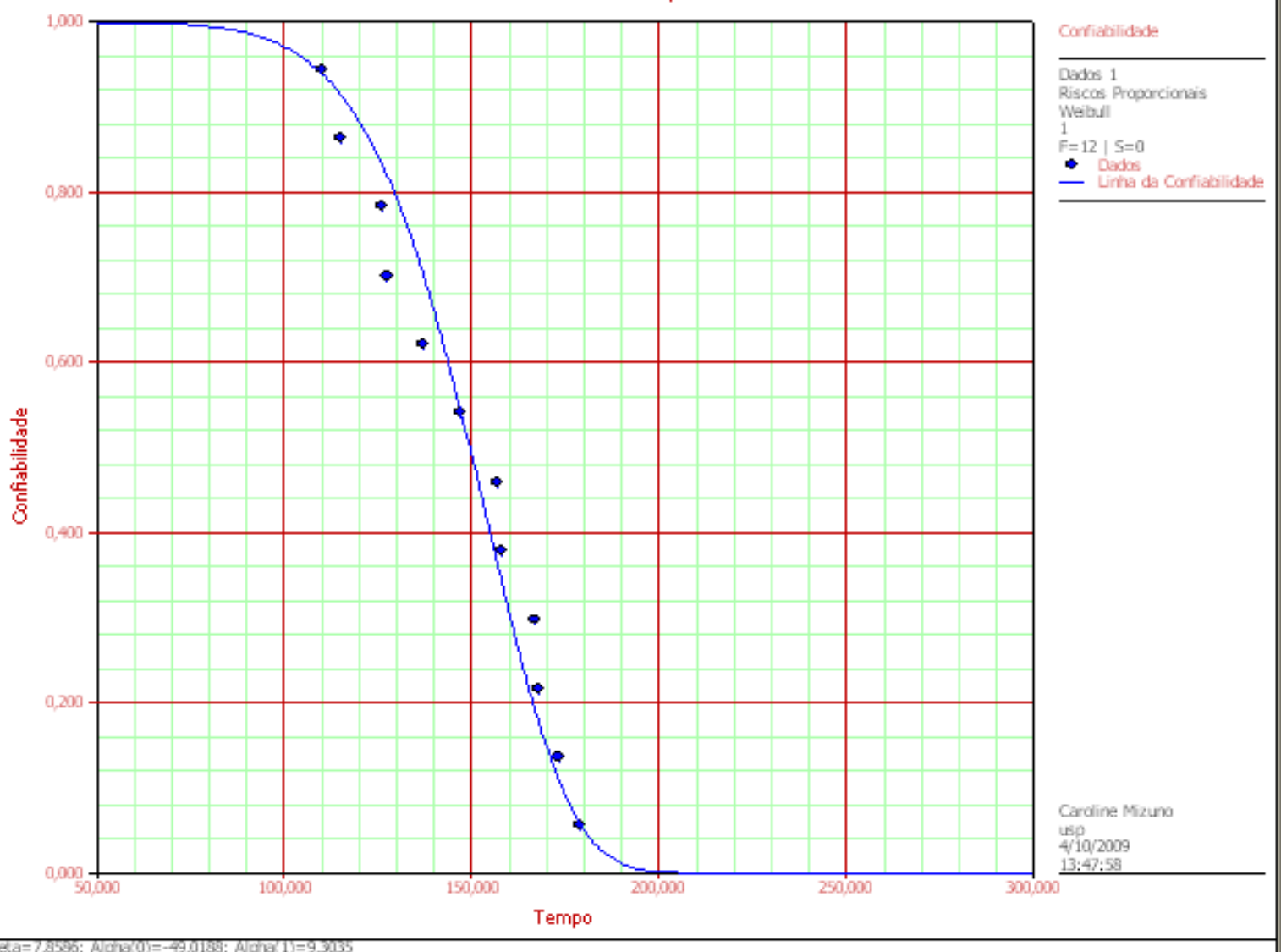

Figura 84 - Curva de confiabilidade para a peça modificada.

Na Figura 85, observa-se a curva de probabilidade de falha no tempo para os dados de ensaio acelerado realizados na peça modificada. 
Probabilidade de Falha us Tempo

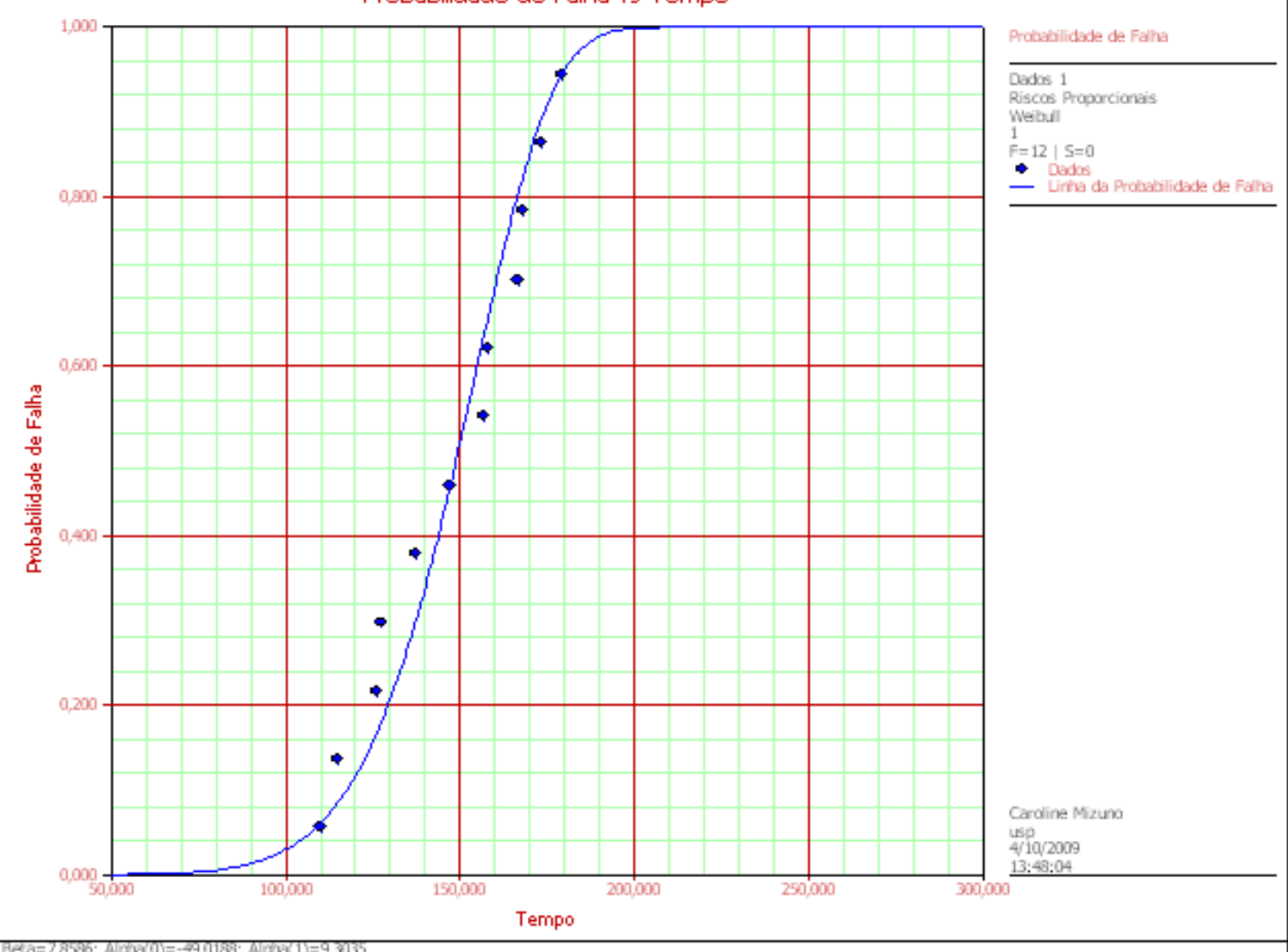

Figura 85 - Curva de probabilidade para a peça modificada.

Na Figura 86, observa-se a curva de função densidade de probabilidade. 
Função Densidade de Probabilidade

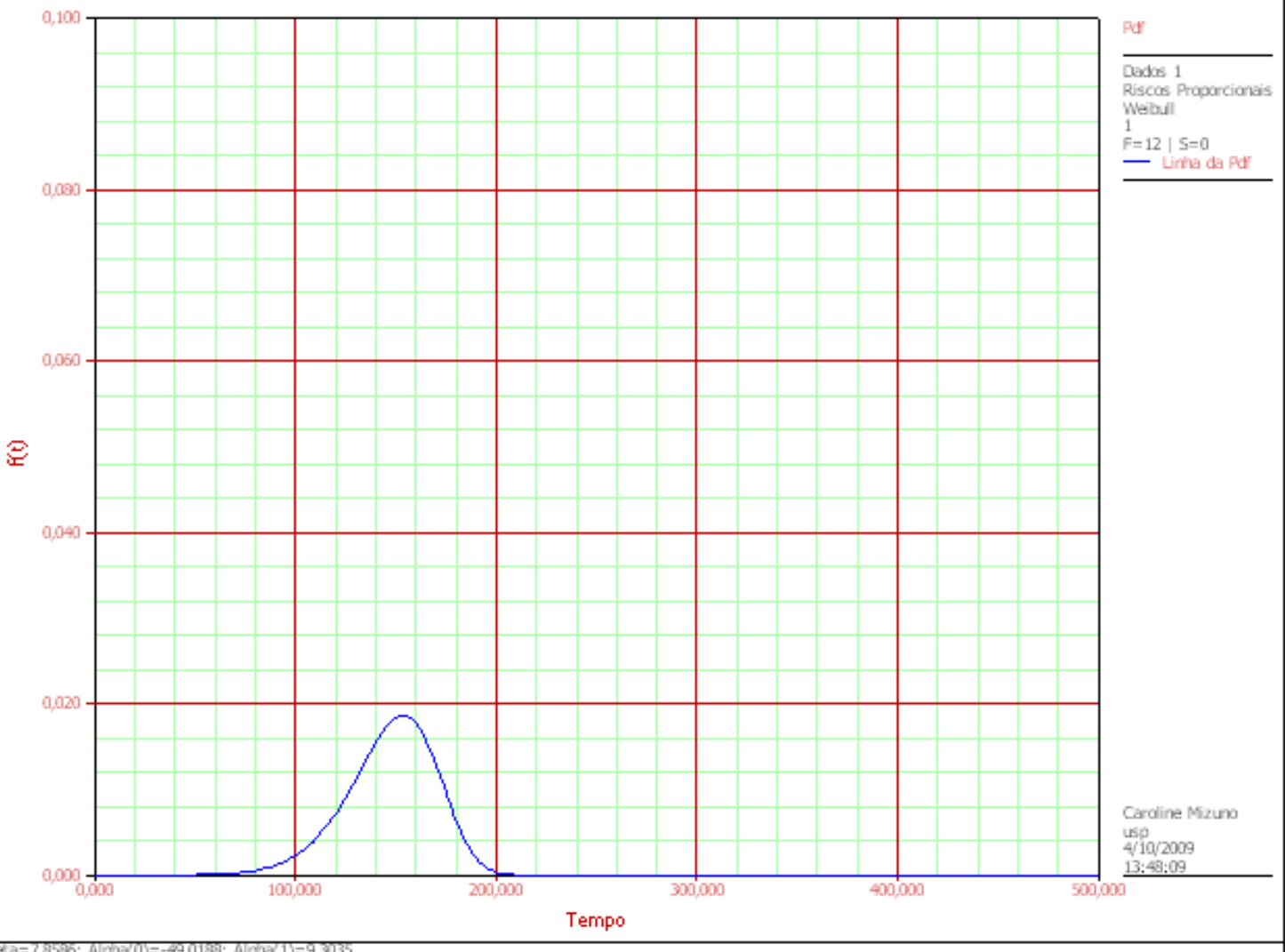

Figura 86 - Curva de função densidade de probabilidade para a peça modificada.

Na Figura 87, observa-se a taxa de falha no tempo. 


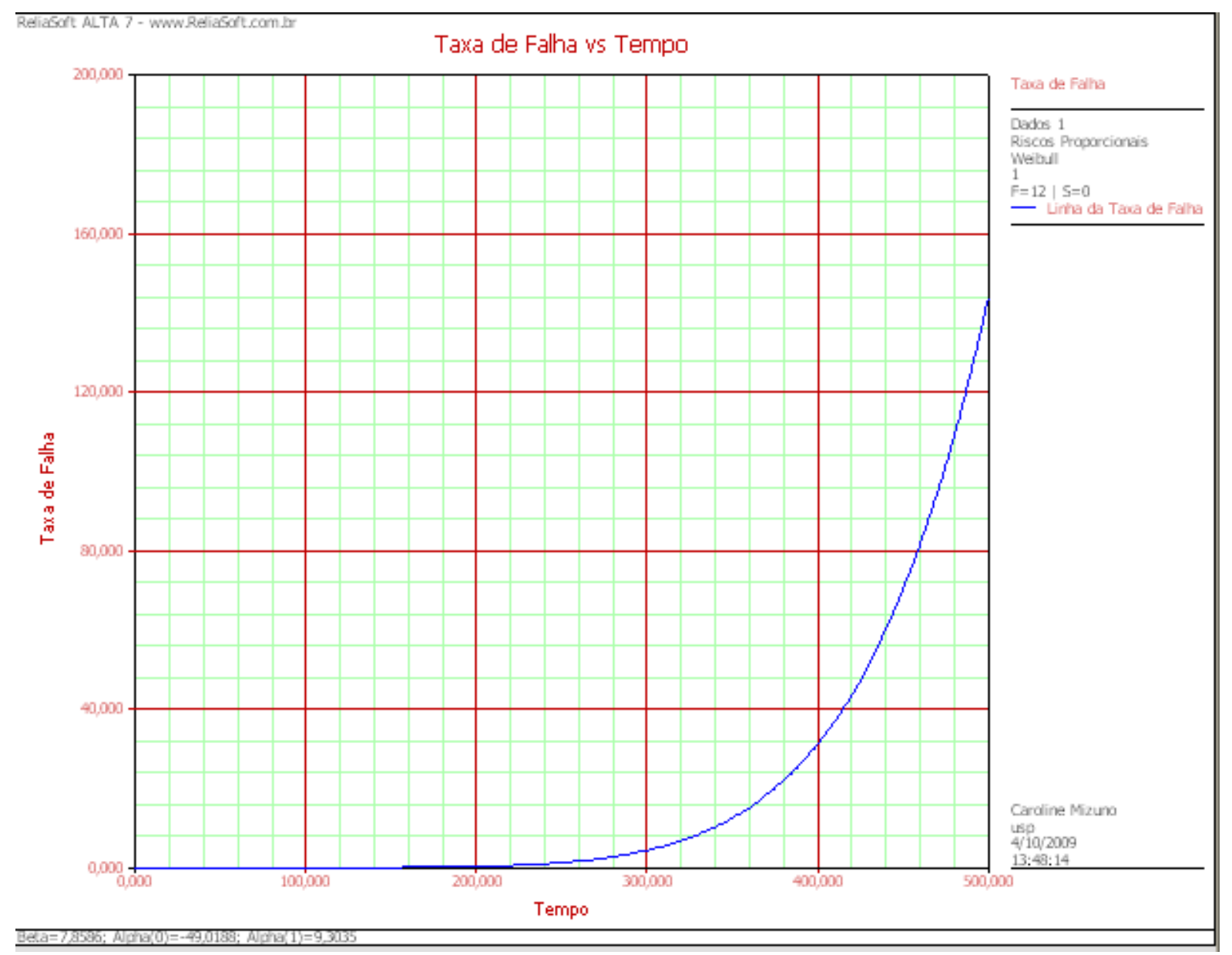

Figura 87 - Taxa de falha da peça modificada.

5.7.4 Comparativo entre dados de garantia e dados do ensaio de vida acelerado por lama

Para calcular o fator de aceleração gerado pelo teste de contaminação externa com lama, primeiramente deve-se buscar a equivalência do tempo do teste com a quilometragem que o mesmo significa.

Para isso deve-se salientar que devido à localização do retentor em estudo ser no eixo de saída da transmissão, a cada unidade de ciclo RPM (rotação por minuto) equivale a uma volta da roda do caminhão.

Sendo o tipo de caminhão em estudo considerado de grande porte, pois se trata de caminhão do tipo canavieiro, considera-se como medida média do diâmetro do pneu o valor de $80 \mathrm{~cm}$, e calcula-se a distância percorrida por uma volta desse pneu utilizando a fórmula de comprimento para um circulo conforme equação (13). 


$$
C=2 \pi^{*} r
$$

C > comprimento percorrido

$2 \pi>$ constante de cálculo

$r>$ raio da circunferência

Com a aplicação da fórmula acima para um diâmetro de $80 \mathrm{~cm}$, o comprimento será de aproximadamente $2510 \mathrm{~mm}$, ou seja, 0,00251 km.

Sendo o ciclo de ensaio utilizado conforme Tabela 13, para cada 24 horas de teste tem-se 20 horas à $2200 \mathrm{rpm}$, ou seja, percorre-se $0,00251^{\star} 2200^{\star} 20$, ou seja 1104 $\mathrm{km}$.

Utilizando-se a relação de quilometragem por hora de ensaio através de divisão de 1104 por 24 , chegando ao resultado de $46 \mathrm{~km}$ rodados/hora de teste.

Com a relação acima é construída a Tabela 17, onde observa-se para os testes realizados, os tempos de falha e a quilometragem equivalente para os mesmos.

Tabela 17: Tabela com ciclagem utilizada nos testes de durabilidade acelerada

\begin{tabular}{|c|c|c|c|c|c|c|}
\hline Teste \# & Peça & Tipo & Inicio & Término & $\begin{array}{c}\text { Duração } \\
\text { [hr.] }\end{array}$ & Duração [km] \\
\hline 1 & \multirow{12}{*}{ 戛 } & \multirow[t]{6}{*}{ Lama } & 4/ago/08 & 5/ago/08 & 24 & 1104 \\
\hline 2 & & & 6/ago/08 & 7/ago/08 & 12 & 552 \\
\hline 3 & & & 11/ago/08 & 12/ago/08 & 15 & 690 \\
\hline 4 & & & 12/ago/08 & 13/ago/08 & 17 & 782 \\
\hline 5 & & & 18/ago/08 & 19/ago/08 & 26 & 1196 \\
\hline 6 & & & 20/ago/08 & 22/ago/08 & 32 & 1472 \\
\hline 7 & & \multirow[t]{6}{*}{ Durabilidade } & 6/out/08 & 8/out/08 & 62 & 2852 \\
\hline 8 & & & 9/out/08 & 13/out/08 & 98 & 4508 \\
\hline 9 & & & 14/out/08 & 19/out/08 & 112 & 5152 \\
\hline 10 & & & 20/out/08 & 27/out/08 & 160 & 7360 \\
\hline 11 & & & 28/out/08 & 3/nov/08 & 156 & 7176 \\
\hline 12 & & & 4/nov/08 & 12/nov/08 & 184 & 8464 \\
\hline 13 & \multirow{12}{*}{ 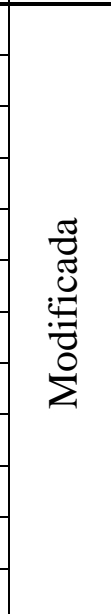 } & \multirow[t]{6}{*}{ Lama } & 10/ago/09 & 12/ago/09 & 42 & 1932 \\
\hline 14 & & & 17/ago/09 & 19/ago/09 & 51 & 2346 \\
\hline 15 & & & 24/ago/09 & 27/ago/09 & 39 & 1794 \\
\hline 16 & & & 31/ago/09 & 2/set/09 & 48 & 2208 \\
\hline 17 & & & $8 /$ set/09 & 10/set/09 & 45 & 2070 \\
\hline 18 & & & $14 /$ set/09 & $16 /$ set/09 & 53 & 2438 \\
\hline 19 & & \multirow[t]{6}{*}{ Durabilidade } & 03/aug/09 & 12/aug/09 & 126 & 5796 \\
\hline 20 & & & 06/aug/09 & 14/aug/09 & 110 & 5060 \\
\hline 21 & & & 11/aug/09 & 21/aug/09 & 168 & 7728 \\
\hline 22 & & & 17/aug/09 & 25/aug/09 & 115 & 5290 \\
\hline 23 & & & 19/aug/09 & 2/set/09 & 179 & 8234 \\
\hline 24 & & & 24/aug/09 & $3 /$ set/09 & 158 & 7268 \\
\hline
\end{tabular}


Os valores da Tabela 17 foram calculados sem a utilização do fator de aceleração, apenas foi utilizada a relação para transformar a unidade dos dados de horas para quilômetros.

O software Alta 7 calcula o fator de aceleração através da relação entre dados de vida com solicitação de uso e dados de vida com o nível de solicitação. [RELIASOFT. User's Guide ReliaSoft's Alta 7 Pro (1997)].

Nesse estudo, os dados são originários dos testes realizados com a peça atual, onde, os dados de vida com solicitação de uso serão os resultados dos testes de durabilidade, e os dados de vida com nível de solicitação serão os dados resultantes do teste de contaminação com lama.

Assim o fator de aceleração calculado é 46,12 , como pode ser observado na Figura 88.

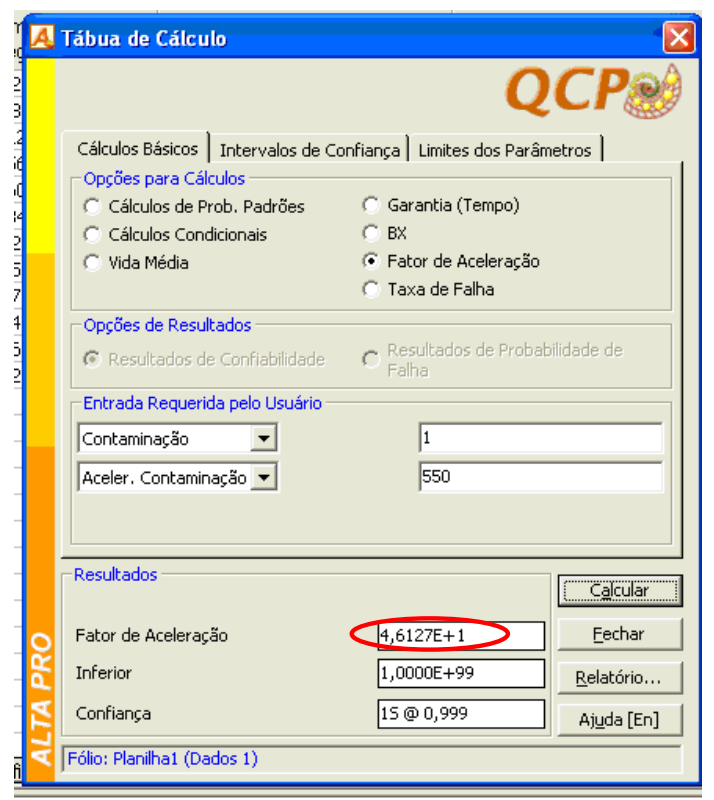

Figura 88 - Fator de aceleração gerado pelo teste.

O fator de aceleração também foi calculado utilizando o valor de garantia em quilometragem para as peças que vazaram devido à contaminação externa e os resultados obtidos, transformados de tempo para quilometragem, nos testes de lama com a peça atual, isso porque tem-se o mesmo modo de falha para ambos.

Para esse cálculo foram utilizados valores médios, ou seja, calculou-se a média dos resultados dos teses 1 à 6, chegando ao valor de 966 quilômetros, e a média das peças que retornaram de garantia, chegando à 45216 quilômetros. Para calcular o 
fator de aceleração foi realizada a divisão de 45216 por 966 chegando ao valor de 46,81 .

Observa-se que os valores para o fator de aceleração obtidos pelos dois tipos de cálculo foram próximos e que a diferença entre eles pode ser explicada pelo fato de que pelo software a relação é buscada entre os dados de teste de durabilidade e de contaminação externa, e, para a segunda maneira, foram utilizados dados de garantia e de teste de contaminação externa, logo pode-se ter uma diferença entre a relação do teste de durabilidade e a vida do produto.

Para os demais cálculos à realizar utilizar-se-á como fator de aceleração o valor de 46,81 .

Com o fator de aceleração acima calcula-se a equivalência em quilômetros para a peça modificada. Para isso, multiplica-se o fator de aceleração 46,81 pelos resultados obtidos em teste de lama na peça modificada, e os resultados podem ser observados na Tabela 18.

Tabela 18: Tabela com ciclagem utilizada nos testes de durabilidade acelerada

\begin{tabular}{|c|c|c|c|c|r|}
\hline Teste \# & Inicio & Término & $\begin{array}{c}\text { Duração } \\
{[\mathrm{hr} .]}\end{array}$ & $\begin{array}{c}\text { Duração } \\
{[\mathrm{km}]}\end{array}$ & $\begin{array}{c}\text { Duração com } \\
\text { fator de } \\
\text { aceleração }[\mathrm{km}]\end{array}$ \\
\hline 13 & $10 / \mathrm{ago} / 09$ & $12 / \mathrm{ago} / 09$ & 42 & 1932 & 90436,92 \\
\hline 14 & $17 / \mathrm{ago} / 09$ & $19 / \mathrm{ago} / 09$ & 51 & 2346 & 109816,26 \\
\hline 15 & $24 / \mathrm{ago} / 09$ & $27 / \mathrm{ago} / 09$ & 39 & 1794 & 83977,14 \\
\hline 16 & $31 / \mathrm{ago} / 09$ & $2 / \mathrm{set} / 09$ & 48 & 2208 & 103356,48 \\
\hline 17 & $8 / \mathrm{set} / 09$ & $10 / \mathrm{set} / 09$ & 45 & 2070 & 96896,7 \\
\hline 18 & $14 / \mathrm{set} / 09$ & $16 / \mathrm{set} / 09$ & 53 & 2438 & 114122,78 \\
\hline
\end{tabular}

Observa-se que a média de duração com fator de aceleração em quilômetros é de 99767.

$\mathrm{Na}$ Tabela 19, pode-se verificar o comparativo para os resultados obtidos em cálculo de confiabilidade para dados de ensaios com a peça atual e ensaios com a peça modificada, utilizando o fator de aceleração. Os resultados de confiabilidade observados foram calculados pelo software Alta 7. 
Os dados inseridos conforme observado nas Figuras 69 e 79, ou seja, dados dos ensaios com a peça atual e dados dos ensaios com a peça modificada, foram os valores utilizados para os cálculos das confiabilidades observadas.

Tabela 19: Tabela comparativa com os resultados de confiabilidade para dados de testes com peça atual e modificada.

Ensaios em peça atual
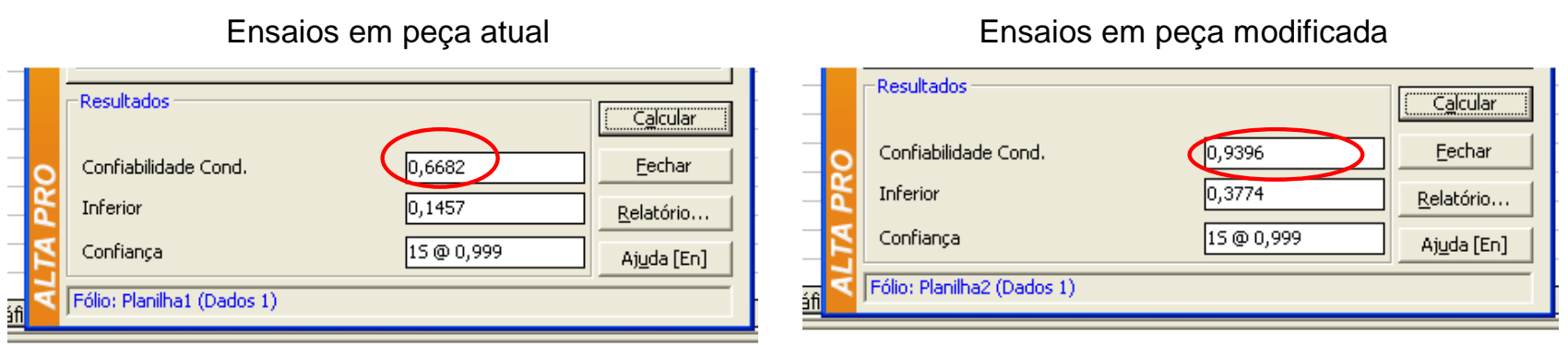

Como se pode verificar o valor de confiabilidade esperado de $99,99 \%$ enunciado no início do estudo não foi obtido com a alteração na peça, pois chegamos ao valor de $93,96 \%$.

Se pode observar que se aperfeiçoou a confiabilidade do item de $66,82 \%$ para os 93,96\%, ou, em cálculos com o fator de aceleração essa melhora foi de uma média de $45218 \mathrm{~km}$ para $99767 \mathrm{~km}$.

No gráfico a Figura 89 observam-se as curvas para os dados de garantia e para os dados dos ensaios nas peças com versão atual e versão modificada em um mesmo gráfico para a comparação dos betas ( $\beta$ ), ou seja, o parâmetro de forma que caracteriza a curva Weibull.

Pode-se observar que a curva para os dados de garantia apresenta $\beta$ igual a 1,24, para a curva referente aos resultados dos testes acelerados com e sem lama na peça atual tem-se $\beta$ igual a 3,47 e na curva referente aos resultados dos testes acelerados com e sem lama na peça modificada tem-se $\beta$ igual 7,86.

Devido à característica do parâmetro $\beta$ na curva de Weibull ser relacionado à forma da curva e todos serem positivos e maiores que 1, conclui-se que todas as curvas apresentam taxa de falhas crescente ou seja, as curvas caracterizam fatos localizados na mesma fase da curva da banheira mostrada na Figura 3, ou seja, falhas por desgaste. 
$O$ fato de os $\beta$ 's das curvas referentes aos ensaios acelerados tanto para a peça atual quanto para a peça modificada, serem maiores que o $\beta$ da curva referente aos dados de garantia demonstra que o desgaste obtido através dos ensaios acelerados se apresenta com crescimento constante durante a vida e abrupto no final da vida, se comparado com o encontrado nos dados de garantia.

Deve-se ressaltar que um dos motivos de observarmos $\beta$ 's diferentes para as curvas de dados de garantia, dado dos ensaios nas peças com versão atual e versão modificada se deve ao envelhecimento da borracha e ao fator de aceleração, pois mesmo utilizando contaminação e temperatura controladas durante os testes, temos uma grande variação dessas características durante a utilização do produto, refletindo nos dados de garantia.

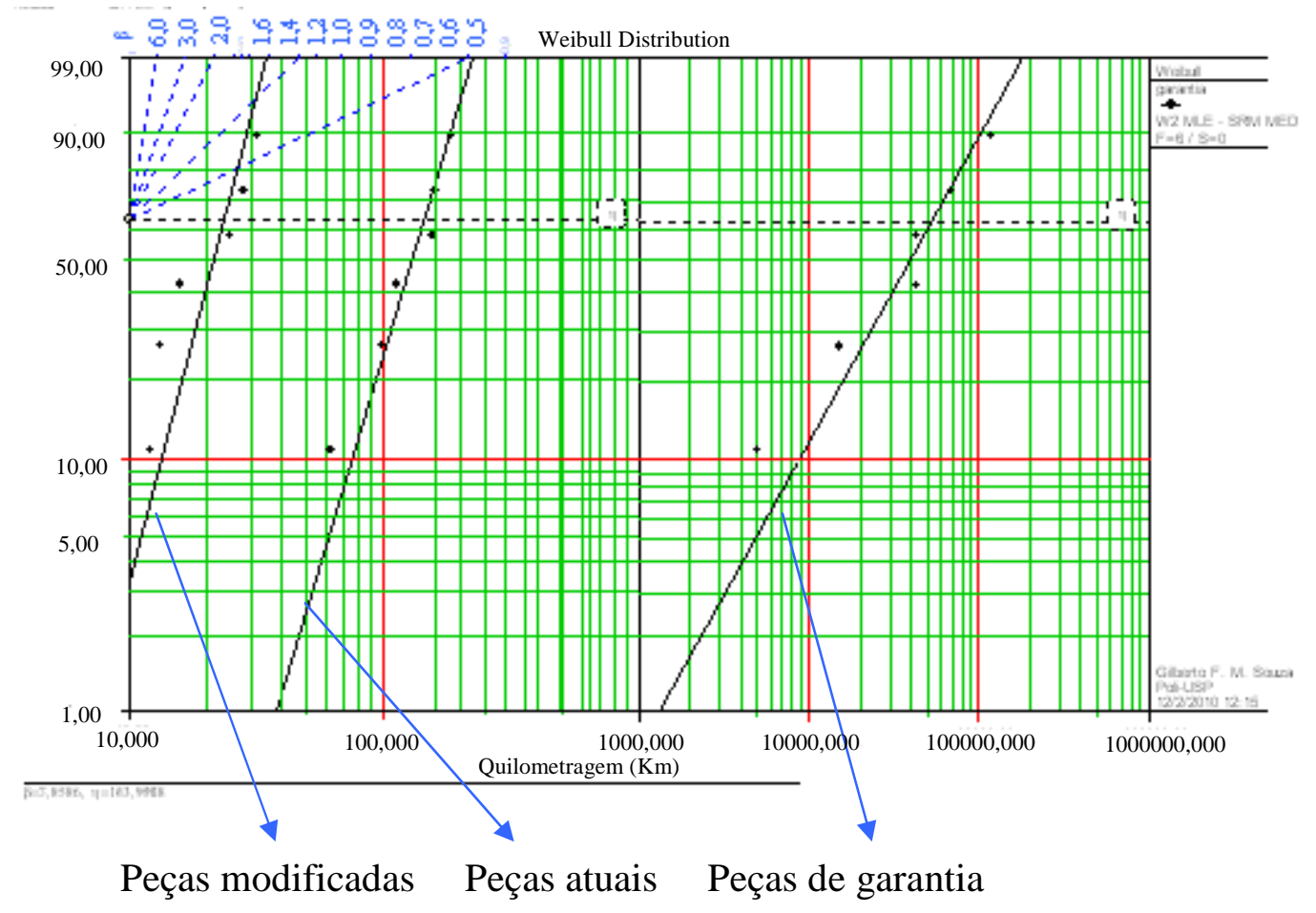

Figura 89 - Gráfico comparativo com curvas de confiabilidade para dados de garantia, dados de ensaios em peça atual e ensaios em peça modificada.

De acordo com Pinto e Xavier (2002) tem-se que na curva para os dados de garantia, que apresenta $\beta$ igual a 1,24, observam-se falhas que dependem do tempo de uso, o que implica em desgaste prematuro sendo que as falhas ocorrem dentro 
da vida projetada e mecanicamente as falhas que caem nesta classe são: fadiga em baixos ciclos, a maior parte das falhas de mancais, erosão e corrosão.

Já para a curva referente aos resultados dos testes acelerados com e sem lama na peça atual, com $\beta$ igual a 3,47 tem-se falhas por desgaste, de corrosão ou de ultrapassagem de um patamar de deformação plástica, o que também implica em desgaste prematuro e estas falhas ocorrem dentro da vida e as falhas que caem nesta classe, assim como para os dados de garantia, são: fadiga em baixos ciclos, a maior parte das falhas de mancais, erosão e corrosão.

E finalmente, na curva referente aos resultados dos testes acelerados com e sem lama na peça modificada, tem-se $\beta$ igual 7,86, o que implica em idade avançada ou fim de vida, com desgaste rápido a partir de certo ponto ou tempo de uso, onde a falha típica é por corrosão, por fadiga, por variação e/ou perda das propriedades físicas e/ou químicas dos materiais, material com revestimento de cerâmica, erosão e/ou fratura sem deformação plástica prévia

Ainda segundo Pinto e Xavier (2001) tem-se que o fato de o $\beta$ da curva referente aos ensaios acelerados com as peças modificadas ser o maior demonstra que as peças modificadas apresentam o desgaste em um intervalo de tempo que tende a zero, e em um pequeno instante a mais, um desgaste abrupto, originando a falha.

$\mathrm{Na}$ Figura 90 observa-se um comparativo da confiabilidade para os dados de garantia, dados de ensaios, já utilizando o fator de aceleração, em peça atual e ensaios em peça modificada.

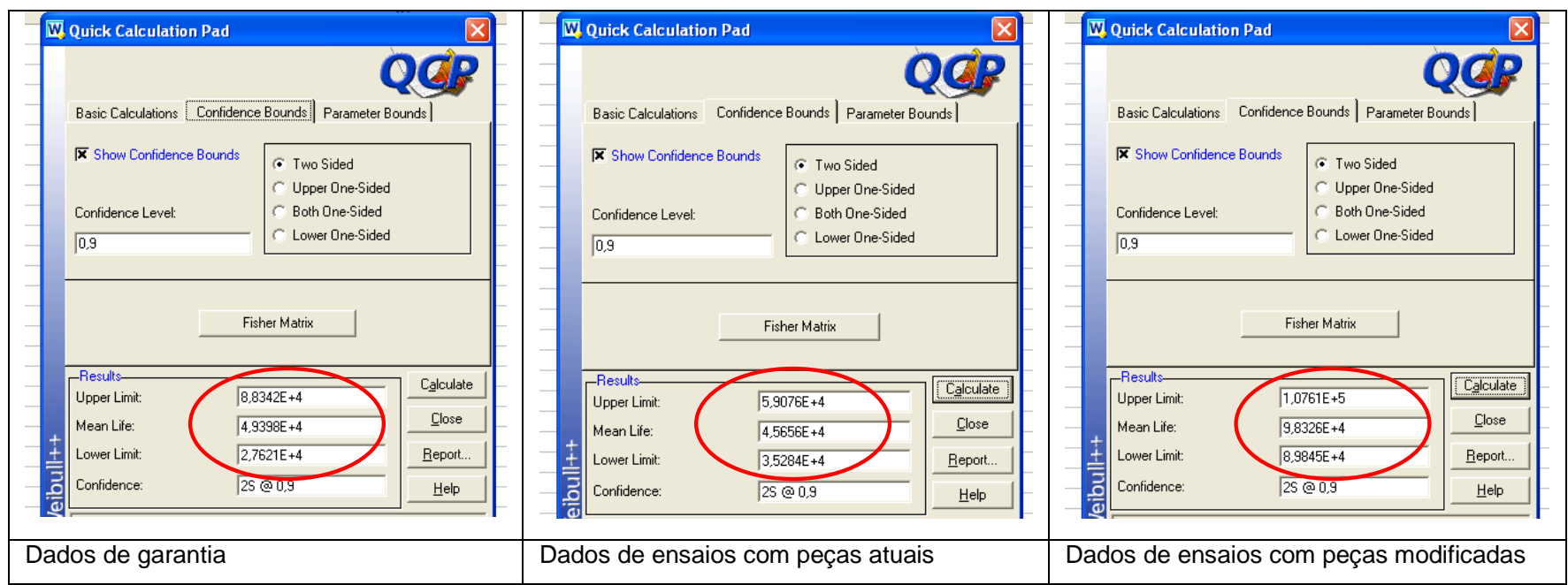

Figura 90 - Comparativo dos cálculos de tempo médio até a falha para os dados de garantia, dados de ensaios em peça atual e ensaios em peça modificada. 
Dos dados da Figura 90 observa-se que o intervalo de confiança para a quilometragem média até a falha é com um nível de confiança de $90 \%$ é:

- dados de garantia: 27621 à 88342 km;

- dados de ensaio com a peça atual: 35284 à 59076 km;

- dados de ensaio com a peça modificada: 89845 à $107610 \mathrm{~km}$.

Nos dados acima já esta considerado o fator de aceleração. 


\section{CONCLUSÃO}

Esse trabalho teve como objetivo exemplificar o processo de melhoria de um produto através da utilização de estudos de confiabilidade somados à técnica de análise do valor, o qual foi atingido através das passagens do Capítulo 5.

Esses métodos podem auxiliar a planejar e garantir que os requisitos dos clientes sejam atendidos na concepção do no produto, pois sendo utilizados no início do desenvolvimento de um item similar faz com que o item novo tenha uma maior confiabilidade.

Durante esse trabalho, realizou-se análise de confiabilidade de um item de produção através de seus dados de retorno em garantia, na seqüência aplicou-se a técnica de análise de valor para selecionar o item a ser melhorado no produto.

Para verificar e eficácia da melhoria realizada, foram utilizados testes acelerados com e sem lama nas duas versões do produto.

Os ensaios acelerados indicaram o mesmo mecanismo de falha que o observado nas peças de garantia, ou seja, falha por desgaste excessivo gerado por atrito com contaminação externa, evidenciando que o mecanismo de degradação foi corretamente selecionado.

Adicionalmente, a execução deste tipo de ensaio exige a determinação de um princípio de extrapolação dos resultados obtidos nas condições aceleradas para as condições normais de uso, ou seja, uma forma de definir a confiabilidade na condição normal de uso a partir da estimativa de confiabilidade obtida experimentalmente. Para a extrapolação mencionada utilizou-se 0 fator de aceleração obtido nos ensaios.

A extrapolação dos resultados obtidos nos ensaios acelerados para as condições normais de uso apresentou um aumento significativo na confiabilidade, de 66,82\% para os $93,96 \%$, comparando-se a confiabilidade do produto corrente e do produto melhorado.

Durante a execução da análise de confiabilidade com dados de garantia do produto em estudo observou-se ser de fundamental importância analisar os dados considerando a censura dos produtos que não falharam no período de garantia, e que se deve conhecer com precisão o número de produtos fabricados, os tempos 
até a falha e o número de produtos que falharam, para se ter um estudo com alta credibilidade.

Durante a execução do estudo, verificou-se que na execução de um estudo de confiabilidade, mais relevante que os cálculos estatísticos que se deve realizar, a maneira de trabalhar, planejar, coletar informações, assim como a visão sistêmica do produto em estudo, são pontos relevantes no processo.

Observa-se também que o tema confiabilidade é bem recente, década de 70 aproximadamente, logo se tem muito a explorar sobre o mesmo assim como aumentar sua utilização em grandes indústrias.

Para o método proposto, ficou demonstrado através do exemplo utilizado que o mesmo auxilia no aperfeiçoamento de produto, podendo ser utilizado em muitos produtos nas mais diversas indústrias. Prova disso foi o resultado verificado no aperfeiçoamento do exemplo realizado, onde os cálculos com o fator de aceleração mostraram um aumento na quilometragem de ocorrência da falha, melhoria de uma média de $45216 \mathrm{~km}$ para $99767 \mathrm{~km}$.

Ao longo do desenvolvimento desta pesquisa verificou-se que a confiabilidade de sistemas mecânicos que utilizam borracha é um estudo complexo e que até o presente momento não existem grandes quantidades de literaturas ou normas sobre 0 assunto.

Considerando as conclusões anteriores e visando complementar o trabalho exposto, sugere-se as seguintes recomendações para trabalhos futuros:

i) Avaliação da confiabilidade do processo de manufatura dos retentores a fim de verificar a influencia funcional em defeitos originados durante o processo de fabricação

ii) Além da variável analisada no presente estudo, referente à contaminação externa, poderiam ser avaliadas outras condições como, por exemplo, contaminação interna gerada por desgaste de componentes internos do sistema a ser vedado, ou a reação devido ao uso de óleos lubrificantes diferentes a serem vedados. 


\section{REFERENCIAS}

ASSOCIAÇÃO BRASILEIRA DE NORMAS TÉCNICAS NBR-12906,

Vedadores radiais de fluidos para veículos automotores - NBR, 1993.

BAZOVSKY, I. Reliability theory and practice 4 th ed. New Jersey: Prentice-Hall, Inc, 1965. (International series in engineering)

BILLINTON, R., ALLAN, R.N., Reliability Evaluation of Engineering Systems, England: The Bath Press, Avon, 1987, 349p.

BORGES, W.S.; COLOSIMO, E.A.; FREITAS, M.A. Métodos estatísticos e melhoria da qualidade: construindo confiabilidade em produtos São Paulo: ABE-Associação Brasileira de Estatística, 1996

CBV VEDAÇÕES. Catálogo Técnico, São Paulo, Brasil. Disponível em:

< http://www.vedacoes.com.br/catalogo/Retentor.pdf >Acesso em 18 maio 2009

COOPER, R.G.: EDGETT, S.J.; KLEINSCHMIDT, E.J. Portfolio Mangement for New Products, second edition, 2001

CROWE, D. \& FEINBERG A. Design for reliability, CRC Press, Washington, D.C., 2000.

CSILLAG, J. M. Análise do valor: metodologia do valor: engenharia do valor, Gerenciamento do valor, redução de custos, racionalização administrativa, 3.ed. São Paulo: Atlas, 1991, 303p.

CUEDRAS, C.M., CUEDRAS D., LAHLOU Y,. Principal directions of the general Pareto distribution with applications. JOURNAL OF STATISTICAL PLANNING AND INFERENCE. December 07 2004. Disponível em:

<http://www.sciencedirect.com/science?_ob=ArticleURL\&_udi=B6V0M-4DYVTPY$1 \& \_u s e r=10 \& \_r d o c=1 \& \_f m t=\& \_o r i g=s e a r c h \& \_s o r t=d \& \_d o c a n c h o r=\& v i e w=c \& \_s e a r c$ 
hStrld=935456607\&_rerunOrigin $=$ google\&_acct $=$ C000050221 \&_version $=1$ \&_urlVersi on $=0 \&$ \&userid $=10 \& \mathrm{md} 5=\mathrm{ae} 5105 \mathrm{~d} 7 \mathrm{~b} 8 \mathrm{eb} 78 \mathrm{a} 2 \mathrm{bb} 1 \mathrm{a} 2 \mathrm{~b} 6 \mathrm{a} 41$ eefbb4>Acesso em 18 maio 2009

DEUTSCHES INSTITUT FÛR NORMUNG DIN 3760 - Rotary shaft lip type seals 1983

DEUTSCHES INSTITUT FÛR NORMUNG DIN 1367-1 - Seal Wires of Galvanized Steel Wire - 1974

DEUTSCHES INSTITUT FÛR NORMUNG DIN 19541 - Trap seals for special uses Requirements and test methods - 2004

DEUTSCHES INSTITUT FÛR NORMUNG DIN EN 14840 - Joint fillers and sealants Test methods for preformed joint seals; German version EN 14840:2005

DEUTSCHES INSTITUT FÛR NORMUNG DIN 51524 - Pressure fluids; hydraulic oils; HLP hydraulic oils; minimum requirements - 2006

DEUTSCHES INSTITUT FÛR NORMUNG DIN EN ISO 15783 - Seal-less rotodynamic pumps - Class II - Specification (ISO 15783:2002); German version EN ISO 15783:2003

DEUTSCHES INSTITUT FÛR NORMUNG DIN ISO 8791-4 - Paper and board Determination of roughness/smoothness (air leak methods) - Part 4: Print-surf method (ISO/DIS 8791-4:2006)

DELLARETTI, O. F. As sete ferramentas do planejamento da qualidade, Fundação Cristiano Ottoni, Escola de Engenharia da UFMG, 1996

DENSON W. The History of Reliability Prediction, IEEE Transaction on Reliability, Vol 47, 321 -328, 1998. 
Transaction on Reliability, Vol 47, 379 - 389, [S.I.], 1998.

ESTADOS UNIDOS. DEPRATMENT OF COMMERCE RADC-TR-58-111: RADC Rome Air Development Center - Reliability notebook New York: 1959 (Astia document No. AD-148868)

ESTADOS UNIDOS. DEPARTMENT OF DEFFENCE MIL-HDBK-338: RELIABILITY DESIGN HANDBOOK Washington: 1950

FISHER, R. A. On an absolute criterion for fitting frequency. Messeng. Math., v.41, p.155-160, 1912.

FREITAS, M. A, COLOSIMO, E. A. Confiabilidade: análise de tempo de falha e testes de vida acelerados, Belo Horizonte: Fundação Cristiano Ottoni, Escola de Engenharia da UFMG, 1997, 326p.

GUIDA, M., PULCINI, G. Automotive reliability inference based on past data and technical knowledge, Reliability Engineering and System Safety 76 (2002) 129-137.

HELMAN, H., ANDERY, P.R.P. Análise de Falhas (Aplicação dos métodos de FMEA e FTA), Belo Horizonte, MG: Fundação Cristiano Ottoni, Escola de Engenharia da UFMG, 1995

IRESON, G.; CLYDE F. COOMBS; JR., RICHARD Y. MOSS. Handbook of reliability engineering and management, $2^{\circ}$ edição, McGraw- Hill Companies, Estados Unidos, 1995.

ISHIKAWA, K. TQC - total quality control; estratégia e administração da qualidade. São Paulo, SP: IMCl, $1986.220 \mathrm{p}$.

JURAN, J. M. Planejando para a Qualidade, São Paulo: Pioneira,1992, 394p.

JURAN, J M.. A qualidade desde o projeto; novos passos para o planejamento da qualidade em produtos e serviços. São Paulo, SP: Pioneira, 2001. 551p. 
KAMINSKI, P. C. Desenvolvendo Produtos com Planejamento, Criatividade e Qualidade, Livros Técnicos e Científicos SA. ISBN 85-216-1200-1. 2000. LAFRAIA, J.R.B. Manual de Confiabilidade, Mantenabilidade e Disponibilidade. Editora. Qualitymark, Petrobrás, Rio de Janeiro, 2001.

LEITCH, R. Reliability Analysis for Engineering. Oxford Press, New York, 1995.

LEME, E C. Aspectos da distribuição de pareto no problema de ajustamento de distribuições a dados alterados. Universidade de São Paulo - Instituto de Ciências Matemáticas de São Carlos, 1985.

MAJESKE, K.D. A Mixture model for automobile warranty data, Reliability Engineering and System Safety 81 (2003) 71-77.

MANN, N. R.; SCHAFER, R.E.; SINGPURWALLA, N.D. Methods for statistical analysis of reliability and life data New York: John Wiley \& Sons, Inc, 1974 (Wiley Series in Probability and Mathematical Statistics

McCORMICK, N.J. Reliability and Risk Analysis New York; Academic Press. 1981. KALBFLEISCH, J.D.; PRENTICE, R.L. The Statistical Analysis of Failure Time Data. $2^{\text {nd }}$ ed. New Jersey : John Wiley \& Sons, Inc,. 2002 (Wiley series in probability and statistics)

MEEKER, W. Q. \& NELSON, W. Optimum accelerated life tests for Weibull and extreme value distribution and censored data, IEEE Transaction on Reliability, vol 24, 1975.

MEEKER, W. Q. \& ESCOBAR L. A. Pitfalls of Accelerated Testing, IEEE Transaction on Reliability, vol. 47, 1998.

MEEKER, W. Q. JR. \& ESCOBAR, L. A., Statistical Methods for Reliability Data, Wiley, New York, 1999. 
MOHAMMADI, B., REDONT, P., Improving the identification of general Pareto fronts by global optimization. COMPTERS RENDUS MATHEMATIQUE. February 12 2009. Disponível em:

<http://www.sciencedirect.com/science?_ob=ArticleURL\&_udi=B6V0M-4DYVTPY$1 \& \_$user $=10 \& \_r d o c=1 \& \_f m t=\& \_o r i g=s e a r c h \& \_s o r t=d \& \_d o c a n c h o r=\& v i e w=c \& \_s e a r c$ hStrld=935458749\&_rerunOrigin $=$ google \&_acct $=$ C000050221 \&_version $=1 \&$ _urlVersi on $=0 \&$ \&userid $=10 \& \mathrm{md} 5=5 \mathrm{e} 692 \mathrm{f} 3 \mathrm{f} 57731 \mathrm{~d} 5850925 \mathrm{f} 4 \mathrm{~d} 5 \mathrm{de} 39 \mathrm{~d} 4 \mathrm{~b}>$ Acesso em: 10 maio 2009

MOURA. E. C. A Method to Estimate the Acceleration Factor for

Subassemblies. IEEE Transactions on Reliability, Vol 41, No3, 1992.

LYNN, H. PROVIDING A TURN FOR THE BETTER. NASA TECHNICAL REPORTS - NTRS, 2004

Disponível em:

<http://ntrs.nasa.gov/search.jsp?R=991457\&id=3\&qs=Ntt\%3Dcause\%252Bchallenge r\%252Baccident\%26Ntk\%3Dall\%26Ntx\%3Dmode\%2520matchall\%26N\%3D0\%26Ns \%3DHarvestDate\%257c1>. Acesso em: 22 mar. 2009

NELSON, W. Accelerated Testing: Statistical Models, Test Plans, Data Analyses. Wiley, New York, 1990.

NELSON, W. A Bibliography of Accelerated Test Plans, IEEE Transaction on Reliability, Vol 54, No 2, 2005.

NELSON, W. Applied life data analysis New York: Jonh Wiley \& Sons, Inc., 1936 (Wiley series in probability and statistics)

$\mathrm{OH}$, Y.S., BAI, D.S. Field data analyses with additional after-warranty failure data, Reliability Engineering and System Safety 72 (2001) 1-8

PERROW, C. Normal Accidents: Living with High Risk Technologies, Princeton University Press, 1999. 
PINTO, A. K; XAVIER, J. A. N. Manutenção: Função estratégica. $4^{\circ}$ ed. Rio de Janeiro. Qualitymark Ed. 2001

RAI, B., SINGH, N., Hazard rate estimation from incomplete and unclean warranty data, Reliability Engineering and System Safety 81 (2003) 79-92.

RAMAKUMAR, R. Engineering Reliability: Fundamentals and Applications, Oklahoma: Prentice- Hall International, 482p. 1993.

RELIASOFT CORPORATION. User's Guide ReliaSoft's Weibull++ Version 6, [S.I.], 1997

RELIASOFT CORPORATION. User's Guide ReliaSoft's Alta 7 Pro, [S.I.], 2008

SABÓ. Catálogo Técnico, São Paulo, Brasil, 1998. Disponível em: <http://www.sabo.com.br/si/site/0708?idioma=portugues>Acesso em 18 maio 2009

SOUZA, G. F. M. Análise de Confiabilidade Aplicada ao Projeto de Sistemas Mecânicos, Apostila do curso, São Paulo, Brasil, 2003.

SILVA, C. L. Gestão Estratégica de Custos em Cadeias de Valor, VI Congresso Brasileiro de Custos, São Paulo, Universidade de São Paulo, 1999.

TERNINKO, J. Step-by-Step QFD - Customer-Driven Product Design, Florida: St.Lucie Press, 1997, 224p.

VDMA 24317 - Líquidos de pressão dificilmente inflamáveis, 2005

VDMA 24320 - Fluidos hidráulicos de rápida degradação biológica, 2005 
ZHAO, Y.X., et al., An approach for determining an appropriate assumed distribution of fatigue life under limited data, Reliability Engineering and System Safety 67 (2000) 1-7.

ZOU, T., et al., Reliability analysis of automotive body-door subsystem, Reliability Engineering and System Safety 78 (2002) 315-324. 
APÊNDICE A - Tabela 4 - Modos de falha dos dados de retorno

\begin{tabular}{|c|c|c|c|c|c|c|c|}
\hline peça\# & $\begin{array}{l}\begin{array}{l}\text { data do } \\
\text { retorno }\end{array} \\
\end{array}$ & Relatorio\# & $\begin{array}{l}\text { Nota fiscal } \\
\text { recebida\# }\end{array}$ & $\begin{array}{l}\text { quant.peças } \\
\text { recebidas } \\
\text { para analise }\end{array}$ & Cód & Conclusão & $\mathrm{KM}$ \\
\hline 1 & jan & 6 & 510 & 2 & 4 & Desgaste acentuado & 963 \\
\hline 2 & jan & 6 & 510 & 2 & 7 & $\begin{array}{l}\text { não apresentaram } \\
\text { problemas que } \\
\text { justificasse o } \\
\text { vazamento }\end{array}$ & 772 \\
\hline 3 & fev & 15 & 733 & 6 & 1 & Descolagem & 1437 \\
\hline 4 & fev & 15 & 733 & 6 & 5 & $\begin{array}{l}\text { impurezas na área de } \\
\text { vedação }\end{array}$ & 1424 \\
\hline 5 & fev & 15 & 733 & 6 & 6 & montagem inadequada & 1001 \\
\hline 6 & fev & 15 & 733 & 6 & 7 & $\begin{array}{l}\text { não apresentaram } \\
\text { problemas que } \\
\text { justificasse o } \\
\text { vazamento }\end{array}$ & 1001 \\
\hline 7 & fev & 15 & 733 & 6 & 7 & $\begin{array}{l}\text { não apresentaram } \\
\text { problemas que } \\
\text { justificasse o } \\
\text { vazamento }\end{array}$ & 1048 \\
\hline 8 & fev & 15 & 733 & 6 & 7 & $\begin{array}{l}\text { não apresentaram } \\
\text { problemas que } \\
\text { justificasse o } \\
\text { vazamento } \\
\end{array}$ & 1310 \\
\hline 9 & mar & 24 & 930 & 11 & 3 & $\begin{array}{l}\text { danificadas na } \\
\text { desmontagem } \\
\text { impossibilitado sua } \\
\text { análise }\end{array}$ & 1493 \\
\hline 10 & mar & 24 & 930 & 11 & 3 & $\begin{array}{l}\text { danificadas na } \\
\text { desmontagem } \\
\text { impossibilitado sua } \\
\text { análise } \\
\end{array}$ & 1612 \\
\hline 11 & mar & 24 & 930 & 11 & 3 & $\begin{array}{l}\text { danificadas na } \\
\text { desmontagem } \\
\text { impossibilitado sua } \\
\text { análise }\end{array}$ & 2071 \\
\hline 12 & mar & 24 & 930 & 11 & 3 & $\begin{array}{l}\text { danificadas na } \\
\text { desmontagem } \\
\text { impossibilitado sua } \\
\text { análise }\end{array}$ & 2297 \\
\hline 13 & mar & 24 & 930 & 11 & 5 & $\begin{array}{l}\text { impurezas na área de } \\
\text { vedação }\end{array}$ & 1703 \\
\hline 14 & mar & 24 & 930 & 11 & 5 & $\begin{array}{l}\text { impurezas na área de } \\
\text { vedação }\end{array}$ & 1944 \\
\hline 15 & mar & 24 & 930 & 11 & 5 & $\begin{array}{l}\text { impurezas na área de } \\
\text { vedação }\end{array}$ & 1944 \\
\hline 16 & mar & 24 & 930 & 11 & 6 & montagem inadequada & 1603 \\
\hline 17 & mar & 24 & 930 & 11 & 6 & montagem inadequada & 1603 \\
\hline 18 & Mar & 24 & 930 & 11 & 6 & montagem inadequada & 1612 \\
\hline
\end{tabular}


Continuação da Tabela 4 - Modos de falha dos dados de retorno

\begin{tabular}{|c|c|c|c|c|c|c|c|}
\hline 19 & Mar & 24 & 930 & 11 & 6 & montagem inadequada & 1800 \\
\hline 20 & abr & 29 & 1115 & 16 & 6 & $\begin{array}{l}\text { danificadas na } \\
\text { desmontagem } \\
\text { impossibilitado sua } \\
\text { análise } \\
\end{array}$ & 2634 \\
\hline 21 & abr & 29 & 1115 & 16 & 6 & $\begin{array}{l}\text { danificadas na } \\
\text { desmontagem } \\
\text { impossibilitado sua } \\
\text { análise } \\
\end{array}$ & 3050 \\
\hline 22 & abr & 29 & 1115 & 16 & 6 & $\begin{array}{l}\text { danificadas na } \\
\text { desmontagem } \\
\text { impossibilitado sua } \\
\text { análise } \\
\end{array}$ & 4549 \\
\hline 23 & abr & 29 & 1115 & 16 & 3 & $\begin{array}{l}\text { danificadas na } \\
\text { desmontagem } \\
\text { impossibilitado sua } \\
\text { análise }\end{array}$ & 4658 \\
\hline 24 & $a b r$ & 29 & 1115 & 16 & 2 & $\begin{array}{l}\text { deformações e riscos } \\
\text { na vedação }\end{array}$ & 2930 \\
\hline 25 & $a b r$ & 29 & 1115 & 16 & 2 & $\begin{array}{l}\text { deformações e riscos } \\
\text { na vedação }\end{array}$ & 3100 \\
\hline 26 & $a b r$ & 29 & 1115 & 16 & 2 & $\begin{array}{l}\text { deformações e riscos } \\
\text { na vedação }\end{array}$ & 3284 \\
\hline 27 & abr & 29 & 1115 & 16 & 5 & $\begin{array}{l}\text { impurezas na área de } \\
\text { vedação }\end{array}$ & 3200 \\
\hline 28 & $a b r$ & 29 & 1115 & 16 & 5 & $\begin{array}{l}\text { impurezas na área de } \\
\text { vedação }\end{array}$ & 3284 \\
\hline 29 & $a b r$ & 29 & 1115 & 16 & 5 & $\begin{array}{l}\text { impurezas na área de } \\
\text { vedação }\end{array}$ & 4243 \\
\hline 30 & $a b r$ & 29 & 1115 & 16 & 6 & montagem inadequada & 2406 \\
\hline 31 & $a b r$ & 29 & 1115 & 16 & 6 & montagem inadequada & 3525 \\
\hline 32 & $a b r$ & 29 & 1115 & 16 & 6 & montagem inadequada & 3525 \\
\hline 33 & $a b r$ & 29 & 1115 & 16 & 6 & montagem inadequada & 4078 \\
\hline 34 & $a b r$ & 29 & 1115 & 16 & 7 & $\begin{array}{l}\text { não apresentaram } \\
\text { problemas que } \\
\text { justificasse o } \\
\text { vazamento }\end{array}$ & 2479 \\
\hline 35 & $a b r$ & 29 & 1115 & 16 & 7 & $\begin{array}{l}\text { não apresentaram } \\
\text { problemas que } \\
\text { justificasse o } \\
\text { vazamento } \\
\end{array}$ & 4078 \\
\hline 36 & mai & 42 & 1254 & 18 & 3 & $\begin{array}{l}\text { danificadas na } \\
\text { desmontagem } \\
\text { impossibilitado sua } \\
\text { análise } \\
\end{array}$ & 4780 \\
\hline 37 & mai & 42 & 1254 & 18 & 3 & $\begin{array}{l}\text { danificadas na } \\
\text { desmontagem } \\
\text { impossibilitado sua } \\
\text { análise } \\
\end{array}$ & 4868 \\
\hline 38 & mai & 42 & 1254 & 18 & 3 & $\begin{array}{l}\text { danificadas na } \\
\text { desmontagem } \\
\text { impossibilitado sua } \\
\text { análise }\end{array}$ & 4987 \\
\hline 39 & mai & 42 & 1254 & 18 & 3 & \begin{tabular}{|l|} 
danificadas na \\
desmontagem \\
impossibilitado análise
\end{tabular} & 8155 \\
\hline
\end{tabular}


Continuação da Tabela 4 - Modos de falha dos dados de retorno

\begin{tabular}{|c|c|c|c|c|c|c|c|}
\hline 40 & mai & 42 & 1254 & 18 & 1 & Descolagem & 4992 \\
\hline 41 & mai & 42 & 1254 & 18 & 4 & desgaste acentuado & 4987 \\
\hline 42 & mai & 42 & 1254 & 18 & 5 & $\begin{array}{l}\text { impurezas na área de } \\
\text { vedação }\end{array}$ & 5000 \\
\hline 43 & mai & 42 & 1254 & 18 & 5 & $\begin{array}{l}\text { impurezas na área de } \\
\text { vedação }\end{array}$ & 9747 \\
\hline 44 & mai & 42 & 1254 & 18 & 6 & montagem inadequada & 4952 \\
\hline 45 & mai & 42 & 1254 & 18 & 6 & montagem inadequada & 4952 \\
\hline 46 & mai & 42 & 1254 & 18 & 6 & montagem inadequada & 4981 \\
\hline 47 & mai & 42 & 1254 & 18 & 6 & montagem inadequada & 4997 \\
\hline 48 & mai & 42 & 1254 & 18 & 6 & montagem inadequada & 9625 \\
\hline 49 & mai & 42 & 1254 & 18 & 6 & montagem inadequada & 10535 \\
\hline 50 & mai & 42 & 1254 & 18 & 6 & montagem inadequada & 10535 \\
\hline 51 & mai & 42 & 1254 & 18 & 7 & $\begin{array}{l}\text { não apresentaram } \\
\text { problemas que } \\
\text { justificasse o } \\
\text { vazamento }\end{array}$ & 4981 \\
\hline 52 & mai & 42 & 1254 & 18 & 7 & $\begin{array}{l}\text { não apresentaram } \\
\text { problemas que } \\
\text { justificasse o } \\
\text { vazamento }\end{array}$ & 8921 \\
\hline 53 & mai & 42 & 1254 & 18 & 7 & $\begin{array}{l}\text { não apresentaram } \\
\text { problemas que } \\
\text { justificasse o } \\
\text { vazamento }\end{array}$ & 9657 \\
\hline 54 & jun & 47 & 1315 & 21 & 3 & $\begin{array}{l}\text { danificadas na } \\
\text { desmontagem } \\
\text { impossibilitado sua } \\
\text { análise }\end{array}$ & 10666 \\
\hline 55 & jun & 47 & 1315 & 21 & 3 & $\begin{array}{l}\text { danificadas na } \\
\text { desmontagem } \\
\text { impossibilitado sua } \\
\text { análise }\end{array}$ & 11369 \\
\hline 56 & jun & 47 & 1315 & 21 & 3 & $\begin{array}{l}\text { danificadas na } \\
\text { desmontagem } \\
\text { impossibilitado sua } \\
\text { análise }\end{array}$ & 11992 \\
\hline 57 & jun & 47 & 1315 & 21 & 3 & $\begin{array}{l}\text { danificadas na } \\
\text { desmontagem } \\
\text { impossibilitado sua } \\
\text { análise }\end{array}$ & 12384 \\
\hline 58 & jun & 47 & 1315 & 21 & 3 & $\begin{array}{l}\text { danificadas na } \\
\text { desmontagem } \\
\text { impossibilitado sua } \\
\text { análise }\end{array}$ & 13300 \\
\hline 59 & jun & 47 & 1315 & 21 & 3 & $\begin{array}{l}\text { danificadas na } \\
\text { desmontagem } \\
\text { impossibilitado sua } \\
\text { análise }\end{array}$ & 13300 \\
\hline 60 & jun & 47 & 1315 & 21 & 3 & $\begin{array}{l}\text { danificadas na } \\
\text { desmontagem } \\
\text { impossibilitado sua } \\
\text { análise }\end{array}$ & 14121 \\
\hline
\end{tabular}


Continuação da Tabela 4 - Modos de falha dos dados de retorno

\begin{tabular}{|c|c|c|c|c|c|c|c|}
\hline 61 & jun & 47 & 1315 & 21 & 3 & $\begin{array}{l}\text { danificadas na } \\
\text { desmontagem } \\
\text { impossibilitado sua } \\
\text { análise } \\
\end{array}$ & 15473 \\
\hline 62 & jun & 47 & 1315 & 21 & 3 & $\begin{array}{l}\text { danificadas na } \\
\text { desmontagem } \\
\text { impossibilitado sua } \\
\text { análise } \\
\end{array}$ & 16025 \\
\hline 63 & jun & 47 & 1315 & 21 & 4 & desgaste acentuado & 15328 \\
\hline 64 & jun & 47 & 1315 & 21 & 5 & $\begin{array}{l}\text { impurezas na área de } \\
\text { vedação }\end{array}$ & 10974 \\
\hline 65 & jun & 47 & 1315 & 21 & 6 & montagem inadequada & 10666 \\
\hline 66 & jun & 47 & 1315 & 21 & 6 & montagem inadequada & 11001 \\
\hline 67 & jun & 47 & 1315 & 21 & 6 & montagem inadequada & 11001 \\
\hline 68 & jun & 47 & 1315 & 21 & 6 & montagem inadequada & 11566 \\
\hline 69 & jun & 47 & 1315 & 21 & 6 & montagem inadequada & 11566 \\
\hline 70 & jun & 47 & 1315 & 21 & 6 & montagem inadequada & 13300 \\
\hline 71 & jun & 47 & 1315 & 21 & 6 & montagem inadequada & 15474 \\
\hline 72 & jun & 47 & 1315 & 21 & 7 & $\begin{array}{l}\text { não apresentaram } \\
\text { problemas que } \\
\text { justificasse o } \\
\text { vazamento }\end{array}$ & 12066 \\
\hline 73 & jun & 47 & 1315 & 21 & 7 & $\begin{array}{l}\text { não apresentaram } \\
\text { problemas que } \\
\text { justificasse o } \\
\text { vazamento }\end{array}$ & 14059 \\
\hline 74 & jun & 47 & 1315 & 21 & 7 & $\begin{array}{l}\text { não apresentaram } \\
\text { problemas que } \\
\text { justificasse o } \\
\text { vazamento }\end{array}$ & 15912 \\
\hline 75 & jul & 60 & 1752 & 16 & 3 & $\begin{array}{l}\text { danificadas na } \\
\text { desmontagem } \\
\text { impossibilitado sua } \\
\text { análise }\end{array}$ & 18881 \\
\hline 76 & jul & 60 & 1752 & 16 & 3 & $\begin{array}{l}\text { danificadas na } \\
\text { desmontagem } \\
\text { impossibilitado sua } \\
\text { análise }\end{array}$ & 20352 \\
\hline 77 & jul & 60 & 1752 & 16 & 3 & $\begin{array}{l}\text { danificadas na } \\
\text { desmontagem } \\
\text { impossibilitado sua } \\
\text { análise }\end{array}$ & 21122 \\
\hline 78 & jul & 60 & 1752 & 16 & 3 & $\begin{array}{l}\text { danificadas na } \\
\text { desmontagem } \\
\text { impossibilitado sua } \\
\text { análise }\end{array}$ & 21388 \\
\hline 79 & jul & 60 & 1752 & 16 & 3 & $\begin{array}{l}\text { danificadas na } \\
\text { desmontagem } \\
\text { impossibilitado sua } \\
\text { análise }\end{array}$ & 22235 \\
\hline 80 & jul & 60 & 1752 & 16 & 3 & $\begin{array}{l}\text { danificadas na } \\
\text { desmontagem } \\
\text { impossibilitado análise }\end{array}$ & 22457 \\
\hline
\end{tabular}


Continuação da Tabela 4 - Modos de falha dos dados de retorno

\begin{tabular}{|c|c|c|c|c|c|c|c|}
\hline 81 & jul & 60 & 1752 & 16 & 3 & $\begin{array}{l}\text { danificadas na } \\
\text { desmontagem } \\
\text { impossibilitado sua } \\
\text { análise }\end{array}$ & 24318 \\
\hline 82 & jul & 60 & 1752 & 16 & 1 & Descolagem & 18152 \\
\hline 83 & jul & 60 & 1752 & 16 & 1 & Descolagem & 20529 \\
\hline 84 & jul & 60 & 1752 & 16 & 5 & $\begin{array}{l}\text { impurezas na área de } \\
\text { vedação }\end{array}$ & 17756 \\
\hline 85 & jul & 60 & 1752 & 16 & 5 & $\begin{array}{l}\text { impurezas na área de } \\
\text { vedação }\end{array}$ & 19873 \\
\hline 86 & jul & 60 & 1752 & 16 & 6 & montagem inadequada & 17925 \\
\hline 87 & jul & 60 & 1752 & 16 & 6 & montagem inadequada & 18257 \\
\hline 88 & jul & 60 & 1752 & 16 & 6 & montagem inadequada & 20352 \\
\hline 89 & jul & 60 & 1752 & 16 & 6 & montagem inadequada & 20852 \\
\hline 90 & jul & 60 & 1752 & 16 & 7 & $\begin{array}{l}\text { não apresentaram } \\
\text { problemas que } \\
\text { justificasse o } \\
\text { vazamento } \\
\end{array}$ & 17106 \\
\hline 91 & ago & 63 & 1824 & 24 & 3 & $\begin{array}{l}\text { danificadas na } \\
\text { desmontagem } \\
\text { impossibilitado sua } \\
\text { análise }\end{array}$ & 30852 \\
\hline 92 & ago & 63 & 1824 & 24 & 2 & $\begin{array}{l}\text { deformações e riscos } \\
\text { na vedação }\end{array}$ & 30374 \\
\hline 93 & ago & 63 & 1824 & 24 & 2 & $\begin{array}{l}\text { deformações e riscos } \\
\text { na vedação }\end{array}$ & 30732 \\
\hline 94 & ago & 63 & 1824 & 24 & 1 & Descolagem & 36413 \\
\hline 95 & ago & 63 & 1824 & 24 & 5 & $\begin{array}{l}\text { impurezas na área de } \\
\text { vedação }\end{array}$ & 34987 \\
\hline 96 & ago & 63 & 1824 & 24 & 5 & $\begin{array}{l}\text { impurezas na área de } \\
\text { vedação }\end{array}$ & 36413 \\
\hline 97 & ago & 63 & 1824 & 24 & 5 & $\begin{array}{l}\text { impurezas na área de } \\
\text { vedação }\end{array}$ & 36509 \\
\hline 98 & ago & 63 & 1824 & 24 & 5 & $\begin{array}{l}\text { impurezas na área de } \\
\text { vedação }\end{array}$ & 37598 \\
\hline 99 & ago & 63 & 1824 & 24 & 6 & montagem inadequada & 24318 \\
\hline 100 & ago & 63 & 1824 & 24 & 6 & montagem inadequada & 24329 \\
\hline 101 & ago & 63 & 1824 & 24 & 6 & montagem inadequada & 29170 \\
\hline 102 & ago & 63 & 1824 & 24 & 6 & montagem inadequada & 30000 \\
\hline 103 & ago & 63 & 1824 & 24 & 6 & montagem inadequada & 30019 \\
\hline 104 & ago & 63 & 1824 & 24 & 6 & montagem inadequada & 30374 \\
\hline 105 & ago & 63 & 1824 & 24 & 6 & montagem inadequada & 30852 \\
\hline 106 & ago & 63 & 1824 & 24 & 6 & montagem inadequada & 30988 \\
\hline 107 & ago & 63 & 1824 & 24 & 6 & montagem inadequada & 33470 \\
\hline 108 & ago & 63 & 1824 & 24 & 6 & montagem inadequada & 33470 \\
\hline 109 & ago & 63 & 1824 & 24 & 6 & montagem inadequada & 34626 \\
\hline 110 & ago & 63 & 1824 & 24 & 6 & montagem inadequada & 35815 \\
\hline 111 & ago & 63 & 1824 & 24 & 6 & montagem inadequada & 37598 \\
\hline
\end{tabular}


Continuação da Tabela 4 - Modos de falha dos dados de retorno

\begin{tabular}{|c|c|c|c|c|c|c|c|}
\hline 112 & ago & 63 & 1824 & 24 & 7 & $\begin{array}{l}\text { não apresentaram } \\
\text { problemas que } \\
\text { justificasse o } \\
\text { vazamento }\end{array}$ & 24329 \\
\hline 113 & ago & 63 & 1824 & 24 & 7 & $\begin{array}{l}\text { não apresentaram } \\
\text { problemas que } \\
\text { justificasse o } \\
\text { vazamento }\end{array}$ & 30792 \\
\hline 114 & ago & 63 & 1824 & 24 & 7 & $\begin{array}{l}\text { não apresentaram } \\
\text { problemas que } \\
\text { justificasse o } \\
\text { vazamento }\end{array}$ & 34408 \\
\hline 115 & set & 71 & 1915 & 18 & 3 & $\begin{array}{l}\text { danificadas na } \\
\text { desmontagem } \\
\text { impossibilitado sua } \\
\text { análise }\end{array}$ & 37766 \\
\hline 116 & set & 71 & 1915 & 18 & 3 & $\begin{array}{l}\text { danificadas na } \\
\text { desmontagem } \\
\text { impossibilitado sua } \\
\text { análise }\end{array}$ & 38015 \\
\hline 117 & set & 71 & 1915 & 18 & 3 & $\begin{array}{l}\text { danificadas na } \\
\text { desmontagem } \\
\text { impossibilitado sua } \\
\text { análise }\end{array}$ & 39937 \\
\hline 118 & set & 71 & 1915 & 18 & 3 & $\begin{array}{l}\text { danificadas na } \\
\text { desmontagem } \\
\text { impossibilitado sua } \\
\text { análise }\end{array}$ & 39962 \\
\hline 119 & set & 71 & 1915 & 18 & 3 & $\begin{array}{l}\text { danificadas na } \\
\text { desmontagem } \\
\text { impossibilitado sua } \\
\text { análise }\end{array}$ & 47956 \\
\hline 120 & set & 71 & 1915 & 18 & 3 & $\begin{array}{l}\text { danificadas na } \\
\text { desmontagem } \\
\text { impossibilitado sua } \\
\text { análise }\end{array}$ & 47956 \\
\hline 121 & set & 71 & 1915 & 18 & 2 & $\begin{array}{l}\text { deformações e riscos } \\
\text { na vedação }\end{array}$ & 49588 \\
\hline 122 & set & 71 & 1915 & 18 & 4 & desgaste acentuado & 43821 \\
\hline 123 & set & 71 & 1915 & 18 & 4 & desgaste acentuado & 43821 \\
\hline 124 & set & 71 & 1915 & 18 & 5 & $\begin{array}{l}\text { impurezas na área de } \\
\text { vedação }\end{array}$ & 49215 \\
\hline 125 & set & 71 & 1915 & 18 & 5 & $\begin{array}{l}\text { impurezas na área de } \\
\text { vedação }\end{array}$ & 50845 \\
\hline 126 & set & 71 & 1915 & 18 & 6 & montagem inadequada & 44874 \\
\hline 127 & set & 71 & 1915 & 18 & 6 & montagem inadequada & 44874 \\
\hline 128 & set & 71 & 1915 & 18 & 6 & montagem inadequada & 45775 \\
\hline 129 & set & 71 & 1915 & 18 & 6 & montagem inadequada & 47639 \\
\hline 130 & set & 71 & 1915 & 18 & 6 & montagem inadequada & 47639 \\
\hline 131 & set & 71 & 1915 & 18 & 7 & $\begin{array}{l}\text { não apresentaram } \\
\text { problemas que } \\
\text { justificasse o } \\
\text { vazamento }\end{array}$ & 37664 \\
\hline
\end{tabular}


Continuação da Tabela 4 - Modos de falha dos dados de retorno

\begin{tabular}{|c|c|c|c|c|c|c|c|}
\hline 132 & set & 71 & 1915 & 18 & 7 & $\begin{array}{l}\text { não apresentaram } \\
\text { problemas que } \\
\text { justificasse o } \\
\text { vazamento } \\
\end{array}$ & 38050 \\
\hline 133 & out & 78 & 2003 & 16 & 3 & $\begin{array}{l}\text { danificadas na } \\
\text { desmontagem } \\
\text { impossibilitado sua } \\
\text { análise }\end{array}$ & 53028 \\
\hline 134 & out & 78 & 2003 & 16 & 3 & $\begin{array}{l}\text { danificadas na } \\
\text { desmontagem } \\
\text { impossibilitado sua } \\
\text { análise }\end{array}$ & 55225 \\
\hline 135 & out & 78 & 2003 & 16 & 3 & $\begin{array}{l}\text { danificadas na } \\
\text { desmontagem } \\
\text { impossibilitado sua } \\
\text { análise }\end{array}$ & 56846 \\
\hline 136 & out & 78 & 2003 & 16 & 3 & $\begin{array}{l}\text { danificadas na } \\
\text { desmontagem } \\
\text { impossibilitado sua } \\
\text { análise }\end{array}$ & 59499 \\
\hline 137 & out & 78 & 2003 & 16 & 3 & $\begin{array}{l}\text { danificadas na } \\
\text { desmontagem } \\
\text { impossibilitado sua } \\
\text { análise }\end{array}$ & 64865 \\
\hline 138 & out & 78 & 2003 & 16 & 3 & $\begin{array}{l}\text { danificadas na } \\
\text { desmontagem } \\
\text { impossibilitado sua } \\
\text { análise }\end{array}$ & 65854 \\
\hline 139 & out & 78 & 2003 & 16 & 2 & $\begin{array}{l}\text { deformações e riscos } \\
\text { na vedação }\end{array}$ & 50969 \\
\hline 140 & out & 78 & 2003 & 16 & 5 & $\begin{array}{l}\text { impurezas na área de } \\
\text { vedação }\end{array}$ & 58595 \\
\hline 141 & out & 78 & 2003 & 16 & 5 & $\begin{array}{l}\text { impurezas na área de } \\
\text { vedação }\end{array}$ & 63444 \\
\hline 142 & out & 78 & 2003 & 16 & 5 & $\begin{array}{l}\text { impurezas na área de } \\
\text { vedação }\end{array}$ & 65025 \\
\hline 143 & out & 78 & 2003 & 16 & 6 & montagem inadequada & 52493 \\
\hline 144 & out & 78 & 2003 & 16 & 6 & montagem inadequada & 60680 \\
\hline 145 & out & 78 & 2003 & 16 & 6 & montagem inadequada & 60680 \\
\hline 146 & out & 78 & 2003 & 16 & 6 & montagem inadequada & 64279 \\
\hline 147 & out & 78 & 2003 & 16 & 6 & montagem inadequada & 64359 \\
\hline 148 & out & 78 & 2003 & 16 & 7 & $\begin{array}{l}\text { não apresentaram } \\
\text { problemas que } \\
\text { justificasse o } \\
\text { vazamento }\end{array}$ & 62159 \\
\hline 149 & nov & 83 & 2145 & 24 & 3 & $\begin{array}{l}\text { danificadas na } \\
\text { desmontagem } \\
\text { impossibilitado sua } \\
\text { análise }\end{array}$ & 71649 \\
\hline 150 & nov & 83 & 2145 & 24 & 3 & $\begin{array}{l}\text { danificadas na } \\
\text { desmontagem } \\
\text { impossibilitado sua } \\
\text { análise }\end{array}$ & 72741 \\
\hline 151 & nov & 83 & 2145 & 24 & 3 & $\begin{array}{l}\text { danificadas na } \\
\text { desmontagem } \\
\text { impossibilitado análise }\end{array}$ & 72958 \\
\hline
\end{tabular}


Continuação da Tabela 4 - Modos de falha dos dados de retorno

\begin{tabular}{|c|c|c|c|c|c|c|c|}
\hline 152 & nov & 83 & 2145 & 24 & 3 & $\begin{array}{l}\text { danificadas na } \\
\text { desmontagem } \\
\text { impossibilitado sua } \\
\text { análise }\end{array}$ & 75671 \\
\hline 153 & nov & 83 & 2145 & 24 & 2 & $\begin{array}{l}\text { deformações e riscos } \\
\text { na vedação }\end{array}$ & 72958 \\
\hline 154 & nov & 83 & 2145 & 24 & 2 & $\begin{array}{l}\text { deformações e riscos } \\
\text { na vedação }\end{array}$ & 78340 \\
\hline 155 & nov & 83 & 2145 & 24 & 4 & desgaste acentuado & 69355 \\
\hline 156 & nov & 83 & 2145 & 24 & 5 & $\begin{array}{l}\text { impurezas na área de } \\
\text { vedação }\end{array}$ & 74999 \\
\hline 157 & nov & 83 & 2145 & 24 & 5 & $\begin{array}{l}\text { impurezas na área de } \\
\text { vedação }\end{array}$ & 78340 \\
\hline 158 & nov & 83 & 2145 & 24 & 5 & $\begin{array}{l}\text { impurezas na área de } \\
\text { vedação }\end{array}$ & 81188 \\
\hline 159 & nov & 83 & 2145 & 24 & 5 & $\begin{array}{l}\text { impurezas na área de } \\
\text { vedação }\end{array}$ & 88799 \\
\hline 160 & nov & 83 & 2145 & 24 & 6 & montagem inadequada & 71903 \\
\hline 161 & nov & 83 & 2145 & 24 & 6 & montagem inadequada & 72156 \\
\hline 162 & nov & 83 & 2145 & 24 & 6 & montagem inadequada & 72365 \\
\hline 163 & nov & 83 & 2145 & 24 & 6 & montagem inadequada & 72411 \\
\hline 164 & nov & 83 & 2145 & 24 & 6 & montagem inadequada & 72872 \\
\hline 165 & nov & 83 & 2145 & 24 & 6 & montagem inadequada & 74996 \\
\hline 166 & nov & 83 & 2145 & 24 & 6 & montagem inadequada & 79135 \\
\hline 167 & nov & 83 & 2145 & 24 & 6 & montagem inadequada & 82613 \\
\hline 168 & nov & 83 & 2145 & 24 & 6 & montagem inadequada & 90212 \\
\hline 169 & nov & 83 & 2145 & 24 & 6 & montagem inadequada & 90212 \\
\hline 170 & nov & 83 & 2145 & 24 & 7 & $\begin{array}{l}\text { não apresentaram } \\
\text { problemas que } \\
\text { justificasse o } \\
\text { vazamento }\end{array}$ & 66059 \\
\hline 171 & nov & 83 & 2145 & 24 & 7 & $\begin{array}{l}\text { não apresentaram } \\
\text { problemas que } \\
\text { justificasse o } \\
\text { vazamento }\end{array}$ & 69355 \\
\hline 172 & nov & 83 & 2145 & 24 & 7 & $\begin{array}{l}\text { não apresentaram } \\
\text { problemas que } \\
\text { justificasse o } \\
\text { vazamento }\end{array}$ & 87879 \\
\hline 173 & dez & 91 & 2315 & 39 & 3 & $\begin{array}{l}\text { danificadas na } \\
\text { desmontagem } \\
\text { impossibilitado sua } \\
\text { análise } \\
\end{array}$ & 96000 \\
\hline 174 & dez & 91 & 2315 & 39 & 3 & $\begin{array}{l}\text { danificadas na } \\
\text { desmontagem } \\
\text { impossibilitado sua } \\
\text { análise } \\
\end{array}$ & 104580 \\
\hline 175 & dez & 91 & 2315 & 39 & 3 & $\begin{array}{l}\text { danificadas na } \\
\text { desmontagem } \\
\text { impossibilitado sua } \\
\text { análise }\end{array}$ & 105117 \\
\hline 176 & dez & 91 & 2315 & 39 & 3 & $\begin{array}{l}\text { danificadas na } \\
\text { desmontagem } \\
\text { impossibilitado análise }\end{array}$ & 105994 \\
\hline
\end{tabular}


Continuação da Tabela 4 - Modos de falha dos dados de retorno

\begin{tabular}{|c|c|c|c|c|c|c|c|}
\hline 177 & dez & 91 & 2315 & 39 & 3 & $\begin{array}{l}\text { danificadas na } \\
\text { desmontagem } \\
\text { impossibilitado sua } \\
\text { análise } \\
\end{array}$ & 143553 \\
\hline 178 & dez & 91 & 2315 & 39 & 3 & $\begin{array}{l}\text { danificadas na } \\
\text { desmontagem } \\
\text { impossibilitado sua } \\
\text { análise }\end{array}$ & 143553 \\
\hline 179 & dez & 91 & 2315 & 39 & 3 & $\begin{array}{l}\text { danificadas na } \\
\text { desmontagem } \\
\text { impossibilitado sua } \\
\text { análise }\end{array}$ & 148949 \\
\hline 180 & dez & 91 & 2315 & 39 & 3 & $\begin{array}{l}\text { danificadas na } \\
\text { desmontagem } \\
\text { impossibilitado sua } \\
\text { análise }\end{array}$ & 149936 \\
\hline 181 & dez & 91 & 2315 & 39 & 3 & $\begin{array}{l}\text { danificadas na } \\
\text { desmontagem } \\
\text { impossibilitado sua } \\
\text { análise }\end{array}$ & 149936 \\
\hline 182 & dez & 91 & 2315 & 39 & 3 & $\begin{array}{l}\text { danificadas na } \\
\text { desmontagem } \\
\text { impossibilitado sua } \\
\text { análise }\end{array}$ & 152022 \\
\hline 183 & dez & 91 & 2315 & 39 & 3 & $\begin{array}{l}\text { danificadas na } \\
\text { desmontagem } \\
\text { impossibilitado sua } \\
\text { análise }\end{array}$ & 375550 \\
\hline 184 & dez & 91 & 2315 & 39 & 3 & $\begin{array}{l}\text { danificadas na } \\
\text { desmontagem } \\
\text { impossibilitado sua } \\
\text { análise }\end{array}$ & 962240 \\
\hline 185 & dez & 91 & 2315 & 39 & 2 & $\begin{array}{l}\text { deformações e riscos } \\
\text { na vedação }\end{array}$ & 164582 \\
\hline 186 & dez & 91 & 2315 & 39 & 2 & $\begin{array}{l}\text { deformações e riscos } \\
\text { na vedação }\end{array}$ & 166038 \\
\hline 187 & dez & 91 & 2315 & 39 & 2 & $\begin{array}{l}\text { deformações e riscos } \\
\text { na vedação }\end{array}$ & 261180 \\
\hline 188 & dez & 91 & 2315 & 39 & 4 & desgaste acentuado & 119700 \\
\hline 189 & dez & 91 & 2315 & 39 & 5 & $\begin{array}{l}\text { impurezas na área de } \\
\text { vedação }\end{array}$ & 104995 \\
\hline 190 & dez & 91 & 2315 & 39 & 5 & $\begin{array}{l}\text { impurezas na área de } \\
\text { vedação }\end{array}$ & 152022 \\
\hline 191 & dez & 91 & 2315 & 39 & 6 & montagem inadequada & 90759 \\
\hline 192 & dez & 91 & 2315 & 39 & 6 & montagem inadequada & 90759 \\
\hline 193 & dez & 91 & 2315 & 39 & 6 & montagem inadequada & 93226 \\
\hline 194 & dez & 91 & 2315 & 39 & 6 & montagem inadequada & 96000 \\
\hline 195 & dez & 91 & 2315 & 39 & 6 & montagem inadequada & 108180 \\
\hline 196 & dez & 91 & 2315 & 39 & 6 & montagem inadequada & 140315 \\
\hline 197 & dez & 91 & 2315 & 39 & 6 & montagem inadequada & 143553 \\
\hline 198 & dez & 91 & 2315 & 39 & 6 & montagem inadequada & 147942 \\
\hline 199 & dez & 91 & 2315 & 39 & 6 & montagem inadequada & 147942 \\
\hline 200 & dez & 91 & 2315 & 39 & 6 & montagem inadequada & 148291 \\
\hline
\end{tabular}


Continuação da Tabela 4 - Modos de falha dos dados de retorno

\begin{tabular}{|c|c|c|c|c|c|c|c|}
\hline 201 & dez & 91 & 2315 & 39 & 6 & montagem inadequada & 164358 \\
\hline 202 & dez & 91 & 2315 & 39 & 6 & montagem inadequada & 166038 \\
\hline 203 & dez & 91 & 2315 & 39 & 6 & montagem inadequada & 223222 \\
\hline 204 & dez & 91 & 2315 & 39 & 6 & montagem inadequada & 264852 \\
\hline 205 & dez & 91 & 2315 & 39 & 6 & montagem inadequada & 313871 \\
\hline 206 & dez & 91 & 2315 & 39 & 6 & montagem inadequada & 335306 \\
\hline 207 & dez & 91 & 2315 & 39 & 7 & $\begin{array}{l}\text { não apresentaram } \\
\text { problemas que } \\
\text { justificasse o } \\
\text { vazamento }\end{array}$ & 90935 \\
\hline 208 & dez & 91 & 2315 & 39 & 7 & $\begin{array}{l}\text { não apresentaram } \\
\text { problemas que } \\
\text { justificasse o } \\
\text { vazamento }\end{array}$ & 102914 \\
\hline 209 & dez & 91 & 2315 & 39 & 7 & $\begin{array}{l}\text { não apresentaram } \\
\text { problemas que } \\
\text { justificasse o } \\
\text { vazamento }\end{array}$ & 103237 \\
\hline 210 & dez & 91 & 2315 & 39 & 7 & $\begin{array}{l}\text { não apresentaram } \\
\text { problemas que } \\
\text { justificasse o } \\
\text { vazamento }\end{array}$ & 136880 \\
\hline 211 & dez & 91 & 2315 & 39 & 7 & $\begin{array}{l}\text { não apresentaram } \\
\text { problemas que } \\
\text { justificasse o } \\
\text { vazamento }\end{array}$ & 168839 \\
\hline
\end{tabular}


APÊNDICE B - Tabela 7 - Tabela para o cálculo do estimador de Kaplan Meier

\begin{tabular}{|r|r|r|r|}
\hline & & $N$ & \multicolumn{1}{l|}{$\begin{array}{l}\text { Ronfiabilidade } \\
\mathrm{R}(\mathrm{t})\end{array}$} \\
\hline 0 & 0 & 11818 & 1 \\
\hline 772 & 1 & 11817 & 0,999915376 \\
\hline 963 & 1 & 11816 & 0,999830752 \\
\hline 1001 & 1 & 11815 & 0,999746128 \\
\hline 1001 & 1 & 11814 & 0,999661505 \\
\hline 1048 & 1 & 11813 & 0,999576881 \\
\hline 1310 & 1 & 11812 & 0,999492257 \\
\hline 1424 & 1 & 11811 & 0,999407633 \\
\hline 1437 & 1 & 11810 & 0,999323009 \\
\hline 1493 & 1 & 11809 & 0,999238385 \\
\hline 1603 & 1 & 11808 & 0,999153762 \\
\hline 1603 & 1 & 11807 & 0,999069138 \\
\hline 1612 & 1 & 11806 & 0,998984514 \\
\hline 1612 & 1 & 11805 & 0,99889989 \\
\hline 1703 & 1 & 11804 & 0,998815266 \\
\hline 1800 & 1 & 11803 & 0,998730642 \\
\hline 1944 & 1 & 11802 & 0,998646018 \\
\hline 1944 & 1 & 11801 & 0,998561395 \\
\hline 2071 & 1 & 11800 & 0,998476771 \\
\hline 2297 & 1 & 11799 & 0,998392147 \\
\hline 2406 & 1 & 11798 & 0,998307523 \\
\hline 2479 & 1 & 11797 & 0,998222899 \\
\hline 2634 & 1 & 11796 & 0,998138275 \\
\hline 2930 & 1 & 11795 & 0,998053652 \\
\hline 3050 & 1 & 11794 & 0,997969028 \\
\hline 3100 & 1 & 11793 & 0,997884404 \\
\hline 3200 & 1 & 11792 & 0,99779978 \\
\hline 3284 & 1 & 11791 & 0,997715156 \\
\hline 3284 & 1 & 11790 & 0,997630532 \\
\hline 3525 & 1 & 11789 & 0,997545908 \\
\hline 3525 & 1 & 11788 & 0,997461285 \\
\hline 4078 & 1 & 11787 & 0,997376661 \\
\hline 4078 & 1 & 11786 & 0,997292037 \\
\hline 4243 & 1 & 11785 & 0,997207413 \\
\hline 4549 & 1 & 11784 & 0,997122789 \\
\hline 4658 & 1 & 11783 & 0,997038165 \\
\hline 4780 & 1 & 11782 & 0,996953542 \\
\hline 4868 & 1 & 11781 & 0,996868918 \\
\hline 4952 & 1 & 11780 & 0,996784294 \\
\hline 4952 & 1 & 11779 & 0,99669967 \\
\hline 4981 & 1 & 11778 & 0,996615046 \\
\hline 4981 & 1 & 11777 & 0,996530422 \\
\hline & & & \\
\hline & & &
\end{tabular}


Continuação da Tabela 7 - Tabela para cálculo de estimador de Kaplan-Meier

\begin{tabular}{|r|r|r|r|}
\hline 4987 & 1 & 11776 & 0,996445798 \\
\hline 4987 & 1 & 11775 & 0,996361175 \\
\hline 4992 & 1 & 11774 & 0,996276551 \\
\hline 4997 & 1 & 11773 & 0,996191927 \\
\hline 5000 & 1 & 11772 & 0,996107303 \\
\hline 8155 & 1 & 11771 & 0,996022679 \\
\hline 8921 & 1 & 11770 & 0,995938055 \\
\hline 9625 & 1 & 11769 & 0,995853431 \\
\hline 9657 & 1 & 11768 & 0,995768808 \\
\hline 9747 & 1 & 11767 & 0,995684184 \\
\hline 10535 & 1 & 11766 & 0,99559956 \\
\hline 10535 & 1 & 11765 & 0,995514936 \\
\hline 10666 & 1 & 11764 & 0,995430312 \\
\hline 10666 & 1 & 11763 & 0,995345688 \\
\hline 10974 & 1 & 11762 & 0,995261065 \\
\hline 11001 & 1 & 11761 & 0,995176441 \\
\hline 11001 & 1 & 11760 & 0,995091817 \\
\hline 11369 & 1 & 11759 & 0,995007193 \\
\hline 11566 & 1 & 11758 & 0,994922569 \\
\hline 11566 & 1 & 11757 & 0,994837945 \\
\hline 11992 & 1 & 11756 & 0,994753321 \\
\hline 12066 & 1 & 11755 & 0,994668698 \\
\hline 12384 & 1 & 11754 & 0,994584074 \\
\hline 13300 & 1 & 11753 & 0,99449945 \\
\hline 13300 & 1 & 11752 & 0,994414826 \\
\hline 13300 & 1 & 11751 & 0,994330202 \\
\hline 14059 & 1 & 11750 & 0,994245578 \\
\hline 14121 & 1 & 11749 & 0,994160955 \\
\hline 15328 & 1 & 11748 & 0,994076331 \\
\hline 15473 & 1 & 11747 & 0,993991707 \\
\hline 15474 & 1 & 11746 & 0,993907083 \\
\hline 15912 & 1 & 11745 & 0,993822459 \\
\hline 16025 & 1 & 11744 & 0,993737835 \\
\hline 17106 & 1 & 11743 & 0,993653211 \\
\hline 17756 & 1 & 11742 & 0,993568588 \\
\hline 17925 & 1 & 11741 & 0,993483964 \\
\hline 18152 & 1 & 11740 & 0,99339934 \\
\hline 18257 & 1 & 11739 & 0,993314716 \\
\hline 18881 & 1 & 11738 & 0,993230092 \\
\hline 20352 & 1 & 11737 & 0,993145468 \\
\hline 20529 & 1 & 11736 & 0,993060845 \\
\hline & 1 & 11735 & 0,992976221 \\
\hline & & & 0,992891597 \\
\hline
\end{tabular}


Continuação da Tabela 7 - Tabela para cálculo de estimador de Kaplan-Meier

\begin{tabular}{|r|r|r|r|}
\hline 20852 & 1 & 11733 & 0,992806973 \\
\hline 21122 & 1 & 11732 & 0,992722349 \\
\hline 21388 & 1 & 11731 & 0,992637725 \\
\hline 22235 & 1 & 11730 & 0,992553101 \\
\hline 22457 & 1 & 11729 & 0,992468478 \\
\hline 24318 & 1 & 11728 & 0,992383854 \\
\hline 24318 & 1 & 11727 & 0,99229923 \\
\hline 24329 & 1 & 11726 & 0,992214606 \\
\hline 24329 & 1 & 11725 & 0,992129982 \\
\hline 29170 & 1 & 11724 & 0,992045358 \\
\hline 30000 & 1 & 11723 & 0,991960735 \\
\hline 30019 & 1 & 11722 & 0,991876111 \\
\hline 30374 & 1 & 11721 & 0,991791487 \\
\hline 30374 & 1 & 11720 & 0,991706863 \\
\hline 30732 & 1 & 11719 & 0,991622239 \\
\hline 30792 & 1 & 11718 & 0,991537615 \\
\hline 30852 & 1 & 11717 & 0,991452991 \\
\hline 30852 & 1 & 11716 & 0,991368368 \\
\hline 30988 & 1 & 11715 & 0,991283744 \\
\hline 33470 & 1 & 11714 & 0,99119912 \\
\hline 33470 & 1 & 11713 & 0,991114496 \\
\hline 34408 & 1 & 11712 & 0,991029872 \\
\hline 34626 & 1 & 11711 & 0,990945248 \\
\hline 34987 & 1 & 11710 & 0,990860625 \\
\hline 35815 & 1 & 11709 & 0,990776001 \\
\hline 36413 & 1 & 11708 & 0,990691377 \\
\hline 36413 & 1 & 11707 & 0,990606753 \\
\hline 36509 & 1 & 11706 & 0,990522129 \\
\hline 37598 & 1 & 11705 & 0,990437505 \\
\hline 37598 & 1 & 11704 & 0,990352881 \\
\hline 37664 & 1 & 11703 & 0,990268258 \\
\hline 37766 & 1 & 11702 & 0,990183634 \\
\hline 38015 & 1 & 11701 & 0,99009901 \\
\hline 38050 & 1 & 11700 & 0,990014386 \\
\hline 39937 & 1 & 11699 & 0,989929762 \\
\hline 39962 & 1 & 11698 & 0,989845138 \\
\hline 43821 & 1 & 11697 & 0,989760515 \\
\hline 43821 & 1 & 11696 & 0,989675891 \\
\hline 44874 & 1 & 11695 & 0,989591267 \\
\hline 44874 & 1 & 11694 & 0,989506643 \\
\hline 45775 & 1 & 11693 & 0,989422019 \\
\hline 47639 & 1 & 11692 & 0,989337395 \\
\hline 47639 & 1 & 11691 & 0,989252771 \\
\hline & & & \\
\hline
\end{tabular}


Continuação da Tabela 7 - Tabela para cálculo de estimador de Kaplan-Meier

\begin{tabular}{|r|r|r|r|}
\hline 47956 & 1 & 11690 & 0,989168148 \\
\hline 47956 & 1 & 11689 & 0,989083524 \\
\hline 49215 & 1 & 11688 & 0,9889989 \\
\hline 49588 & 1 & 11687 & 0,988914276 \\
\hline 50845 & 1 & 11686 & 0,988829652 \\
\hline 50969 & 1 & 11685 & 0,988745028 \\
\hline 52493 & 1 & 11684 & 0,988660405 \\
\hline 53028 & 1 & 11683 & 0,988575781 \\
\hline 55225 & 1 & 11682 & 0,988491157 \\
\hline 56846 & 1 & 11681 & 0,988406533 \\
\hline 58595 & 1 & 11680 & 0,988321909 \\
\hline 59499 & 1 & 11679 & 0,988237285 \\
\hline 60680 & 1 & 11678 & 0,988152661 \\
\hline 60680 & 1 & 11677 & 0,988068038 \\
\hline 62159 & 1 & 11676 & 0,987983414 \\
\hline 63444 & 1 & 11675 & 0,98789879 \\
\hline 64279 & 1 & 11674 & 0,987814166 \\
\hline 64359 & 1 & 11673 & 0,987729542 \\
\hline 64865 & 1 & 11672 & 0,987644918 \\
\hline 65025 & 1 & 11671 & 0,987560294 \\
\hline 65854 & 1 & 11670 & 0,987475671 \\
\hline 66059 & 1 & 11669 & 0,987391047 \\
\hline 69355 & 1 & 11668 & 0,987306423 \\
\hline 69355 & 1 & 11667 & 0,987221799 \\
\hline 71649 & 1 & 11666 & 0,987137175 \\
\hline 71903 & 1 & 11665 & 0,987052551 \\
\hline 72156 & 1 & 11664 & 0,986967928 \\
\hline 72365 & 1 & 11663 & 0,986883304 \\
\hline 72411 & 1 & 11662 & 0,98679868 \\
\hline 72741 & 1 & 11661 & 0,986714056 \\
\hline 72872 & 1 & 11660 & 0,986629432 \\
\hline 72958 & 1 & 11659 & 0,986544808 \\
\hline 72958 & 1 & 11658 & 0,986460184 \\
\hline 74996 & 1 & 11657 & 0,986375561 \\
\hline 74999 & 1 & 11656 & 0,986290937 \\
\hline 75671 & 1 & 11655 & 0,986206313 \\
\hline 78340 & 1 & 11654 & 0,986121689 \\
\hline 78340 & 1 & 11653 & 0,986037065 \\
\hline 79135 & 1 & 11652 & 0,985952441 \\
\hline 81188 & 1 & 11651 & 0,985867818 \\
\hline 82613 & 1 & 11650 & 0,985783194 \\
\hline 87879 & 1 & 11649 & 0,98569857 \\
\hline 88799 & 1 & 11648 & 0,985613946 \\
\hline & & & \\
\hline
\end{tabular}


Continuação da Tabela 7 - Tabela para cálculo de estimador de Kaplan-Meier

\begin{tabular}{|r|r|r|r|}
\hline 90212 & 1 & 11647 & 0,985529322 \\
\hline 90212 & 1 & 11646 & 0,985444698 \\
\hline 90759 & 1 & 11645 & 0,985360074 \\
\hline 90759 & 1 & 11644 & 0,985275451 \\
\hline 90935 & 1 & 11643 & 0,985190827 \\
\hline 93226 & 1 & 11642 & 0,985106203 \\
\hline 96000 & 1 & 11641 & 0,985021579 \\
\hline 96000 & 1 & 11640 & 0,984936955 \\
\hline 102914 & 1 & 11639 & 0,984852331 \\
\hline 103237 & 1 & 11638 & 0,984767708 \\
\hline 104580 & 1 & 11637 & 0,984683084 \\
\hline 104995 & 1 & 11636 & 0,98459846 \\
\hline 105117 & 1 & 11635 & 0,984513836 \\
\hline 105994 & 1 & 11634 & 0,984429212 \\
\hline 108180 & 1 & 11633 & 0,984344588 \\
\hline 119700 & 1 & 11632 & 0,984259964 \\
\hline 136880 & 1 & 11631 & 0,984175341 \\
\hline 140315 & 1 & 11630 & 0,984090717 \\
\hline 143553 & 1 & 11629 & 0,984006093 \\
\hline 143553 & 1 & 11628 & 0,983921469 \\
\hline 143553 & 1 & 11627 & 0,983836845 \\
\hline 147942 & 1 & 11626 & 0,983752221 \\
\hline 147942 & 1 & 11625 & 0,983667598 \\
\hline 148291 & 1 & 11624 & 0,983582974 \\
\hline 148949 & 1 & 11623 & 0,98349835 \\
\hline 149936 & 1 & 11622 & 0,983413726 \\
\hline 149936 & 1 & 11621 & 0,983329102 \\
\hline 152022 & 1 & 11620 & 0,983244478 \\
\hline 152022 & 1 & 11619 & 0,983159854 \\
\hline 164358 & 1 & 11618 & 0,983075231 \\
\hline 164582 & 1 & 11617 & 0,982990607 \\
\hline 166038 & 1 & 11616 & 0,982905983 \\
\hline 166038 & 1 & 11615 & 0,982821359 \\
\hline 168839 & 1 & 11614 & 0,982736735 \\
\hline 170135 & 1 & 11613 & 0,982652111 \\
\hline 175408 & 1 & 11612 & 0,982567488 \\
\hline 179123 & 1 & 11611 & 0,982482864 \\
\hline 184553 & 1 & 11610 & 0,98239824 \\
\hline 193257 & 1 & 11609 & 0,982313616 \\
\hline 195725 & 1 & 11608 & 0,982228992 \\
\hline 198352 & 1 & 11607 & 0,982144368 \\
\hline & & & \\
\hline
\end{tabular}

